\title{
WOMEN'S LEADERSHIP IN TRADITIONAL VILLAGES \\ IN SAMOA: THE CULTURAL, SOCIAL, AND RELIGIOUS CHALLENGES
}

\author{
By \\ SILIA PA'USISI FINAU
}

A thesis submitted to the Victoria University of Wellington in fulfilment of the requirements for the degree of Doctor of Philosophy

\section{VICTORIA UNIVERSITY OF WELLINGTON}




\begin{abstract}
Samoan legends and myths document that matriarchal leadership existed prior to colonisation and Christianity. This was evident in the administration of Queen Salamasina, the first official tafa'ifã (holder of four paramount chiefly titles) in the history of the country. However, the era of matriarchs began to erode and was completely worn away with the introduction of male leadership, firstly, and most severely, by Christian missionaries in 1830, and later by colonial powers after World War 2. Leadership positions in families, churches, local government, national government, and most cultural, religious, and modern organisations have been predominantly held by males. Aspiring women leaders strive to gain leadership positions, but are faced with a variety of restrictions. Therefore, a search for gender equality in participation and representation in traditional village judiciaries (local government) warrants this study.
\end{abstract}

This study focussed on exploring the challenges that impede Samoan women from leadership positions in local government (pulega o nu'u). This qualitative study employed multiple methods for data collection consisting of interviews, observations, and document analysis. Interviews and observations were facilitated by the talanoa research framework, an indigenous research method effective for indigenous people conversing in their own vernacular, in this case, in the Samoan language. The data collected from interviews and observations was analysed by thematic analysis where major themes were constructed from consistent patterns emerging from coding, recoding, and interpreting data. Participants were selected through a purposeful sampling technique to yield in-depth information for the study.

The study found that barriers limiting women's opportunities for leadership positions in traditional villages in Samoa are based on cultural values, religious beliefs, and social assumptions. Cultural values are most influential in people's perception of a leader, as male leadership is entrenched as the true cultural norm. Religious beliefs that emphasise the importance of the father as the leader and the head of the family reinforce cultural restrictions on women accessing leadership positions. Social assumptions that associate women's work with household tasks further curb women's leadership aspirations.

The participants in this study believed their rights to leadership were disrupted by the structure of the local government, as leadership for them has been restricted to the confinement of the women's committees. Women cannot participate fully in village councils (fono a le nu'u) because they neither hold matai titles nor recognised by male leaders. In addition to not gaining 
full participation in village councils, women without matai titles were excluded from standing for parliament.

This study sets the platform to generate further dialogue about the exclusion of women from positions of authority in local government, as well as addressing general gender inequality issues. This study also makes a valuable contribution to feminist thinking, promotes the field of women's leadership, and makes an important contribution to the Pacific cultural leadership, specifically. 


\section{ACKNOWLEDGEMENT}

First and foremost, let all the glory be to God Almighty for He has guided and protected me safely throughout this challenging journey. Without His grace, I would not have been able to complete the writing of this thesis.

I wholeheartedly acknowledge with sincere gratitude my primary supervisor, Dr Cherie Chu, for her guidance, generous support, patience, understanding, and providing constant constructive feedback from the initial to the final stage of my thesis. I am also thankful to my secondary supervisor, Dr Lex McDonald, for his assistance and support. I wish to express a heartfelt thank you to Laura van Peer for tirelessly proofreading my thesis and making thoughtprovoking suggestions. I am sincerely grateful to all the participants who contributed their energy, time, and thoughts to the field work. I am deeply appreciative of Victoria University of Wellington for providing funds as well as to the National University of Sāmoa. I am forever thankful to afioga Luamanuvao Winnie Laban and the Pasefika Staff for their support. I recognise the friendship and hospitality of Dr Sue Walbran, Director of the Academic Office. I acknowledge the blessings, prayers, and encouragement of my spiritual parents, Reverend I'aeva and Fa'aatuolo Amitai, as well as the Congregational Christian Church in Safa'ato'a Tai. Mālō fa'afetai, o la outou pule lea. I am forever grateful to my dearest paternal aunty Aunty Silia Tuimuai'ava Kuka, whom I am named after for her encouragement and tapua'iga. Faafetai fa'alototele ao feagai ma le taua o mafaufauga. I recognise the support of my cousin Reverend Elder Malaki Tuimuai'ava, his wife Rosalili, and their children. I am also thankful to my cousin, the lay preacher of the Uniting Church in Stokes Valley, Seleisa, her husband Faletolu, and their children for providing financial support, comfort, and necessities required for my study. I thank Reverend Hana Popea, her mother Mapu, and their family for their support, love, and care. I am greatly appreciative of the friendship and hospitality of Martyn and Sylvia Reynolds and their children David and Florence, who accommodated me for five months in 2015. Thank you guys for your kindness, love, and care. A big fa'amalo too to Martyn and Sylvia for spending time to proofread my thesis and suggesting ideas for improvement. I would like to thank Mike and Kaye Stannard for their friendship and for Kaye's willingness to read part of my thesis and providing feedback. I am grateful to Niusila Fa'amanatu Eteuati, a colleague, and friend who shares with me the positives, frustrations, and challenges of the $\mathrm{PhD}$ journey. I also thank my friend Vaigafa Taefu for the good times we shared during my stay in Wellington, and for hosting me in the last two months of my study. 
Thanks very much to the Aualuma Safa'ato'a Tai for keeping the saofa'iga intact while I was away studying. Mālō le lotogatasi. Fa'afetai mo talosaga molia.

I am indebted to my mother Tuta'itaga Āsōmaile Lepetiomālō for her prayers and blessings. I would like to thank my siblings, Tuimuai'ava Pusa Fai'upu, Finau Faitala, Sui Finau, Vaiaso Paulo and Fofoaivao'ese Viona Finau, their children, and grandchildren for taking care of our mother while I concentrated on my studies. Thanks to my sister Vaiaso, her husband, and their children, Aden, Charai, Silia, and Pa'usisiofetalaigaatuisavailu'u for looking after our home while I was away for three years. I am especially grateful to those few, unnamed, but noble souls who prayed for me over the period of writing, rewriting, and finalising this thesis.

Lastly, I acknowledge the spirits of my ancestors, my late paternal grandparents Finau Siaunu'ua Fai'upu Fuāmatu and Vaiaso, who groomed me to be a brave leader. I would also like to recognise my late father, Finau Pa'usisiofetalaigaatuisavailu'u Finau who disciplined me to be successful in life. 


\section{SAMOAN-ENGLISH GLOSSARY}

\begin{tabular}{|c|c|}
\hline ’āìga & family \\
\hline 'àīga potopoto & extended family \\
\hline aualuma & association of village daughters \\
\hline 'augafa'apae & the most elite lady \\
\hline 'aumaga & untitled man \\
\hline 'afa & sennit \\
\hline aga fa'atamāli'i & chiefly manner \\
\hline aga'ifanua & unique protocol \\
\hline ali’i & chief \\
\hline aloiafi & fire embers \\
\hline alofa & love \\
\hline alofaga & fishing expedition \\
\hline ava & more respectful term of respect \\
\hline 'ava niukini & poisonous liquid \\
\hline ’ietoga & finemat \\
\hline onomea & appropriateness \\
\hline oso & a gift or gifts presented by the visitor to the host \\
\hline ositaulaga & ceremonial clergy-like post \\
\hline utu & a basket that stores fishing lures \\
\hline fa'aaloalo & respect \\
\hline fa'aSāmoa & Samoan way \\
\hline fa'amatai & in the way of matai \\
\hline fa'alavelave & obligation \\
\hline fa'alelegāpepe & showcasing newly woven finemats \\
\hline fa'alupega & dignitary connotations \\
\hline fa'atōsaga & midwife \\
\hline fai'oa & wealth maker \\
\hline faleva'a & shelter of a canoe \\
\hline faletua & wife of a chief \\
\hline fanai’a & dynamite \\
\hline fatafata & chest \\
\hline feagaiga & covenant \\
\hline
\end{tabular}




\begin{tabular}{|c|c|}
\hline fetu'utu'una'i & flexibility \\
\hline filigā 'afa & plaiting sennit \\
\hline fono & meeting \\
\hline fono a le nu'u & village council meeting \\
\hline fuata & harvesting season \\
\hline lou & long pruning pole \\
\hline loto maualalo & humbleness \\
\hline mauli & inner person \\
\hline māliliega 'autasi & consensus \\
\hline maluali'i & salience \\
\hline magālafu & small fire burnt in the middle of a Samoan house \\
\hline mana & spirit \\
\hline matai & cultural title/holder of the cultural title \\
\hline mata'igātila & to examine sails of a fishing canoe \\
\hline mōlīpopo & coconut lamp \\
\hline muniao & trap for catching pigeons \\
\hline nu'u & village \\
\hline Nu'u o 'aumaga & sub-village of untitled men \\
\hline Nu'u o ali'i & sub-village of chiefs and orators \\
\hline Nu'u o Tama'ita'i & sub-village of females \\
\hline pae ma le 'āuli & peace maker \\
\hline pāpā & paramount chiefly title \\
\hline pule & authority \\
\hline pūlea & control \\
\hline pule na lua & second ranking leaders \\
\hline pūlega o nu’u & local government \\
\hline pūlega fa'amatai & matai system \\
\hline pulenu'u & village mayor \\
\hline seugālupe & hunting pigeons \\
\hline siapo & tapa \\
\hline soa & pair \\
\hline soālaupule & consultation \\
\hline sui o le mālō & government representative \\
\hline ta'iga/ta'ita'iga & leadership \\
\hline
\end{tabular}




$\begin{array}{ll}\text { tafa'ifā } & \text { holder of four paramount chiefly titles } \\ \text { tausi } & \text { wife of an orator } \\ \text { taulāsea } & \text { healer } \\ \text { tausala } & \text { liberator } \\ \text { tama'ita'i } & \text { female } \\ \text { Tama'ita'i Sāmoa } & \text { Samoan female } \\ \text { tamasā } & \text { sacred sibling } \\ \text { taupou } & \text { village maiden } \\ \text { tautua } & \text { service } \\ \text { tila } & \text { spirit of a sail } \\ \text { tōfā } & \text { perception } \\ \text { tōfā fetu'utu'una'i } & \text { flexible thinking } \\ \text { tūlāfale } & \text { orator } \\ \text { tuliloa } & \text { pursuit } \\ \text { tulituliloa } & \text { to give chase } \\ \text { vā feāloa'i } & \text { sacred space } \\ \text { vā tapuia } & \text { sacred relationship }\end{array}$




\section{TABLE OF CONTENTS}

ACKNOWLET

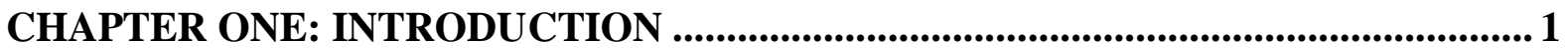

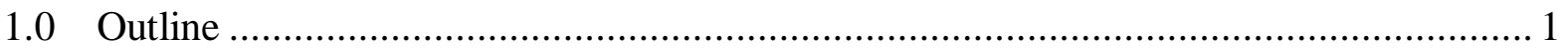

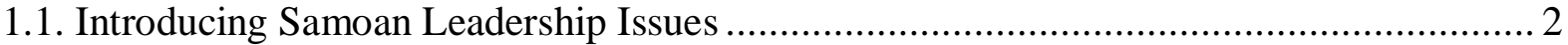

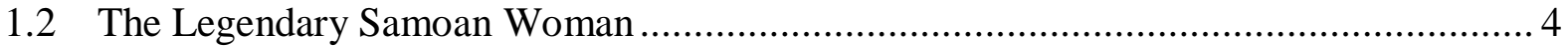

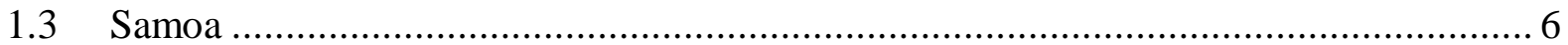

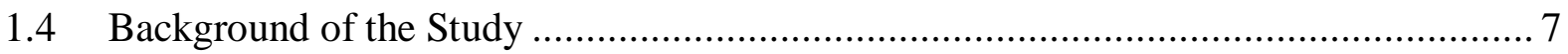

1.5 Cultural and Social Philosophy of the Research Context ........................................ 10

1.6 Leadership Definition and Styles Targeted ..................................................... 11

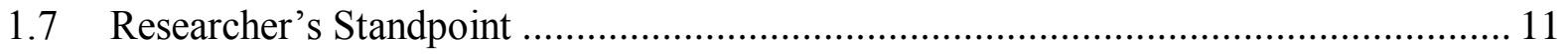

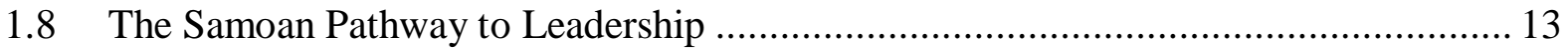

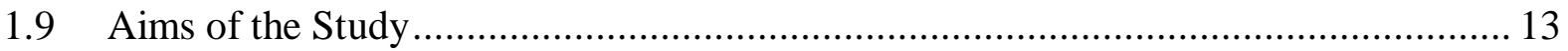

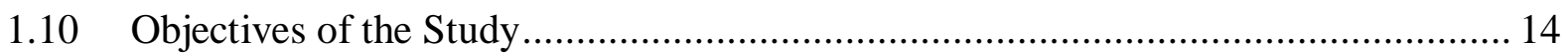

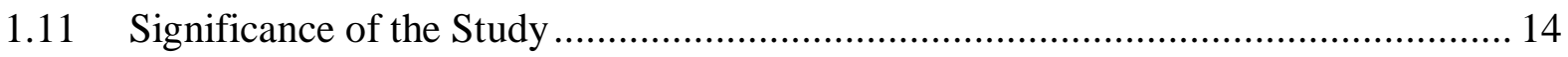

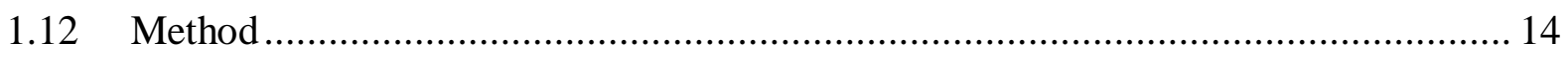

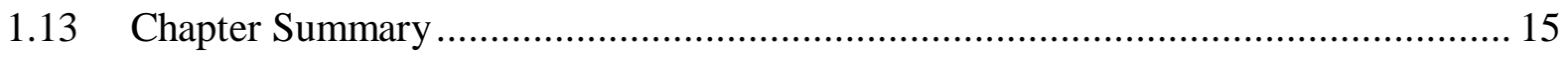

CHAPTER TWO: LITERATURE REVIEW ............................................................ 17

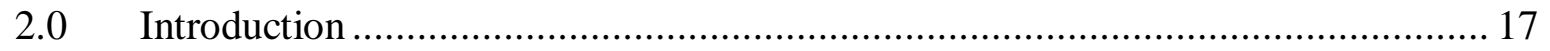

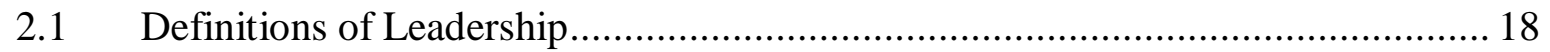

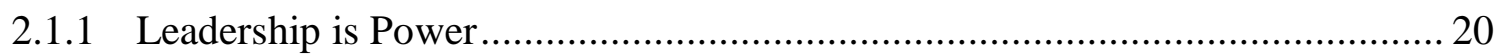

2.1.2 Leadership is a Process and a Property........................................................ 22

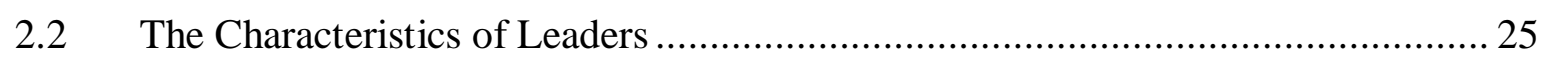

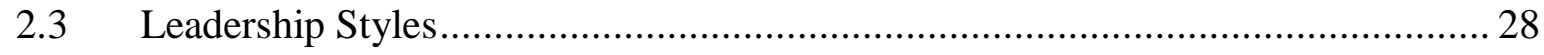

2.4 Leadership in Traditional Communities of Pacific Islands ................................ 32

2.4.1 Leadership Thinking of New Generation Leaders of the Pacific ...................... 36 


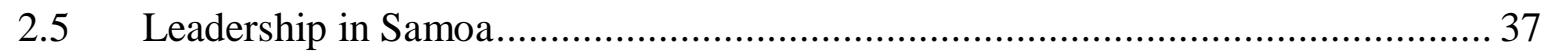

2.6 Leadership Characteristics: A Gender Issue ................................................... 42

2.7 Leadership Challenges for Women ............................................................ 44

2.8. Leadership in Local Government in Samoa.................................................. 47

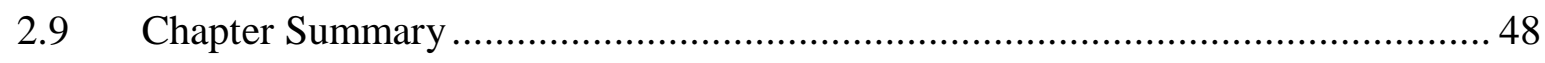

CHAPTER THREE: THEORETICAL FRAMEWORK............................................... 49

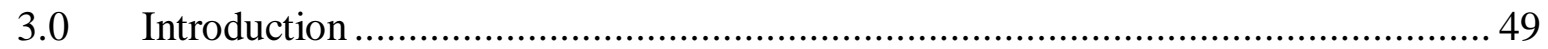

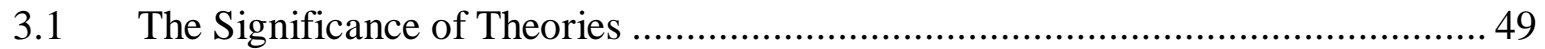

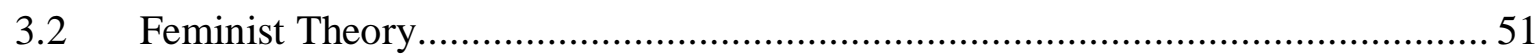

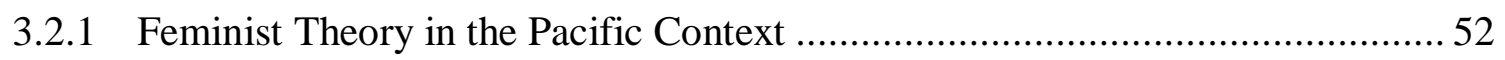

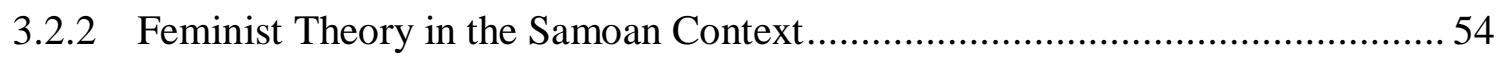

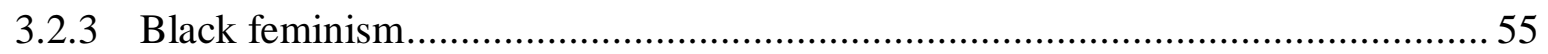

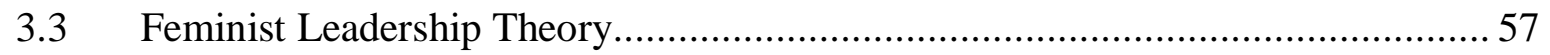

3.3.1 Characteristics of the Female Leader........................................................ 58

3.3.2 Pacific Context of the Feminist Leadership Theory …................................... 59

3.3.3 Samoan Context of the Feminist Leadership Theory …................................. 61

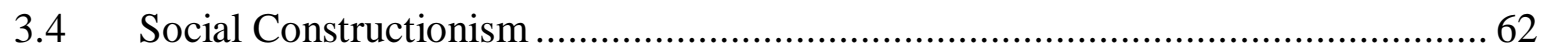

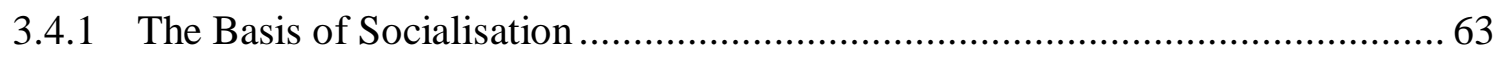

3.4.2 How Socialisation Facilitates the Construction of Knowledge ......................... 64

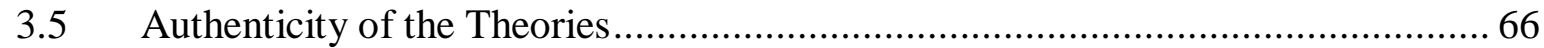

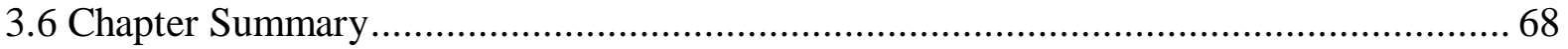

CHAPTER FOUR: METHODOLOGY ................................................................69

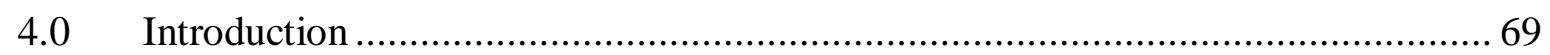

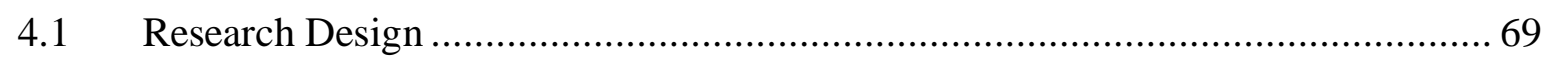

4.1.1 Summary of the Purpose of the Study ......................................................... 71

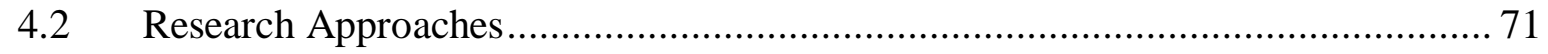

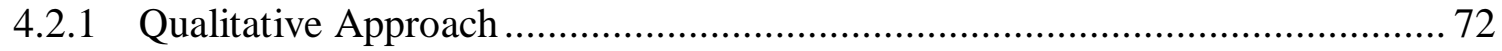

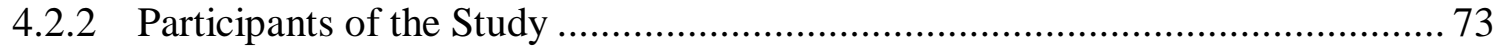

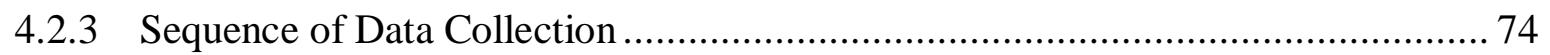

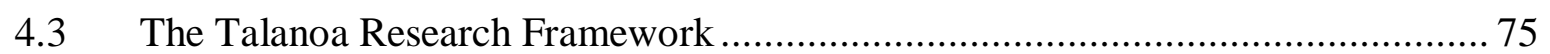

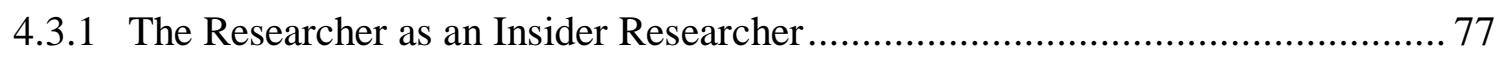

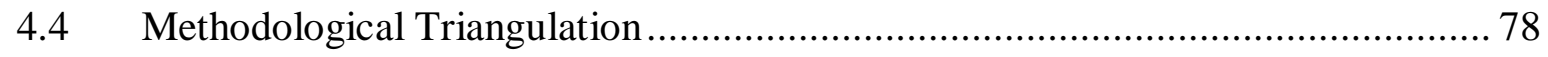

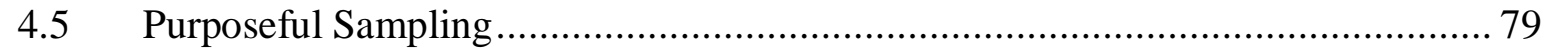

4.6 Data Collection Method and Procedures ............................................................... 79 


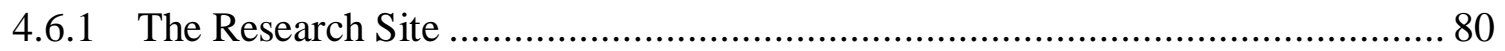

4.6.2 Gaining Access to the Participants' Locations ................................................ 80

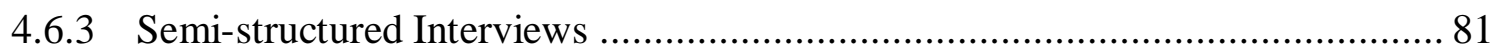

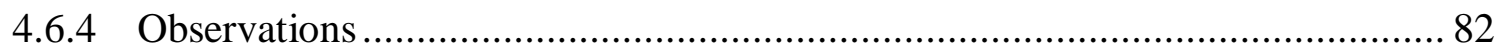

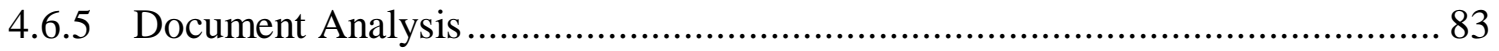

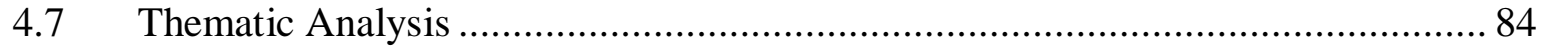

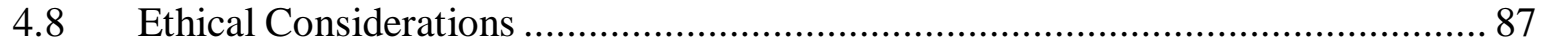

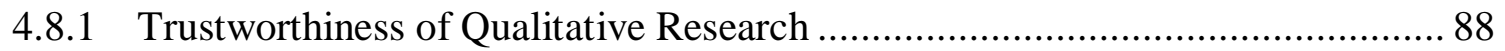

4.8.2 Trustworthiness Across Language Translations ......................................... 90

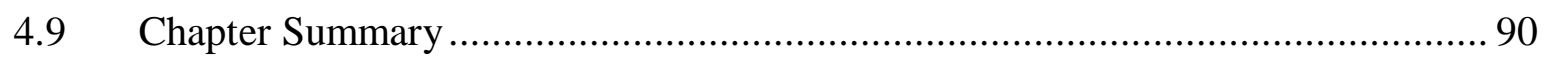

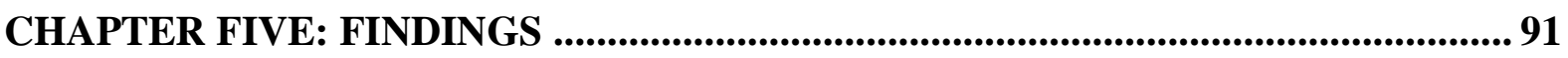

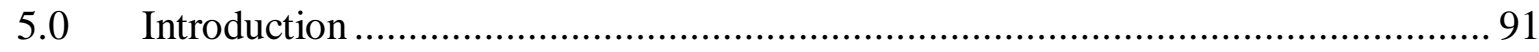

5.1 Background and Experience of Participants in the Sample ................................ 91

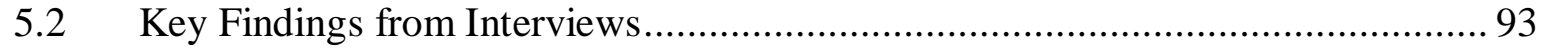

5.2.1 Servant Leadership Nature of Community Women ......................................... 94

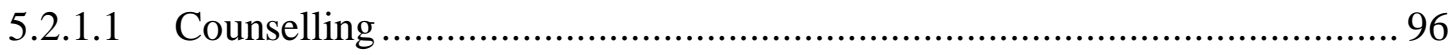

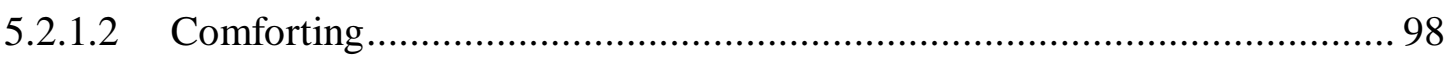

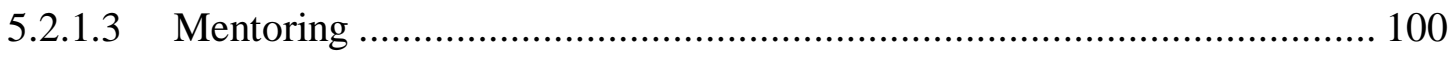

5.2.1.4 Maintaining Cleanliness and Hygiene................................................. 101

5.2.1.5 Traditional Healers and Midwives ....................................................... 104

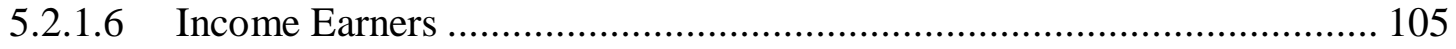

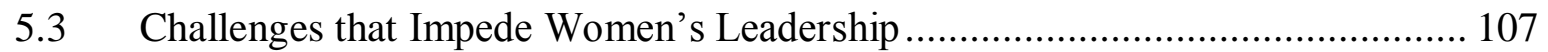

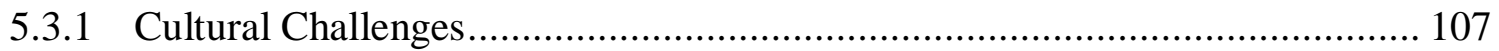

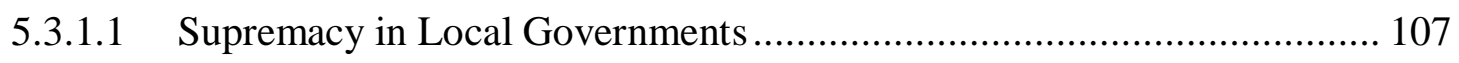

5.3.1.2 The Authoritarian Nature of Patriarchal Communities ........................... 110

5.3.1.3 Extended Families' Influence …....................................................... 111

5.3.1.4 Women Leaders are Second in Rank ................................................. 113

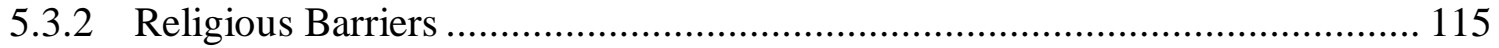

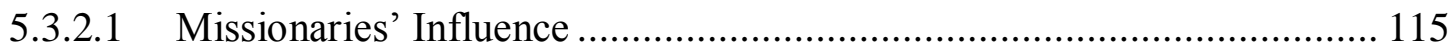

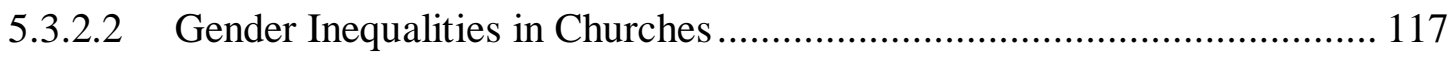

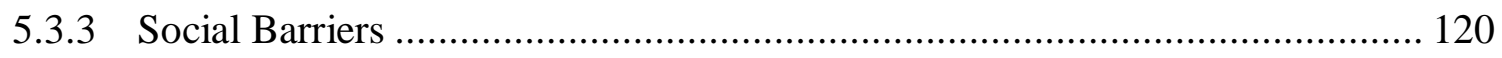

5.3.3.1 Assumptions that Hinder Women's Leadership ................................... 121

5.3.3.2 Women Prefer to be Subordinates ................................................... 124

5.3.3.3 Unequal Opportunities for Men and Women ..................................... 125 
5.4 Women's Second Ranking Status and their Development

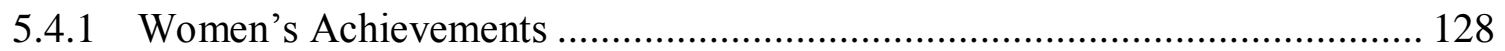

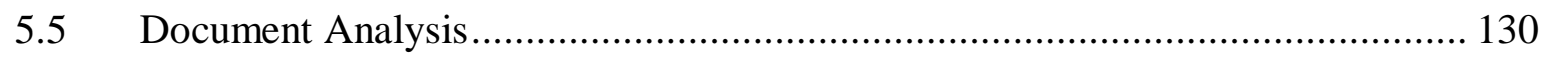

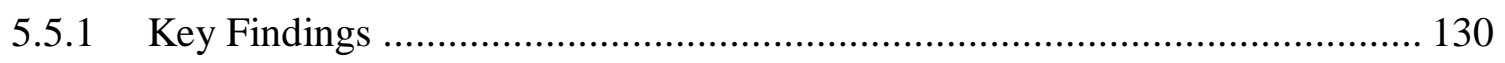

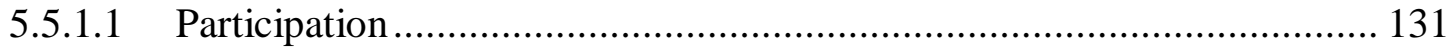

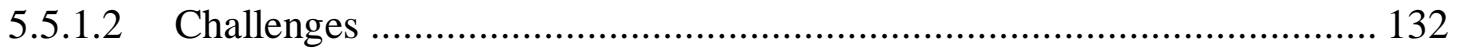

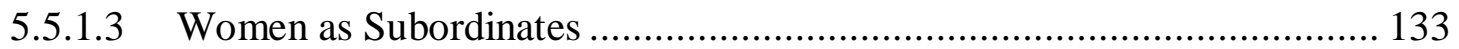

5.5.1.4 Women's Leadership is Providing Services ......................................... 133

5.5.1.5 Women in Power and Decision-making............................................. 134

5.6 Characteristics of Samoan Women Leaders .................................................... 134

5.6.1 Participatory Nature of Women Leaders .................................................. 135

5.6.2 Non-hierarchical Behavior of Women Leaders ............................................ 136

5.6.3 Flexibility and Group Orientation......................................................... 136

5.6.4 The Meaning of Dialogic Interactions ...................................................... 137

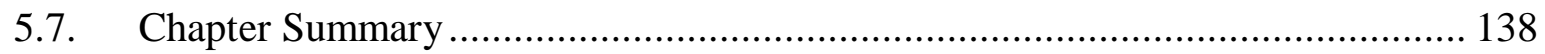

CHAPTER SIX: DISCUSSION....................................................................... 139

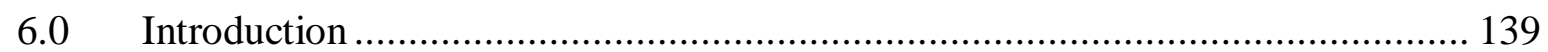

6.1 Women's Expressions of Themselves and their Positions .............................. 140

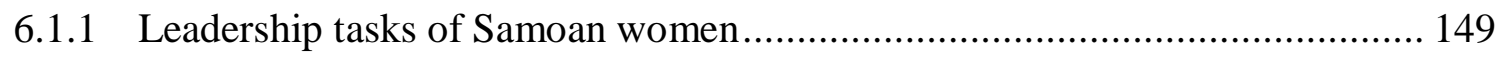

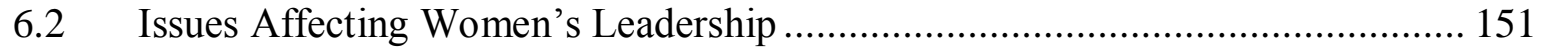

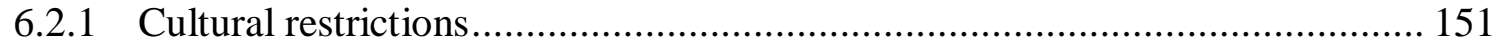

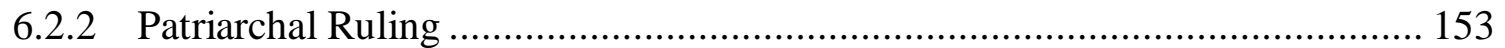

6.2.3 The Influence of the Matai System ......................................................... 155

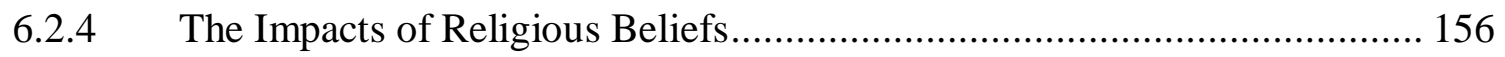

6.2.5 Social Assumptions About Women's Roles ............................................... 158

6.3 The Reality of Women in Village Communities ............................................. 159

6.3.1 Salary packages for men and women village representatives .......................... 161

6.4 Theoretical Assessment of the Samoan Women's Suppression.......................... 163

6.5 A Practical Exploration of the Tasks of Servant Leaders ................................... 167

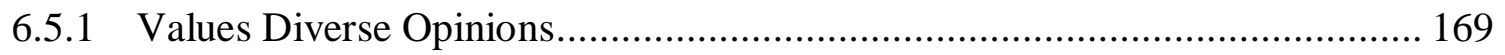

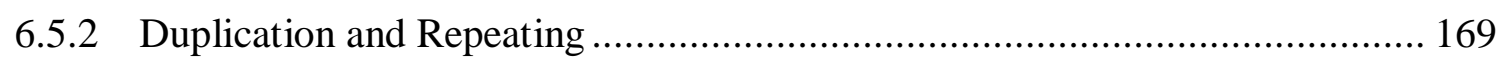

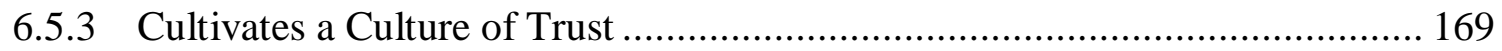

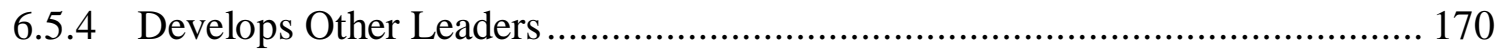

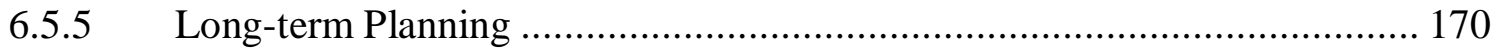




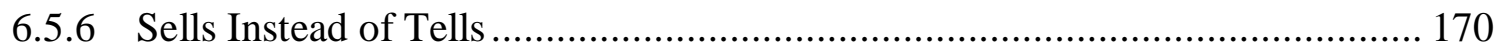

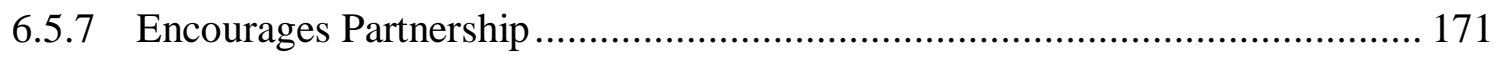

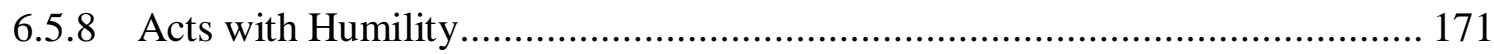

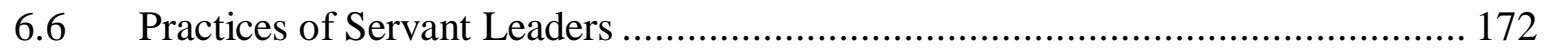

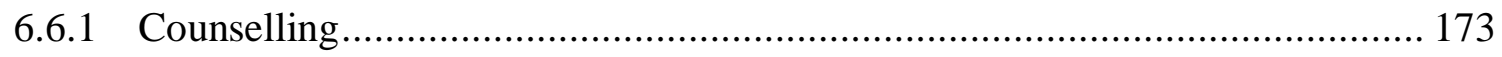

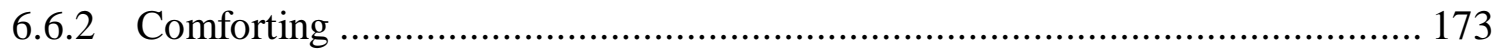

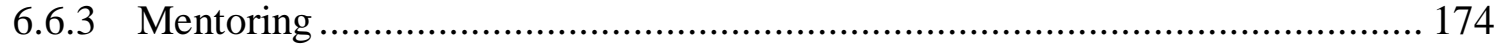

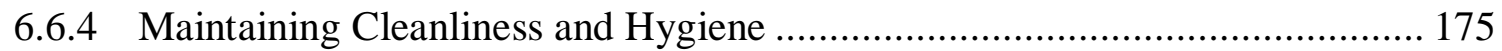

6.6.5 Traditional Healers and Midwives............................................................ 176

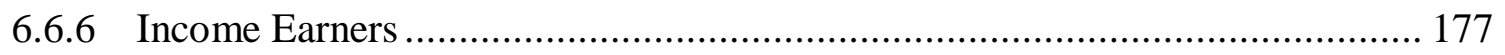

6.7 Samoan Women's Leadership in Traditional Village Communities is Compromised 177

6.7.1. The Role of Samoan Women in Moving the Matai System Forward .............. 179

6.8 Proposed Leadership Model for Local Government in Samoa .......................... 180

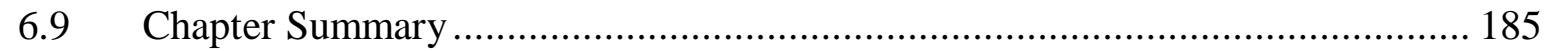

CHAPTER SEVEN: CONCLUSION.................................................................................... 186

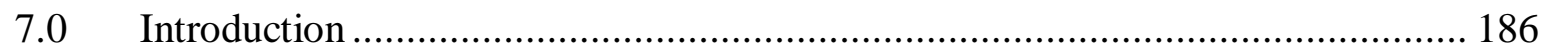

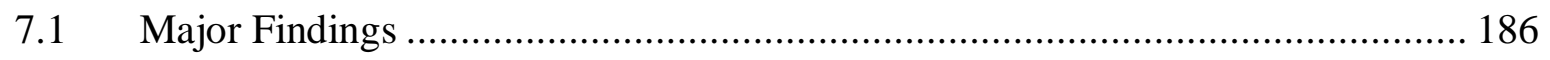

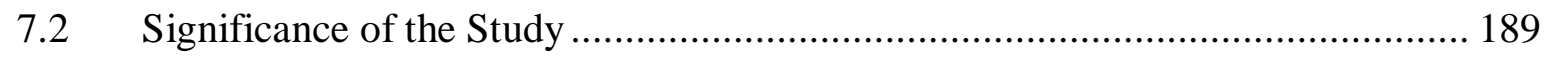

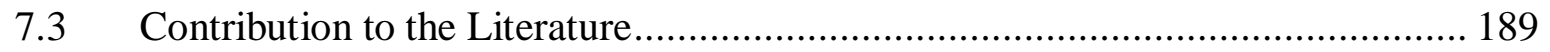

7.4 Contribution to Future Studies ........................................................................ 190

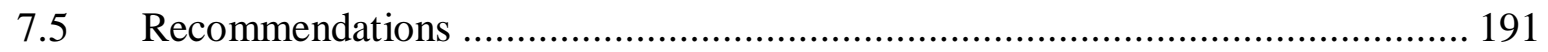

7.5.1 Training to empower community women ................................................... 192

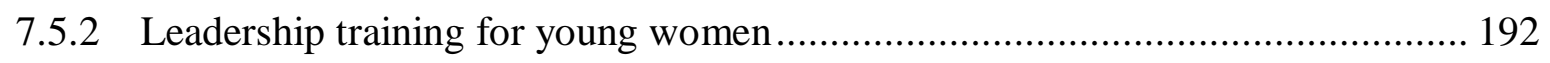

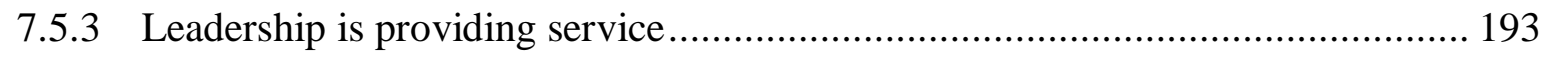

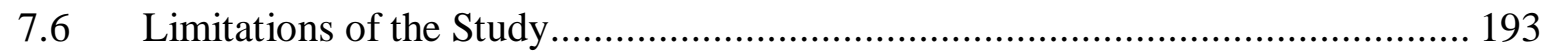

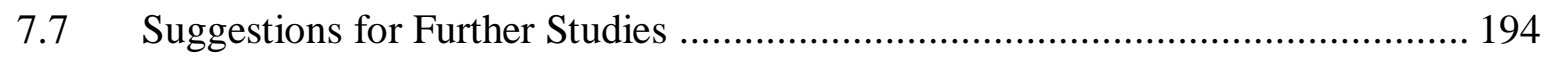

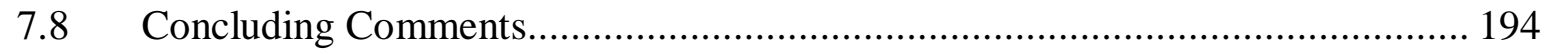

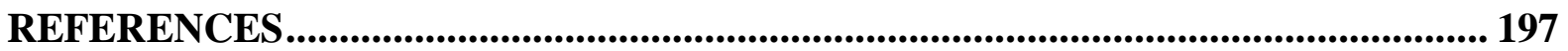

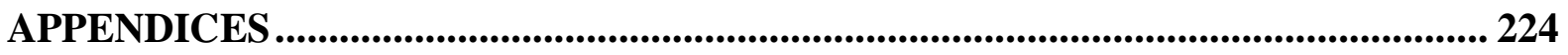

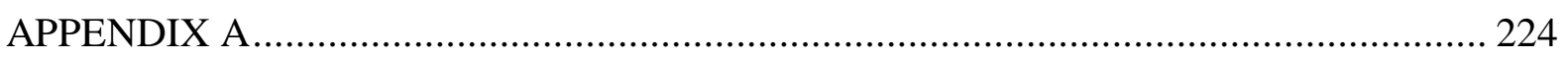

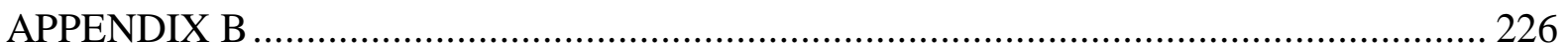

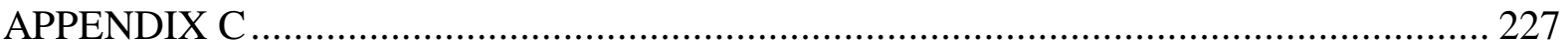

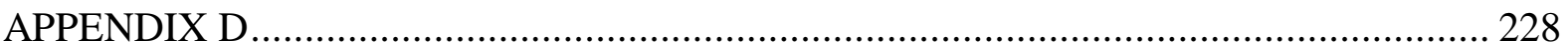


APPENDIX E

238

APPENDIX F 


\section{LIST OF DIAGRAMS}

Diagram A. The hierarchical leadership structure of village communities .......................... 10

Diagram B. Qualities of servant leadership (adapted from (Prichard, 2013)...................... 168

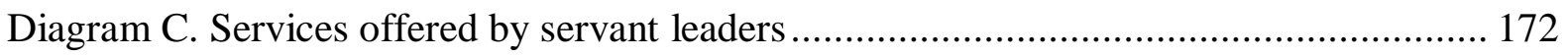

Diagram D. A traditional Samoan village in the pre-colonisation and Christianity eras...... 177

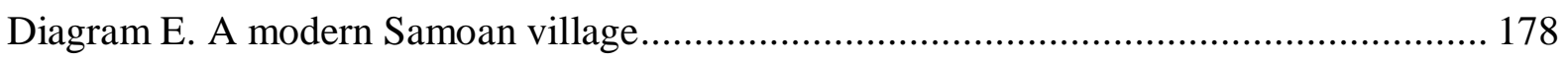

Diagram F. Proposed leadership model for local government of village communities........ 181 


\section{LIST OF TABLES}

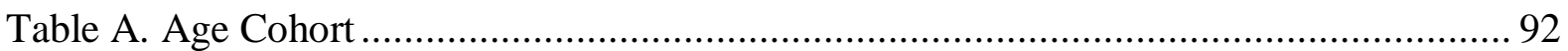

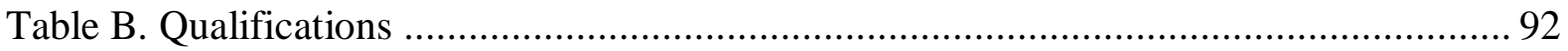

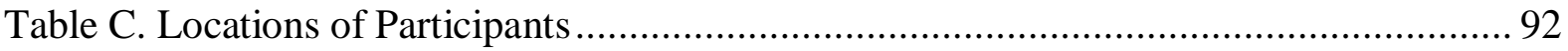

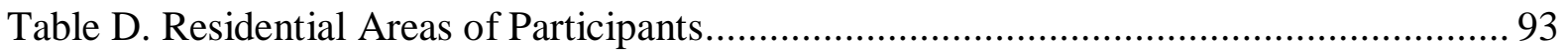

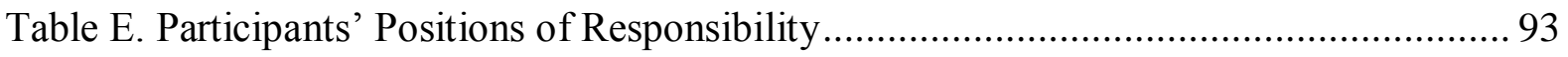




\section{ABBREVIATIONS AND ACRONYMS}

AUSAid

CEO

CSS

CCCS

CEDAW

MESC

MOH

MNRE

MWCSD

NZAid

NGO

SBS

SPBD

SUNGO

UN

UNDP

UNFP
Australian Aid

Chief Executive Officer

Centre for Samoan Studies

Congregational Christian Church in Samoa

Convention on the Elimination of All Forms of Discrimination Against Women

Ministry of Education, Sports, and Culture

Ministry of Health

Ministry of Natural Resources and Environment

Ministry of Women, Community, and Social Development

New Zealand Aid

Non-Government Organisation

Samoa Bureau of Statistics

South Pacific Business Development Organisation

Samoa Umbrella of Non-Government Organisations

United Nations

United Nations Development Programme

United Nations Fund for Population Activities 


\section{CHAPTER ONE: INTRODUCTION}

\subsection{Outline}

This study seeks to cross-examine the extent which limits women's opportunities for authority and power in traditional village communities in Samoa. The preposition of this thesis argues that the challenges women encounter in striving for leadership positions are initially rooted in the nomination of family leaders (matai) where preference is predominantly for males. Furthermore, local government endorse male appointments through the establishment of cultural structures and social systems to restrain potential women leaders. Religious beliefs that emphasise the uniqueness of the father as the head of the family couples with the entrenched mentality of honouring male leaders add more pressure to the prospective women leaders' struggle.

This qualitative study employs a triangulated methodology consisting of interviews, observations, and document analysis. The talanoa research framework (Vaioleti, 2006) facilitates the data collection tools while the theories of feminist, feminist leadership, and social constructionism authenticate the encompassing of a systems of concepts, the leadership characteristics of women, and the construction of knowledge through dialogic interactions respectively. The data analysis employs the thematic analysis process described by Braun and Clarke (2006).

This dissertation contains seven chapters. The first chapter introduces the study, explains the rationale, and outlines the objectives. Chapter 2 presents a literature review in which definitions and interpretations of the concept 'leadership' are presented from a general perspective in relation to the Western context and Pacific perceptions, as well as the practical leadership situation of women in Samoa. Chapter 3 defines the theoretical framework which incorporates feminist, feminist leadership, and social constructionism theories. This chapter also explains the significance of utilising and engaging these particular theories. Chapter 4 discusses the research methodology and design with a description of the data collection tools and data analysis method. In Chapter 5 findings from interviews, observations, and document analysis are presented and discussed. The discussion and interpretation of the results are provided in Chapter 6. Finally, Chapter 7 underlines conclusions and recommendations. 


\subsection{Introducing Samoan Leadership Issues}

The significance of the Samoan leader's role is that it is often deemed fundamental in the administration, implementation, and monitoring of village affairs (Iati, 2000). Matai hold the highest portfolio and take full control as the judiciary of traditional village societies, a legal transformation forum of a practice in the nineteenth century when chiefs were responsible for keeping order without an official central government of any kind (Davidson, 1970). The local government as it is known now consists of chiefly and oratory matai depending on the status of the title granted by respective extended families (Keesing \& Keesing, 1956). This decisionmaking forum is dominated by males due to them restricting women from holding matai titles, and their refusing of women's participation in local government meetings (Centre for Samoan Studies, 2015). These challenges are justified and motivated by cultural, religious, and social conventions.

The evidence is that 41 of the 240 traditional villages do not allow women to be bestowed with matai titles. Additionally, 34 villages do not allow resident female matai to participate in village council meetings (fono) (Centre for Samoan Studies, 2015). Fono is a Samoan term for a meeting or council. In Samoa, the Village Fono Act 1990 was enacted to give state recognition of the importance of the village fono to local governance, among other things. Overall, less than $10 \%$ of the matai population in Samoa were women in 2011 (Sāmoa Bureau of Statistics, 2015). These figures reveal the essence of two major impediments. Firstly, the authority of local government restrain extended families from selecting women leaders, and furthermore confine women heirs from accessing titles of the families they belong to. Secondly, the obsession hampers women matai from opportunities to become national leaders. At the time of writing, only five of the 49 parliamentary seats were occupied by women. Four were respective winners of their constituencies in the general election, and one was appointed as a result of the $10 \%$ allowance for women representatives, in response to Goal 3 of the Millenium Development Goals and Beyond 2015 (United Nation@UNFP 2005). The figure, 10\% is alarmingly low, considering the fact that women make up $48 \%$ of the country's total population (Sāmoa Bureau of Statistics, 2015).

Historically, Samoan people have had a tradition of female chiefs as traditional leaders (Gunson, 1987). For example, the war goddess and female warrior Nāfanua, ruled some constituencies of the country, and Queen Salamasina, the original holder of four paramount chiefly titles (tafa'ifā) gained sovereign control of the nation for more than 40 years (Meleisea, 
1987). Women were among those who made resolute actions to make sure that Samoa would one day be ruled again by Samoans. They established their own Mau in 1930 against the New Zealand administration, irrespective of the harsh circumstances (MacQuoid, 1995). The Women's Mau Movement appealed to the United Nations Organisations to grant independence for Samoa in support of the national petition filed by chiefs and orators. The success of the petition was proven when Samoa gained independence on January $1^{\text {st }} 1962$.

Generally, women gain their strength from the ultimate norm of Samoan ideology, feagaiga, the covenant between sisters and brothers (MacQuoid, 1995). Under a feagaiga relationship, brothers are obliged to serve and protect their sisters as well as any of her offspring for life (Holme \& Holme, 1992). Having determination in executing leadership roles is a feagaiga's tradition persisted strong with females until contacts with missionary and colonial powers where this traditional system of leadership battered (Schoeffel, 1979). The missionary and colonial eras saw an erosion in social systems, and many of these alterations diminished the status of Samoan women. The leadership authority that had been equivalent to the chiefs and orators dissolved as a result of women's lesser rank. Alteration of some characteristics of the traditional Samoan culture were made when Christianity replaced the Samoan indigenous religion (Kamu, 1996).

Women's leadership in Samoan village communities is neither recognised nor acknowledged due to cultural restrictions, religious beliefs, social assumptions, and the patriarchal nature of the administration of local government. Women leaders in women's committees are not usually consulted in the decision-making of village councils (Quay, 2006). Therefore, the Samoan cultural system does not recognise the existence of women leaders, since the expectation is that the village council is an all-male operation (Schoeffel, 2015). However, in spite of the maledominated leadership traditions, women consolidate avenues that strengthen leadership empowerment (Samoa Women Empowerment Project Report, 2015). For example, women undergo training on basic sewing, tailoring, weaving, cooking, stencil design, fabric printing, floristry, maintaining cleanliness and hygiene, financial literacy, and child protection (Ministry of Women, Community \& Social Development, 2013-2014). Income-generating activities utilising the skills obtained improve the financial status of families and people's living standards. Furthermore, women have become more alert to safety precautions regarding looking after the children and family members. Women gauge that their successful engagement in these activities proves the applicability of their leadership skills. Nevertheless, their dedication to the advancement of communities still does not eligible them to participate in local 
government since women's leadership is restricted to the confinement of women's committees. Women believe that they are leaders in their own rights because in the original Samoan tradition, women embrace authority over families and village communities (Gilson, 1970). Further to this, Gilson argues that the traditional activities which recognised the importance of Samoan women were deplored by missionaries in the $19^{\text {th }}$ century. Since then, the high ranking power of females gradually diminishes until the traditional administration of village communities is dominated by males (Silipa, 2008). Women categorise themselves as servant leaders by practising the qualities underlined in the servant leadership model (Prichard, 2013) which includes, valuing diverse opinions, duplicating and repeating effective tasks, cultivating a culture of trust, developing other leaders, planning long term goals, selling and not telling the goals of the organisation, encouraging partnership, and acting with humility. Women do not pay much attention to being labelled as second ranking leaders (pule na lua) in the hierarchal structure of traditional village communities, but prioritise other people's needs first. They believe that enabling the full potential in others enables the leader to make the most out of every situation (Chemers, 1997).

In positioning myself as a Samoan female leader, I gauged that ambitious women leaders are under severe restrictions established and enforced by local government. The influence of local government on the selection of family leaders compromise the integrity of the selection process, and threatening the participation of women matai in village council meetings is prejudice towards women. Furthermore, not providing women with equal opportunities to access matai titles like men extinguishes the traditional form of leadership noted by Meleisea (1987) prior to the advent of colonial powers and Christianity. The Samoan history of leadership documented by Meleisea illustrates the ruling occupation of queens for more than 40 years, demonstrating the matriarchal leadership nature of the Samoan society before contact with foreigners. Therefore, exploring the barriers that restrain women from accessing authority and power in local government forms one of many basis for further discussions on general gender inequalities in Samoa. Most importantly, this study may have the potential of reviving the female leadership dominion since it is the original form of leadership before outside influence.

\subsection{The Legendary Samoan Woman}

Samoan people respectfully regard the elite status of the woman in the hierarchical structure of traditional families and village communities. The dignitary connotations (fa'alupega) fitting to 
the prestigious status of the Samoan female (Tama'ita'i Samoa) is highly honoured, normalised, and respected. The esteemed inference constitutes the sacredness of the female who holds a ceremonial clergy-like position (ositaulaga). Sacredness was noted by Burrows (1939) as the most important aspect of leadership. In fulfilling this role, the tama'ita'i conducts a morning-prayer utilising the light from a coconut lamp (molipopo) that complements embers (aloiafi) from a 24 hour fire burnt in the middle of the house (magalafu) for the old people's Samoan tobacco. The prayer calls for the spirits of the ancestors to protect family members from enemies and accidents. If the family is preparing for a domestic battle or the village planning a civil war, the tamaita'i submits requests for the blessings and guidance of the ancestors' spirits. This role is done by the tama'ita' $i$ in her capacity as the leader of the family. The argument here is that, she is already a leader who should be involved in the decision making of local government. Unfortunately, male chiefs and orators are territorial in safeguarding village councils for themselves.

Another Samoan ritual addresses the woman as the wealth-maker (fai'oa) pertaining to weaving, crafting, and producing handicrafts. Traditionally, the standard of economy depended on the number of fine-mats, tapa and other handicrafts in the possession of families. These customary necessities were prepared for weddings, funerals, bestowment of a new matai title, opening of a new house, hosting guests, and other ceremonies. In present times, labouring for the family remains a service which should be considered in the recruitment of matai, similar to considering the untitled man's (taule'ale'a) labour. Regrettably, the service of the untitled man (taule'ale'a) is regarded by many as a service, while the woman's labour is labelled a contribution. It is unfortunate, but these are negative impacts of the changes introduced by colonisation and reinforced by Christianity.

The Samoan woman is known as the most sacred (tamasa) of all the siblings. The concept literally means that no one is allowed to counter or disobey her. Most importantly, the brothers should by no means lay hands on her. Added to this is the notion of being the most privileged lady ('augafa'apae), who is also the peace-maker (pae ma le auli) who irons out differences and harmonises people. The female is also the liberator (tausala) who rescues her family when defeated in a battle. Each of these cultural connotations denotes the privileges of the Samoan woman expected to be observed and treasured. Sadly, women leaders can only lament these ceremonial addresses because they have become gradually ignored by male leaders of local government and the church as well as other women. In my view, the highly-regarded status of women is now compromised, preventing them from authority in families, churches, and politics 
in Samoa. At the moment, women leaders provide services to village communities through a variety of skills and talents as servant leaders.

With reference to human rights, one of the weaknesses is how this Western concept is explained to other societies. It is problematic because how the messengers convey the message can bring a huge amount of damage to people's understanding of what human rights are. This may have caused local government to minimise and limit women's participation in decision making. Perhaps males feel that giving equal opportunities for women either threatens or weakens their power. The Samoans look at criticisms in the church and the matai system, and state that by comparison to the divine and the traditional, human rights or women's rights appear to be human constructs. In this logic, the Bible and the divinity of the Bible are beneath the power of local government.

\subsection{Samoa}

Samoa's beginning is explained in the language of marriages, genealogy, and heritage. Samoan myths and legends articulate Tagaloaalagi as the original creator. $\mathrm{He}$ was the ultimate autonomy, antecedent, and premier of other gods and humans. ${ }^{1}$ However, archaeologists concluded after assessing the Lapita pottery remains, that people initially settled in the Samoan group of islands at about 1500 B.C (Turner, 1884).

Samoa is a set of nine volcanic islands, located in the southwest of the Pacific Ocean. The two larger islands of Upolu and Savai'i have a land area of 2,820 square kilometres and there are seven smaller islands scattered around the two relatively big islands. Apia is the capital of Samoa, and is located in the main island of Upolu. The country lies between latitudes 13 and 15 degrees, and longitudes 168 and 173 degrees west of the Tropic of Capricorn (Fox \& Cumberland, 1962). Samoa is renowned as the heart of Polynesian, from which familial oceangoing voyages navigated from to all four directions of the Pacific Ocean (Te'o, 2011). Previously known as Western Samoa, the country gained its independence from New Zealand on January $1^{\text {st }} 1962$. In 2011 , the total population was 187,820 , comprising $48 \%$ females and $52 \%$ males (Sāmoa Bureau of Statistics, 2015). The government is a constitutional monarchy led by the Head of State who is appointed by Parliament on a five year term. In 2015, an amendment to the constitution ensured that the appointment of the Head of State was vested with the Cabinet. The two official languages are Samoan and English. 


\subsection{Background of the Study}

I initiate setting the context for the study by exploring the leadership strategies in traditional communities in the Pacific before any outside contacts. According to the literature, the traditional framing of leadership in Pacific islands is uniformity in terms of maintaining the intact fundamental values and beliefs. For example, most Tongan communities desire to maintain the monarchical system (Taufe'ulungaki, 2009). Similarly, the Vugalei clan in Fiji believe in the notion of "i solisoli - a gift from some spiritual source, an ancestor, or some unspecified and often mystical source" (Nabobo-Baba, 2009, p. 148). According to Teaero (2009), all Pacific cultures have indigenous philosophies, theories, and metaphors incorporated into their leadership paradigms. These leadership paradigms are executed in ways that reflect the conservation of cultural values and beliefs. Therefore, this study examines the practicality of leadership traditions in local government in Samoa, and the interpretation of these leadership traditions in holding back women leaders. This study also scrutinises the traditional leadership values and beliefs of other Pacific islands to determine the restrictions that hinder women's leadership in general. Examples are drawn from two unique roles that signify the leadership prerogative of women before the introduction of the male leadership concept in the $19^{\text {th }}$ century. Subsequently, the discussion features transitional factors which led to a diminishing of women's leadership, resulting in the establishment and continuation of male leadership precedents. Links to similar scenarios are drawn from international contexts as well as Polynesian and Melanesian settings to determine the degree of suppression Pacific women experience in their struggle for authority and power.

Samoan myths, genealogies, and traditional roles of women demonstrate the power attributed to them in the Samoan culture. Two significant core leadership roles of women were highly regarded and associated with specific responsibilities (Le Tagaloa, 1996). Firstly, the female was considered the traditional priest (ositaulaga), a role originally designated to the war goddess Nafanua (Williamson, 2013). Hence, succeeding females inherit the ositaulaga role, personifying the spirit (mana) that guides, protects, and blesses daily activities of the family (Barclay, 2005). In Barclay's view, Samoan females succeed to the roles of a traditional healer (taulāsea), a person who leads in worship (ositaulaga), peace maker (pae ma le 'āuli), and health maker (fai'oa). All these roles according to Barclay, forms the foundation of professional nursing in Samoa (Barclay, 2005, p. 206). Secondly, the female is esteemed as the covenant (feagaiga), the embodiment between herself and her brothers (Aiono, 1986). Whether the 
feagaiga relationship is formalised or not, it involves distinctly ascribed statuses and roles that are quite different, while being complementary (Schoeffel, 1979). This role assumes that the feagaiga finalises family decisions; it was taboo to challenge her judgement irrespective of the circumstances. These fundamental leadership roles of Samoan females are now ceremonial (Maiava, 2001), resulting in either diminished or halted leadership privileges.

The colonial authorities destabilised women's leadership by establishing new types of leaders and power centres which contested with the islands' traditional systems in the $19^{\text {th }}$ century (Feinberg \& Watson-Gegeo, 1996). These transitional structures confronted and threatened the traditional political leadership of the countries of Oceania. Furthermore, Christian missions comprehensively challenged spiritual power that had often signified precedence in the old systems (Gustafsson, 1992). These new systems did not recognise the Samoan myths and legends that documented the patriotic nature of women (Fairbairn-Dunlop, 1996). Classic recorded examples of these include masterminding and executing civil war battles. For example, Nafanua, the war goddess, who obtained four paramount chiefly titles (pāpā) as rewards of war victories (Isaia, 1999). Nafanua proved the contention that leadership requires willpower, bravery, and perseverance. The legend, 'E au le inailau a Tama'ita' $i$ ' explains the determination of women to beat men in thatching and re-thatching, leaving men in embarrassment (Papali'i, 2002). The myth from which the proverb, 'Ua fa'alava le Amoā' emerges denotes Amoa's bravery in rescuing the people of Sa Tagaloa from Lu's mischievousness (Le Tagaloa, 1996). In ancient times, Samoan females dedicated their lives to their families and the communities they represent, as evident in Amoa's determination to free her people. The holiness of the Samoan female as the feagaiga inaugurates dignity and legitimacy to the action of Amoa (Schoeffel, 1995). Hence, showing a leader's determination in going to the extreme to save her people. The legacies of Nafanua and Amoa are told in Samoan myths and legends (Fairbairn-Dunlop, 1996) to remind the present and future women about the leadership styles of Samoan women in the past. The leadership behaviour of these females and many others guaranteed the success of female leaders who participated in the administration of village communities in Samoa. However, females gradually withdrew in the wake of male matai (cultural title) domination.

A noteworthy feature of the appointment of Samoan leaders or matai is that anyone who is kin qualifies, regardless of gender or age (Holmes, 1980). Nevertheless, gender is the most notable criterion that diminishes women's chances to become matai. The social notion of associating women with household tasks plays an influencing role in the selection of matai (Saolotoga, 
1995). The same supposition lingers over women in their battle for leadership positions in many countries of the world. For example, women are not attaining top jobs in companies in the United States because their managers assume that their family roles hamper carrying out their responsibilities at work (Hoobler, Lemmon, \& Wayne, 2011). Along the same line is what Simpson (1997, p. 122) alludes to as stereotyping women into "role traps which includes the mother", a typecasting barrier that isolates women from management posts. Gender biases that regard leadership qualities to be more suitable for men endure and are hard to subdue in some organisational cultures (Schwanke, 2013). In addition to gender bias is the influence of cultural norms which results in some women's refusal to take leadership obligations (Akao, 2008).

From the local to the global level it is evident that cultural, religious, and social barriers threaten the participation of women in positions of authority. Almost all cultures craft social distinctions between men and women and in many cases women's identities are compromised in social hierarchical systems (Harris, 1991). This incorporates certain matters of intimidation which label women as being inferior and incompetent (Eagly \& Mladinic, 1994). Men with aggressive attitudes towards women target status-seeking women, and when women are in senior positions, they appear to them as having threatened male territory. This, together with the fact that women leaders are surrounded mostly by male colleagues, places women at further risk of discrimination (Broughton \& Miller, 2009).

Similar cases of the difficulties in accessing leadership positions also exist for women in other Pacific countries. The traditional kin-based stratification of the oldest male in the family having the final decision-making is culturally active in Tonga for example. Although the highest female holds a given title, she lacks any decision-making power in extended family matters (James, 1995). In consequence, she cannot represent her family in the decision-making forum of her village community.

The same scenarios affect women in Papua New Guinea. Here, women are confronted with culturally biased values and males' controlling power. Historically, the situation has been difficult with a strong gendered-bias against women in leadership positions throughout the country. The difficulty of challenging power and cultural barriers limit women's participation in making decisions. Consequently, women continuously experience hardship in striving for authority and power. Their voices are unheard because public spheres are traditionally-oriented and continue to be male domains (Vali, 2010). These harsh circumstances point to kinship. In most traditional Melanesian societies, these kinship systems prescribe the way people socialise 
and function (Sanga \& Walker, 2005). Leadership in these kinship systems are maledominated. For example, in the case of extended families ('âiga potopoto) in Samoa, the elected leaders are matai, and the majority of these matai are males. These male matai control the affairs of extended families as well as being members of the local government, the judiciary for traditional village communities established by the Village Fono Act 1990 and the Internal Affairs Act 1995 (Ministry of Women, 2016). The local government is the highest authority in village communities which creates and enforces rules and sanctions for the whole community. I have posted the leadership structure in the following diagram.

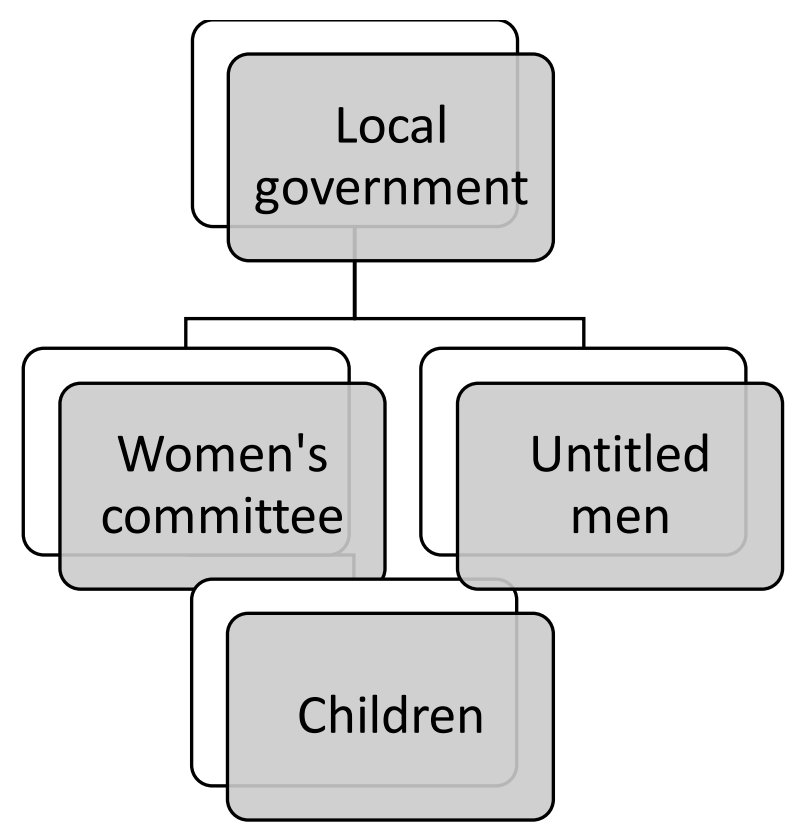

\section{Diagram A. The hierarchical leadership structure of village communities}

Critiquing cultural paradigms permits an understanding of the history of leadership in Samoa to inform understanding of the modern construct. The Samoan context of leadership signifies carrying the spirits of ancestors and representing the mauli of your family members in leadership posts (Sanga \& Chu, 2009). The mauli upholds the spirit (mana), equipping leaders of families ('âiga) and village communities (nu'u) with the wisdom to impartially execute leadership roles (Aiono, 1986).

\subsection{Cultural and Social Philosophy of the Research Context}

The social philosophy of this research is exploring the validity of the leadership assumptions in Samoa that associates with being male, and the sincerity of the respect accorded to them in cultural, social, and religious activities. According to the Samoa Millennium Development Goals Progress Report 2010, Samoan women have limited access to customary land and are 
largely excluded from dealings in customary land, such as customary leases. Although they have equal rights over freehold land, women do not charge well in practice, as they do not often avail themselves of the right to be included on the title as a registered owner. This particular report explains land ownership as another hindrance to Samoan women's leadership due to restricted access and their exclusion from land dealings. There is a huge gender gap with leadership roles in the villages (Schoeffel, 2015). For that reason, this study is intending to change people's mind-set about the male leadership preference by suggesting that women have equal rights to become leaders of their families by holding matai titles as mandated in the constitution of the independent state of Samoa.

\subsection{Leadership Definition and Styles Targeted}

Leadership definitions vary in the research and literature. However, I am drawn to a leadership definition by Burns (1978) who refers to leadership as a process and a property, and it is this framing that helps position this study. According to Burns, the leadership process entails how an individual or a group influences others towards a particular goal or objective, and leadership is about developments that occur across one's life span. This process is "where an individual inspires a group of individuals to achieve a common goal" (Northouse, 2007, p. 3). Burns (1978) also notes that leadership is a property of an organisational structure, mandated to align with the expectations and norms of the organisation. In addition to Burns, Gardner (1990) sees the components of process and property in leadership as a sub-set of the broader concept of communal purpose. Further, Sanga (2005) denotes the village community as a setting for communal purposes. In Samoa, village communities and women's committees come together to do communal activities either as a collective body, or in separate organisations. Furthermore, the study explores the leadership styles and whether autocratic, democratic, and laissez- faire styles (Lewin, Lippit, \& White, 1939) are apparent in women leaders' practice of communal activities in women's committees and village communities.

\subsection{Researcher's Standpoint}

When I was a young woman in the village, I used to listen to narratives of great leaders, and I developed this philosophy of trying to be one of those great leaders. Now, I have finally realised that leadership is not about replicating someone's behaviour, or trying to be someone else. I have learnt that leadership is not about having power over other people, but it is about stepping up to lead. 
My upbringing in a village community revolves around cultural and religious principles. Hence, my leadership journey was guided by the moral values of respect (fa'aaloalo), love (alofa), and humbleness (loto maualalo). These principles were complimented with a comprehensive knowledge of the essence of Samoan and Christian ethics, learnt within the vicinity of the family, and taught by my paternal grandparents who additionally groomed me to be a leader at a very young age. Fundamentally, my excursion into the leadership world began with learning basic survival skills by observing and assisting my grandfather in farming, carving, and fishing. Although I did not pay much attention to my grandmother's talents of traditional healing (taulāsea) and midwifery (fa'atōsaga), I credit her expertise in serving the village community. In addition to learning survival skills, I also learnt to be self-sufficient, relying on what I was able to afford. These trainings initially nurtured my leadership knowledge and experience. I commend my grandparents for envisaging my leadership potentials and I am forever grateful to them for making me the leader I am today.

I am passionate about leadership in village communities because the environment is integral to upholding true Samoan values as well as keeping the culture alive. Through experience, I am of the opinion that these gender disparities need to be addressed in order to acknowledge women's statutory right to leadership. According to Haider (2009), participation in decisionmaking must be inclusive, and should incorporate groups that are marginalised such as women. This argument is supported by Freire (1983, p. 76) who states "Participation in decision-making processes is the right of all people to individually and collectively speak their word". As leadership is not the privilege of some, it is my intention for local government to implement an innovative culture where people's ideas are expressed, recognised, and valued by involving them in decision-making. For example, community leaders must believe that implementing appropriate changes allows growth, reflecting maturity, and stability in leadership. As Chambers (1983) suggests that participation can potentially develop into empowerment, it is my goal to see that many women are empowered to partake in local government. Though faced with a lot of challenges, my journey through the leadership sphere has enabled me to experience theoretical perspectives and practical approaches pertaining to female leadership. This leadership excursion has also familiarised me with the practicalities of leadership characteristics particular to female leaders in comparison to their male counterparts. 
I am inspired to explore the original status of the cultural context of the Samoan female as the feagaiga (covenant), adviser, and decision-maker. The literature documents the elite status of the Tama'ita'i Samoa (Samoan female), her unique responsibilities, and her decision-making power as evident in (Aiono, 1986; Fairbairn-Dunlop, 1996; Le Tagaloa, 1996; Meleisea, 1987; Schoeffel, 1979). These literature carefully remind me, a Tama'ita'i Samoa about women's position in society, and motivate me to explore, identify, and address the hurdles that restrict women from leadership positions.

\subsection{The Samoan Pathway to Leadership}

"O le ala i le pule o le tautua" is translated as: the way to authority and power is through service. The Samoan proverb grounds the foundation of gaining leadership in Samoa. Some scholars refer to leadership as providing service. "Leadership is tautua [service]" (Rimoni, 2009, p. 51) and "genuine leadership is true service" (Samala, 2009, p. 63). The selection of matai to lead extended families is based on the quality of service rendered. Family decisionmakers deliberate on the type of services and the standard of performance. In most cases, the final candidate is the one who provides the family with outstanding services - for example, serving the family with dignity and honesty in his position as an untitled man (taule'ale'a). This includes preparing and presenting food to the matai, rendering all expected services, doing as instructed, and protecting the matai and his family from enemies (Macpherson, 1997). There are other factors such as seniority, having cultural knowledge, and being wealthy. In whatever manner, service is the most considered aspect in the selection process. Males have advantages because of the apparent nature of their services while the female's contribution is less visible. Contributions from females are neither announced nor revealed. Consequently, the preference for matai is males, and females are seldom selected after serious consideration. Hence, the patriarchal nature of the Samoan society continues to thrive.

\subsection{Aims of the Study}

The study aims to address the following issues:

1. Factors affecting women's leadership in traditional village communities in Samoa

2. Gender inequalities in participation and representation in village council meetings (local government)

3. The meaning of leadership for women in traditional village communities 


\subsection{Objectives of the Study}

To address the objectives of the study, one main research question and four sub questions were posed.

"What are the gender inequalities pertaining to Samoan women's leadership, representation, and participation in the local government of the village?"

1. What are the challenges that prevent Samoan women from being positional leaders?

2. What is leadership for women in traditional village communities in Samoa?

3. What are the strategies Samoan women use to serve as leaders?

4. How do Samoan social philosophies, cultural beliefs, and perceptions inform women's leadership?

\subsection{Significance of the Study}

This study establishes a platform to identify, discuss, and address gender inequalities in leadership in local government in Samoa. It serves to generate further dialogues about general gender disparities and practices in traditional village communities, churches, and the national government. My research provides a voice for women with leadership skills and knowledge to participate in local government, a decision-making forum that creates, authorises, and enforces rules for traditional village communities. The study is also enlightening the notion of gaining political opportunities as a result of participating in local government since the majority of women are capable academics and professionals. In terms of opportunities for leadership development, I envision and remain hopeful that if general gender inequalities start to become part of the leadership dialogue, there may also be potential to increase the number of women leaders in local and national governments in Samoa, as well as in churches and traditional structured-organisations.

\subsection{Method}

In exploring encounters regarding gender inequalities in leadership, representation, and participation in Samoa for women, this qualitative study uses a triangulation methodology for data collection. The instruments include recorded semi-structured interviews, observations, and document analysis. These tools aim at exploring the challenges that restrict Samoan women from accessing leadership positions in local government. The study adopts an interpretive multiple-case study qualitative approach, a methodology supported and recommended by many authors (Creswell, 1998; Klein \& Myers, 1999; Morgan \& Smircich, 1980; Morse, 1994). The focus of this kind of study is on the meaning of actions that occur, both in face-to-face 
interactions, and in the wider society surrounding the immediate scene of action. To conduct interpretive research in a certain setting, intense and long-term participant observation is required, followed by deliberate and long-term reflection on what was observed. The researcher's point of view, previously learned theories and cultural conditioning need to be considered while engaging in the field work.

The talanoa research framework (Vaioleti, 2006) facilitated the interviews and observations, and formed the basis of the field work. Talanoa is described by Churchward (1959) as to talk, to tell stories, or to relate experience. Pacific researchers like Otukunu (2011), Vaioleti (2006), and others recommend talanoa as a research approach practical in Pacific culture. The customary benefits of talanoa consist of no time-limited, guided by spirits of participants, internal control by participants, likely to be cultural obligation to participate, using ceremonies to set scene and establish will to participate (Robinson \& Robinson, 2005). These advantages of talanoa makes it suitable for this research.

Three meeting sessions with each interview participant concentrated on different purposes. The sequence involved performing cultural protocols of acceptance, an hour long interview, and data validation exercises. Each encounter lasted between one to one and a half hours. The meetings started with greetings followed by a prayer. They were conducted with a business agenda of asking and answering questions as well as elaborating important concepts and information.

Participants were observed while engaging in communal activities like a weaving expedition, tapa (siapo) making, and hosting guests. Like the interviews, the observations were also facilitated by the talanoa research framework (Vaioleti, 2006). However, the purpose of observations was to discover the encompassing of concepts, leadership characteristics of women, and meanings constructed through dialogic interactions.

Policies, surveys, reports, and artefacts for document analysis were obtained from the United Nations Women Office in Apia, Ministry of Women, Social and Community Development and Internal Affairs, and the Centre for Samoan Studies at the National University of Samoa. Documentaries of women's activities were provided by the Tiapapata Art Centre.

\subsection{Chapter Summary}

The first part of the introduction (1.0) presents the outline of the study, while (1.1) introduces Samoan leadership issues. The next section (1.2) provides information about the Samoan 
legendary woman. Section (1.3) gives information about Samoa, the location of the study. Section 1.4 explains background information about the study, and Section (1.5) outlines the cultural and social philosophies of the research context. Explanation of the definitions and styles of leadership the study targets is given in Section 1.6. Section 1.7 consists of the researcher's reasons and motivation to do this research, while Section 1.8 submits information about the Samoan pathway to leadership. The aims of the study are explained in Section 1.9. The next section (1.10) provides objectives of the study. Section 1.11 defines the significance of the study, Section 1.12 explains the methods the study utilises, and concludes with a summary in Section 1.13. 


\section{CHAPTER TWO: LITERATURE REVIEW}

\subsection{Introduction}

This literature review provides a background for the study by examining leadership in local government, and what has been said about leadership in a number of contexts in the developed and developing countries. Special attention needs to be paid to the models of leadership and the ways in which these impact on gender. Diverse perspectives of leadership are discussed highlighting the diverse interests and backgrounds of researchers. Goals and processes pertaining to leadership are discussed to distinguish between general leadership assumptions and aspects that are culture specifics.

Section 2.0 provides a brief introduction to the content coverage of the chapter. Section 2.1 yields information on the definitions of leadership, paying attention to the diversity in perceptions and experiences of researchers. The characteristics of leaders is the focus of Section 2.2, featuring what works and what does not work for organisations. Section 2.3 describes leadership styles, underlining the commonalities and differences in the execution of leadership roles. An account of leadership in traditional communities of Pacific islands is given in Section 2.4, narrating the appropriateness of particular leadership styles suitable for cultureoriented societies. Section 2.5 explains leadership in Samoa, reflecting on the dominance of male leaders in local government, and illustrating challenges encountered by women in accessing power and authority in village communities. Section 2.6 gives information about the leadership characteristics of females, comparing the way men and women lead, and ascertaining what the literature has to say about the question of whether women leaders are different from their male counterparts. Section 2.7 centres around the leadership challenges for women, shedding light into the suppression of women in certain organisations, especially in traditionally-oriented societies. The last chapter, Section 2.8 submits an overall framing of the leadership paradigm, depicting the influence of the administrations of local government in Samoa, and concludes with a summary on Section 2.9. The discussion begins with general definitions of leadership which then leads to certain focusses reflected in a variety of no specific definitions. 


\subsection{Definitions of Leadership}

From a range of definitions, researchers tend to select those most appropriate to their research purposes. Certain contextual spheres of leadership have thus been examined and investigated by researchers, and their subsequent theories and culturally conditioned conclusions reflect key areas of the leadership philosophy. McLeod (2008) observes that the range of leadership definitions denotes a variety of approaches and perceptions of scholars about leadership, reflecting the leadership interests of academics from diverse backgrounds.

In scrutinising the copious definitions of leadership, Stogdill (1974) says the number of descriptions available is virtually equal to the number of people who have tried to attach meaning to the concept. Stogdill (1974) sees complications and diverse interpretations in many researchers' attempts to explain what leadership is or might be. Clearly, this variance is itself a difficulty for leadership-based research. Between 1902 and 1967, Stogdill (1974) in his Handbook of Leadership, revised 72 definitions of leadership suggested by leadership scholars (Kets De Vries, 1998). Fortunately, there are many specific definitions to inform researchers of what is interesting and contextually useful in various research fields. These include leadership as guidance, the way leaders anchor organisations, flat models of leadership, and leadership as empowerment. These are each briefly discussed below.

Leadership is defined as a guiding process which requires leaders to "have honesty and integrity, and involves doing the right thing when it would be so much easier to do the wrong thing" (Stanfield, 2009. p.13). This interpretation of leadership focusses on the significance of the leadership task of guiding, ensuring that it is done with uprightness and honour. Guiding is leading the way, embracing people's needs, and striving for success (Stanfield, 2009). Included in Stogdill's (1974) list of reviewed definitions is Gardner's (1990) description which refers to leadership as something that holds together, to anchor the integral parts of the system, despite the fact that they are subject to forces that affect the system. Safeguarding the system is important because it shows that leadership protects the crucial elements of the organisation to cope with influences. This definition highlights the importance of safeguarding the organisation from disruptions of any nature. However, in my view, disturbances are natural parts of any process. Therefore, by definition, the leader is mandated to protect the organisation from any turbulences. The protective duty of the leader should couple with ensuring that he or she takes a neutral stance, seeking the common, not personal good. 
In Bensimon (1989) reinterpretation of the leadership definition by College President Wittman, she reasons leadership to mean being first among equals. This is a non- hierarchical, or flat model interpretation. Respecting equality is the essence of leadership in this definition, and placing the leader first involves identification of the leading figure, seeing their potential, denoting that he or she is responsible for leading, but not elevating their formal status as a result. The definition acknowledges equality, one of the characteristics of a democratic leader that Sanga (2005) alludes to. In this case, democracy means 'of people' status is present but hierarchy is played down. This flat but inspirational version of leadership is not universally held. Bensimon (1989), for example, suggests the principles of persuading, educating, consulting, pulling, shoving, and biting in the directions the leader wants people to move. This definition seems contradictory since persuading, educating, and consulting are consultative and interactive while pulling, shoving, and biting are deemed autocratic and forceful. I feel that it is very important for the leader in this situation to ensure that people are consulted before pushing them to achieving the goals of the organisation. This leads to accepting people for who they are, and involving them in the activities. This is in turn consolidates community.

Leadership can also be about involvement. West-Burnham (2003, p. 9) defines leadership as "the active promotion of a society based on positive acceptance and engagement". This encouraging definition values communal cohesion. This links to Gardner's (1990) interpretation which refers to leadership as a sub-set of the broader concept communal purpose. Sanga (2005) extends this definition to refer to societies and organisations such as villages, church groups, tribes, government ministries, schools, and national states which all exist for communal purposes. The leader in a communal situation is important in that leaders recognise people and involve them in activities that advance the community. This notion is relevant in this study because communal purpose is the key factor in propelling cooperation and teamwork of women's committees in Samoa. The communal purposes of these village women range from being in-charge of the overall health and hygiene, engaging in fine-mat weaving, tapa making, and income-generating activities, as well as providing a variety of services such as traditional healing and midwifery for people. These competencies of village women enable them to gain power to be self-sufficient and communal capable. 


\subsubsection{Leadership is Power}

Another facet of leadership is that it is a dynamic process based on power, not a static commodity. Researchers have described leadership processes as empowerment, value-laden, as divisible into power and influence, and as the result of personal powerful attributes. "Leadership is an aspect of power, but it is also a separate and vital process in itself" (Burns, 1978, p. 18). Burns' definition clarifies two significant factors of leadership. Power, which refers to the authority of the leader, and vital process, that requires the leader to be vigorous, energetic, and self-motivated, given the rights vested in them. Self-motivation connects to selfmanagement, an aspect of personal competence which enables a leader to be psychologically sensitive of relational matters (Goleman, 1995).Leaders in this situation are required to understand their feelings, be considerate of others' feelings, and be motivated to drive the organisation to achieving its goals. McLeod (2008) explains leadership as an integral component of good governance, the main determining factor central to all types of development. Decision-making is central to leadership since leaders must possess effective decision-making skills to achieve sound policies and procedures in addition to good working relationships. If leadership aims at initiating developments, analysis of developmental outcomes is significant because not all developments are beneficial. Considering good governance as the best possible process for making good decisions places much emphasis on the fundamental values of transparency, accountability, responsiveness, inclusivity, equity, effectiveness, efficiency, and participation. The exercise of these values is likely to encourage leadership potential that empowers people.

Leadership principles and discourses in Western countries regarding the functions of organisations highly regard empowerment in addition to teamwork, delegation, listening, and learning (Conger, 1989). This kind of leadership cannot be separated from organisational culture (Bate, 1990), and it is sometimes affirmed that the culture of an organisation can be manipulated, changed, or even substituted by top management (Meek, 1992). The philosophy of exploring changes seems to be the focus of Western researchers, which sometimes results in undermining norms of traditional organisations. Scenarios of this nature alert leaders to explore practical settings for empowerment to work, especially in culturally-oriented organisations.

In terms of leadership theories that emphasise task and organisational integrity, Western literature documents the significance of making changes, ignoring the established values of cultural protocols. Where leadership theories emphasise cooperation, ethics, and community, 
Western literature can be seen to give more weight to the rhetoric of management consultants than it is the reality of management practice (Kotter, 1990). This explanation implies that performance justifies leadership. Furthermore, performance cannot guarantee that people continue to stay in the organisation. For example, followers' dissatisfaction in East Asia results in not acknowledging leadership; this is in-consistent with the higher levels of power distance characterising most East Asian societies (Hofstede, 1980). In situations like this, it is quite challenging because the high powers influence the work of most organisations. Therefore leaders, outsiders especially, are caught between pursuing the goals of the organisation and motivating people who respect high authority.

The goals of the organisation and the encouragement of people are the concerns of Lasswell and Kaplan ( 1950) who argue that the relevancy of power is closely connected to the things leaders value; things of importance to the leader themselves or to the employees. The leader and employees' analysis of what is significant for achieving the goals of the organisation must be valued on a similar basis. Therefore, individuals are required to cooperate and be supportive of the vision and mission of the organisation. The implication is that although the leader is the power holder, consideration of the things he or she values is on the same basis as those of the workers. As a result, the organisation perfects relational, collective, and purposeful decisions. The definition about the importance of power relevancy is concerned with relationships and communal purpose guided by determined decisions. However, it is not clear whether decisions reflect the determination of the leader or of the organisation because a lot of problems will arise if the leader and the organisation are committed to different purposes. When such a situation arises, some leaders forcefully impose their values on employees by attempting to change people's behaviours and attitudes. This is explained by Janda (1972) as the capacity to influence people to conform to the expected behaviour by amending the way they behave. This could be more easily accomplished if behaviour aligns with the conventions of the authority. However, it may be hard to convince people to move out of their comfort zones and change. People need to adjust to changes for the organisation to survive and move forward.

One way to differentiate the various ways that leaders lead can be expressed as exercising power and exercising influence (McFarland, 1969). Leaders who execute intentional changes are exercising power. On the other hand, leaders who make changes unintendedly exercise influence. I agree with Burns (1978) that exercising influence does not constitute firm leadership because unexpected changes may be the results of unplanned activities. Therefore, the impact on the organisation could be either positive or negative, depending on the 
circumstances. In my view, it is significant for leaders to ensure the execution of valid tasks which correspond with the followers' morals and inspirations (Burns, 1978). If leaders intend to empower people, they should at the same time impart to them the knowledge required to utilise power (Baldwin \& Grayson, 2004). We normally examine leadership in relation to exploring the types of institutional monopoly and their activation of power in making decisions.

Burns (1978) believes that leaders hold specific powers that are interpersonal, communal, and decisive. Although leaders potentially possess powers, not all leaders are capable leaders. The power invested in leaders should enable them to connect with different people involved in the operation of the institution. When it comes to decision-making, democratic leaders take an active role but others also participate (Lewin et al., 1939). The authors claim that leadership procedures and strategies utilised must be meaningful in terms of the goals of the organisation. However, Lewin et al. (1939) have advised leaders to be mindful of effective ways to exercise power for the benefit of people and the institution.

\subsubsection{Leadership is a Process and a Property}

Several of the researchers claim leadership as either a process or a property or both, depending on the nature and setting of the study. Jago (1982) defines leadership as both a process and a property, an idea suitable for use across cultures. According to this definition, the process of leadership refers to utilising gentle stimuli to organise and guide the tasks of members towards accomplishing the goals of the group. These goals are termed property, or a set of potentials credited to people who have effectively commissioned them. French and Raven (1959) have seen the efforts of leaders in influencing group members and directing them towards a common goal. Another idea of property explains universal characteristics of personality that determine a leader's effectiveness (Kets De Vries, 1998). Ciulla's (1998) definition resonates with Jago's (1982) in differentiating process and property.

Leadership is also an ethical process. Ciulla (1998) gives effectiveness and ethics as the main principles of leadership alluding to the importance of gaining a clear, comprehensive understanding of what true leadership means and the weighty ethical responsibility that comes with it. These hefty responsibilities frame the leader's performance in achieving goals of the organisation. According to Pfeffer and Salanick (1978, p. 111) responsibility is connected to the construction of knowledge and meaning-making and is: 
associated with a set of myths reinforcing a social construction of meaning which legitimates leadership role occupants, provides belief for potential mobility for those not in leadership roles, and attributes social causality to leadership roles, thereby providing a belief in the effectiveness of individual control. (p.111).

This definition acknowledges the significance of traditions in creating meaningful constructs to consolidate leadership tasks of people, nurturing aspiring leaders, and valuing the interconnectedness of individuals. The ambitious definition indicates the importance of recruiting efficient, ethical, and effective leaders since it involves legitimisation and outcome.

Western literature focusses on interaction amongst people and includes definitions of leadership as "a process of social influence in which one person can enlist the aid and support of others in the accomplishment of a common task" (Chemers, 1997, p. 1). Chemers (1997) explicitly defines this progression as the ability to influence others towards the leader's goal, assumed to also be the goals of the organisation. He affirms the notion of process used by Jago (1982) to illuminate leadership. However, Chemers (1997) emphasises the influential role of the leader while Jago (1982) highlights the significance of incentives in achieving goals. Both definitions centre on the advancement of targets in order to gain contextualised success, the most important objective of any organisation. Bass (1990) does not look at success, but rather places the value on group process. In his definition, he tenders the understanding that leadership is regarded as "the focus of group processes" (Bass, 1990, p. 20). He believes that group processes are central to leadership. Therefore, the leader is the most important person in facilitating changes and embracing the communal goals of the group. Like Chemers (1997), Bass (1990) also discusses the significant role of the leader in achieving the goals of any organisation. Rost (1995) also proposes leadership as a commitment to attaining common goals, which brings to the forefront the prominence of leadership practices in any context.

Despite the domination of Western views in the literature, comparative studies concentrate on evaluating traditional leadership against locally effective management skills and leadership processes (Ayman, 1993; Smith \& Peterson, 1988). Practices that cluster people into culture examine unique cultural characteristics to determine diverse leadership strategies in distinct traditions (Hofstede, 1993). Researchers who support this cultural analysis frequently quote the individualistic nature of the United States in support of the claim that leadership theories constructed in the United States cannot be generalised to include other cultures (Triandis, 1993). On the other hand, some new scholars have argued that culture exists as a world-wide 
trend for leadership processes (Bass \& Avolio, 1993). Bass (1990) has identified culturespecific versus universal culture as two principles behind the understanding of leadership. According to Bass (1990), both philosophies are valid for researchers and research purposes. A study on "Leadership in Western and Asian Countries" focussing on commonalities and differences in effective leadership processes across cultures found that inspiring leaders are effective in South Korea, Mexico and the United States, while this quality has no effect in Japan and Taiwan (Dorfman et al., 1997). These results show specific bias in the way different cultures respond to certain leadership styles, as well as leaders of different calibres.

The development of hypothesis and research methods distinguishes between culture-specific and culture-universal researchers. For example, the literature review by Smith and Peterson (1988) reveals a pattern of task, and relationship orientation in the general behaviour of leaders, a feature which has been noticeable in many leadership models in the United States. Task, and relationship-orientated are particular features operative in the study of collective culture. Since these strategies are consistent with cultural values, managers who employ them are successful (Jackofsky, Slocum, \& McQuaid, 1988). However, the acknowledgement of cultural values in the leadership literature signifies that the perspective of non-dominant cultures is distinctive, and can make a contribution. For example, Klitgaard (1994, p. 76) states:

Differing cultures deserve respect. Too much has been made of the negative features of traditional societies and not enough of the positive, from which so-called modern societies can learn. Cultures manifest their own configurations of motivations and incentives, as a consequence of their specific cultural capital. There are no necessary or sufficient cultural preconditions for economic development...development itself is a culturally loaded term, ready to succumb to ethnocentrism.

This definition of leadership refutes research which assesses traditional societies against the expectation of modern Western-orientated organisations. It stresses that traditional organisations conform to their cultural disciplines in achieving various kinds of wealth. This relative view suggests that there is no culture superior in gaining economic growth. I think this definition weakens the superiority in modern societies to overpower traditional societies, contradicting Burn's (1978) definition of power as an essential element of leadership relationship. Burns (1978) claims that power saturates all human relationships. According to the author, those who exert power over others are not leaders, but power-manipulators. By contrast, especially in traditional societies, leaders share power to empower their followers. 
Leadership as power and a vital process (Burns, 1978) explain the situation of women in village communities in Samoa. The power of women is communal since knowledge is imparted and expertise shared to enhance empowerment (Conger, 1989). Empowerment is enforced through teamwork and collaboration. Women interact in the construction of knowledge, revival of traditional healing and herbal medicines, weaving and crafting, implementing community projects, and engaging in income-generating activities. These communal goals have been achieved by going through certain processes together. For example, weaving of fine-mat and tapa making are time consuming processes which women successfully go through by working together and supporting a collective goal.

\subsection{The Characteristics of Leaders}

The discussion now focusses on what the literature reveals about the key characteristics of leaders. This literature alerts those in positions of authority to the importance of aligning the characteristics of leaders with the goals of their particular organisation. Leadership is universal, but practiced differently in various settings. The leader's situation does not guarantee effective leadership because people and circumstances vary (Wright, 2009). Basically, practical leadership encompasses the capacity to run through changes. So far, there seems to be no single agreement on the characteristics of a good leader even though there has been considerable research into this (Vojta \& Associates, 2010). The literature does reveal, however, the significance of a number of characteristics; these include having vision, being peopleorientated, being flexible, involving subordinates, executing accountability and transparency, possessing emotional intelligence, and practising good decision-making skills.

According to the literature, vision is one characteristic of an effective leader. Greenleaf (1977) believes that the fundamental role of a leader starts with initiating a vision to direct the organisation's future activities. This vision could be a representation of a dream or an idea of what the organisation is capable of doing. A leader can bring into reality the aims and goals of a group through denoting what is practical and how it is practical, as these are the components required for reaching the vision of the organisation. Greenleaf (1977) explains that initially, effective leadership starts with believing in yourself, having maturity, principle-oriented thinking, and the know-how to realise perseverance. With this clear vision, the great leader gains self-assurance in assuming the responsibility of imparting encouragement, selfconfidence, and team work. Leaders with visions are well organised intellectuals who have 
confidence in their perceptions (Greenleaf, 1977). Although visionary, some leaders are sometimes manipulative to push through their personal agenda. This is not healthy in my view since it affects relationships and people's morale. For example, those who are supportive of the leader's vision may have more privilege than the non-supporters. Hence, creates frustrations and tensions amongst employees.

According to Getzels and Thelen (1960), leaders cannot afford to become distant from environment and people, since they need to have a concrete understanding of their surroundings, be able to convert circumstances, and achieve transformation of situations to attain a recognised vision. The authors point out that leaders function through certain combinations of circumstances. For example, combining change and growth, accommodating judicious risks, and exhibiting reasonable problem solving skills. Furthermore, leaders are supposed to be people-oriented, considerate of others' needs and be able to acknowledge a person's central principles. In this way, they will effectively re-design encounters to earn benefits by establishing an organisation that builds and nurtures success (Getzels \& Thelen, 1960).

The process of building and nurturing success requires the leader to be flexible to adjust to a range of solutions and perspectives (Jones, 1997). The author emphasises that the key is to visualise diverse situations and barriers, but not to lose focus on the vision of the organisation. As Bennis (2003) argues, the main reason for a decline in a leader's efficacy is not having a clear vision despite the urge to transfer their ideas and dedicate their time and effort to the results. Further to this, Shields and Sayani (2005) say that a leader's vision must be transformed into an all-encompassing situation to accommodate the trust and dedication of people who are willing to accomplish the purpose of the organisation (Shields \& Sayani, 2005). My interpretation of the authors' suggestion is that a visionary leader must be approachable, adjustable, and trustworthy in order to earn the faith and dedication of the employees. Gardner (1990) notes that including supporters in the discussion justifies the significance of relationships. He goes further to suggest that leaders who care about relationships are effective in working together with people. According to the author, linking leaders and followers is critical in ensuring that the goals of the organisation are met (Gardner, 1990).

Burns, (1978) supports the notion of connecting leaders to followers by stating that, "Leaders need followers and followers need leaders" (p. 6). In here, Burns is reminding leaders about the vitality of relationships in organisations. He stresses that sustaining good working 
relationships is critical for ensuring the flow of communication. By emphasising the significance of sustaining relationships, Burns (1978) recommends that a leader who sustains good relationships with followers demonstrates transparency and accountability. In essence, this particular leader plays the crucial role of clarifying organisational matters to followers and is accountable for any decision made. Leadership according to Burns (1978) is the interdependence between a leader and his followers. Most importantly, a relationship should be made explicit to both individuals (Hollander, 1992) and collective bodies (Burns, 1978).

The discussion now turns into the kind of leader Burns (1978) refers to as "institution-bound policy makers" (Burns, 1978, p. 409). These leaders as explained by Burns grope along, operating by feel and feedback. The author notes that how the organisation runs and accepting opinions consume the leader's attention who worries about these factors while ignoring the big picture. Further to this, Burns (1978) explains that leaders who are protective of the aims of the establishment ends up managing more than administering. He concludes that this manner of leaders result in more restrictions than opportunities, more negotiations than analytical decisions, and more institution-oriented thinking rather than opportunities for introducing new initiatives. According to (Burns, 1978), these types of leaders can only make policies if they are receptive to the public needs and goals of the organisation.

Consideration of the needs of the employees, stakeholders and the organisation is one focus of a decisive leader, who should be quick to make decisions and communicate goals to everyone involved (Kase, 2010). One kind of decision which leaders have to make is that of thoughtprovoking decisions. These include decisions such as the direction to move the organisation; whether to keep, relocate, or terminate an employee; whether or not to share problems with stakeholders and so on (Coleman, Boyatzis, \& McKee, 2004). Coleman et al. (2004) refer to the emotional intelligence quality of a leader that allows for comprehension, appreciation, and coping with his own emotions and those of others. The skills incorporated in possessing emotional intelligence involve self-awareness, self-management, social awareness, and relationship management so that decisions made are holistic and not selfish. These core components enable the leader to perfectly assess ideas, opinions, feelings, and actions to change mind-set and behaviour. "Decisions are the coin of the realm. Every success, every mishap; every opportunity seized or missed is the result of a decision someone made or failed to make" (Evans \& Ward, 2007, p. 125). The significance of decision-making skills should not be compromised in a leadership position, and is deemed to be the most important characteristic of leadership for the organisation. 
The leadership literature, then, highlights a number of leadership characteristics. These include having vision, being people-orientated, flexibility, involving subordinates, executing accountability and transparency, possessing emotional intelligence, and practising good decision-making skills. The literature shows that these characteristics are operationalised by leaders in a variety of contexts and through a variety of styles.

\subsection{Leadership Styles}

Having discussed the key characteristics of leaders, the discussion now turns to what the literature documents about leadership styles to illustrate the significance of employing particular leadership styles. Additionally, examining the literature will reveal leadership styles that restrain leadership opportunities for women. It is espoused that generic leadership styles are superior than a mixed strategy (Miller, 1992). According to the author, a specialised leadership approach is appropriate when numerous strategies do not match. However, this may have been a very special case of a pure cost leadership where customers compete for price and profits. In a broader sense of leadership styles, not a single style fits all situations (Sanga, 2005). Sanga's illumination of leadership styles implies that leaders employ different styles of leadership that vary in disciplines and forms.

Lewin et al. (1939) identify three leadership styles - autocratic, democratic, and laissez-faire. The autocratic style allows no consultation on the basis that any input will not alter the result. Consequently, it does not matter if people are willing or unwilling to support the decision. This is forceful. Sanga (2005) explains autocratic as indicating a situation where the leader is domineering and takes full control of the decisions and people. However, Bass and Bass (2008) redefine this by arguing that while these leaders are labelled as controlling and close-minded, the potential positives of stressing rules, expecting obedience, and taking responsibility are overlooked. I would argue in this study that this is not a healthy strategy as it affects people's morale especially when they do not participate in making decisions. This style contradicts with the consultative nature of honouring and executing democracy.

A democratic leader involves people in the decision-making process. Although the leader has the final say, relating the decision to people facilitates consensus (Lewin et al., 1939). Sanga (2005) refers to this type of leader as being participative and consultative. Participation includes appreciating people's involvement in making decisions as well as consulting and seeking people's views and opinions. Bass and Bass (2008) note that this leadership style 
centres on followers and is very effective in maintaining relationships with others. Findings of this study show the practicality of democracy in women's committees. In traditional societies, this kind of leadership can be seen in context such as fine-mat weaving, tapa making, and hosting guests. The skills of participatory, consultative, and cooperative come out strongly in the women's performances. They deliberate on issues, solve problems, and come to consensus through compromise or unanimous decisions. Conflicts and arguments are easily controlled and solved as women believe in togetherness to achieve a common goal.

The other leadership style is laissez-faire. This style according to Lewin et al., (1939) is when the leader's involvement in decision- making is minimised allowing people to make their own decisions. This style works best with capable and motivated people, and when there are no restrictions such as allocating resources to a variety of group and people (Cherry, 2006). Sanga (2005) defines laissez-faire as delegation and hands-off.

In summary, the scholars agree that no one best leadership style is suitable for all situations as consideration of the most effective strategy depends on the nature and goals of the organisation. Myers (2015) believes that a good leadership style focusses on the promotion of particular morals and standards in addition to maintaining the group focus on the most important things. Ethics and principles of organisations must be the core values unique to their purpose (Wijnen \& Wildschutt, 2015). In that manner, Wijnen and Wildschutt (2015) claims that the things that are not important are given very little attention in setting the direction the organisation is heading. Myers (2015) notes that respecting and practising certain morals and standards should not affect the group focus on high priority targets. For leadership styles to be embraced by an over-arching umbrella, Burns (1978) proposes a model of ideologies which includes “cognition, conflicts and values" (p. 250).

Leaders need to understand how to take care of those ideologies by gaining the support of the people they lead, which leads to communal cooperation and determination (Smith, Misumi, Tayeb, Peterson, \& Bond, 1989). However, the authors warn that it is essential to understand other factors that influence ideology. Butler (2014, p. 4) cites "the role of dominant actors when knowledge becomes ideological and biased in favour of particular actors through a conflictural process". Domineering people, on the basis of their natural and original sources of ideas, can show favouritism towards specific individuals in conflicting procedures, a situation when leaders hold prejudiced principles. However, ideology refers to values, standards, philosophies and morals, not pragmatic bias. 
Van Dijk (2006) argues that cognition refers to the "beliefs of a group that facilitate their acquisition and use in everyday situations" (p. 116). No problems emerge if people's reasoning is the same, but conflicts arise when the thinking, rationales, and priorities of people are different. Counts (1951) states that conflicts centre on power struggles that occur internally and externally. For example, people within organisations may fight for power as well as organisations against other organisations. The tension may have caused from differences in values, principles, and targets.

Values, an element in the ideological leadership model (Burns, 1978), refers to principles deeply held by people, and the concept can also be defined as priorities and underlying assumptions that influence attitudes and behaviours. People and their organisations behave in ways that are generally consistent with their values. However, it seems that most conflicts are caused by differing values (Prajogo, 2007). Lichtenstein (2005) states that values have a direct and significant impact on the communal performances of people and institutions. Therefore, everyone can play a role in achieving the aims and goals of a group, institution or organisation. It is always expected that leaders and workers cooperate for the common good of the particular entity they work for (Lichtenstein, 2005). Spillane (2004) speculates that the interaction of people and the situations mould leadership practices better than the actions of an individual. Gaining similar understanding of language and working on the same stage reflect a grouporiented leader who is accountable, responsible, and cooperative (Getzels \& Thelen, 1960).

Being responsive to group dynamics is one of the techniques to overcome psychological barriers to effective leadership (Gill, 2001). Some of these barriers include low self-esteem, lack of self- worth, displeasure, mental depression, and hostile moments of stress. Offering support and comforting others during these episodes create healthy environment and allows people to move forward with assistance guaranteed. According to Gill (2001), moving forward alleviates tension not only amongst workers but also between workers and leaders. The author expresses that the effects of cooperating as a group include establishing relationships, earning trust, and developing belief in the overall goal of the organisation (Gill, 2001).

A group of interacting individuals crafts openness in acknowledging limitations and therefore build and allocate a range of leadership experiences across many people in the cluster (Bennett, Wise, Woods, \& Harve, 2003). The authors allude to the notion that although the make-up of groups consists of individuals, people need to discard their individualism in order for groups 
to thrive. Sacrificing one's own agenda for the benefit of the whole organisation is a crucial requirement, although personal differences and social barriers sometimes discredit group efforts (Hunt, 2000). Hunt (2000) advises leaders to understand the collective purpose of the group and the practical strategies to inform their communal decisions. Furthermore, the author claims that it is important to be flexible to adopt and adjust to new initiatives for the sake of the organisation.

The process of imparting new ethics, approaches, standards, and manners within an organisation supports new practices which initiates harmony among customers and stakeholders (Booth \& Philip, 1998). Further to this, the authors suggest that explicit changes planned to better meet the needs, strategies, and challenges are all executing aspects of the transition from one organisational structure process to another. Naturally, people are not always receptive to changes. In some situations, change is rejected when it contradicts another's agenda. Other changes are rejected because workers do not support the leader's initiatives (Berrett \& Slack, 2001). The authors on the other hand state that change is welcome when it serves the organisation's purpose. For these reasons, it is significant to understand the basic elements of changes to visualise the changes that leadership offers.

Basically, leaders and workers of respective organisations must have an awareness of the need to change (Heikkurinen, 2010). In addition to recommending an understanding of change, Heikkurinen (2010) adds that is not worth initiating unnecessary change that does not express any valid reasoning, but it is better to introduce changes based on needs. In terms of implementing changes, Hyun and Choi (2011) highlight the significance of the willingness in workers to participate and offer support. The authors explain this kind of participation as intentional or voluntary. According to Hyun and Choi (2011), intentional participation and backing eliminate any difficulties that may have arisen between the leader and workers. Hence, a smooth flow of operations is guaranteed.

Another significant factor is having the knowledge of how to change. My understanding is, leaders need to know how the change will impact on the workers' attitudes, values, and behaviours. "Changes should address the reasons to change and the worries employers initially have" (Elving, 2005, p. 131). Strategic thinking and critical reasoning come into play for the leader to effectively implement changes without threatening the norms of workers. In addition to knowing how to apply changes, it is also crucial for leaders to have a readiness for change (Smith, 2005). Change is successful when leaders and employees embrace the change with 
enthusiasm (Chreim, 2006). In advocating for changes, "leaders assume initiatives and organise support on the basis of the structure of wants, needs, expectations, and demands that lie beneath value and purpose" (Burns, 1978, p. 408). Furthermore, Burns (1978) recommends that in order for changes to be effective, leaders must prioritise the significant elements that possibly achieve the aims of the organisations. It may be argued that leadership styles and priorities are influenced by context, such as in traditional Pacific communities.

The literature provides a variety of leadership elegances including autocratic, democratic, laissez-faire, an ideological model underlining cognition, values, beliefs of a group, grouporiented, and group dynamics. Additionally, it offers leadership styles of imparting new ethics, approaches, standards, manners, knowledge of how to change, strategic thinking, and critical reasoning. These leadership styles can be utilised in certain conditions and standards.

\subsection{Leadership in Traditional Communities of Pacific Islands}

In this section, literature about leadership in the Pacific Islands is explored to determine the feasible leadership styles of Pacific people, and how they create gender inequality in representation and participation in cultural communities. Considering the fact that the Pacific Ocean accommodates Polynesian, Melanesian, and Micronesian peoples, the leadership styles practiced vary depending on the culture of the respective societies. Leadership in the Pacific is stereotypically mounted in the framework of two cultural models: 'big man and chiefly leaderships' (Bhim, 2006). According to Bhim, the acquired status of big men stems from demonstrating particular skills such as magic, bravery, and wealth. Chiefly titles are inherited, though accomplishment has some influence on attaining the title. Chief or matai in Samoa possesses authority over traditional villages in Samoa. Matai are members of the village council who act as the judiciary (local government). This power is mandated, adhered to, and not to be challenged. The matai system in village communities is autocratic (Lewin et al., 1939), when it comes to imposing fines and making decisions. For example, people involved are not given a fair trial and families are required to provide the fine immediately or within certain days, and failure to do so results in either banishment forever or eviction for a certain period of time.

Before the Pacific countries were colonised, a variety of different types of chieftainship and community leadership were based on matrilineal or patrilineal systems which were either hereditary or merit-based, and some were ritual and spiritual (Gustafsson, 1992).These leadership structures were challenged and undermined when various colonial authorities settled in the islands (Feinberg \& Watson-Gegeo, 1996). Moreover, the Christian missions were more 
influential in challenging the spiritual supremacy that symbolised superiority in the traditional leadership systems. One of the classical examples is when the sub-village of female descendants of the village (Nu'u o Tama'ita'i) was dismantled, lessening the elite status of the Samoan woman. At the moment, women face the hardship of striving for leadership positions since the removal of their leadership status. Consequently, problems continue while countries attempt to associate old colonial and old traditional systems into something modern (Churney, 1998). At the moment, many Pacific societies are debating the meaning of leadership in response to a variety of political and socioeconomic factors (Besnier, 1996).

Many people of the Pacific believe that accountability and transparency are the significant aspects of good governance (FSPI, 2003) ${ }^{2}$. They wish to see the operation of these elements in the leadership of government authorities. However, leadership varies widely in the Pacific regions of Melanesia, Polynesia, and Micronesia. The complexity occur as an influence of postcolonial eras where traditional leadership philosophies overlap with modern establishments (McLeod, 2008). Although leadership now adopts the Western leadership styles in the political arena, most Pacific Islands maintain traditional leadership values as the core element of leadership practices (Hassall, 2012). Leaders of Pacific Island nations at large strive to preserve languages, culture, and traditions (Gunson, 1987 ).

Some leaders of the Pacific provide better platforms for the effective and efficient delivery of programmes that benefit the whole region (Foundation of the Peoples of the South Pacific International 2003), and simply ignore the challenges and obstacles that hold them back from making changes (McLeod, 2008). Leadership models in the Pacific are sketched historically in early observations by anthropologists throughout the region. Burrows (1939) notes a universal similarity in the political autonomy of Polynesian governments, with power being basically vested on the eldest lineage kin irrespective of the importance of personal capabilities. He recognises sacredness as the most important aspect of leadership which makes chiefs more familial powerful than people who do not possess cultural titles. However, traditional societies are mostly communal as they share common values and implement similar practises. For example, in village communities in Samoa, each village has its own unique protocols (agaifanua) which links them to the communal traditions of the whole country (Toleafoa, 2007).

\footnotetext{
${ }^{2}$ Foundation of the Peoples of the South Pacific International (FSPI), 2003. FSPI Survey: Good Governance. Organizations and Activities, Federated States of Micronesia.
} 
Pacific cultures are collectivist in nature, that is, they value the group over the individual (Hofstede, 1993). It is clear from the definition that at the national and organisational levels, culture has the potential to confound ethnocentric ideological prescriptions regarding economic or enterprise management. The two key principles to explain leadership in the traditional communities of Pacific Islands are communal and contextual factors (Sanga, 2005). According to the author, the former defines the aspiration for harmony and peaceful living, while the latter refers to the essence of social interactions within people's social environment. The notion of interacting with people links with the people-orientated characteristic of a leader that Getzels and Thelen (1960) allude to. This brings to the fore the fact that there are similarities in the way leaders of the Pacific and the Western world lead. However, the context and nature of being people-orientated depends on how societies function considering the diversity in behaviour, resources, and skills.

The context and people's attitudes determine the direction of the organisation in achieving its goals. Therefore, the fundamental role of a leader is to eliminate any confusions in driving the organisation. In that manner, leaders who aim for survival begins with creating a vision (Greenleaf, 1977) approved and turned into a communal vision of the group. In most of the traditional societies in the Pacific, women are active demonstrators of communal visions of groups initiated by male leaders. Male leaders on the other hand are faced with the challenging responsibilities of maintaining communal visions. Most of these communal visions uphold women as subordinates. For example, in traditional villages in Samoa, women sustain health and hygiene, execute community projects, and engage in interactive activities. These chores are assigned to them in addition to household tasks, and place them at a disadvantage in terms of accessing leadership positions in village communities.

Another concern with leadership in traditional communities of the Pacific Islands is leadership styles. Gardner (1996) postulates that leadership styles depend on the leader, how the organisation perceives what leadership is, and the leader's choice of leadership methods. From experience of living in the village for many years, this definition by Gardner may not be applicable for most of the leaders in traditional communities who neither have visions nor know the directions the organisations are headed. In contrast, the most suitable leadership style is the one that incorporates aspects such as the relationship between the leader and follower, activities, materials, competency level, time frame for action, hierarchy, and other contextual features (Yamin, Mavondo, Gunasekaran, \& Sarros, 1997). 
Historically, Lindstrom and White (1997) record that political environments of the South Pacific, continue to be ruled in many areas by 'custom chiefs'. The authors further state that the post-colonial era sees the number of chiefs multiplying, extending the chiefly empire, and gaining more power. In most Pacific communities today, people are still assessing the significance and legitimacy of the recent administrative practices of the chiefs. Therefore, the debate between tradition and democracy, custom and legal authority continues to linger along Polynesian island leadership practices as well as the big men bureaucrats in Melanesian societies (Bhim, 2006).

Lindstrom and White (1997) have documented that indigenous leaders of Pacific Islands invented traditional systems to accommodate chiefly ruling. The authors claim that:

On some islands (Tonga notably), certain leading families founded chiefdoms and kingdoms that they continue to rule. In the Cook Islands, the House of Ariki Act of 1966 established a constitutional body of titled chiefs modelled on the British House of Lords. Elsewhere (e.g., the Solomon Islands and Vanuatu), new chiefly positions including that of paramount chief-emerged during colonial history and have solidified in the context of national independence and the independent state's new institutional needs. .....and in Western Samoa and Indonesia, state leaders and chiefs possess sometimes parallel, sometimes divergent, interest. (p.2).

The given account by Lindstrom and White underlines the established chiefly structures in the course of the colonisation periods of Pacific Islands. At the moment, the chiefly leadership style endures, honoured, and respected by Pacific Island people. In terms of the interpretation of leadership in the Western context, Hassall (2012) argues that these construal are not consistent with Pacific people who are usually identified more with their birth places and indigenous groups than with their nations (Hassall, 2012). Furthermore, the author alludes to the fact that Pacific nations have had many noticeable leaders at national levels, but many of them have worked for the benefit of the constituency level rather than the government. As a personal observation, I believe that the constituency level of leadership is dominated by male leaders and this domination is suppressing potential women leaders. Nevertheless, women persevere to demonstrate working together to achieve the communal visions of the women's groups and villages (Sanga, 2005). However, gender divisions hinder women from accessing cultural knowledge, leadership positions, and disadvantage them as potential candidates for Parliament (Martire, 2014). 
The literature pertaining to Pacific leadership in traditional communities indicate that the systems of big man and chiefly leadership are underpinning in shaping traditional leadership modes. It also prompts aspects such as communal, contextual, and collective leadership. However, it is obvious in the literature that there is an ongoing debate between traditions and democracy leadership as well as between custom and legal authority in leadership of traditional communities in the Pacific. To explore a balance in these ongoing debates, the following discussion focusses on the leadership experiences and interpretation of new Pacific leaders.

\subsubsection{Leadership Thinking of New Generation Leaders of the Pacific}

Under the guise of Leadership Pacific, there has been a 'new generation' of leadership thinkers and developers, of which is articulated in Sanga and Chu (2009). The first narrative explains that "leadership begins with a splash" (Chu, 2009, p. 15), narrating an experience of being led into the deep end of a swimming pool at the age of four and was told to swim. The choice of keeping her legs kicking and her arms moving keeps the author afloat. The story illustrates that leadership is about making immediate decisions. The author relates her experience in the swimming pool to the foresight of her classroom mentor who encourages her to succeed in her studies. She concludes that "leadership is about relationships of influence" (Chu, 2009, p. 21) since her relationship with her classroom mentor motivates her to move forward in pursuing her academic dreams. The idea of moving forward is embraced by Fito'o (2009) who sees leadership as a journey of failures, promises, recovery, and exceeding expectations. The author sums up his leadership experiences by stating that leadership is a never-ending challenge. One of the strategies suggested to counter the continuous challenges of a leadership journey is to pass the knowledge of the things we treasure to our sons (Southon, 2009). In Southon's view, some of these treasured things are the things she learnt from the advice of the elders which she never queried. Southon goes further to say that in following the advice of her elders, she takes initiatives, and holding herself accountable. The same author views leadership as having a positive attitude towards situations, since things happen for a reason. She concludes by saying; "If you have nothing nice to say about someone, don't say anything at all" (Southon, 2009, p. 49). The idea of serving silently is embraced by Rimoni (2009) who suggests that leadership is service (tautua), and service to the church is an example of one of the many services people can do in order to give back to those who shelter and guide like parents, siblings, relatives, and community. Furthermore, Rimoni alludes to leadership as learning about patience, respect, and restraining behaviour, as well as sincerely holding communitarian values. The author relates leadership to the feelings of being "humble, uncertain, risky, challenging, unsupportive, 
trusting, at peace, loyal and it feels like a summit and with beings assured of support" (Rimoni, 2009, p. 55). The list of the feelings involved in becoming a leader submitted by Rimoni complements Fito'o's (2009) account of never-ending challenges in the leadership environment. In conclusion, Rimoni acknowledges leadership as "rewarding, inspirational, powerful, natural, stressful, exciting, hungry, determined, warm, tired, busy, active, and energetic" (p.55).

Vunariri (2009) states that leadership is about "mentors who are by your side on your leadership journey, who listens to you, walk and eat with you, as well as share your dull and bright days" (p.58). In his leadership account of duties, the author manifests on the belief that leadership is supposed to fit the context of leaders and followers. The author's experience is about the events happening in his country where people respect foreign leadership values, ignoring the leadership offerings of the traditional societies. In his view, leadership should emphasise the importance of local concepts and practices of leadership, paying much attention to the moral and ethical values that maintain harmony in societies. Sustaining harmonious societies is encompassed by Samala (2009) who states that genuine leadership is providing true service to others. In explaining leadership, Samala illustrates it as leading without expecting anything in return. Further to this, Samala believes that a leader needs to show his concerns of the people he leads, demonstrates care, and puts decisions into actions. Actions result in making a difference, and leaders are not scared to make changes that prosper the organisation and grow the leadership potential in people. In conclusion, the author recommends that self-empowered leaders have faith in their leading spirits, do what is considered right, but gently own up to his faults and make himself accountable for his actions. Making oneself accountable is a manner of an ordinary person who shows care and taking responsibility for themselves and those around them (Raivoka, 2009). These stories of leadership provide a platform for exploring leadership by ordinary people in Pacific contexts. The leadership voices of future leaders of the Pacific should inspire leaders of different leadership spheres to revisit and re-examine their leadership styles, values, and beliefs for the betterment of the organisations they lead. It is such stories which provide a level of influence for further analysis of Samoan leadership.

\subsection{Leadership in Samoa}

The Samoan context of leadership comes alive in myths about civil wars; for example, the legend of Nafanua, the war goddess who was awarded with four paramount chiefly titles (pāpā) in respect of being victorious signifies bravery and dedication of a leader. To illustrate the 
modern suppression of women leaders in Samoa, the discussion now focusses on how leadership is defined by the Samoan society and the role of the traditional leader (matai) in village communities.

The term leadership is translated into the Samoan language as ta'iga, (Milner, 1966, p. 391), meaning "the leader leading." This means that the quality of ta'iga depends on the kind of leader and how he or she drives the organisation. Leadership in Samoa functions on the matai system. This system predominantly differentiates two distinct categories of matai according to the social role they play in the village council (fono) or in ceremonial activities (Hennings, 2007). These two-matai types are referred to as chief (ali'i) and orator (tūlāfale). Both chief and orator are matai who play different roles outside their families, but execute the same responsibilities of exercising authority and control (pule) over all family affairs. The main role of orators is presenting speeches, a similar manner to that of Maori male leaders in the marae (Mahuika, 1992). Aiono and Crocombe (1992) explain that the matai is the leader of the Samoan extended family ('āiga potopoto). The authors further comment that:

The matai is a complete and separate entity that speaks in a specific vocabulary, that behaves and thinks in a distinctive manner, and that is dedicated and committed to the achievement and maintenance of peace. A matai is an heir who has been selected to the matai title of an extended family by all heirs of the matai title (Aiono \& Crocombe, 1992, p. 120).

The above quotation explains the status, selection, eligibility, and explicit roles of the matai. The matai bears a family name or title which succeeds from one holder to another. There is nothing in Samoan custom to prevent a matai holding two or more titles (Grattan, 1985), so people hold as many matai as possible, provided that they are able to fulfill the obligations.

A person's lineage secures a matai title, as well as holding a status that is not accessible by others. At the same time, the Samoan proverb, "O le ala i le pule o le tautua - the path to power is through service - demonstrates the importance of achievement as heredity" (Iati, 2000, p. 72). Both men and women are entitled to hold matai titles, although currently fewer than $10 \%$ of matai are women (Samoa Bureau of Statistics, 2011). However, this is progressively changing as more Samoan women seek to attain matai status.

Each household has its chief, or matai, a man or woman whose authority extends to all members in their performance of domestic tasks, in the maintenance of orderly relation among them, and in the regulation of their relations with other village households. The 
chief controls the recruitment of members and may expel anyone who, by refusing to submit to his authority, threatens the unity of the group....The chief's authority, then, applies irrespective of the places from which people of his household may have come, of the terms of their residence in his household, and of the authority to which they are, or have been, subject elsewhere (Gilson, 1970).

Matai are members of the village council or the local government (pulega a le nuu), a rulemaking body whose decisions hold an immense weight in Samoan traditional villages (Techera, 2006). The village council or local government have the power to deal with matters of the village, in accordance with the custom and usage of that village as provided for in the Village Council Act 1990 (White \& Lindstrom, 1997). The rule-making body is free to create its own laws and guidelines for how village life should be carried out, and matai act as the judicial and executive authority of each village (Grattan, 1985). In the author's view, jurisdiction of the village fono is limited to the residents of each particular village, except those on government, freehold, or leasehold land.

The local government system is provided for by the Village Fono Act 1990 and the Internal Affairs Act 1995 (Ministry of Women, 2016). The division of Internal Affairs of the Ministry of Women, Community and Social Development is responsible for local government, which consists of the National Capital District Council of 26 urban authorities, and 286 village councils (fono a nu'u) of traditional village communities. The local government authorities have revenue-raising powers, as well as receiving transfers from national government for specific projects from time to time. They work with the national government on the delivery of public health and hygiene, education, law and justice, water supply, construction of plantation roads, agriculture and fisheries support services, and leisure facilities (Ministry of Women, 2016). The matai system extends to countries where title holders reside such as American Samoa, New Zealand, Australia, and the United States of America, and are very active in churches (Toleafoa, 2007). However, Toleafoa argues that the roles and responsibilities are compromised due to the situation and circumstances in foreign countries. It is mandated that Samoan citizens and people with Samoan blood ties, men and women, are entitled to holding matai titles if they are 21 years and over (Le Tagaloa, 1996).

To gain a better understanding of the matai's role within the Samoan culture, the Village Council Act of Samoa is briefly discussed as reported by White and Lindstrom, 1997. In the time of the post-independence era, the Samoan Parliament passed the Village Fono Act of 1990 
to increase the power and influence of matai in the areas that are most crucial: the village (nu'u). Following is an outline of the Act:

The Act allowed every village council (fono) to exercise any power or authority in accordance with the customs and usage of that village (Section 3.2). It established that any past and future exercise of power and authority by any village council (fono) with respect to the affairs of its village that is in accordance with custom and usage is validated and empowered. In addition to powers and authority conferred in this act, every village fono was to enjoy such other powers, authorities, and functions as may be conferred by any other act (p.42).

The Act manifests and reinforces the power and authority of village councils in Samoa. Through observation, this power is sometimes over-exercised because the act does not specify the customs it refers to. The contradiction is that, traditional villages practice unique protocols (agaifanua) and adhere to particular sanctions. Therefore, there is no consistency in the execution of power since it varies from one village to the other. This inconsistency sometimes causes problems through mobility, as in the case of people married and adopted to certain villages. Migrants, take time to familiarise themselves with the system of administration and the practises of people in their host village.

Traditional leadership has been merged into national political avenues to a greater extent compared to past years. Like traditional leadership, the political arena is also controlled by people of high status with matai (holders of cultural titles) being the representatives of political constituencies. Universal suffrage was introduced to Samoa in 1991, but only matai are eligible to stand for parliament (Macpherson, 1997). Matai hold power and authority both at the local and national levels as a result of the alteration of Samoan power structures and historical circumstances. Inheritance and status are the basis of the matai system.

At the national level, leadership can be seen located in the power of parliamentary members. This stems equally from their matai status and as nominated officers (Macpherson \& Macpherson, 2000). In efforts to empower more people in the leadership arena, Samoans have generated new titles and allowed numerous titles to be singly or jointly held. This has increased the number of matai, and can be seen as continuously adopting the traditional hierarchical system in alignment with the Westminster style of political administration.

Leadership is held by village councils or local government, consisting of matai. These exist in every village in Samoa. This council, also known as Pulega Fa'amatai, is the rule-making body 
of the village. The village structure has three to five components, all under the watchful eye of local government. Aiono and Crocombe (1992) identify five components within the cultural structure of traditional villages:

(1) The council of matai, consisting of chiefs and orators; (2) Faletua ma Tausi, which consists of chiefs and orators' wives; (3) Aumaga, servants of the matai which consists of untitled men and sons of matai; (4) Tama'ita'i, daughters of matai and untitled men of the village; (5) Tamaiti, which consists of children in the village (Aiono \& Crocombe, 1992, p. 119).

Membership of local government is mandatory. This council is known as the local government or the decision-making forum for the village. It has the authority and power to make rules and sanctions for village communities. According to Le Tagaloa (1996) the matai system is not powerful unless the organisations work together to support and serve them. At the local government level, matai with high ranks hold extensive power, making decisions and socially controlling village and district councils, known as fono. Matai must appropriately uphold the Samoan values of honesty, integrity, reliability, and respect. Matai are also expected to ensure the safety of their families. The title may become void if they fail to perform their responsibilities (Tcherkesoff, 2000). At the local government level, the influence of matai is not challenged in making decisions on the basis of what is right and what is wrong and issuing severe punishments to people who disobey village rules. Harsh punishments include burning houses and being evicted from the community (Va'a, 2000). These severe penalties cause terrible damage to the economy and sanity of punished families. Women leaders may advise local government to lessen the harsh punishment, considering its effect on the families concerned. Furthermore, it may be argued that a gender-balanced decision-making cohort where a broad-base of leadership is valued - is likely to result in more judicious conclusions than those (decision-making bodies) that are heavily gender-biased.

There has been no change in the formal structure of the village and district fono (meeting) since contacts with Europeans in the 1880's (Tcherkesoff, 2000). However, most of the administration tasks are passed on to committees headed by younger and active matai (Davidson, 1967). All levels of administration are male dominated in Samoa. The traditional communities uphold and enhance male preference in the selection of family and village leaders. Thus, male domination endures in village councils, making it very hard for women leaders to challenge the status quo. The effect is that, men have gained ascendancy in leadership despite 
Samoa's history. According to Macpherson (1985), initial contacts with Europeans assured the continuation of chiefly ruling in Samoa.

In summary, leadership in Samoa has a history which offers precedents for female leaders who can follow the role-models of great leaders of the past, both mythical and actual. However, due to cultural values, religious beliefs and social assumptions, leadership is currently, patrilineal both in local and national government, as well as in families and churches. While in theory, traditional posts such as matai are non-gendered, new traditions have arisen which are impediments to Samoan women's involvement in leadership. These impediments assume women's engagement in child rearing and household commitments, tasks that they are skilled in doing. Unfortunately, this assumption decreases women's opportunities for leadership positions and acts to bolster the exclusive practices in place in Samoa at this time.

\subsection{Leadership Characteristics: A Gender Issue}

This section examines the leadership characteristics of females to assess whether gender minimises the exact difficulties of leadership. The literature indicates a number of femaleoriented characteristics of leadership that are deemed to make women better leaders than their male counterparts, thus strengthening the main argument of this study, that is; that challenges affecting women's leadership in Samoa consists of cultural values, religious beliefs, and social assumptions.

Blackmore (1999) cited in Pounder and Coleman (2002) differentiates the nature of female and male leadership styles. From findings of a research on educational leadership, Blackmore (1999) concludes that females are relationship-oriented and democratic while males are taskoriented and autocratic. These unique characteristics of female leaders are activated in other leadership arenas women attend. With reference to women's committees in Samoa, for example, women socialise in communal activities such as fine-mat weaving, tapa making, and hosting guests. Additionally, they interactively work for the common good of the society by providing services and community work.

Others like Chodorow (1978) and Gilligan (1982) claim that another characteristic of a female leader is being more socialised while men retain their independence when interacting with people. Socialisation constitutes the people-oriented nature of females according to the stated studies. Socialising is networking with people to embrace relationships and share views while men, on the other hand, tend to focus on completing tasks, achieving goals, hoarding information, and winning (Chliwniak, 1997). 
With reference to decision-making, Porat (1991) argues that women most of the time support consensual agreement, but men tend to lean towards the majority rule and emphasise the goal. Espousing relationships and distributing knowledge are effective tools in decision-making. Women in leadership posts tend to confront obstacles, consult people, and seek consensus before finalising decisions. Such decisions are based on the construction of plans and strategies for the organisation, something the women leaders are more capable of doing, according to Cohen (2003). However, some have found that, these characteristics make very little difference in the results men and women achieve as leaders (Anderson, Lievens, Van Dam, \& Born, (2006). Furthermore, while Yukl (2002), reveals that female leaders are more inclusive, interpersonally sensitive, and nurturing; Morgan (2004) argues that although these particular fortes of women indicate their effective leadership styles, they have very little impact on the outcomes. Alternatively, women leaders have the potential to acknowledge and appreciate people from all walks of life (Yukl, 2002). Nonetheless, different cultures have particular preferences for leaders pertaining to the norms, values, beliefs, and unique expectations of the culture. The globalisation of management brings to the forefront the need to examine this phenomenon in international arenas (Yukl, 2002).

Riggio (2010) argues that there are no distinctions between the behaviours of men and women leaders, perhaps because responding to leadership challenges demands particular engagements, attitudes, and values: the required standards of performance have to be achieved, and a leader, whether male or female, has to lead the organisation to meet certain goals. Irrespective of any perceived gender differences, Cliff (2005) and Dobbins and Platz (1986) support the notion that a leader is genderless. This correlates with other researches cited by Vecchio (2002) as well as Engen, Leeden, and Willemsen (2001) who all argue that no significant gender differences in leadership exist. In contrast, Bart and McQueen (2013) commended the ability of women leaders to make fair decisions - a factor that the authors say makes them better leaders.

In light of the transformational leadership theory (Burns, 1978) women leaders seem to possess the required characteristics of being socialised, communicative, interactive, consultative, constructive, inclusive, sensitive, and nurturing. The question that arises is -Will men see the value of adopting these characteristics? This is clearly a topic worthy of further research. However, as the literature portrays, these characteristics allow female leaders to edge out male leaders, although that is not the reality in the world today. The theoretical perspective is yet to be executed to reflect gender equality in leadership. 
Another characteristic of a female leader is that she has a vision (Seeley, 1992). Vision guides the organisation to the goals it aims to achieve. It functions as a marker to indicate the direction where the organisation is heading for the understanding of every corresponding individual, stakeholder, and authority. Vision provides a picture which articulates goals and direction as well as ways of attainment. Seeley (1992) describes vision as a goal-oriented mental paradigm that directs people's behaviour. Most of the traditional leaders have difficulties in adjusting to changes and different value structures. Therefore, as pointed out by Sanga (2005) who writes widely about leadership in the Pacific contexts, it is very hard for them to direct and guide the traditional communities to a particular direction.

According to Macpherson (1997), the style of leadership has to be strategically selected and implemented in order to benefit the organisation. Therefore, the success of the chosen style depends on the leader, the situation, and the kind of institution or organisation. Clearly, leaders need to possess a certain competency level to lead their organisations effectively and efficiently. According to Sanga (2005), traditional leaders who have had little or no exposure to education are academically weak in visualising issues of the outside world. As a result, traditional morals of group beliefs decrease, adding more pressure to the society. Sanga's view contradicts with the situation of some traditional leaders of women's committees in Samoa as some of them are well-educated, have a wide exposure to international forums, and have very effective leadership skills. As a result, women's committees are very successful in playing their roles, and responding to the needs of village communities.

The literature provides a range of female characteristics of leadership such as being relationship-oriented, democratic, socialised, interpersonally sensitive, communicative, interactive, consultative, sensitive and nurturing in addition to the competencies that enable them to practically execute these leadership characteristics in organisations they lead. These leadership features of women coupled their communal and solidarity efforts (Harding, 1997 \& 1998) in striving for leadership opportunities. Although many women leaders possess these characteristics, it does not deviate them from encountering many challenges, especially when competing with men for leadership positions.

\subsection{Leadership Challenges for Women}

In this section, literature that documents challenges women face in struggling for leadership is examined to show gender inequalities in representation and participation. This is significant in identifying the impediments that women in general encounter while striving for leadership 
posts. Analysis of the literature pays attention to the nature of the challenges and the underpinning reasons. Barriers to women in leadership positions seem to be universal. In a global summary of women in management positions, Berthoin and Izraeli (1993) found that the major obstacle facing women managers was the stereotypical belief that associated managerial positions with being male. According to the authors, both male and female managers demonstrated similar certainties in this regard. Their typical sentiments correlate with findings of a pragmatic examination of managerial sex-role stereotyping that also revealed the 'think manager-think male' belief (Schein, 1973) in the United States. As a mental hurdle to the progression of women in administrative posts, a 'think manager-think male' philosophy raises prejudice against women in managerial selection, placement, promotion, and training decisions (Schein, 2001). These selection criteria are easily accessed by men as documented in many leadership studies where people's views of the type of leaders required are very much influenced by research findings. For instance, Inglehart and Norris (2000) in a comparative wide-reaching research of 55 societies concluded that the two major barriers to leadership opportunities for women are (1) traditional attitudes towards women as leaders, and (2) political cultures in governments. Inglehart and Norris alluded to demotivating scenarios for women running for political posts. Hence, fewer women show interest in competing for positions of authority.

According to Riggio (2010) who conducted a study of chief executive officers, both genders manifest the same kind of leadership behaviours. Support for this finding is highlighted by Bolman and Deal (1991) in a frame-orientation survey among men and women leaders which resolved that no dissimilar elements surfaced in the behaviour of men and women. Nevertheless, research reveals that men and women approach leadership similarly in cultures that have different gender perceptions and values for leaders. In some cultures, the views of the minority are suppressed, especially those of minority women. For example, records at the National Women's History Museum show the oppression encountered by African American women in the United States of America. According to the records of the African American Women Suffrage (1998), black women strived through harsh conditions in a fight to be included in the women's suffrage movement after the eradication of slavery. Moreover, the suffrage movement leaders were political policy makers who manoeuvred complex government processes to attain their goal. They recruited both revolutionaries and conventional activists to push their agenda. The considerable skills of both contributed to the final accomplishment of the goal for the movement without shedding any blood. Adler (1994) 
alludes to this as a very extraordinary effort by women. In a study of emigrant managers, Adler (1994) concludes that women were more outstanding in their performances than men despite the suppressive pressures they had encountered in struggling for leadership positions. Furthermore, it was noticeable that when women finally got to positions of authority, they proved themselves to be very capable leaders.

In the meantime, women leaders in politics and business continue to increase and they bring a set of experiences and perspectives different from the male leaders of the twentieth century (Adler, 1997). Additionally, the women leaders' familiarities and viewpoints of the leadership domain provide a transition from the typical male style of administration. Nevertheless, when women are evaluated in leadership positions, they are more undervalued in taking a place typically held by men. It is even worse when their assessors are predominantly men (Denmark, 1993).

The universal tenure of leadership barriers for women motivate male leaders to continue the status quo. The philosophy of 'think male-think manager' (Schein, 2001) is widely adopted, even in traditional societies like village communities in Samoa, where local government continue to function on the male leadership system. One of the challenges for women's leadership this study has found is the reluctance of community women to challenge male leaders due to respecting cultural norm and practices. In that regard, community women do not want to become leaders at all in fear of upsetting local government.

In the Pacific region, a scoping study of women's leadership outside of national politics in Bougainville, Solomon Islands, Tonga, Samoa, and Fiji concluded that culture was often seen as a barrier for women's leadership (Quay, 2006). The study found that there were extreme cases where culture disadvantaged women from gaining leadership positions and men refused to support women leaders. This is a major impediment affecting women's leadership, and widening the gap for gender inequality in leadership forums.

The literature explains obstacles women face in striving for leadership world-wide, and the universal challenges for women's leadership present in many traditional societies. The restrictions include the association of managerial positions with being male, think-managerthink-male philosophy, research findings that target male leaders and their potentials, political cultures, traditional attitudes, and the overall exclusive of women from power and authority. However, the literature also reveals the affirmative female leadership characteristics of being 
communal and having solidarity, in striving for leadership posts (Harding 1997 \& 1998), aspects of the black feminism that contribute to achieving its goals.

\subsection{Leadership in Local Government in Samoa}

Samoa has two levels of government; national government consisting of the legislative assembly with 49 parliament members representing each constituencies, and village local government based on traditional structures (Commonwealth Local Government Forum, 2016). The Village Fono Act 1990 and the Internal Affairs Act 1995 are the two pieces of legislation that outline the functions of the local government (Ministry of Women, 2016). Each of the acts were established to target particular core functions of local government. For example, the Village Fono Act legalises and authorises the exercise of power and authority by village councils (fono) in accordance with custom and usage of their villages, and to confirm or grant certain powers, while the Internal Affairs Act 1995 establishes the Ministry of Internal Affairs and the promotion and wellbeing of villages and village authorities, as well as providing the appointment of government representatives (pulenu'u), who are based in the village and act as informants of the village to the government (Commonwealth Local Government Forum, 2016).

There are 286 traditional villages, each has its own local government that is separate and independent from others. Local government determine their own structure according to their custom, usage, and history. This forum, which consists of chiefs and orators representing extended families administers the village (Toleafoa, 2007). The village council or the local government serves as the legislative body, the executive body, and also the judiciary. Samoa's local government system is based on customs observed and practised by traditional leaders whose roles consist of providing leadership and making laws (Te'o, 2011). There is no elected local government, since village council members are there by right as the head of extended families (Iati, 2000). According to Iati, the government representative (pulenu'u) is selected by each local government according to the practice of that village, for a period of three years. Often, the position rotates among members or among groups. Decision-making is the prerogative of local government (Techera, 2006). Other formalised groups within the village such as the women's committee and the untitled men's organisation may be consulted, depending on the precedent of the local government. Power flow is strictly topped down

(Grattan, 1985). Local government have remained largely separate from its national government counterpart. The two are based on different and often conflicting principles, values, and institutions (Commonwealth Local Government Forum, 2016). 


\subsection{Chapter Summary}

The literature review section of this study incorporates definitions, characteristics, leadership styles, and leadership capabilities of males and females. It also explains the similarities and differences in leadership performances and beliefs of various leaders. A variety of leadership settings and contexts such as the world, Pacific, local government, and families are investigated to gain a predominant view of practical leadership practices. The chapter places emphasis on the reasons why females' leadership styles may be advantageous over that of their male counterparts. Nevertheless, the literature indicates that leadership styles has very little to do with the results leaders achieve. These findings could form the basis of further investigations. The literature defines the psychology of leadership and related disciplines in different environments. Specifically, as the study is focused on exploring the leadership qualities of Samoan women engaged in interactive activities, the literature review targets effective female leadership skills. In contextualising the literature, it is obvious that most of these activities are operational in traditional village communities in Samoa, although women leaders there are acknowledged as subordinates. The literature indicates that the barriers experienced by women world-wide also restrain women in Samoa from attaining positions of authority. 


\section{CHAPTER THREE: THEORETICAL FRAMEWORK}

\subsection{Introduction}

This chapter explains the theories the study employs, the supporting literature, and the significance of theoretical lenses to the research. To establish the rationale for the selection of a theoretical framework for this study, section 3.1 explores the significance of utilising theories in studies of a qualitative nature, Section 3.2 defines feminist theory as a system of concepts, assumptions, expectations, and beliefs (Miles \& Huberman, 1994), and explores its application to the Samoan context. Section 3.3 discusses feminist leadership theory pertaining to validating women leaders' characteristics of being participatory, non-hierarchical, flexible, and grouporiented (Eagly \& Johnson, 1990). Section 3.4 describes social constructionism theory, in relation to the understanding that the search for truth is collectively constructed through people's dialogic interactions (Bakhtin, 1984). In this context, social constructionism scrutinises the women's interactive dialogue, and meaning-making while engaged in the interactive activities of fine-mat weaving, tapa making, and hosting guests. Section 3.5 validates the harmonisation of the theories of feminism, feminist leadership, and social constructionism to define particular components of the study. Section 3.6 gives a summary of the chapter.

\subsection{The Significance of Theories}

It is assumed that theoretical connections are our everyday life responses to specific situations that define and interpret the social and natural spectacles in our surroundings (Klein, 2013). In light of the discussion by Klein, I contemplate the need for theories to explain occurrences and to react to certain circumstances. According to Reeves, Albert, Kuper, and Hodges (2008), "theories give researchers different lenses through which to look at complicated problems and social issues, focusing their attention on different aspects of the data, and providing a framework within which to conduct their analysis"(p. 2). I have gathered from this explanation that it is important to apply many lenses to understand a problem. These many lenses have to be facilitated by a framework that frames the research guidelines. Furthermore, I regard the framework to be the overarching spectrum which incorporates the theoretical interpretation of the important elements targeted by the study.

Valentine (1982) notes another significant feature of theories is that they serve to summarise and organise data by bringing order and cohesion to material. Additionally, Valentine believes that theories give empirical meaning to facilitate the management of research. The author 
further points out that, because the direction of the study is guided by theory, it is important to select theories that appropriately serve the goals and objectives of the study. On the other hand, some research generates new theories from findings (Eisenhardt, 1989). In Eisenhardt's view, the identification of theories cannot always be pre-determined because they can eventually emerge as the study progresses. This position is supported by Ruiz-Ortega and GarciaVillaverde (2008) who advise that in most case study researches, the usefulness of theories depends on the circumstances surrounding the research, and theories gradually develop to direct the research to achieving its goals.

In his book, "The Structure of Scientific Revolutions" (1970) Kuhn argues that scientific research and thought are defined by paradigms or conceptual world-views that consist of formal theories, classic experiments, and trusted methods (White \& McCain, 1998). Theories are significant mechanisms to organise, summarise, and explain a great deal of information or facts (Lakatos, 1970). According to Lakatos, the ability of theories to connect facts means that theory-based research will not produce ad-hoc pieces of important knowledge, but allow findings to fit into a framework that connects to other studies. The author proposes that theories tend to be more consistent with existing facts. However, I argue that theories sometimes ignore problems that are not consistent with the direction of existing research. For example, my assumption is that if the research is about leadership in village communities, the focus will be on leadership roles, leadership styles, or problems affecting leadership. It will not include the suppression people encounter from leadership practises. This suggestion aligns with Kuhn's (1970) stance that when emerging problems do not suit the prevailing theories, they tend to be discarded. It is my view that such discarded information might be useful in designing new research or strengthening arguments in existing studies. Therefore, problems that may have risen during the course of the research must be safeguarded for future use.

Often, theories are constructed by systematically collecting data and carefully analysing the data for patterns. In other words, a theory is clearly entangled in practice since explanation enables forecast which in turn enables control (Laudan, 1977). Laudan also claims that theory influences research design, decisions about what to research, and the development of research questions. Furthermore, the author endorses that theory underpins methodology, and has implications for data analysis and data interpretation. Finally, Laudan concludes that theory about a particular phenomenon may be developed, contributing to what is already known about the topic, or the focus of the study. However, Greenwald, Leippe, Pratkanis, and Baumgardner (1986) argue that the use of pre-existing theories can create and generate new arguments. The 
significant of employing theories in a qualitative study as discussed supports the commissioning of the theories of feminist, feminist leadership, and social constructionism in this study.

\subsection{Feminist Theory}

Feminist theory is an outcome of the general movement to empower women worldwide (Malabre, 1978). According to Malabre, the feminist movement can be broadly defined as a critique of male authority together with efforts to change it. The author states that the goals of the feminist petition are to demonstrate the importance of women, and to bring about gender equity. The modern feminist movement originated from the abolitionist movement of the 1830s (Malabre, 1978). This feminist movement, occurring in three different waves, has been organised into three different categories with slightly different aims (Humm, 1995). Humm explains that the first-wave feminist emerged in the $19^{\text {th }}$ and early $20^{\text {th }}$ Century, and was mainly aimed at overthrowing disparities authorised by law, especially the right of women to vote in general elections. The author further declares that the target of the primary movement was extended when a second-wave feminist arose in the 1960s through to the 1980s. According to Humm, attention at that time was paid to addressing cultural barriers, gender standards, and women's status in society. The third-wave of the feminist theory emerged from feminist activities to strengthen the aim of the second-wave, and to respond to challenges in the 1990s and 2000s (Krolokke \& Sorensen, 2005). The authors articulate that the main goal of the thirdwave petition was to seek more changes in stereotypes, media portrayals, and the language used to describe women.

As a result, a few changes were seen in people's attitude towards women as demonstrations continued. For example, according to Engel (2005), some people seemed more willing to accept women as who they are and appreciate their efforts in fighting for their rights. Further to this, the author comments that these minimal changes in people's attitudes help women demonstrators control their opponents in rallies and meetings. In the meantime, people have come to gradually acknowledge women's rights for the things they have asked for indicates that scholars who are interested in exploring the concept of feminist theory, provide numerous contextualised explanations to serve the needs of their research. The author notes that in most cases outside of research, women are portrayed as unequal to men in status, privilege, and power (Barton, 2006). According to Barton, feminist theory is about social justice, advocating for women and others who are marginalised, and attending to injustices. The notion of 
promoting social justice is fitting for this study given the situation of women within village communities in Samoa who are not gaining opportunities for leadership positions and privileges equal to those of men. There are benefits of the feminist theory that must be appreciated. According to Tong (1989), the lens of feminist theory is one of the many paths towards self-love and respect, promoting a sense of belonging, helping people to honour the feminine, and encouraging both men and women to be more authentic. These advantages may gradually become possible in village communities in Samoa as a result of advocating for social justice, a major component of feminist theory.

Feminist theory is utilised in this study because of its capacity to validate the expectations, assumptions, and beliefs of Samoan women engaging in societal activities. The theory's appropriateness authenticates a system of ideas, conceptions, potentials, and philosophies (Miles \& Huberman, 1994) that support and inform this study. The discussion of feminist philosophical discourses highlights the nature of gender inequalities affecting women's leadership in local government in Samoa, taking into account women's social roles, experiences, interests, and politics in history and culture. Potential themes emerging from this study include oppression and stereotyping in the Samoan women's struggle for leadership. The black feminism movement (Collins, 1991; Harding, 1993; Butler, 2007), strengthens the feminist theory in challenging the cultural protocols of patriarchal societies.

\subsubsection{Feminist Theory in the Pacific Context}

Feminist theory in the Pacific context is explained as an effort to despise violence, reasserts the importance of community, a belief in sisterhood, that actions with lasting effects are actions taken collectively, standing for equality - not the equality of women and men, but the equality of all people - and for social justice (Griffen, 1989). According to Griffen in her book titled, "Women, development, and empowerment,"(1989), the explanations incorporate feminist perspectives of Pacific women from Guam, Tonga, Tuvalu, Kiribati, Cook Islands, and Samoa. Griffen also identifies some negativities towards the concept 'feminist' raised by women in her study. It was perceived as a Western construct, applying to women in industrial societies; it was perceived to be about women wanting to be separate from the rest of society, in which case, it would undermine the traditional power source of women in the Pacific, which is the family; and it was perceived to be about women being discriminated against; something that her informants claim to be unusual for Pacific women who are not discriminated against. Furthermore, according to Griffen, Pacific women think that feminist is relevant to highly 
educated women, and the word feminist is not relevant to rural women. The overall thought of Pacific women in Griffen's study was that women were all feminists in the Pacific, because they were looking for the betterment of women and women's lives, and were working for the liberations of their people (Griffen, 1989).

It has been claimed that in the Pacific, women have their own ideas of what is a Pacific feminist, and that there are benefits to defining and identifying with a particular feminist perspective that cover issues relevant to them, such as cultural imperialism, for example (De Lauretis, 1990). According to De Lauretis, intervention is significance to counter the cultural restrictions of many traditions in the Pacific that restrain women from positions of power and authority. Further to this, the author believes that Pacific women developed a feminist ideology to analyse the wider issues of women's struggles, which were important to them as women and as Pacific people; for example, all forms of dominance, social inequalities, and the role and influence of institutions such as the church.

Locks (1989) observes that feminist theory allows Pacific women to question in a different way issues such as colonialism and imperialism (Locks, 1989). In my own experience and observation, colonialism has played a very vital role in undermining the status of women since colonial powers promoted male leadership in government, churches, and traditional organisations. Jill (1974) argues that the advantage of having a feminist perspective would influence the questions Pacific women ask about institutions and enable women to challenge conditions and cultural practices that contribute to their oppression. In Jill's stance, one of the positive reasons for developing a Pacific feminist perspective was the understanding that men were still in charge. Therefore, it was important for women to identify with feminism if it represented what they stood for and the changes in society women wanted. Ortner (1974) states that an advantage of constructing a Pacific feminist perspective is the need for women to be seen as persons and as human beings. In Ortner's view, the development of a Pacific feminist perspective enables Pacific women to identify and look for solutions for all forms of dominance, social inequalities, and the role and influence of cultural and religious institutions in undermining their status. A Pacific feminist perspective can be adopted by Samoan women in village communities who experience similar scenarios from cultural and religious structures. Additionally, the strategies of communal (Butler, 2007) and solidarity (Massey \& Denton, 1993) of the black feminism movement must be observed and implemented in order for the feminist struggle to work. 


\subsubsection{Feminist Theory in the Samoan Context}

Prior to colonisation, indigenous communities were not structured on the basis of hierarchy, oppression, or patriarchy (Smith, 2005). In Smith's view, our understanding that a society without structures of oppression was possible in the past tells us that our current political system is anything but natural and expected. Further to this, Smith believes that if people lived differently before, then people can live differently in the future. The notions of restricting women and not recognising their participation in modern leadership forums in village communities in Samoa paint a contradictory image from the leadership system before colonisation where people were neither ranked nor suppressed, and without male domination. This is the main reason for women leaders in village communities to fight for their rights to leadership since they believe, it is not a practice in the past, but an influence of colonisation and Christianity. This belief of women leaders about the administration of Samoan society in the past is supported by Coulthard (2006) who argues that indigenous societies have truths to teach the Western world about the establishment and preservation of relationships between people and the natural world that are not governed by empires. In village communities, women's rights to compete for positions of authority and power, as described by Andersen and Taylor (2009), are plagued by rules of local government that forbid women from holding matai title, and not acknowledging their participation in village council meetings.

Feminist theory solicits opportunities for women to freely express their rights and compete for leadership positions in the same way as males. Therefore, addressing the differences and inequalities in gender, as well as structural oppressions for women (Andersen \& Taylor, 2009), directly and indirectly influence women's struggle for leadership in many countries and different societies of the world. Like many cultures in the world, the Samoan culture associates women with child bearing, domestic tasks, and taking care of the family. These connotations deny women their worthiness, dignity, and aspirations in wider contexts (Walker, 1972). In Samoa, local and national government structures as well as religions favour male leaders. According to Sier, the opportunities for men provided by local and national governments as well as religions in decision-making forums make things difficult for women, and contradicting the principle of empowering women, as legislated by the feminist theory. The restricted opportunities for women also hamper exercising their freedom of expression as one of the constitutional rights in Samoa (Jewell, 1977). 
The modern hierarchical structure of the Samoan society assumes males as leaders and women as subordinates. Nevertheless, contrary to popular belief, feminism does actually benefit men because it centres on equality, and does not create a matriarchy (Ritzer \& Goodman, 2004). The neutral opportunity proposed by Ritzer and Goodman (2004) in equating men and women looks appealing in my view. I particularly acknowledge its healthiness in the provision of similar prospects, and argue that creating equal openings is likely to erase any negative feelings between the genders. In context, feminist theory endorses the explanation of concepts, assumption of responsibilities, expectations, and beliefs of women in this study, as well as scrutinising their behaviour, values, and common beliefs reflected in their performances. Some of the factors to be theoretically examined include interaction, cooperation, and interdependence to justify the women's communal performances.

\subsubsection{Black feminism}

Black feminism has similar intents to the feminist theory in challenging the patriarchal societies of traditional communities. However, black feminism argues from a standpoint that the social interactions amongst people determine relational patterns between social power and how knowledge is perceived, interpreted, and claimed (Harding, 1993). According to Harding, there is a lot of enlightening potential in observing the everyday activities allocated to different genders, classes, or races, as these define organised patterns between people's tasks and what they need to know. Further to this, Harding notes that both feminist standpoint and multicultural science arguments see that some complex situations in societies are harder to comprehend than others because of their unique functions (Harding, 1998). The difficulty of understanding these hard conditions in traditional communities may have caused previous observers to ignore the significance of these unique circumstances to the natives of respective traditions and customs. One of the most noticeable elements of difficulties is women's leadership status in patriarchal societies, especially when the observers are males. As Harding (1998) states, the movement of woman's suffrage advocates for removal of gender-based oppression, but ignores suppression about race and class. Therefore, this tendency should be refuted since it is based on the ignorance of different kind of restrictions black women have encountered (Harding, 1998). The author appreciates the effort of the black feminism in understanding how black women negotiate race, class, and gender boundaries locally and globally. This resonates with the perspective of this study in commending the success of the black feminism and holding the hope that women worldwide who advocate for leadership can 
do likewise. Women who struggle for leadership should pay attention to certain strategies to facilitate the movement, and one of the recommended approaches is being communal.

The approach of being communal puts feminism in its rightful place by incorporating both theory and practice into global feminist discourse, and was applauded when these were accepted in black religious circles as expressions of black women's spirituality and an anchor for activism (Butler, 2007). A collective approach was initiated by the leaders of the black feminism in 1970s, and materialised in 1980s and 1990s when black African American women finally developed a voice, a self-defined, collective black women's standpoint about black womanhood (Collins, 1991). According to Collins, black women utilised this standpoint to talk back, which resulted in achieving a milestone of being heard, visible, and freely expressing concerns. Consequently, black African American women's voices were absorbed in classrooms of higher education, marking the symbolic inclusion of their contribution to the collective design of educational policies, processes, and procedures (Carby, 1992).

Another practical approach that manifests the success of black feminism is solidarity, ensuring group unity and togetherness (Massey \& Denton, 1993). The authors note the team spirit in the black feminism movement to fight against unethical political circumstances which disturb black women as a group. For instance, the tension between naming the standpoint womanism or black feminism replicates the challenge of catering for a range of black women. However, Walker (1983) explains womanism, appealing to her metaphor of a garden where room exists for all flowers to bloom equally and differently. This implies that there are superior attitudes pertaining to black women with reference to black folk traditions. These characteristics of black feminism can be implemented in many traditional societies that restrict women from positions of authority and power.

In analysing Collins' theory of black feminism, Dotson (2015) establishes four fundamental viewpoints such as placing emphasis on meaning explained by people's lived experiences and practical images, communal understanding to achieve a common goal, competency to survive on the expectations of a community, and having adequate knowledge in relation to the morals and ethics pertaining to certain claims (Collins 2009. Many recent authors of black feminism continue to write about individual suppressions as shades of the original black feminism. 


\subsection{Feminist Leadership Theory}

The discussion now turns to feminist leadership theory, examining the characteristics that are relevant to the situation of women in traditional societies. The feminist movement and forecasts of a deficit in managerial capacity during the previous decade have led to increased pressure for better participation of women in leadership roles during the 1970s (Jewell, 1977). Nevertheless, the evolution of assimilating women into management positions achieved minimal success (Malabre, 1978). Furthermore, there was an increased body of literature about the issue of sex discrimination against women in management, and the unfair treatment of women was reported in relation to selection, remuneration, promotion policies, training, and employee satisfaction (Terborg, 1977). One explanation for the distinct treatment stems from sex-role stereotyping, which postulates that women do not possess the appropriate leadership qualities and abilities required for managerial positions (Bryce, 1970). In Bryce's view, management appeared to hold the belief that males were more independent, objective, competitive, and better suited to handling responsible leadership positions than the typically gentle, sensitive, passive stereotyped women. In general, those holding this type of stereotypic view are likely to perceive women as ineffective leaders in jobs which are in-congruent with females' more traditionally submissive sex role (Bryce, 1970). However, Rosener (1995) categorises women leaders as being collaborative, interactive, and empowering. The author compares the different ways men and women lead, and concludes that men's style of leadership is out-dated and most of the time does not serve the need of most modernised corporations. In contrast, women have the flexibility to adjust to situations and manage to control discrepancies within the organisations through solving problems and maintaining good-working relationships. These outstanding capabilities of women may have been key factors to attaining leadership positions (Rosener, 1995).

Helgesen (2011) and Rosener (1995) are well known commentators of leadership literature who believe that successful leadership corresponds with how women lead. However, many restrictions limit women's chances to occupy leadership posts. Eagly and Karau (2002) identify that the prejudice against females stems from societal expectations of the female gender that are not harmonious with being a leading figure. The authors argue that this explanation perceives women as common people and men as representatives of the society. Research into stereotypes reveals that men are regarded to be more representative and women to be more community-orientated (Deaux \& Kite, 1993). Some researchers find some benefits of the distinctive leadership style of women in comparison to male leaders (Eagly \& Carli, 2003). 
However, prejudiced evaluation of the women's capabilities as leaders disadvantage them in masculine organisational contexts. In the meantime, more women are achieving leadership roles at all levels, including elite executive roles (McCall, 2003).

\subsubsection{Characteristics of the Female Leader}

Tong (1989) argues that a feminist leader pursues resolutions to accommodate inequalities in gender, race, class, sexuality, and economic status. This typical leader counters social problems by overtly protecting individual freedom, gender equity, ethnic, and class equality in addition to promoting communal actions (McCall, 2003). Collective agreements according to McCall connect people and form links. The author further alludes to the fact that a feminist leader establishes bonds that bind members of the organisation and works closely with co-workers to develop personal relationships. Grogan (1998) claims that female leaders value teamwork, personal contribution, and family commitments. Additionally, they are more thoughtful than males regarding plans, processes and procedures as well as being more able to locate both professional and personal discussions in the workplace. Covey (1990) in association with Grogan's (1998) caring leadership, does not mention women but includes feminine scopes of leadership. Covey makes reference to how this particular style of leadership places emphasis on the employees' personal and interpersonal beings. To these authors, people's emotions and feelings rather than anything else in the organisation are the most important concern of the leader; and considering people's feelings is a focus of an authentic leader. Sergiovanni (1991) links the authentic leadership style to the head, the heart, and the hand, highlighting the significance of the cooperation of these parts of the body in executing leadership roles. The question that arises is; "Which gender does the coordination better?" Following the female's caring capacity that Grogan (1998) and Covey (1990) allude to, it is logical to conclude that females are more accommodating than male leaders in this capacity. Despite this, Fletcher (1994) argues that, irrespective of the females' leadership skills, due to values of many Pacific cultures which places respect on kingship, and honour male leaders as the norm, in Pacific contexts, characteristics of women leaders tend to be overlooked.

Bolman and Deal (1997) note a concern in women leaders to strengthen the relationship between the organisation and leadership. According to the authors, the emphasis here is based on the fundamental hypothesis that organisations attend to human needs, while people and organisations depend on each other's support. Bolman and Deal suggest a value of a positive team player who is naturally enthusiastic to work for the betterment of the organisation and its 
stakeholders. Women leaders are more operative when they develop goals that align with their personal values, taking into account the communal good of the organisation and its employees (Lord \& Hall, 2005). The authors imply that the purpose of considering communal good fulfils an essential human need for connectedness. Women leaders who continuously pursue determination for connectedness experience themselves and are experienced by others as trustworthy (Tong, 1989). With a higher sense of connectedness, women leaders are provoked to move outside of their comfort zones, alter their focus from what is to what is possible, allow for a captivating reason to resolve their uncertainties, and take action irrespective of the circumstances (Quinn, 2004). When leaders and others are connected to intense commitments, they instigate confidence, increase others' sense of perseverance, and help them find greater sense in their work (Jung \& Avolio, 2000).

In context, women in traditional communities in Samoa effectively practise the characteristics of being protective of individual freedom and promoting communal actions proposed by McCall (2003), evident in the establishment of women's committees, and achieving communal targets. Additionally, women value teamwork, personal and family obligations -elements of caring leadership suggested by Grogan (1998) and Covey (1990), obvious in engaging in community projects of the village, and income-generating activities to assist themselves and their families. With reference to Sergiovanni's (1991) authentic leadership of executing leadership through coordinating the head, heart, and hands, women in village communities assured during our attachment that they are driven by their hearts to work for themselves, their families, and the community at large. The perception of successful leadership corresponding to how women lead (Helgesen, 2011; Rosener, 1995), was well reflected in the work of the women's committees I observed. Therefore, the essence of feminist leadership theory fundamentally captures the context of how leadership is executed by women in village communities in Samoa. Unfortunately, as Fletcher (1994) puts it, more leadership characteristics of women leaders are overlooked. This is understandably, the case of Samoan women leaders whose many leadership potentials are curbed by cultural values, religious beliefs, and social assumptions.

\subsubsection{Pacific Context of the Feminist Leadership Theory}

Pacific women's representation in parliaments stands at $15.7 \%$ (International Women's Development Agency -IWDA -Pacific women's Leadership Program 2012-2015). This report documents that women's absence from formal politics reflects and perpetuates the male- 
dominated cultures and gendered role divisions common in all Pacific countries. Furthermore, patriarchal governance structures as well as cultural and religious norms have contributed to a situation where women are disempowered, have limited access to services, and are excluded from formal and informal decision-making. In order to counter these harsh conditions faced by women in Pacific countries and evidently in traditional societies, women involved in programmes to increase women's participation and inclusion in formal and informal leadership roles. As noted in the same report, the objectives of these programmes consist of improving gender sensitivity of local government policy-making, programming, and service delivery. In addition to general goals, there are also specific aims for women in specific countries. For example, for women in Fiji, Solomon Islands, and Papua New Guinea, these empowerment programmes aim at increasing voter willingness and ability to support women candidates in local, provincial, and national elections.

The international literature highlights the multiple aspects of change in making progress towards gender equality and the need for multiple strategies at multiple levels that are responsive and appropriate to the local context of Pacific women (Helgesen, 2011). However, the major difficulty in the author's view is policies that cannot be implemented because of traditional and religious restrictions of some societies. Therefore, the policies for gender equity look perfect in paper, but cannot be transferred into reality. Thus, women continue to be suppressed of their rights to leadership and decision-making, besides other oppressions that compromise their status.

The prejudice evaluation of women's capabilities as leaders (Eagly \& Carli, 2003) is another factor that disadvantage them from traditional organisations common in the Pacific. Therefore, male dominance continues to survive as women continue to be seen as ineffective leaders (Bryce, 1970). Although authors like Helgesen (2011) and Rosener (1995) argue that women leaders are successful in leadership arenas, many of the traditional societies prefer male leaders as it is the norm. For that reason, feminist leadership is a hard core element to be adopted in indigenous cultures. However, the lens of this theory enable women leaders and aspiring women leaders to explore the unjust of the administrative rules, cultural structures, and religious beliefs that restrain them from positions of authority and power. According to the literature pertaining to leadership in Pacific island communities, male leaders have the honour to present speeches in ceremonial grounds, create and enforce rules, impose punishments, and make decisions (White \& Lindstrom, 1997). As documents reinforce the male leadership mentality engrained in indigenous people, therefore, it is significant at this point in time to 
examine these norms using the feminist leadership theory in order to constitute the understanding that gender inequality exists in almost every sphere of traditional societies. Additionally, these gender inequalities are evident in people's everyday activities, performances, rituals, and celebrations.

\subsubsection{Samoan Context of the Feminist Leadership Theory}

The concept of feminist leadership has not been popular in Samoa at the moment, although initial attempts have been made to promote gender equality in leadership. The national government in response to the Millenium Development Goal 3 -To promote gender equality and empower women in targeting the elimination of gender disparity preferably by 2015 , (Millenium Development Goals and Beyond 2015- Fact Sheet by United Nations \& UNFP 2005), implemented the $10 \%$ women representation in the Parliament of Samoa in March this year. Starting this year, five seats will continue to be occupied by women in the Legislative Assembly. This is great in the sense that the national government responds immediately to the requirement of the United Nations. However, promoting gender equality in leadership is not happening in local government or village councils of village communities.

In terms of empowerment, it was seen in the observations that community women were heavily involved in income-generated activities, utilising the skills gained from community projects. Nevertheless, these empowerment skills attach women to household chores, caring for families, and looking after old people, roles that are assigned to them by males and the general society. None of these empowerment trainings develop or acknowledge women's leadership skills. In the context of feminist leadership, I gauge that there is a need for greater clarity and a more analytical approach to leadership, in order to distinguish between the different forms, models, and styles of leadership, the purposes to which it is applied, and the ideological frameworks that inform its practice. This is where Samoa should move beyond the descriptive - looking merely at what leadership is - towards the norm, which concerned with what good leadership should be. This is crucial in the context of feminist leadership, since our concern as women is not merely forcing more women to play leadership roles, but to lead differently, with feminist values and ideology. Such clarity would also build feminist leadership capacities in nonfeminist women and men.

Feminist leadership no doubt upsets traditional village communities which are administered by local government, and dominated by men. Therefore, the findings of this study intends to peacefully appeal to male leaders in local government for an opportunity to dialogue about the 
significance of allowing women to participate in village councils. I think, the long-standing gender stereotypes are sometimes unintentional, and the common threads against women leaders may have been resolved by holding numerous discussions.

Leadership from a feminist standpoint is informed by the power of the feminist lens, which enables the feminist leader to identify injustices and oppressions and inspires her to facilitate the development of more inclusive, holistic communities (Barton, 2006). According to Barton, feminist leaders are motivated by fairness, justice, equity, and strive to keep issues of gender, race, social class, sexual orientation, and ability at the forefront. It is the intention of this study to contribute to the promotion of feminist leadership in local government in Samoa, leading to increasing the number of women parliamentarians in the legislative assembly.

\subsection{Social Constructionism}

The theory of social constructionism is employed to scrutinise the understanding that knowledge is collectively constructed through people's dialogic interactions (Bakhtin, 1984). In the context of this study, the theoretical lenses examined the everyday conversation of women in their communal work, and how they attach meaning to their formal and informal discussions.

Social constructionism has been instrumental in attempting to make sense of the social world. Knowledge is viewed by social constructionists as being constructed, not created (Andrews, 2012). Andrews further argues that because the theory's core concern is the nature of knowledge and its construction, it does not consider any issues about actuality. According to Andrews, society exists both as a personal and an impartial reality, implying that meaning is shared. I subscribe to the view that this shared meaning is the foundation of the construction of knowledge, and that knowledge extends and changes as new information comes in.

Berger and Luckman (1991) explain that the notion of social constructionism originated in an effort to understand what is actually happening in our surroundings. According to the authors, social constructionism materialised some 30 years ago, and has its roots in sociology. The theory (social constructionism) has supplemented the post-modern era in qualitative research (Berger \& Luckmann, 1991). For these particular researchers, their concern is with nature, the construction of knowledge, how it emerges, and its meaning to society. The constructed knowledge is referred to by Schwandt (2003) as an outcome of the interactions of individuals within society. Schwandt claims that the result of the contact between people in their respective societies is an integral factor to social constructionism. The author further deliberates on the 
notion that knowledge and truth are both created, but not discovered by the mind. Berger and Luckmann (1991) note that the factors contributing to gaining knowledge are the division of labour, the emergence of more complex forms of knowledge, and what they call economic surplus. In promoting the discussion, Berger and Luckman exemplify that once knowledge is constructed, experts claim definite prerogative over that knowledge.

Grieco (1988) views reality in society as having both impartial and personal traits. The author detects that impartialities are neutral aspects which emerge from people's interaction with the social world. Consequently, the outcome of how the social world impacts on people allows the execution of routine and habitual schedules. However, Jervis (1988) interprets the interaction between the social world and people as a duplication that occurs without the influence of patterns formed of commonly constant action. According to Jervis, this duplication liberates people to improve what is in existence instead of starting everything once again. Berger and Luckman (1991) make reference to the harmony that emerges when new knowledge is added to existing knowledge as significance of habitual schedules, which gradually becomes routines, establishing a universal store of knowledge. In the process of harmonisation that takes place between new and existing knowledge, a lot of problems arise because people lack the skills and worldly exposure to function in a modern context, a scenario that motivates indigenous people to write and record their own cultures based on their indigenous theory of knowledge (Gegeo \& Watson-Gegeo, 2001).

\subsubsection{The Basis of Socialisation}

The basis of socialisation aims at detecting whether there are changes in the way knowledge is constructed through women's social interactions in this study. Primary socialisation breeds personal reality as reflected in people's attitude and behaviour, together with a few experiences accomplished by secondary socialisation (Burr, 1995). According to Burr, gaining an identity and a place in society are basic socialisation values that are very important in explaining our association with others. The author believes that our identity originates from our interaction with the social society rather than from the person's inner being.

Socialisation also arises from the impartial reality of society in an effort to solidify and internalise it (Berger \& Luckmann, 1991). The authors place great emphasis on how people utilise language to construct their reality. Nye (1988) comments that within social constructionism, language facilitates thoughts and feelings by building concepts. In other words, it is language that makes thoughts and concepts thinkable and not the other way around. 
Berger and Luckman (1991) agree that language exists before concepts and delivers a meaningful structure to people in order to make sense of the world. In their view, activating language in conversations sustains, alters, and rebuilds subjective reality, a combination of concepts that can be shared with others without causing any problems (Berger \& Luckmann, 1991). I interpret this to mean that the shared meaning and understanding should be clearly understood in normal dialogues. Therefore, these discussions should encourage parties to make effective decisions on consensual agreements.

Burningham and Cooper (1999) believe that social constructionism can be contextualised by making unbiased judgements and considering the consequences. The two key concepts in the description of Burningham and Cooper are unbiased judgements and consequences. In my view, unbiased judgements in context reflect the ability of the leader to consider the diverse ways of how people construct knowledge. In terms of consequences, I relate to the context of a visionary leader who is prepared for the worst all times. Craib (1997) suggests that social constructionism is similar to interactionism in the sense that they are mechanisms to deal with speedy changes. Craib alerts leaders to think critically about matters and to be flexible in adopting variations while adjusting to changes. Furthermore, the author enlightens the attitude of social constructionists to grasp changes, in avoiding defence or presenting justification to substantiate their positions. Side-stepping defence and justifying the leader's positions are social constructions that should be influenced by many other forces (Craib, 1997).

Another capability of social constructionism is that it places great emphasis on how people utilise language in their everyday dialogues to construct their reality (Berger \& Luckman, 1991). According to the authors, social constructionism considers the social practices people employ as the integral part of the investigation, in the absence of natural existences. In the context of this study, women in women's committees establish their reality in formal and informal conversations. The social interaction amongst women in village communities imply that their reality is constructed through language and dialogues.

\subsubsection{How Socialisation Facilitates the Construction of Knowledge}

Bakhtin (1984) argues that the search for truth is collectively constructed through people's dialogical interactions. The author believes that people commonly discover the truth through their discussions and interactive activities. The discovery of truth in conversations and communal activities mirrors the belief that knowledge is constructed, collectively defined, implemented, and accepted by the community. As a result, construction, understanding, and 
interpreting knowledge forms the foundation of employing the principles of social constructionism in this study.

Social constructionism can be defined as focusing on the impact of social and interpersonal factors in human life, and the construction of knowledge by groups to strengthen collaboration in sharing a common culture (Gergen, 1994). According to Gergen, culture is an important aspect in the development of knowledge, in that culture equips people with the necessities to make sense of their heritage, identity, values, and morals. The author further emphasises the importance of a shared understanding gained from working together to construct, interpret, and maintain cultural objects. According to the author, the important aspects of culture emerge from the interaction of people and therefore facilitate language, history, culture, and social activities (Gergen, 1994). In making particular reference to culture, I agree that in order to appreciate one's culture and identity, it is crucial to understand and value the cultural diversity that exists in the world around us:

Understanding others makes possible a better knowledge of oneself: any form of identity is complex, for individuals are defined in relation to other people - both individually and collectively - and the various groups to which they owe allegiance, in a constantly shifting pattern. (UNESCO, Learning: The Treasure Within, 1996).

McNamee and Shotter (2004) argue that the constant relations in the spaces between people and their setting influences their interpretation of corresponding situations. Additionally, connections help to facilitate people's relationship with the environment. Subsequently, the individual's life is not about the inner being of the individual alone, but about how the individual lives in relation to others in the same surrounding (McNamee \& Shotter, 2004). Garfinkel and Englewood (1967) suggest that it is important for people living in the same environment to understand the meaning that are socially constructed and regarded as the norm of the society.

Social constructionism implies that knowledge evolves from one's own identity without the mind exploring it (Schwandt, 2003). Schwandt's belief is that being a realist correlates with being a constructionist, enabling a person to visualise reality to construct knowledge accordingly. Steedman (2000) postulates that most of what we know involves understanding who we are versus knowledge gained from proven research, refuting scientific evidence to prove our identity and natural experiences. Experiences and interactions develop understanding. These things do not exist separately within a person, which makes everyone 
unique (Kirk \& Miller, 1986). For Hammersley (1992), social constructionism is the adoption of the term subtle realism, which means, people make certain assumptions based on background information, or information gathered from past experiences, and these assumptions shape our perceptions. The author also states that such a sociological perspective allows people to assign symbols for meanings, and to create meaning based on their interactions with one another, and this symbolic interactionism is based on three tenets:

- $\quad$ People act towards things based on the meanings they assign to those things.

- $\quad$ The meanings come from the social interactions people have with other people.

- We interpret and modify meanings by using those things.

The deliberations on social constructionism in context portray interpretations of the construction of knowledge of Samoan women. For example, older and experience members impart knowledge that is expected to be maintained and applied according to the cultural expectation of the community. However, this study has observed that modification of knowledge is proper with reference to the resources available, and the situation of women in traditional societies. Another mechanism of constructing knowledge is creating a communal understanding of all cultural honorifics pertaining to the Samoan woman that are supposed to be honoured and implemented with pride. The different ways women in village communities construct knowledge justifies employing the social constructionist theory, enabling the researcher to note the constructed understanding of Samoan women in leadership positions. Social constructionism contextualises the unearthing of social and cultural hindrances affecting Samoan females in their striving for leadership. Most importantly, it has the potential to reveal the cultural and social factors that impede females' chances to acquire leadership status in the village and all the other organisations therein.

\subsection{Authenticity of the Theories}

Overall, the theories of feminist, feminist leadership, and social constructionism facilitated the field work for this study. The theories are treated in this study as models that work in the traditional leadership setting of Samoan women. They guide the search to understand the meaning of the women's individual and communal activities. Theories examine in context the roles women play in families, churches, villages, and other organisations they belong to. Most importantly, application of these theories reveal the general impediments that women experience in their everyday lives. Utilising the theories enabled the researcher to identify the information needed to address the gender inequalities in leadership and provide insight into 
how to design a successful strategy to increase the participation of women in local government in Samoa.

Harmonising the theories of feminist, feminist leadership, and social constructionism enables the researcher to theoretically examine and contextually ground certain aspects of the research. For example, feminist theory investigates the system of concepts, assumptions, expectations, and beliefs of Samoan women. This theoretical lens scrutinises how women maintain their organisations (women's committees) and ensure that the expected roles are performed well. In utilising the theoretical lenses, consideration can be given to certain concepts that explain roles, conventions, and principles. Roles, conventions, and principles were assessed by the description of assured performances to validate the assumptions and beliefs of women in village communities.

The feminist leadership theory validates the leadership characteristics of females such as being participatory, non-hierarchical, flexible, and group-orientated. The feminist leadership theory enables me to scrutinise the deficiencies and positive leadership practices of women leaders in women's committees to determine the level and impact of their leadership. Furthermore, the theory also highlights the types of contribution leaders provide to support young and new members. An examination of the ranking is facilitated by the feminist leadership theory in determining the non-hierarchical characteristic of female leaders, as well as defining how flexible they are in adjusting to changes and considering people as individual members of the committee. The essence of the group-oriented capacity of women leaders is validated through the theoretical lenses of the feminist leadership theory to determine how they handled consultations and general discussions.

The theoretical lenses of social constructionism authenticated the collective construction of knowledge through the women's dialogic interactions (Bakhtin, 1984). Women in Samoa have an independent relationship with the environment as it is the basic source of food and materials used in their communal activities. Their knowledge of the things surrounding them is another part of their everyday dialogues. Using the vernacular language to impart knowledge and experience facilitated the discussions and improved the understanding of matters central to their organisation. These aspects were validated in the observations to explain how women constructed knowledge collectively. Another factor taken into account was the way in which women created a common understanding of the terminology, concepts, and constructs to facilitate the interactive activities. Attention was also given to the adoption and implementation 
of guidelines, processes, and procedures as well as monitoring and assessment mechanisms. One of the factors taken into account is the social relationship as it was structurally connected with logic, social constraint, and cooperation. These traits contributed to determining the incorporation of perceptions, traditions, and philosophies of Samoan women. Validation also considered the typical nature of the Samoan society where authority, prestige, and strong hierarchy govern organisations. Therefore, possible influences from the structure of the traditional community impact people's beliefs. Another element that defines the constructs of the society are formal and informal dialogues (Garfinkel \& Englewood, 1967). Observing discussions determined an understanding of the constructs and standardised customs of Samoan women in traditional village communities. In these ways, then, the theories of feminist, feminist leadership, and social constructionism facilitated the fieldwork, and revealed the nature of the challenges faced by the women.

\subsection{Chapter Summary}

The theoretical framework of this study includes the theories of feminist, feminist leadership, and social constructionism. The chapter places emphasis on the significance of employing theories in studies of a qualitative nature. The theories target particular elements of the study, in the context of the Pacific and Samoan women in traditional communities. Special attention is given to addressing the contradictions between theory and practise to strengthen the argument that leadership opportunities for noticeable women leaders are hindered by cultural structures, social assumptions, and religious establishments. 


\section{CHAPTER FOUR: METHODOLOGY}

\subsection{Introduction}

This chapter describes and justifies the methodological approaches, data collection tools, and analysis procedures implemented in this study. The first section (4.1) presents an overview of the research design, incorporating a summary of the purpose of the study. To remind the readers of the aims and focus of the research, the research questions are also restated. The next section (4.2) discusses qualitative, interpretive, and inductive research approaches, portraying the suitability of these and of case study design for the requirements of this study. Section 4.3 provides clarification of the talanoa research framework, highlighting its appropriateness for framing studies in indigenous context such as traditional villages in Samoa. Section 4.4 explains the benefits of commissioning a methodological triangulation approach to data collection - in this study, through interviews, observations, and document analysis, to validate information. Section 4.5 addresses the purposeful sampling technique and its significance in selecting participants for the study. Section 4.6 discusses the data collection tools, and describes the sequence of events followed through in the field work. Section 4.7 explains the thematic analysis approach (Braun \& Clarke, 2006) and, the individual stages of the data analysis process. Section 4.8 presents a complete account of the ethical consideration process, and matters of trustworthiness. The chapter concludes with a summary on Section 4.9.

\subsection{Research Design}

This qualitative research is descriptive and employs a multiple-case study approach. The study adopts a triangulated data collection method consisting of interviews, observations, and document analysis. Interviews focussed on the participants' experiences and critical incidents, highlighting the challenges that prevent Samoan women from being positional leaders, the strategies Samoan women use to serve as leaders, how Samoan social and cultural beliefs and perceptions inform women's leadership, and what leadership means for Samoan women in their villages. Observations explored how women utilise their leadership roles in the cultural activities of fine-mat expedition, tapa making, and hosting guests. Other interactive undertakings of women in village communities were observed to obtain more data about their leadership roles, and the services they provide to their societies. Document analysis involved examining policy documents, surveys, reports, and documentaries on women's empowerment and avenues of achievements, to cross-check the information gathered from interviews and observations. 
Participants were selected using a purposeful sampling technique, based on the selection criteria of age (50 years and over), being the holder of a matai title, and a village resident. Each of the selection criteria targets an important element of the study. For example, the age criteria is related to the experience of engaging in village activities; holding a matai title links to understanding the responsibilities of a leader; and being a village resident connects to a knowledge of the village protocols, processes, and procedures. The talanoa research framework (Vaioleti, 2006) facilitates interviews and observations. This research approach is effective for indigenous people to talk in the vernacular while enjoying the tranquillity of a familiar environment. For this study, most of the interviews were conducted at the homes of the participants, so the participants were seen relaxing and appreciating the discussions. The data was analysed using the thematic analysis approach (Braun \& Clarke, 2006). In employing this tool, the audio-recorded data was firstly transcribed, then translated into English. The translation ensures that the views of the participants are fully captured and reflected. The English version scripts were then coded and recoded to identify emerging patterns. Similar patterns were then turned into themes that were combined to construct overarching themes that incorporate all the main themes from the data. Ethical issues were validated utilising the fundamental ethics of the participants' rights (Martyn, 2006), and approval was granted by the Victoria University of Wellington Research Ethics Committee.

The specific research questions, previously presented in the introduction chapter, are restated below. The main research question is:

"What are the gender inequalities pertaining to Samoan women's leadership, representation, and participation in local government of the village?"

The main research question generated the following questions:

1. What are the challenges that prevent Samoan women from being positional leaders?

2. What is leadership for women in traditional village communities in Samoa?

3. What are the strategies Samoan women use to serve as leaders?

4. How do Samoan social philosophies, cultural beliefs, and perceptions inform women's leadership?

The components of the research design presented in this brief description, are addressed in details in the following sections. 


\subsubsection{Summary of the Purpose of the Study}

This study was borne out of my leadership aspirations and a willingness to be directly involved in decision-making forums. I have observed a few women participating in the politics of local and national governments, churches, and many traditional organisations, and wondered about the factors affecting women's leadership in Samoa. Thus, warranting this research, and I was eager to start from the local government since its locality is familiar. I have seen gender inequality in representation and participation in local government, and was curious to explore causes of such inequity as well as the implications on aspiring and current women leaders.

This study identifies cultural, religious, and social challenges pertaining to women's leadership in local government in Samoa. Therefore, these findings will form a platform for dialogues about gender inequality in representation and participation, and addresses general gender inequality issues in village communities. I envision that gender equality will be achieved when both women and men participate in making it happen. On the other hand, women need to display leadership, confidence, openness, and a vision. Men's roles are totally different. They control access to leadership positions, yet those positions are often filled by those most familiar - that is, those who most resemble men. However, the main purpose of this study is to advocate for gender equality in the leadership of local government. Furthermore, this study appeals to local government that do not allow women to be bestowed with matai title and not recognising their participation in village council to revisit their decisions. The appeal is additionally for the three mainline churches to allow women to attend Theological Colleges, and be ordained as priests. The study's long term goal is to increase the participation of women in parliament and churches.

\subsection{Research Approaches}

This section presents the approaches used for this study. Firstly, the qualitative approach is fitting to yield in-depth investigation about the challenges encountered by women leaders in local government of traditional village communities in Samoa. Employing a case study approach was to gain detailed information of selected cases for the study. A comparison of 15 multiple cases warrants commissioning a multiple case study to explore the similarities and commonalities within and among cases. 


\subsubsection{Qualitative Approach}

The qualitative approach is appropriate since it incorporates all the relevant components that capture the essence of the research. "Qualitative researchers approach their studies with a certain paradigm or world view, a basic set of beliefs or assumptions that guide their inquiries" (Creswell, 1998, p. 74). After calculating the scope of the data collection for this study, I concluded that a qualitative approach would provide the most suitable enquiry paradigm. "Qualitative findings grow out of three kinds of data collection: in-depth and open ended interviews; direct observation; and written documents" (Patton, 2002, p. 4). This understanding strengthened my enthusiasm for adopting a qualitative approach, and all of the three methods that were utilised in this study. Each of the methods yields particular information. For example, interviews aim at gaining direct quotations from participants about their experiences, opinions, feelings, and knowledge. Observation data contains detailed accounts of people's activities, behaviours, actions, and the complexity of people's interaction, as well as societal procedures that measure humans' participation. Document analysis consists of examining excerpts, programme records, official publications, and reports (Patton, 2002). Implementing these three data collection tools obtained substantial information for this research.

Qualitative studies produce thick descriptions explaining compact accounts of the participants' familiarity with the area of study (Denzin, 1999). It was assumed that complete, detailed accounts of the participants' perceptions and encounters would be generated through engaging qualitative methods. In this study, the nature of the data is exploratory and the purpose is to gain insight into a topic that has been little researched. In Samoa, there is very little information about this topic. Minimal data can be extracted from the findings of the research on political representation and women's empowerment in Samoa (Centre for Samoan Studies, 2015). However, that study strictly targeted the barriers that restrain women from becoming parliament members.

Guba and Lincoln (1994) indicate the significance of understanding a framework of basic assumptions and beliefs rather than relying heavily on the outcome of the observations and discussions. The researcher is guided by a world view, a system of beliefs contextualised to serve the purpose of the exploration. In the case of this study, the major data for qualitative analysis comes from talanoa with participants. 
Creswell (1998) defines qualitative inquiry as "an inquiry process of understanding based on distinct methodological traditions of inquiry that explore a social or human problem. The research builds complex, holistic pictures, analyses words, reports detailed views of informants, and is conducted in a natural setting" (p. 15). Activating and rephrasing questions as part of the inquiry process results in providing elaborated responses. Further, Denzin and Lincoln (1998) explain qualitative research as "a field of inquiry in its own right. It crosscuts disciplines, fields, and subject matters" (p. 2). In the light of Denzin's explanation regarding coverage of a qualitative research, my intention is to unveil all the restrictions and inequalities surrounding women's struggle for leadership. For the purpose of this study, the approach is appropriate, as it enables me to obtain detailed descriptions of the participants' perspectives and their lived experiences.

Qualitative research also has the ability to help researchers to tackle sensitive issues (Griffin, 2004). Issues look sensitive when the problems discussed pose threats. Traditional village communities in Samoa have been exposed to male leadership for a very long time, and most seem comfortable with it. Hence, when someone scrutinises problems concerning the authority, it may unsettle specific people and the community in general. Thus, the ability of the approach to accommodate these delicate matters is helpful as this specific study investigates many issues of that nature. The sensitivity of such issues hinder conversations because these could either be discussed privately or not discussed at all. This study is a ground-breaking platform for women to openly express their struggle for leadership in traditional communities.

Patton (2002) reassures us that "the quality of qualitative data depends to a great extent on the methodological skill, sensitivity, and integrity of the researcher" (p. 5). Learning about the important role of the researcher in executing the qualitative study data collection methods, I went to the field prepared to accommodate any challenges encountered in the contact with participants and traditional villages, since I was conscious of locating myself as an 'insider researcher' who is familiar with the context, the issues, the sensitivities, traditions, culture, language, and the roles of women.

\subsubsection{Participants of the Study}

In a qualitative research, participants are selected according to their experience of the phenomenon under investigation (Ryan et al., 2007), since this kind of selection ensures the richness in data. This study comprises 15 women selected using the purposeful sampling approach. As the respective approach aims at producing detailed information about the 
explored phenomenon (Patton, 2002), therefore, choosing these 15 women who experience the challenges of striving for leadership in local government substantiates extracting substantial information for the study. These women either hold matai titles, president of women's committees, leaders of the sub-village of female descendants of villages, or senior employees of the government, private entities, and non-governmental organisations. The majority of participants $(60 \%)$ reside permanently in village communities, and involve in daily activities of families, churches, and women's committees. These particular women hardly attend monthly meetings of the local government because they are either quietly threatened to do so, or are fully occupied with domestic roles. On the other hand, $40 \%$ of the research sample live permanently in Apia, and sometimes participate in meetings of the local government if they have the chance to do so.

Each of the 15 cases was treated independently, and all were later compiled to form the basis of the investigated data. The conclusions from 15 interviews were compared and contrasted. The selection of the cases is literal replication - meaning the cases were selected due to certain similarities and the results were predicted to be similar too (Yin, 1994). The unit of analysis under investigation has to be acknowledged according to Baxter and Jack (2008). In this study, the phenomenon investigated is the challenges that restrict women from leadership positions in local government, and the context in which it takes place is village council meetings of traditional village communities in Samoa. 15 women leaders were interviewed, and nine of them were observed in women's committee activities of a fine-mat weaving, tapa making, and hosting guests.

\subsubsection{Sequence of Data Collection}

I started the data collection process by interviewing the participants either in their offices in town, or in their families at village communities. The purpose of the interviews was to explore the challenges that prevent Samoan women from being positional leaders, and the strategies Samoan women use to serve as leaders. Additionally, there were questions about what leadership is for women in traditional village communities in Samoa, and how Samoan social philosophies, cultural beliefs, and perceptions inform women's leadership. The round of 15 interviews was completed within two months, and observations took up the last month of the field work. 
Observations took place at three women's committees in the rural areas of Upolu and Savaii. In this study, I was a non-participatory observer. This is a role that maintains a degree of distance with the participants and is focussed on witnessing and interpreting events as they take place (Halcomb \& Davidson, 2006). Observations enabled me to observe and record the women's activities as they took place, which provided me with the overall picture of their assumptions, beliefs, values, leadership characteristics, and how they constructed the truth through their dialogic interactions. I concentrated on the focus of my observations throughout the whole process without being anxious of women being distracted. Therefore, I played a nonparticipatory role since I was not a source of interruption in the women's activities.

\subsection{The Talanoa Research Framework}

The talanoa research framework (Vaioleti, 2006) is a Pacific research methodology practical with indigenous people who share information and experience in their own mother tongue. Acknowledging the diversity of indigenous people's ways of knowing, how they engage with the world, their beliefs and values indicate the need for research models that are congruent with an indigenous world view (Brayboy, Gough, Leonard, Roell, \& Solyom, 2012). The authors believe that serving the needs of traditional communities encompasses acknowledging environmental, plant, animal, and spiritual realms. They explain that research methods that are rooted in indigenous knowledge systems, knowledge making, anti-colonial, and community focusses are practical characteristics of an indigenous research framework (Brayboy et al., 2012).

Vaioleti (2006) presents talanoa as an indigenous research approach, effective for indigenous people. The author refers to talanoa as a meeting where people narrate their stories of lived experiences, actualities, and ambitions. He argues, in light of the "tuikakala methodology" (Helu-Thaman, 1997), that activating talanoa accommodates Pacific issues. Talanoa is an existing cultural practice of the Pacific (Fa'avae, Jones, \& Manu'atu, 2016). Talanoa as an oratory tradition is a concept recognised in Samoa, Fiji, Tonga, Cook Islands, Niue, Hawai'i, and the Solomon Islands (Prescott, 2008). Talanoa comprises of two intangible words: "tala, which means to tell or to talk, and noa which means anything or nothing in particular" (Otukunu, 2011, p. 45). Talanoa is an exchange of information between two people or within a group of people. According to Johansson Fua (2014, p. 99), "the interests of the participants themselves and their immediate surroundings and world views" is the nature and focus of talanoa. Manu'atu (2000) claims that the context in which people activate talanoa is both formal 
and informal. Talanoa is all about relationship building (Fa'avae et al., 2016). In the absence of relationship building, the authors believe that talanoa only takes place at a level where no meaning is attached to the discussion. In developing the concepts of 'malie' and 'mafana' as aspects of talanoa, Manu'atu (2000) relates to energising and uplifting spirits to a positive state of connectedness and enlightenment, which creates engagement in the sharing of stories, emotions, and experiences. The author refers to the inward warmth in the person's inner-being as 'mafana'. Farrelly and Nabobo-Baba (2014) note that talanoa creates empathy with people and families before collecting data, a good Pacific research practice. Talanoa provides flexibility to adjust and compromise (Vaioleti, 2006). Talanoa upholds practices that elevate people's identity, strengthen contextual cultural elements, and simplify evidence of activities in the Pacific context (Anae, Mila-Schaaf, Coxon, Mara, \& Sanga, 2010). Nabobo-Baba (2005) alludes to a major significant element of talanoa whereby people, protocols, and ethical values shape the direction of the research process. An understanding of the norm bridges boundaries and gaps. Ideally, talanoa establishes and strengthens relationships, a platform for building most activities of the Pacific people (Morrison, Vaioleti, \& Veramu, 2002). Clearly, then, talanoa is well-suited to Pacific research such as this study, particularly when such research is conducted by an inside researcher familiar with both talanoa and the people, protocols, and ethical values. The significance of oral communication cannot be compromised in the talanoa research framework. In essence, the interchange of thoughts between people could be a means of learning behaviour (Gergen, 1994; Richards \& Schmidt, 2014), a genuine characteristic of talanoa.

In this study, the talanoa method facilitated 15 interviews and three observations of settings. Talanoa sessions were audio-recorded after ethical consent was given by the participants. Some photos of the women's activities were taken and returned to them as souvenirs. Nine of the participants were interviewed at their homes in the villages and six interviews were held either at the participants' offices or at a restaurant in town. The observations were conducted at three women's committees at a rural village in Savaii, and two rural villages in Upolu. Participants were seen relaxing during talanoa and were willing to provide information for the interviews. The interviews focussed on open-ended prompts, and the talanoa was run responsively.

In negotiating the spaces for talanoa in the participants' homes, cultural protocols were observed, food was provided by the host family, and a gift was presented by the researcher. For the observations, the researcher was hosted by the women's committees for three to four 
days. In return, the researcher presented the women's committees with fine-mats, food, and money. Thus, the cultural practice of reciprocity was very much observed during the field work.

The talanoa research framework was very appropriate for this study since it provided space for the researcher and participant to share information and experiences without any restrictions. Although a time frame was scheduled for the interviews, participants were given amble time to construct, think through, and reconnect their ideas for the interview questions. There was flexibility in the manner in which the interviews were conducted as this is one of the advantages of talanoa. However, I made sure not to lose focus of the research questions. The talanoa process makes room for the cultural norms to be observed, and this is one of the highlights of the research since it results in appreciation and acknowledgment of our cultural values, identity, and heritage.

\subsubsection{The Researcher as an Insider Researcher}

As a holder of a matai title and a leader of the sub-village of female daughters of the village (Nu'u o Tama'ita'i) coupled with having a good oratory knowledge and an understanding of cultural values, I was confident in approaching the participants, especially with rural participants who reside in village communities, areas where traditions are very much upheld. I approached the participants in respectful Samoan terms that suit their status since it is a cultural requirement to use the Samoan connotations particular for people's status. Participants of the study are chiefs, orators, presidents of women's committees, or elite ladies of their villages. Therefore, particular traditional connotations were used to address each of the participants. I was also hosted by three women's committees, who also have their own traditional references. Again, I was confident in presenting the addresses pertaining to my knowledge of the cultural values and its implications. Addressing people and presenting speeches in the mother tongue is a very practical aspect of the talanoa that I greatly appreciated during my fieldwork. When it came to the exchange of gifts, it was swiftly done as the speeches were all in Samoan. I felt a sense of belonging and pride in performing the cultural protocols during my field work, crediting the talanoa research framework. I knew that I should not alter the flow of social interaction with the participants, and had an established intimacy of telling and judging the truth. Although I went into the participants' homes and offices, and village committees knowing the cultural protocols, people's behaviours, their privileges, and perspectives, I was well aware of the focus of my research, and targeted the areas that I planned to investigate. The encounter with participants in rural villages and women's committees turned into a well- 
established relationship, and I am looking forward to going back to discuss the findings of the study.

\subsection{Methodological Triangulation}

The three methods of interviews, observations, and data analysis were used to collect information, since using multiple tools produce substantial and legitimate data for a research. Triangulation deepens the researcher's understanding of the issues and maximises confidence in the findings of qualitative studies (Denzin, 1978). Triangulated data collection, whereby data is drawn from multiple sources, widens the researcher's perceptions of the phenomenon being studied, as a single method may not adequately obtain relevant data (De Vos, 1998; Patton, 1990). In another reference to triangulation, Webb, Campbell, Schwartz, and Sechrest (1996) emphasise its influence on the integrity of the data by reducing any indefinite interpretations. That is, two or more independent measurement tools produce more reliable data.

Hughes, et al., (1997) commend the complimentary nature of two sets of data from structured interviews and focus groups. The authors suggest that a clear pattern of the themes can emerge from using the triangulation methodology. Another strength of the triangulation approach is that it helps the investigator to reduce bias and cross examine the integrity of the participants' responses (Foster, 1997). Aiming to enhance confidence in the research findings, the methodological triangulation approach utilises more than one method to study a phenomenon (Kennedy, 2009). Kennedy claims that researchers found the well-established technique to be very beneficial in confirming findings. Connelly, Bott, Hoffart, and Taunton (1997) suggest that methodological triangulation obtains a large scope of data, augments validity, and raises understanding of the research paradigm. The benefits of triangulation include increasing confidence in research data, revealing unique findings, challenging or integrating theories, and providing a clearer understanding of the problem (Jick, 1979).

I utilised this approach for data collection due to the benefits it offers, reasoning that activating the triangulation methodology would generate an in-depth knowledge of the challenges that affect women's leadership in local government. The comprehensive nature of the data collected from interviews, observations, and document analysis substantiates the essence of the triangulation methodology. 


\subsection{Purposeful Sampling}

Purposeful sampling is extensively utilised in qualitative research to identify and select information-rich cases related to the phenomenon of interest (Patton, 2002). The process comprises the identification and selection of individuals or groups that are specifically wellinformed and have relevant experience relating to the researched topic (Creswell \& Clark, 2011). Purposeful sampling is strategic and purposeful in ensuring that the selected sample provides the depth and breadth of the required information (Patton, 2002). According to Sandelowski (2000), the fundamental aim of purposeful sampling in any qualitative study is selecting "an information rich case" (p. 250). Patton (1990) and Sandelowski (1995) suggest that the comprehensive characteristic of purposeful sampling embraces all forms of qualitative research sampling.

Knowledge and experience are the two factors which indicate the capacity and suitability of the participants (Spradley, 1979). In addition, Bernard (2002) and Spradley (1979) emphasise the importance of availability and readiness to participate. Another significant factor of purposeful sampling is participants' capacity to explain views and familiarities in a coherent, sensitive, and insightful way (Anderson, 1997). Purposeful sampling is less time-consuming, and the results are likely to be more accurate than those achieved with an alternative form of sampling (Beck, 1997). According to Beck, embedded in the purposeful strategy is the ability to compare and contrast, as well as identifying the similarities and differences in the phenomenon of interest.

I have used the purposeful sampling approach to select the participants for this study for a number of reasons. As well as to save time, I considered the capacity of participants to provide information. I understood that they were well educated, that they have lived in villages, and been involved in village ceremonies and traditional activities, and that they were aware of the challenges they encounter in striving for leadership positions in local government.

\subsection{Data Collection Method and Procedures}

This section explains the process undertaken in collecting data, and the legitimacy of the process in determining the accuracy and reliability of the information for the study. Several sources of data collection methods are normally included in the design of qualitative research (Yin, 2011). According to Baxter and Jack (2008), obtaining data from a variety of sources offers multiple lenses to make sense of the investigation. For this reason, I selected a data collection methodology consisting of interviews, observations, and document analysis. 
I started the data collection process with interviews. Six of the fifteen participants work in town, so they were interviewed at their offices or at a selected restaurant. Nine of the participants were interviewed at their homes in village communities. The purpose of the interviews was to explore the women's perceptions of the challenges of struggling for leadership positions. Interview questions were trialled with Va'aomanū Pasefika staff who teach Samoan courses and language at Victoria University of Wellington, New Zealand; language lecturers at the Faculty of Education, National University of Samoa, and with a staff member of the Ministry of Education, Sports, and Culture in Samoa. Recruiting someone outside of the teaching field to vet the interview questions was intended to further check their validity. This person both holds a Master of Applied Linguistics and represented the public in the trial.

Observations of nine participants in three women's committees were done in rural villages, where the committees are located. The purpose of the observations was to gain an understanding of how women utilise their leadership skills in communal activities of a weaving expedition, tapa making, and hosting guests.

\subsubsection{The Research Site}

This qualitative research was carried out in Samoa. The traditional culture of Samoa is a communal way of life based on fa'a-Sāmoa, the unique socio-political culture. In Samoan culture, most activities are done together (Mallon, 2002; Sowell, 2000) either in the family, village, or in different organisations. A very basic ingredient in Samoan life is the aiga (family). At the head of each aiga is the matai, a position of rank and authority. Families make up a traditional village (Mead, 1928). The majority of participants (60\%) were located in traditional village communities. The study was conducted in the two main islands of Upolu and Savai'i. The four locations of the participants are Apia, (capital) and three traditional villages from the rural areas of both islands. Of the three women's committees, two were selected from Upolu and one from Savai'i.

\subsubsection{Gaining Access to the Participants' Locations}

Access to research sites needs to be decided in the early stages of the study, although negotiations of access continue for the whole life span of the research project (Wang, 2012). Creswell (2007) emphasises the importance of researchers' flexibility to cope with changes to the original plan once they are out in the field. I went to the participants' locations with preconceived ideas about securing access. In fact, I had to change my plan because things did 
not work out as originally planned. For example, in two of the participants' houses, I was greeted with a cultural welcome of an 'ava ceremony'. I did not expect this in the homes of the individuals. Fortunately, what I prepared as my fa'aoso (food) was enough for our meal, and I also had some cash to gift the matai who came to greet me. The interviews were delayed, which also delayed the other interviews scheduled for the same day. The distractions did not impact on the interviews, as all went well afterwards. This was good as I was able to negotiate with the people concerned in the Samoan language, another advantage of the talanoa research approach.

Nabobo-Baba (2008) explains the Fijian customary process for requesting entry into a home or village community that begins with gifting suitable to situations. This is a similar process in Samoa when asking for permission to enter people's lands. As a stranger to the locations, I went through this process with participants in the rural areas. In Samoa, rural dwellers are more culture-oriented than urban residents. Therefore, cultural protocols need to be followed and observed in the rural communities. Gifting is reciprocal in manner, and it continues until the encounter ends (Nabobo-Baba, 2008). I presented participants with food on my first visit and they hosted me for the last two visits. They were again gifted with printed cloths of five yards each on my final visit. I was able to establish good relationships with the participants as well as the village communities that hosted me for the observations. After the first visit, people continued to welcome me for the last two visits and observations. The bond grew stronger when I was fully involved in the celebrations of the culmination of the women's projects I observed. As explained above, talanoa establishes relationships as most of the Pacific activities are built on this harmonious platform (Morrison et al., 2002).

\subsubsection{Semi-structured Interviews}

The interviews aimed at exploring the barriers women encounter while struggling for leadership positions in village communities. In qualitative research, interview questions need to be open-ended, neutral, and vibrant (Patton, 2002). These qualities of the interviews were trialled prior to the actual interviews. Prior to conducting the interviews, I confirmed that the anonymity of the participants would be preserved at all times and reiterated the purpose of the research. Six interviews conducted in the participants' offices and restaurants were private and undisturbed while the interviews conducted in the participants' homes were sometimes disturbed by people who passed by the house, or by uninvited guests. The disturbances were minor as they only delayed or prolonged the interviews. This is one of the strengths of the 
talanoa method since it can accommodate such disturbances. As an insider researcher, I understand that these things happen as they are part and partial of the village life. Therefore, I had the patience to wait until the participants finished engaging in conversations with people who passed by or uninvited guests.

Participants were given a choice of the interview language (English and Samoan). Participants who work full time decided to be interviewed in English in urban areas, while participants in village communities opted for Samoan. Interviews generated subjective informative matters shaped by the interviewees' experiences. Since qualitative interviewing is based on the assumption that the perspective of others is meaningful and knowable, entering into their perspective becomes a major objective for the qualitative researcher. Bisman and Highfield (2012) explain that semi-structured interviews explore multiple views and allows the researcher to probe for information. I sometimes asked the participants to elaborate on particular issues if I did not clearly understand what was explained. Social cues such as voice, intonation, and body language of the interviewee also gave me a lot of extra information to add to verbal answers to questions (Opdenakker, 2006). Thus, signals from the participants were also considered important in expanding their responses.

I scheduled the interviews at two-week intervals to allow ample time for transcribing. The fortnightly rotations were alternated on a three interview basis, and the complete cycle was in full swing for 10 consecutive weeks. The 15 interviews were tape recorded with the permission of the participants. I made notes about the critical incidents that women related to about the challenges they faced in endeavoring to gain leadership positions in village communities. Transcripts were taken back to the participants for verifications, and final scripts were also presented for the participants' confirmations.

\subsubsection{Observations}

Significantly, the researcher must become oriented to the observed situation in order to understand the context (Greene \& Caracelli, 1997). Greene and Caracelli claim that observations ensure the development of relationship and trust between the researcher and participants. Bernard (2006) identifies reasons for conducting participant observation in research. One of the reasons relevant to this study is addressing problems that are simply unavailable to other data collection techniques. In this study, participants could not confirm the practicality of their leadership skills in the interviews. For that reason, observations were utilised as an additional means of obtaining information. 
The other relevant aspect of observation is its ability to identify behaviours that might go unreported (Bernard, 2006). The practical leadership skills of women in cultural activities of village communities could have gone unreported or been missed due to the limitation of the interview time. As a result, I conducted observations of the nine rural participants in their villages weaving fine-mats, making tapa, and hosting guests.

In this study, I was a non-participant observer. This is to keep a distance from the participants and pay attention to receiving and interpreting events as they occurred (Halcomb \& Davidson, 2006). Observing and recording the women's activities provided me with a clear picture of the overall strategic process. In line with this, other women engaged in the activities I observed were previously informed by my participants of my presence and what I was going to do. Throughout my observation, women seemed to be relaxed and acted normal.

I paid three separate visits to the observation sites; first on the planning, secondly on the starting day, and later on the completion of the projects. I contributed food and took part in the celebrations and feasting to culminate the women's activities. I also presented 'ietoga (finemats) to the leaders of the women's committees as a token of appreciation. Reciprocity is culturally significant with Samoan people. Exchanging and presenting gifts symbolise respect and gratitude (Vaioleti, 2006).

\subsubsection{Document Analysis}

Document analysis aims to generate comprehensive understanding of the material being analysed (Corbin \& Strauss, 2008). The authors claim that document analysis can be a systematic procedure for reviewing and evaluating printed or electronic documents. Using document analysis complements other data collection tools in implementing a triangulation methodology (Denzin, 1970). The data collection tool explores data, excerpts, quotations or passages that can be organised into themes and case examples (Labuschagne, 2003). Document analysis is often used in combination with other qualitative research methods as a means of triangulation.

Documents for this study were obtained from the Ministry of Women, Community, Social Development and Internal Affairs; Office of the United Nations for Women in Apia; and the Centre for Samoan Studies, National University of Samoa. The Tiapapata Art Centre provided documentaries of the women's activities. The documentary titled: "Tulitulimatagau le ufi a Sina" screens fa'alelegāpepe - women showcasing fine-mats and tapa as well as short interviews of the problems women face in the process of producing these traditional materials. 
Another documentary consists of women's interviews about how they successfully run their small businesses in village communities. Women were shown in stalls selling german-buns, chips, pies, scones, as well as flowers, fine-mats, tapa, printed fabrics, shirts, dresses, and materials they make and sew.

In reviewing these documents, I examined the Samoan government's role in overseeing policies concerning women's welfare, empowerment, roles, and rights. I also investigated how the written policies were translated into actions and how these policies benefitted women in village communities. While viewing the documentaries, I concentrated on how women's activities impact on village communities and the country at large. I scrutinised the practical ways of exploiting women's leadership skills in the cultural activities of women's committees. Overall, policies, strategies, processes, and procedures to empower women are welldocumented and reported. However, my analysis indicates that the level of empowerment does not improve the women's status to equate with that of the males.

\subsection{Thematic Analysis}

The data collected for the study was analysed through the thematic analysis process (Braun \& Clarke, 2006). The thematic analysis method aims at identifying, analysing, and reporting patterns or themes emerging from the data (Boyatzis, 1998). According to Boyatzis, thematic analysis organises and describes data in many ways, and can get complex when interpreting different aspects of the research. Thematic analysis is one of the most important instruments of interpreting qualitative data analysis (Fielding \& Fielding, 1986). The authors explain that the core units found through thematic analysis are referred to as patterns or themes. The complicated, diverse, and extraordinary nature of qualitative approaches justifies applying the thematic analysis process as the basis for analysing qualitative data (Holloway \& Todres, 2003). Braun and Clarke (2006), advocate thematic analysis as advantageous for qualitative studies because it offers easy access and is adjustable to simplify the examination of data of qualitative research.

The initial task of thematic analysis is coding, the process of breaking down and reducing text into manageable units of analysis (Patton, 2002). I started the thematic analysis process with some prior knowledge of the data after doing the translation and transcribing of interviews myself. Irrespective of having some initial ideas, I immersed myself to become familiar with the data (Braun \& Clarke, 2006) by reading it repeatedly to reason out the depth and breadth of the content. By reading over all collected text, I was able to find meanings and patterns that 
were later formed into meaningful units. The identified meaningful units were extended, reclassified, and renamed during the course of the analysis. All different levels of coding systems play a major role in deciding between what fits together and what to eliminate (Patton, 2002). The data have been transcribed to an appropriate level of detail and the transcripts have been checked against the tapes for accuracy.

The next phase was generating initial codes. The initial list of ideas about the data and meaning was organised further into expressive units (Miles \& Huberman, 1994). This was the "raw information that could be assessed in a meaningful way regarding the phenomenon"(Boyatzis, 1998, p. 63). Tucket (2005) refers to this as organising data into meaningful groups. I gained these units from thoroughly analysing the complete data set to recognise thought-provoking characteristics of the data items. These established the foundation of repeated patterns across the data set. Each data item has been given equal attention in the coding process. The number of initial codes generated from 15 interviews were 425 . One of the key ideas from the initial codes was the suppression of women leaders in village communities from power and authority of village councils or local governments. However, it was also evident that irrespective of the suppression, women leaders engaged in developmental activities, community projects, and provided services for people in village communities. The 425 codes were collapsed, merged, and reduced into 125 new codes (Appendix D). The decreased number of codes was later characterised into six emerging patterns (Appendix E). One of the interesting patterns referred to the cultural challenges that restrict women from leadership positions such as village rules of not allowing women to be bestowed with matai titles and not recognising their participation in village council meetings. Other patterns included the social assumptions that affect women's leadership, religious beliefs that influence people's preference for leaders, perceptions of leadership of the Samoan women leaders, the servant leadership nature of women in village communities, and women's developments and achievement that are not undermined by the Fa'amatai system.

Reviewing patterns resulted in formulating a set of candidate themes. It was obvious at this stage that some of the candidate themes were insubstantial. Themes were disqualified because of lack of data to support them or when they collapsed into each other. The former was obvious when data was too diverse and the latter could be identified as deceptively appearing to be different when, actually, they fitted one theme. According to Patton (1990) there should be a flawless and precise difference between themes. Additionally, themes should be organised together in a very meaningful manner. As a result, three main themes were constructed in 
response to the research questions (Appendix F). An example of one of the emerging themes states that cultural restrictions, religious beliefs, and social assumptions prevent Samoan women from leadership positions in local government of village communities.

Defining and naming themes started when I obtained a satisfactory thematic map of the data. At this point, the terms 'define' and 'refine' came into play. The concepts aimed at identifying the crux of what each theme was about and determining what aspects of the data each theme captured. For each individual theme, I wrote a detailed analysis as well as identifying its story. An important consideration at this stage was to ensure how each theme fitted into the overall story the data tells. Themes have been generated from a thorough, inclusive, and comprehensive coding process. All relevant extracts for each theme have been collated, checked against each other, and traced back to the original data set. Themes are internally coherent, consistent, and distinctive. Data have been analysed, interpreted, made sense of, rather than merely paraphrased or described, and the whole analysis tells a convincing and well-organised story about the data and the research topic (Braun \& Clarke, 2006).

The final stage to complete the thematic analysis is the report writing. Having access to a set of fully worked-out themes, I was prepared to write the report. Write-up of a thematic analysis report for this dissertation aimed at telling the complex story of the collected data and verified the merit and validity of this analysis. Incorporated in the report were data extracts demonstrating the primacy of the final themes that emerged from the data.

The process of analysis is dynamic. Before arriving at any conclusions, "the analyst has to brainstorm, try out different ideas, eliminate some, and expand upon others" (Corbin \& Strauss, 2008, p. 4). Patton (1990) describes analysis as a combination of an art and a science. The author refers to the art aspect as being the invention of a comprehensive story, an outcome of an analytical problem-solving procedure that assess the coherence and descriptive of the data. The researcher is also encouraged to think outside the box and be able to turn raw data into something that promotes understanding and increases professional knowledge (Patton, 1990). The science aspect of analysis refers to grounding concepts in the data that are systematically developed into properties and dimensions (Blumer,1969).Data analysis involves interpretation, a productive process which unlocks the various meanings of an incident, entity, involvement, or test (Denzin \& Lincoln, 1998). At the end of the analysis process, I gained a clear understanding of the overall themes that capture the essence of the data for the study. 


\subsection{Ethical Considerations}

Ethical approval is an important aspect of research, and researchers need to go through the process in ensuring that the study is ethically viable for the researcher and for participants and their rights. The principles of morality according to Wolfensberger (1967) accommodate and protect the participants' rights as well as appreciating their participation in the research. In acknowledging the rights of the participants, consideration must be given to validating directions and internal issues (Martyn, 2006). Martyn emphasises that the importance of respecting participants' rights in any research includes gaining informed consent via a signed consent form, participants having the right to freely withdraw without any harm, and participants receiving proof of the recorded data (Martyn, 2006).

According to Creswell (2012), an important part of the research process is gaining formal ethical approval that is granted by institutions such as universities. Creswell claims that in some cases, these approvals are allowed by professional bodies such as ministries, non-governmental organisations, or the private sector. These ethical approval guidelines aim to protect participants' rights in the research process, and to diminish or abolish the possibility of any harm (Orb, Einsenhauer, \& Wynaden, 2000). Orb et al. (2000) warn researchers to minimise or eliminate risks to participants if ethical problems arise during the field research. Taking these suggestions into account, this study followed the ethical guidelines of the New Zealand Association of Research in Education, where ethical approval was granted from the Victoria University of Wellington Research Ethics Committee

In relation to the ethics of gaining access to the participants' locations, it was necessary to seek permission from them as individuals. Furthermore, I gained the approval of leaders of the three women's committees selected for the observations. I presented the individual participants and leaders of the three women's committees with a Research Information Sheet (Appendix A) which had been approved by the Victoria University of Wellington Research Ethics Committee. The field work started when approval was received from the respective parties.

Informed consent is one important factor in qualitative research, stressed by Orb et al. (2000). In the authors' view, researchers must provide written evidence to signify that participants are fully informed and have willingly and voluntarily participated in the research (Orb et al., 2000). However, the signing of consent forms in rural regions of Samoa is not as important as it might be elsewhere. People are used to giving verbal agreement. Although this was the case, I convinced the rural participants and leaders of the women's committees that it was an 
obligation on my part to provide evidence of the participants' willingness to engage in the field work activities because it was a condition of my research ethics commissioned by the Victoria University of Wellington Research Ethics Committee. The participants signed consent forms (Appendix B) at each stage of the data collection. All consent forms were signed by 15 participants. Additionally, Presidents of the three women's committees where the observations took place also signed consent forms. Consent forms were also signed for the interviews to be audio-recorded (Appendix C).

Ethical issues for this study were clearly discussed between the researcher and the participants. I made it clear to the participants that part of my role was to acknowledge and protect their rights throughout the course of the project, including, keeping confidential any information about themselves, the organisations they work with, and their families (Wiersma \& Jurs, 2005). For example, I firstly allocated pseudonyms to the participants, and then numbered them 1-15. So, they are acknowledged as Participant 1 to 15 in the finding chapter. Clarifications of other rights such as ensuring they would experience no harm from withdrawing if they felt like doing so were also made at the beginning of the research. Later, participants received the interview transcripts for verification purposes. Above all, during the field work, I respected my participants with courtesy and that helped in establishing a good trusting relationship that Mertens (1998) alludes to.

\subsubsection{Trustworthiness of Qualitative Research}

It is significant for any research to reflect trustworthiness in its results for academic and professional credits. Guba and Lincoln (1985) emphasise the significance of trustworthiness in qualitative research, saying that researchers need to ensure the trustworthiness of the research for the findings to be worth taking account of. According to the authors, trustworthiness withstands the reasoning that the inquiry's findings are "worth paying attention to" (p. 290). Guba (1981, p. 85) notes the importance of "member checking” in enhancing credibility. At the appropriate stage of the data collection process, participants are asked to check the accuracy of the information they have provided, as this transparent measure allows participants to scrutinise and finalise the data (Guba, 1981). In this study, when I had transcribed the raw data, I gave the transcribed versions to the participants for further comments. On the other hand, it was not practicable to do member checking for observations because the notes I took were my own interpretation of the situations I observed. Photographs gave further meaning to the recorded notes. Information from observations was cross-checked with data from the 
interviews, and this cross-checking exercise further helped in enhancing the credibility of the study.

Another criterion for judging the trustworthiness of the study is transferability, a possibility of allowing findings of a particular study to apply in circumstances and locations outside the limits of the situation (Jensen, 2008). Transferability, however, depends on the degree of similarity between two contexts (Guba, 1981). It is my intention for this study to offer appropriate data for readers to contextualise some of the findings in their own contexts, something that Shenton (2004) claims important. This study will have implications for the literature on women's leadership in Samoa, as it is the first study of its kind. As Guba and Lincoln (1985) specify, it is the responsibility of the researcher to make data available to enable other people to assess its transferability.

Trustworthiness of the research is also enhanced by its dependability, where reliable data reflect the consistency of findings (Guba, 1981). Guba further explains that clarity in data collection, analysis and interpretation of results must prove the dependability of the research. Coding, re-coding, and revisiting previous codes as part of the analysis also enhances dependability. Final codes representing overarching themes of the research were carefully framed representations of the participants' experiences, constructs, and critical incidents (Krefting, 1990). While going through the stages of the coding procedure in the analysis, I revisited the first coding and did a comparison of the results with the new codes. To increase the accuracy of the study, multiple examination of the codes must be done to capture all relevant information (Goetz \& LeCompte, 1984). To decrease bias, I remained neutral in describing and interpreting the data, by not influencing the data with my personal ideas.

Guba (1981) describes confirmability as another criterion for making a judgement about the trustworthiness of research. This particular principle ensures that findings are determined by participants' responses rather than the biases, motivations, or perspectives of the researcher (Guba \& Lincoln, 1985). To avoid bias while conducting interviews, I avoided control and refrained from imposing my views on the participants. I was also careful not to influence the participants with my perceptions and reasons for exploring the leadership skills of women in traditional communities. This study generated confirmability through triangulation of data from three different sources - interviews, observations, and document analysis, as well as analysing the data using the thematic analysis approach. 


\subsubsection{Trustworthiness Across Language Translations}

The accuracy of a qualitative study is implicated in trustworthiness (Guba \& Lincoln, 1985). When assessing the trustworthiness, qualitative researchers must understand the link between their competence in implementing the study and its trustworthiness (Guba \& Lincoln, 1985; Patton, 2002). Edwards (1998) argue that the trustworthiness of cross-language qualitative research is threatened by the inconsistency and inappropriate use of translators and interpreters. According to Edwards, the inconsistency and inappropriate use of translators and interpreters will later affect the information provided by participants. Being conscious of the impact of translation on my study, I gave the translated and the vernacular versions of the interviews to two language specialists at the Faculty of Education to verify. Interpreters must have a minimum of sociolinguistic language competence (Danesi, 1996). Both of the translators have Masters of Linguistics from the University of Newcastle. So, I trusted that they undertook the task adequately. I took into account the advice of these language specialists in finalising the translations.

\subsection{Chapter Summary}

The chapter provides a complete description and justification of the methodological approaches employed by the study, tools used to collect information, and the process of analysing data. It presents the research design, featuring the overall purpose of the study. The chapter also outlines the research approaches executed, highlighting the appropriateness of these research methods in response to what is required by the study. Additionally, the relevancy of the case study designs are presented to justify the significance of utilising these strategies in studies of a qualitative nature. The talanoa research framework is underlined in the chapter to validate the practicality of this traditional approach in research conducted in traditional settings - in this case, Samoan village communities. The chapter gives an account of a methodological triangulation approach to data collection constituting the rationale that multiple tools yield more reliable data than a single method. Explanation of the purposeful sampling technique is given to commission obtaining rich, detailed information from selected participants. Accenting the sequential events of the field work is given, portraying the systematic procedure followed through in obtaining data. A presentation of the thematic analysis approach is presented to determine how the final themes of the study were obtained, as well as explaining the ethical consideration process in establishing trustworthiness. The chapter concludes with a summary of the activities of the field work. 


\section{CHAPTER FIVE: FINDINGS}

\subsection{Introduction}

This chapter presents findings of the study into challenges that impede Samoan women from leadership positions in local government, strategies Samoan women use to serve as leaders, how Samoan social and cultural beliefs and perceptions inform women's leadership, and what leadership is for Samoan women in their villages. Section 5.1 provides information on the background and experience of participants in the sample, complementing the purposeful sampling selection. Section 5.2 submits key findings from the interviews, featuring the participants' narratives of the challenges that restrict them from positions of authority in local government. Section 5.3, also based on the interview data, gives a detailed description of the cultural, religious, and social factors affecting women's leadership in Samoa, underlining the women's stories and experiences. Section 5.4 outlines results of the document analysis, highlighting the women's empowerment initiatives and achievements. Section 5.5 provides document analysis results, portraying the context of the theoretical lenses of feminist, feminist leadership, and social constructionism in the women's activities. Section 5.6 presents the characteristics of Samoan women leaders, and concludes with a chapter summary on Section 5.7 .

\subsection{Background and Experience of Participants in the Sample}

This study employed a purposeful sampling technique which selected 15 women participants. Participants either held cultural titles (matai), or were presidents of women's committees, or were leaders of the sub-village of female descendants of the village (Nu'u o Tama'ita'i). They were also full-time employees of government and non-government organisations, the United Nations Office for Women in Samoa, and private corporations. Matai title holders participated in village council meetings and financially supported village obligations like special projects, churches, school buildings, rugby fields, women's committee houses, and ceremonial activities. On the other hand, female leaders were active organisers of communal activities, while presidents of women's committee organise and lead community projects. Information about age, qualification, location, and position of authority are contributing factors to the leadership experiences of the participants, and they are presented in the following tables. 
Table A. Age Cohort

\begin{tabular}{|l|l|c|}
\hline Age Range & Total Number & Total percentage \% \\
\hline $50-55$ & 6 & $40 \%$ \\
\hline $56-60$ & 2 & $13.3 \%$ \\
\hline $61-65$ & 4 & $26.7 \%$ \\
\hline $66-70$ & 2 & $13.3 \%$ \\
\hline $70-75$ & 1 & $6.7 \%$ \\
\hline
\end{tabular}

Ages of the participants portrays the years of living in village communities, and their experiences in engaging in village activities, ceremonies, and functions.

Table B. Qualifications

\begin{tabular}{|l|c|c|}
\hline Qualification & Total Number & Percentage \% \\
\hline Doctorate & 5 & $33.3 \%$ \\
\hline Master & 5 & $33.3 \%$ \\
\hline Bachelor & 4 & $26.7 \%$ \\
\hline Diploma & 1 & $6.7 \%$ \\
\hline
\end{tabular}

Qualifications of the participants indicate that they have engaged in higher education to obtain academic qualifications.

Table C. Locations of Participants

\begin{tabular}{|l|c|c|}
\hline Island & Total Number & Percentage \% \\
\hline Upolu & 9 & $60 \%$ \\
\hline Savaii & 6 & $40 \%$ \\
\hline
\end{tabular}

Table C depicts the locations of the participants. Upolu and Savai' $i$ are the two main islands of Samoa. Nine participants or $60 \%$ reside in Upolu while 6 or $40 \%$ of the sample live in Savaii. Although Savaii has the largest land area of 1,700 square kilometres, (Samoa State of the Environment Report, 2013) more participants are recruited from Upolu since it is the most populated of the Samoa islands. 
Table D. Residential Areas of Participants

\begin{tabular}{|l|l|l|l|l|}
\hline Area & $\begin{array}{l}\text { Urban } \\
\text { residents }\end{array}$ & Percentage \% & Rural residents & Percentage \% \\
\hline Upolu & 3 & $20 \%$ & 6 & $40 \%$ \\
\hline Savaii & 3 & $20 \%$ & 3 & $20 \%$ \\
\hline Total number & 6 & $40 \%$ & 9 & $60 \%$ \\
\hline
\end{tabular}

Table D illustrates urban and rural residents of Upolu and Savai'i. According to the figures, $60 \%$ are rural dwellers while $40 \%$ live in urban areas. The $40 \%$ hold matai in rural villages in Upolu and Savai'i, but live permanently in town to work.

Table E. Participants' Positions of Responsibility

\begin{tabular}{|l|l|l|}
\hline Position & Total Number & Percentage \% \\
\hline Chief Executive Officer & 5 & $33.3 \%$ \\
\hline Associate Professor & 1 & $6.7 \%$ \\
\hline Assistant Chief Executive Officer & 3 & $13.3 \%$ \\
\hline Consultant & 3 & $20 \%$ \\
\hline Senior Lecturer & 2 & $13.3 \%$ \\
\hline Principal & 1 & $6.7 \%$ \\
\hline
\end{tabular}

Table E shows positions of responsibility in the government, private sector, and nongovernment institutions occupied by participants. It must be noted that as well as these positions, most participants held other cultural positions and titles (For example: high chiefs, orators, Presidents of women's committees, and leaders of the sub-village of female descendants of villages (Nu'u o Tama'ita'i).

\subsection{Key Findings from Interviews}

Results from the interviews identified cultural, religious, and social barriers as major hurdles that restrained potential women leaders from participating in local government of traditional village communities in Samoa. These major hurdles were enforced by rules and practices in families, churches, and villages; and are controlled and monitored by local government. Participants were divided in their support for local government, but all agreed for women to be 
bestowed with matai titles, and participate in village council meetings. Participants who were permanent residents of village communities who make up $60 \%$ of the study sample believe that the make-up of village councils aligns with the cultural leadership conventions. However, $40 \%$ of the participants who live in town see inequality in representation as problematic, and consider increasing women participation in village councils as a way forward for Samoa. The foremost concern of all participants is not to upset the cultural protocols of village communities while confronting male leaders about the significance of women's participation in local government.

The interview data identified three major themes;

1. Samoan women's leadership in village communities is servant but not status leadership;

2. Cultural restrictions, religious beliefs, and social assumptions pertaining to women's roles prevent Samoan women from leadership positions in local government of village communities;

3. The ascribed lower status of women leaders in the Fa'amatai system does not undermine their perception of developments and achievements.

These are discussed in order. The participants were given pseudonym names and then labelled Participants 1-15. Therefore, they are quoted as Participants 1-15 in the finding and discussion chapters.

\subsubsection{Servant Leadership Nature of Community Women}

When participants were asked to explain how Samoan women exercise their roles as leaders within their village communities, they said that they considered themselves as servant leaders by offering a variety of services to the people, as well as providing for families, churches, and villages. Servant leadership incorporates attitudes, norms, behaviour, and beliefs of women in traditional communities. Providing different services justifies the willingness to serve others first by basically utilising the expertise and skills women possess. Servant leadership for community women is about making services available for people 24 hours and free of charge. In the delivery of services, women promote a sense of community, pride, and share power in decision-making.

Participants openly declared that they utilised certain expertise to serve communities with dignity and pride. Participant 7 said: 
We offer services to the best of our abilities. We have pride in seeing that the village benefits from the services we offer and what we make from our projects. It's just a great feeling to give, and be appreciated by the community. Our goal is to serve.

Participant 15 added:

It's very rewarding to care for the family, village, and church through the services we provide. It's also inspiring to earn by selling what we make, and gift people with the products. I know that women can reach out for others in so many ways. We are proud of our successes and achievements.

The idea of being successful is described as having 'rich hands' was described by another rural participant. Participant 14 said:

E 'oa lima o tama'ita'i. (Females have productive hands).

The term 'productive' explains the numerous talents women have and the services they are capable of offering. This expression links to one of the women's roles of 'fai'oa'- wealth maker. Participant 14 went further to say:

Women always share wealth to make others happy. It is a token of respect for the village and church authorities. It is also to help people with low income and can't afford the expensive goods from the store.

Leaders of women's committees acknowledged the concept of servant leadership to explain how they served the communities. According to many of them, the leadership skills they possess are evident in the services rendered. Furthermore, while their aim was to serve people and the community, they also practised working together to achieve their goals. One of them expressed this using a Samoan proverb:

E mama se avega pe a pulupulu lima fa'atasi. (Many hands make the work lighter).

The metaphor of putting hands together shows how work strengthens relationships and motivates people to work towards a common goal. Women referred to the effectiveness of the leadership skills of collaborating, giving support, and working as a team. Participant 12, president of one women's committee explained. 
We believe that the services we offer demonstrate our practical leadership skills, and our main concern is to yield what we can afford to better people and the community. The spirit of team work maintains stability and consolidates good relationships.

This comment reflects women's understanding that they are serving their communities in their capacity as leaders and that they make the services available when they are needed. Other benefits of the women's services are that they are free of charge and can be accessed for 24 hours daily. Participant 10, president of another women's committee commented:

Because we are located within the vicinity of the village, therefore, people can approach us any time. We are always prepared for any challenges. We never refuse anyone who asks for help. Nothing is impossible.

With laughter she continued saying:

Some women have traditional resources in their beds like sleeping mats, fine-mats or tapa. Others can sew, bake, do floral arrangement, and other things. So, we are never short of things to offer as we are blessed with many talents and skills.

Although women announced that their work was about free services, the cultural norm denotes reciprocity. It is not compulsory, but it is culturally appropriate to show appreciation in return of a favour. Communally, women serve families, churches, and villages by offering or selling the things they produce at affordable prices besides rendering other services. These services include counselling, comforting, mentoring, maintaining overall hygiene and cleanliness, acting as traditional healers and midwives, as well as engaging in income-generating activities.

\subsubsection{Counselling}

One of the chief executive officers offered counselling as part of the community projects coordinated and run by her organisation. She counselled women to be alert of all kinds of abuses affecting themselves and children. Participant 1 believed that if abuse was prevented, it saved time, effort, money, and lives. Her aim in counselling was described as:

Counselling is part of the community projects. I counsel women to protect their families from all forms of abuses, and show them where to find support if needed. I believe in the saying: 'Prevention is better than cure'.

This participant resided permanently in town, but she usually spent time with women's committees overseeing community projects. She conducted counselling for women about kinds 
of abuses and the organisations that offer help for victims. She reported that she was also doing this work in countries other than Samoa:

We do a lot of work in Melanesian and it's very different situation there for women, whereas here the women do have status in many things that depend on them. They are the pride and the embodiment of theirfamilies.

One of the participants played a similar counselling role. She delivered counselling in training workshops for the empowerment of women. In her counselling, she explained the different types and sign of abuses. She also encouraged women to report any abuse cases to the police. This participant said that there were reasons why victims did not report abuse. The major reason was fear of the offender. Many offenders threatened victims and warned them not to tell anyone. Another reason was people's ties to kin, because most abuse happened between close relations in families. Families or relatives may have been another influence, and protecting the family name was another contributing factor. Participant 3 explained the scenario as:

Very complicated because women are aware of the abuses, but they don't report because of the many reasons that I talked about. So, what do we do? To me, we should never give up in supporting women to do what they are supposed to do.

Counselling empowered women and village people who have the chance to attend counselling sessions. It was also very informative for teenage girls who were prone to abuse. The same participant discussed the benefits that women and teenage girls receive from these empowering workshops. Not only did they obtain life skills for survival, but they also gained understanding of the problems that surround them as well as basic solutions to deal with their circumstances:

Victims explain abuses encountered after the training. I report to the village mayor, Samoa Victim Support, or the police depending on the seriousness of the case and the consent of the victim. I give them the assurance for their safety.

The participant admitted that most of the victims came back to thank her. The positive feedback motivated her and officers in her division to continue counselling seminars.

In a similar manner, an education consultant counselled her own children. Her main concern is for her children to use technology wisely, knowing the many problems it brings. She said that she did counselling during evening prayers. Although the main focus of counselling was for technological concerns, she also included the lessons of morals and values as reasons. She explained that: 
As a mother, I am responsible for the future of my children. Therefore, I need to know the television programs they watch, the messages on their mobile phones, how they behave in class, and at home.

This participant understands the importance of disciplining a child, and intends that her children will stay away from problems. She added that:

If a child misbehaves or is problematic, the people will ask. Who is his father? Who is his mother? Which family does he belong to What village does he come from? And a lot more. So who gets the blame?

According to this participant, she would be very sad and ashamed to be identified as the mother of a culprit. So, to avoid getting into trouble, the child needed her guidance and supervision. She stated that she also involved students who were relatives staying with her in the counselling. Besides the counselling process, she monitored the children's behaviour, checked their homework, and monitored their performances at home. Once she saw a problem, she immediately addressed it. She discussed how she influenced children of the Sunday School in her counselling. She stressed that it was better to counsel children using verses from the Bible which described good behaviour. She admitted her love for counselling came from a desire to save children from troubles and misbehaving. She believed that if children kept on misbehaving, they were vulnerable to committing any type of crime. She said:

It's very hard to discipline and control children because they are exposed to all sorts of crimes in the television and the internet especially. As parents, we need to strictly monitor their behaviour and prevent them from all sorts of problems.

Counselling conducted by the participants, then, was aimed at preventing mothers and children from all form of abuse, empowering women, encouraging women to report abuse cases, disciplining children, and teaching youths to use technology wisely.

\subsubsection{Comforting}

Despite playing a lot of motherly roles, women also offered comforting services. Almost all women in the study revealed that they were engaged in comforting to help children, family members, friends, or associates who had problems. Comforting was offered by women as part of the nurturing process for children. Participant 7 revealed that: 
Comforting is part of nurturing. As a mother, I do my best to provide my children's needs. I soothe and care for them at time of discomfort. I'm always around to support, show love, compassion, and lend a helping hand.

This woman commented that with such great love and passion for children, mothers would never fail them irrespective of the circumstances. She differentiated between how fathers and mothers reacted to misbehaving children. In her view, the mother scolded the children if they got into trouble, but she had always been protective of a child from the impatient father who used corporal punishment. In support of the significance of comforting, Participant 11 added:

Comforting starts from home with immediate family members, then reaches out to members of the community. Comforting is embracing others with love and affection. If someone can lean on you during hard times, that's a real credit. It's just pleasing.

She elaborated that women were quick to act when they saw the need to offer this service in situations such as a fight, an argument, sickness, or loss. Women naturally made themselves available to console people and provide urgent assistance. She refuted the opinion of people who thought that women were inquisitive:

Women are good Samaritans who are always willing to give help when it is needed. They don't think twice. They just do what they can afford to offer. It's done out of love. Nothing else.

The two participants who worked with community women also spoke about the value of comforting. They mentioned that comforting was a crucial aspect of the counselling system. In their training, they comforted the victims of abuse cases and referred them to the respective organisations for more help. Participant 4 described comforting:

It's a way of pouring out your heart to someone who's in danger. The victim should see the love, care, and genuineness in you to alleviate the disappointment or grief. Comforting is sometimes offered in extreme circumstances.

The participants' quotes and explanations show how they understood the value of comforting and never gave up even in harsh conditions that might endanger their lives. In life-threatening situations, women utilise their role of a peace-maker (pae ma le 'auli) to iron out arguments and differences between people and families. Participant 5 said: 
In our role as female descendants of the village, we can't sit around and see the situations getting worse. We have to get ourselves involved, knowing that it's one of our core functions to harmonise people in the community.

As shown in the quotes, comforting is for soothing and easing out people's problems. Women willingly provided this service, seeing it as doing justice to one of their fundamental roles and to care for people of the community.

\subsubsection{Mentoring}

The importance of mentoring was to help children, relatives, friends, and followers in their everyday lives. According to the participants, mentoring was not formally executed. However, they believed that imparting new knowledge, demonstrating new skills, observing and assessing the work of mentees equates to performing the art of mentoring. Like the nature of comforting, mentoring began in the home. Women facilitated the exploration of needs, motivations, desires, skills, and thought processes to assist children and family members in making real and lasting change. Participant 12 stated that:

Mentoring is guiding your children to make wise choices. You have to monitor the children's progress in searching for those right choices. Children need to be loyal, and have love and faithfulness in everything they do, and that will give everyone joy.

This participant emphasised the significance of making right choices in avoiding a lot of other problems. However, this was dependent on the mentor's monitoring. She went further to say:

There's no point in mentoring someone who will not be able to take it seriously. I've seen children who disobey and don't want to be taught of anything. As long as we've done our part, we're fine, happy, and proud.

She argued that women were serious in delivering this service to protect children from involving themselves in crimes. In her opinion, mentoring aims to turn children into good and useful citizens. One of the women committees' secretaries added that although women were not formally trained as mentors, they do mentoring well as evidenced by the decrease in children's fights:

Women mentored children very well because nowadays, they hardly fight. I remember seeing a lot of fights in the pool, cricket and rugby fields, on the road, and even in the church. Children are more disciplined and under control now.

Participant 13 added: 
Good mentoring is evident in the decrease of youth problems. Teenage girls who drop out of school now engage in weaving, cooking, sewing, making home-made products, and other money-generating work. Unwanted pregnancy is gradually diminishing. It's a great result.

It was evident that children and teenage problems were minimised as a result of mentoring. The majority of participants agreed on the advantages of mentoring, especially for people in traditional communities where work opportunities are very limited. They claimed that if people were well supported in setting appropriate goals they will become productive; for example, mentoring young men to do basic agriculture and farming to utilise land. Participant 14 alluded to the benefit of being empowered through mentoring:

There are people who have skills, but they need an extra push to continue improving until they are perfect. Additionally, natural farming methods must be utilised to save costs and environmental problems. There's plenty of land uncultivated in village communities.

According to the participants, community women's mentoring was mostly done informally and simply aims at teaching children to make right choices. These women defined mentoring as a way of imparting new knowledge of weaving and making traditional handicrafts, as well as basic agricultural and farming skills to younger generations.

\subsubsection{Maintaining Cleanliness and Hygiene}

Looking after the overall cleanliness and hygiene of village communities was one of the core functions of women. The three women's committees played this same role. They did monthly inspections of churches, houses, kitchens, gardens, toilets, rubbish dumps, and pools. Reports of the inspections were presented and discussed in meetings. The committees imposed fines on individuals and families that did not satisfy the set standards of cleanliness. If women's committees did not receive the fine after a certain period of time, they reported the matter to the village council for further action. As reflected by Participant 10, women reported that they enjoyed doing this service for communities:

We mainly beautify the village, making sure that houses, gardens, kitchens, pools, fields, and churches look good. No roaming pigs, no dangerous animals. I love serving the community this way because it's good to live in a clean environment.

A government official who was a member of the committee that administered the village competition to select the most beautiful village added her approval of a clean environment. She 
commented that competing villages which take part in the competition put in a lot of effort, time, and money to beautify their villages. She alluded to the significance of the saying: 'Cleanliness is next to holiness'. She explained that women's committees were doing the beautifying job and she applauded this service with gratitude. An education consultant added that when visiting village schools, she often saw women bringing bouquets of flowers to decorate the school buildings. She also saw women picking up the rubbish and tidying up the school compounds. Participant 4 too expressed her heart-felt thanks to the women:

I am impressed and touched by the women's services to the communities. They make sure that things are properly organised and looking good. It's just welcoming to see the smile on these women's faces as they engage in beautifying tasks.

Women in rural villages explained their affiliation with the Ministry of Health which allocated a district nurse on a monthly basis to provide basic health clinics and monitored the standard of cleanliness in the village. The partnership was acknowledged by women in enforcing the work they did. However, they were uncomfortable to some extent to work unpaid while the government officials received salaries. Participant 12 commented:

It's good for different government bodies to work together in improving hygiene and cleanliness in communities. However, the government officials are paid but the women's committees don't get paid. Anyway, we are obligated to keep our community clean and attractive.

Although this was the case, community women knew that they were obligated to maintain healthy communities. To them, it was only proper that they did what they have to do for the betterment of the community and its people. Furthermore, women reported that their services were guided by the spirits of their ancestors because these were the same services the ancestors provided for the communities during their time. Participant 7 , one of the rural participants explained her belief:

The spirits guide women in looking after the places people use and the places that connect them to their ancestors. Places like the village pool, committee house, meeting field, and the cemetery are properly looked after by women.

This general understanding and expectation was seconded by one woman president. Participant 15 said: 
This work had been done by our ancestors without pay. Now, it's our turn to do the same. I think it's natural to work for the community without expecting anything in return. It's a blessing, I suppose.

The concept of blessings in return for a service is what all the women agreed upon. They honestly served the community to ensure that it was beautiful, inviting, and comfortable for themselves and their children. These were the reasons why women reminded their children to do all their responsible chores such as cutting the grass, picking up the rubbish, weeding the garden, preparing a safe dumping ground for rubbish, and maintaining the overall cleanliness in the village. Women believed that teaching children and others to serve was a great example to set for others. Participant 9 commented that her service was guided by the proverb: "The way to authority and power is through service". According to her, supporting people and caring for the environment are good services:

If people don't serve, they shouldn't become leaders. Services comes with countless blessings, brings joy to the heart, and entertains the soul. It's self-rewarding and entertaining at times. For me, I'm happy, proud, and humble to be a servant.

Maintaining cleanliness was a communal activity. Participants talked about the love in women to collaborate in interactive activities which allowed them to gain each other's support and guidance. Participant 10, president of one women's committee said:

Supporting and working together as a group facilitate this work. Our main incentive is to live in a community that is free of rubbish, pesticides, diseases, and other environmental problems. We need the community's backing in this campaign.

In general, women worked towards freeing the environment from any hazardous problems. For example, they invited specialists from the Ministry of Natural Resources and Environment to conduct training and demonstrations in protecting the environment. Additionally, women committees did monthly inspections of landfill for rubbish dumping. They also reported people who polluted the environment and used unnecessary fishing techniques with dynamites (fanai'a) and poisonous liquids ('ava niu kini) to the local government. They were obligated to ensure the overall cleanliness of the community, and collaboratively worked towards achieving this common goal. 


\subsubsection{Traditional Healers and Midwives}

Seven of the nine rural participants were traditional healers and two were midwives. One of the six urban participants was a medical doctor. These women thought that the reasons for people resorting to them so often was that their services were free of charge and were easy to access. Although the culture requires reciprocity, people cannot wait until they have something to offer in return. Once someone is not well, villagers immediately seek the help of traditional healers. Midwives remarked that there were more babies born in the community than in the hospitals. Participant 8, a 65 year old traditional healer explained why she placed so much value in helping people:

My knowledge of plants makes this job easy. I know the leaves, branches, and roots suitable for different sickness. I only massage and let the medicine do the rest of the healing. The treatments always work, so I'm happy to continue.

All of the traditional healers grew plants for medicine. The areas for planting were secured to guarantee enough supplies. Traditional healers were protective of the healing plants so they did not want people to access the plantations. Participant 13 commented on the sacredness of the plants.

The plants for medicines are sacred. They are guarded by ghosts and the spirits of our forefathers who imparted to us the wisdom of healing. I don't allow people to step on the allotted land and destroy the plants.

It was evident that the traditional healers were somewhat territorial in protecting the medicinal plants. Furthermore, they were willing to continue the healing legacy passed down from their ancestors. Participant 14, one of the traditional healers explained her grandmother's dedication to the healing tradition:

My poor grandmother walked some distances to attend to sick people. She sometimes got up in the middle of the night or in the early morning hours when a sick person was brought to our house. She never refused anyone.

The participant added that she kept on doing the healing task in honour of her grandmother who committed her knowledge, time, and effort to helping sick people. Another participant who devoted her time to traditional healing embraced the idea that a Samoan woman's fundamental role was being a traditional healer: 
Any Samoan women must be a traditional healer (taulāsea) because it's one of her basic roles. She's got sacred hands to massage and a sacred connection to the land and plants for herbal medicines. She's a spiritual healer too.

This participant based her argument on the understanding that the woman should have a sound knowledge of all the herbs in her family land. Therefore, it was her duty to explore what each herb was used for with the guidance of her adult relatives. The majority of the group of traditional healers gained the healing and medicinal knowledge from their ancestors. Like their ancestors, they too were extremely dedicated to the job. As a group, they were devoted to the healing task, knowing that it was a useful service for community people.

Midwives functioned with the same dedication as the traditional healers. One of them picked up the experience from her late mother while the other one was a trained nurse who resigned from her job six years ago. Both engage in midwifery assistance when required. One discussed the use of herbal medicine for postnatal complications. She described this in Samoan as 'vai o le failele gau'. She added that this herbal medicine was very helpful for many women who could not afford medicines from the hospital.

Participants confirmed that, generally, traditional healing and midwifery were voluntarily performed in traditional communities. The tasks utilised traditional knowledge of plants, while land territories were securely protected to ensure a substantial supply of herbs for medicines. Traditional healers and midwives believed these were basic roles of Samoan women. Some of them embraced the work in memory of their ancestors.

\subsubsection{Income Earners}

Women were in general agreement that they earned money for families, churches, and villages either from paid jobs or from money-generating activities. Full time employees of the government, non-government organisations, and private entities explained that part of their income was directed to family, church, and village commitments. These women who reside permanently in town may have not visited families in the village often, but they normally contributed money to family obligations such as an opening of a new house, a bestowal of a matai title, funerals, weddings, and birthday celebrations. Self-employed women who engaged in weaving, cooking, sewing, arranging flowers, gardening, and operating small businesses made ends meet from these money-generating activities. The majority of participants earned more money than their spouses. Community women expressed gratitude for the assistance from 
community projects that taught them skills to establish their own businesses. Participant 11 expressed joy in running a business of her own:

It's a great feeling to own and budget your own money. It stops me from depending on my husband who's irritated when I ask for money to pay expenses. I deserve my earnings as I've been working hard for it.

Owning a business created freedom that motivated women to work harder to get better results. For most women, the main goals were to obtain money and to offer reasonable prices to people who were struggling financially. They knew that the prices of goods in stores were very high and the cost of living was also very high. Hence, establishing small businesses in the community provides another avenue for people. Participant 9, another small business owner in the community stated:

German-buns, scones, pies, doughnuts, and popcorns are all half price, and they are sold out very quickly. Customers increase in numbers every day. The business is gaining popularity in the community and nearby villages. Things are looking good.

Community women not only earned money for families, but they also helped to lessen the financial burden of village people. For example, an experienced florist sold bouquets of flowers for a living and prepared floral decorations for weddings, funerals, or birthday celebrations at a lesser cost than other suppliers. Participant 7, a village florist revealed that:

I offer very low charges for decorations on any occasions. I believe it's a God given talent, so I've got to use it to help people. Pre and post payment are both accepted. I think I'm a great servant.

Women saw themselves as servants in what they offered. They claimed that they were blessed by the skills to earn and to help others. Women tendered a variety of services to people and were very proud to discuss their achievements. Participant 13, an expert weaver said:

I give the best fine-mats to the family 'fa'alavelave' (obligations). I'm happy when leaders of the family thank me and bless the work I do. Sometimes they give me money. It's a great feeling to serve the family this way. 
All women described 'gift giving' as a common means of serving. Full time employees also claimed their monetary contributions as service paid to their families. Like the community women, they had pride in undertaking such service. Participant 2 explained:

I tell my uncle who is looking after our family to let me know if there is a family fa'alavelave. When he calls, I happily give, knowing that my contribution is service for my family. I willingly contribute.

She added that there were times when her uncle asked for money for himself. She did not refuse if she had enough, but refused when financial demands were high. It was clear that women had an obligation to donate money to families, churches, and village communities. However, women were content to make these monetary donations. Some of the women made donations from their full time salaries, others earned from money-generating activities, and basic entrepreneurial tasks.

\subsection{Challenges that Impede Women's Leadership}

Cultural, social, and religious barriers emerged as major challenges which restrained aspiring women leaders from participating in local government of traditional communities. These fundamental hindrances were elaborated in the participants' narratives.

\subsubsection{Cultural Challenges}

Culture was found to be the major impediment to women's leadership in traditional communities in Samoa. Cultural norms of a patriarchal society enforced rules and sanctions that affected women's leadership. The authority regarding these rules and sanctions resided with local government bodies that influenced extended families to select male matai, and allocated women leaders to a second ranking level (pule na lua) of the traditional hierarchical structure. The impacts of these restrictions disadvantaged women from accessing power and authority in local government. Hence, local government continued to be male-dominated.

\subsubsection{Supremacy in Local Governments}

Nine of the participants believed that the authority of local governments was most influential in diminishing women leadership. They explained how village rules affected prospective women leaders, highlighting their understanding of how people conform to these rules. Participant 10 commented: 
It's amazing to see that villagers strictly follow protocols of local government. The rules to stop women from holding cultural titles (matai) and not allowing them to participate in village council meetings are well practised in most village communities.

Women appeared to be irritated by being refused to have the same privilege as males. They expressed their discomfort in the process through narratives. To most of them, local government were administered by males who constructed and enforced rules to refuse women's participation.

Participant 14, one of the high chief participants said:

In sustaining the male power domain, village councils establish informal concords like protecting the sacred space (vä tapuia) between male and female relatives to justify the authoritative rule. It's an excuse of convenience to suit them and their agenda.

Participant 9, another high chief participant commented on the males' safeguarding of the sacred space saying:

Their concern of the sacred space is only an excuse to refuse women's participation in discussions, in fear of revealing the injustices they do. There's no transparency in the matai system. Male leaders are not accountable for their actions.

Referring to the injustices in the administration of village communities was an interesting phenomenon. One of the matai expressed her disappointment with how a decision was made about an incident in the village. She explained a scenario where an untitled man was reported to have destroyed his neighbour's banana plantation because of an argument over land boundaries. After the village council's deliberation, the culprit was fined five cartons of tinned fish. She felt the village mayor was influenced to impose a very small fine for a serious offence since he is the culprit's cousin. Participant 15 added:

Most of the decisions of the village council are anaemic with the absence of a female voice. This is exactly where the suppression for women leaders is. It's a total ignorance of the women's rights to decision making and power.

Inequality in representation was obvious with a few or no female representative. Matai participants blamed local government in not allowing women leaders' voices to be heard. They advocated for gender equality in participation and representation in local government forums. One participant orator lamented: 
It's really sad to see that women's voices are not heard. This is why most of the decisions are irrational. Women leaders deserve to participate in local government. For women matai, they need to represent the voice of their families.

Participant 13 shared the same regret saying:

As long as local government exists and the majority are males, women are voiceless, powerless, and helpless. There is no flexibility in local government to equate themselves with women leaders. They don't want anyone to challenge their authority and power.

She further stated:

Naturally, most males in village councils think that allowing women to become matai is a new change. So, they forcefully block women from holding power by not permitting them to hold matai titles, and not recognising their participation in local government. Local government are culture-oriented and conservative.

Participants remarked that aspiring women leaders would not do much to resist the status quo. Their experience was that the population respected the decisions of local government. Therefore, women continued to become supporters and males kept on leading. Participant 6, one of the government officials referred to the political power in local governments as a 'kaleidoscope'. According to her:

A kaleidoscope has many colours and each of those individual colours are combined together to form a single image. The kaleidoscope reflects how different administrations implement the same rule to stop women from holding power in village communities.

Although the example given was non-traditional, the modern interpretation of the political power in local government highlighted the same tradition of disadvantaging women from positions of authority. Participant 2 suggested:

It would be better if the national government stepped up to influence the decisions of local government, seeing that providing $10 \%$ seats for women in parliament was a very good step forward. The authorities of local government must follow the example set by the national government. 
The participants highlighted their concerns about the supreme authority of local government and how village communities adhered to verbal rules and sanctions. They felt that restrictions on women becoming matai and the refusal to allow their participation in village council meetings threatened ambitious women leaders. They recommended that the national government could intervene to help women.

\subsubsection{The Authoritarian Nature of Patriarchal Communities}

Eight participants identified patriarchal leadership as a contributing factor to women's submissiveness. They saw this scenario as threatening to women's leadership in local government, and pointed out that patriarchal leadership was the adoption of an imposed concept, thus refuting it as being traditional. Participant 3 described the origin of patriarchal leadership saying:

The idea of patriarchal leadership originated from the West.Because it has been practiced since 1830, village societies see it a norm. If we wind the clock back to the time of Nafanua and Queen Salamasina, we'll know that Samoa had been matriarchal in leadership before the missionaries arrived.

Participant 8 , one of the younger matai participants explained.

The patriarchal power in village councils is regulatory, governing, and controlling.

Male chiefs and orators think their power is fixed. They don't know that they are violating women's rights to leadership and women heirs' rights under the constitution. One of the participants compared the scenarios of not allowing women to become matai and not recognising their participation in village council meetings to a struggle to climb up a cement block where there are no hand holds. Participant 3 explained:

There is no flexibility in these male leaders to see that things should change. They don't even know that the government is moving forward in advocating for gender equality in parliament. They too, need to do the same.

The tough measures affecting women's leadership impacted women participants negatively. They knew that the situation was quite challenging because they had seen how things were done in village communities. Participant 1 commented:

It's very hard to change the patriarchal leadership as the idea is accepted generally. Whether women like it or not, it's there, and the practices say it all. The community needs to be educated to change their mind-set about leadership.

She further added: 
There is no way that women are given the chance to become members of local government. It's an all men's show as this is what people want. As a woman leader, I feel it's about time to challenge the status quo.

One of the supporting factors for the authoritarian leadership was people's expectation. Community people assumed the leadership role to be a male's domain. Participants believed that people's assumptions, expectations, and beliefs were all influenced by patriarchal leadership. This interpretation was explained by Participant 5 who said:

The power in local government is influencing the mentality, expectations, and norm of traditionally-oriented people who believe that males are leaders. The deep-rooted notion of male leadership has to be changed. Otherwise, women leaders continue to suffer the consequences.

While encountering difficulties in striving for leadership positions, some blamed themselves for not standing up for what was right and not being brave enough to challenge the authorities of males. Participant 6 stated:

Women nowadays should learn the patriotic ways of women in the past. It's high time to upset the male leadership power. Not with force, but through consultations and negotiations. We have to activate the academic scholarship to expedite debates. Women are not brave enough to challenge this patriarchal leadership because of the respect they have for their brothers, male relatives, and husbands who are members of the village council. This is why matters are getting worse.

To sum up the participants' opinions of the authoritarian nature of patriarchal leadership, it became clear that local government had a fixed, controlling power. This was a real threat to women's leadership, and women recommended challenging the status quo. In countering the situation, women expressed a need to trace the originality of leadership in Samoa to the time of Nafanua and Queen Salamasina's reign; that is, to a past where a different situation prevailed.

\subsubsection{Extended Families' Influence}

Six participants identified extended families as another cultural barrier for women's leadership. As far as these participants were concerned, extended families prioritise males in the selection of matai. The main eligibility criterion given for male preference was having a sound knowledge of the oratory language. Participant 11 would like to see a change in this mentality arguing that the matai's main task was to be involved in decision-making in the village. She referred to this customary practice as 'old school', or 'out of step' with what was needed: 
This old school belief should change, since the matai's roles are not limited to knowing the oratory knowledge. Matai make decisions for the village. The matai has to have a good knowledge of effective leadership skills practical in village communities.

Participant 8 could not see a value in a matai's knowledge of the oratory language. She explained her observation of some unskilled orators in presenting cultural speeches. She stated that:

Knowing the oratory language is meaningless. When some orators present traditional speeches, they only recite what they heard, and it's problematic when they forget what was memorised. The argument isn't worth discussing. It's a pointless dispute.

Two participants were concerned about other important roles of the matai in addition to having oratory knowledge. Participant 5 commented that:

Oratory knowledge is important, but there are many more important things the matai needs to know in leading and representing the family in the local government. The constitution of Samoa provides equal opportunities for men and women to hold matai titles of their families. So, that should be taken into consideration when selecting family leaders.

Participant 9 supported this:

Having oratory knowledge is just one of the many skills a matai needs to have. I think, this person needs to understand leadership roles as well as knowing how to implement those roles well. A matai should be a good role model, a mentor, and a helper.

Participant 6 indicated the importance for families to have a clear understanding of what to expect of a matai. In her opinion, leadership skills must be included in the selection criteria. Her concern was explained as:

Families need to understand the significant role played by matai. Selection should not be based on only one criterion. Other criteria include reliability, accountability, transparency, and integrity. Families must confirm the leader's readiness to take up the challenge.

Women showed a sound understanding of the important roles of a leader. They judged that families could be well led by a leader with effective leadership skills. Participant 14 noted that 
male matai exercised influence in the selection of family leaders. As a result, families elected further male matai:

The major influence in selecting male matai comes from the other male matai. This culture continues to disadvantage positional women leaders. Families must be given the freedom to nominate someone who can do the job well regardless of the gender.

One of the five doctorate-holding participants suggested that the belief held by some families of male heirs becoming matai while women descendants become the most elite lady ('augafa'apae) could be a reason why males were always selected over women. However, Participant 3 strongly refuted the belief saying:

This requires an understanding of the constitution which states that male and female inheritances of families have equal rights to holding matai titles. Therefore, men and women must be given a fair chance in the selection of the family leader.

In summary, the participants felt the recruitment process for family leaders was biased towards males, and that women were disadvantaged because of not having the oratory knowledge, and because of the influence of other male matai. A further reason for the status quo was assumed to be the belief that women heirs hold the 'augafa'apae title while men descendants hold matai titles. This thinking was strongly refuted by participants who expressed the intention to make extended families aware of what the constitution stated about the eligibility of both men and women to hold matai titles of their families.

\subsubsection{Women Leaders are Second in Rank}

Seven of the participants identified different power rankings as a cultural barrier to women's leadership. In their views, the Samoan culture gave a lower rank to women while males held the highest leadership rank in traditional communities. Participant 1 who administered women's small businesses said:

Every time when we start a new project in the village, it is always men who greet us in an 'ava ceremony', and bid us farewell officially. Women only showcase their materials and prepare food. They never talk about their experiences.

The same sentiment was shared by Participant 5 who trained women in writing proposals for community projects: 
In opening and closing ceremonies of community projects, a male chief or orator is the spokesperson for the women's committees. It looks funny because it's the women's projects. I've always wanted to hear the women's experiences, but they are not part of the formalities.

The two explanations showed that in traditional communities, male leaders had the honour of speaking on behalf of women who were the main doers of the activities. Although women's committees had their own leaders who are the President, Secretary, Treasurer, and Executive members, when the community hosted guests, it was always chiefs and orators who were members of the local government that controlled the event. Participant 15, one of the presidents said:

They call us 'pule na lua' (second ranking leaders). So, village activities are usually controlled by the first ranking leaders. This ranking system is discriminatory in the sense that it advantages men and disadvantage us, women. It's a prejudicial treatment.

The president referred to members of the local government as being first rank leaders. She explained the norm of giving the honour to first ranking leaders to officiate and conclude village activities. Participant 12, another woman president complained about power ranking. She argued:

Power ranking differentiates men and women leaders. The society thinks the highest ranking is appropriate for men while women settle in the second rank. This isn't fair. But, what can we do? We are powerless because the community favours male leaders.

This unfairness in treatment and labelling diminished opportunities for women leaders. Participant 11, one of the rural participants explained that a number of practical women leaders settle for the second level ranking. She said:

Many women leaders are congregated at the second level of authority. Women with matai titles are silent leaders. Village ceremonies, affairs, and activities are all conducted and run by male matai. They make rules, impose fines, and distribute wealth.

The idea of holding a second rank did not sit in well for Participant 6 who complained:

This power ranking system isn't doing justice to women with leadership capabilities. The lower rank impedes women from planning developments, implementing welfare 
projects, and participate in decision-making forums of village communities. Approval for any development comes from the local government.

Another reason for being in the second rank was not holding a matai title. Having no title means that the person is not eligible to participate in village council meetings. Participant 4 discussed the potential in women to involve themselves in other leadership forums, a potential restrained by not having a matai title. She said:

Women are also eligible to hold the highest leadership level. But, we are restricted by the eligibility criterion of having a cultural title (matai). This limits other leadership opportunities like running for a parliamentary seat in the national government.

Participant 2 noted that Samoa had been administered by queens in the ancient times:

Leadership wise, ancient Samoa had been matriarchal. Women dominated societies. Some of those aspects still exist today. Women leadership still come through in our tradition, where the role of the woman is still very much held important in the family. But now, they've introduced a lot of changes which sees us holding second rank in power.

Overall, the women participants argued that leadership in the olden days was matriarchal, but changes determined that currently, women were relegated to second ranking. They felt this placement reduced leadership opportunities for eager women leaders, and that their leadership potentials were compromised.

\subsubsection{Religious Barriers}

Six participants claimed that religious practices were another barrier to women's leadership. They saw the blending of male leadership into Biblical teachings as a way of disadvantaging capable women leaders, resulting in gender inequalities in churches, and they put the blame for this on the influence of missionaries.

\subsubsection{Missionaries' Influence}

Participants believed that missionaries and their teachings were influential in imposing male leadership, and that our ancestors were receptive to the idea. 
Participant 7 said:

Missionaries have a lot to answer for. When they came, they brought essentially a very delicious sweet, the essence of the gospel was very sweet to taste. But, unfortunately, they wrapped in it a culture that they enjoyed in England and the Samoans, being as open as they were, took the entire lolly with its wrapper and swallowed it.

The explanations suggested that our forefathers who accepted Christianity were not aware of the culture introduced to them. The participant continued saying:

With the sweetness of the gospel digested together with the cultural wrapping of Victorian England, we now see the elements of the Samoan culture that further in some ways reinforce some of these power dynamics. These driving forces are our norms now.

Participant 9 stressed the risks involved in imitating an overseas culture, such as not knowing what is appropriate. Consequently, people unconsciously practice a strange culture without any understanding of its values. She stated that:

This is the danger of copy-catting a culture. Copy-catting is adopting foreign cultural values without assessing their practicality. The danger is, we now struggled with many unfathomed issues. These issues deny our identity and create many gender inequalities.

She added that:

Influences from the western culture in terms of political advocacy absolutely change power and authority in Samoa, just like the influential tactics of the missionaries. They teach us to respect males as leaders of families, churches, and communities.

With reference to Biblical teachings, Participant 11 suggested that:

The teachings of Saint Paul in Corinthians seems to be extremely influential in how women perceive themselves as leaders. The particular reference Saint Paul made to men being the head of the woman is problematic for Samoan women taking up leadership roles because they now begin to see themselves as preserving the divinely structured role for men to be head and leaders. 
Participant 8 supported the point by saying:

This is something that is being inculcated to women over generations now, which is quite sometimes since Christianity arrived. At the moment, both men and women have been fully immersed with the notion that men are leaders.

She continued, stating:

Because of these constructs, these beliefs which come from the divinely inspired teachings, the patterns of behaviour have become entrenched. The feelings and interpretation people have about these roles and many other roles are now firmly fixed in society.

Participant 15 discussed how the Samoans responded to the new values in adopting the womanly roles pertaining to the teaching of the Bible. She commented:

Samoans emulated to the values of the introduced lifestyles. Because missionaries started teaching like they were in education, their values were also being passed down, and one of those values is to respect the father as the head of the family.

Participant 5 did not agree with the adoption of the introduced canons saying:

Churches should not adopt foreign principles that contradict with the reality in Samoa. Instead, they must look properly into the impacts of these foreign values. Now, church teachings emphasise male leadership, disadvantaging women - especially those with leadership and administration skills.

In summary, participants argued that missionaries blended the notion of male leadership culture with Biblical teachings that were well received without Samoans assessing their practicalities. The women confidently claimed that not all Biblical teachings should be taken for granted since some altered original practices. They thought that missionaries were responsible for imposing male leadership concepts on Samoan village communities.

\subsubsection{Gender Inequalities in Churches}

When asked to elaborate on religious barriers to women's leadership, twelve participants identified gender inequalities in teachings of the Bible as a contributing obstacle. 
Participant 3 said:

I blame the missionaries. In the United States, Europe and Britain in particular, the Congregational Christian Church is progressive. They've been ordaining women for over a hundred years and advocate for equality, and it's very democratic sort of a church.

She went further to say:

The Samoan three mainstream churches are still not allowing women to become priests. They are very conservative of the church policies designed and implemented since the mid-eighties. I think, it's a way of safeguarding and preserving the male territory of leaders.

This participant observed how a particular church in other parts of the world was moving forward while Samoa was still static. She saw that ordaining women priests and lobbying for equality were great milestones which reflected democracy, while the dominant churches in Samoa - Catholic, Congregational Christian, and the Methodist churches - continued to practice male leadership without giving a chance to women. Participant 9 gave a brief history of how Samoans came to a belief that they were doing things the Christian way:

Samoans received the Congregational Christian Church at a time in 1830, when it was a different social system that was really fascinating and the Samoans have preserved it, thinking, it's the only right way. But, it's not in my view.

She continued saying:

Now, the way the church is run here is like they used to run in England nearly 200 years ago, and they have this idea that this is the Christian way, and it's the only Christian way. Unfortunately, it's not.

Participant 6 related to the messages pastors preached on special days for mothers. In her view, these messages strengthened the belief that mothers needed to concentrate on the designated roles. She stated:

On Mothers' Day, church ministers praise a good wife, good mother, good role model, good adviser, and a good supporter of male leaders. This is blackmailing women to stick to their motherly, wifely, advisory roles, and leave leadership obligations to males. 
Participant 11 talked about the impact of unclear messages in the Bible which created confusion:

There are many confusing messages about leadership in Biblical teachings. Genderrelated inequalities are presented in these confusing messages. The missionaries, bring with them a style of leadership that sees the status of a female as lower than a male and it is well supported by churches.

Participant 8 discussed male domination in the three mainstream churches:

In the three mainstream denominations in Samoa - such as the Congregational Christian Church, Methodist, and Catholic - males take up most if not all of the leadership positions. For instance, pastors, deacons, chairmen, and other positions of authority.

She continued to argue that not only were women not ordained as pastors, but these mainstream churches only gave the chance to certain women leaders on certain conditions:

These mainstream churches do not allow women to be ordained as pastors. Women are only eligible to hold other leadership posts if they are single, a widow, or a holder of a matai title; a very unhealthy and prejudice system.

Participant 14 commented on her knowledge of gender inequality issues in churches:

The churches can be very progressive, and they are in many countries, and here the Christian way is very conservative, and the church has a lot of problems with gender inequalities. These same problems influence our cultural values and norms.

Seeing that churches were not progressing in terms of gender equality in leadership, she suggested a need to accommodate gender inequalities taught by the Bible and preached by church ministers:

With all due respect to the church authorities, churches are advocating for male leaders as most of the teachings promote males as leaders and women as supporters. There is a need to tackle these gender inequalities in Biblical teachings and sermons. 
Participant 2 critiqued the inequality in participation and representation in church. In her view, women had no voice in male dominated institutions like the church:

Women are silent observers of discussions and decisions in churches controlled by males. The women's silence undervalues their participation in a place typically occupied by men. This is a double-block for women as they are also suppressed by cultural structures.

Participant 4 discussed her reservations in telling her older female relatives to change their belief about male leadership. She showed respect in acknowledging the values of people older than her. However, she felt that these inequalities undermined the potential women leaders:

Women in my family are very active in church, but they too believe in these teachings that males are family leaders. I don't see it as proper, but I respect the things my older female relatives believe in.

She added that:

As a frequent church goer, I can see, feel, and understand a lot of gender inequalities in the teachings of the Bible, and these things are very influential in the way people see leaders of any institutions in Samoa.

Gender inequalities in the church, identified by participants, included not ordaining women to become ministers or pastors, restrictions on holding other leadership posts, the absence of a woman's voice in decision-making, and women who accept and don't query the inequalities. A central feature was the belief that things were being done in the Christian way - an idea which participants critiqued.

\subsubsection{Social Barriers}

Social barriers affected women's leadership in local government. As people congregated in traditional communities, their assumptions, expectations, and beliefs were the norms. These culture-oriented, conservative norms restrained women from becoming leaders. One of those norms required women to be responsible for all domestic tasks. Hence, some women chose to be subordinates, but not leaders. Another custom was granting different remuneration packages to men and women government representatives based in village communities. These government representatives performed similar tasks, but received different salaries. 


\subsubsection{Assumptions that Hinder Women's Leadership}

Participants identified people's assumptions about women as hindrances to women's leadership. The participants believed that such assumptions affected people's choice of leaders. Participant 7's view was that putting leadership to the Samoan context was a threat to women. In her opinion, the changes in the Samoan culture had no effect on the male leadership preference.

She stated:

Assumptions for leadership are all in context to detain women from becoming leaders. That is, the level of leadership people hold has to be in the Samoan context, which is different from New Zealand, Australia, England, or Fiji.

She added that:

The Samoan culture is changing, but does not change the male leadership favouritism.

The male leadership concept is ingrained, conserved, and respected in practices and ceremonies. Women leaders have a very slim chance to share power due to cultural structures and social systems established by male leaders.

Favouring male leaders was a cultural aspect enforced by Biblical beliefs. Participant 10 thought that this cultural norm must be changed as it impacted negatively on aspiring women leaders. She commented:

We need to change these perceptions that are culturally-based in a way, especially as you know, the Bible enforces the belief that women take care of the family, and the father is the leader. That's why it's stronger.

The popularity of these assumptions was mentioned by another participant as being evident in village communities. She remarked on the influence of religious beliefs in facilitating the expectations, citing Biblical teaching of the woman cooking and serving her spouse:

Especially in traditional communities, people take these assumptions seriously because women were first taught to cook and serve their husbands by wives of missionaries. But, in the Samoan culture, untitled men prepare food for their sisters who are their feagaiga (covenant). 
She continued saying:

To most people, the woman's place is in the kitchen. It's very sad seeing that this kind of mentality is entrenched. It's about time to educate people to change their mind-set of the women's roles, their potential, and what they are worth.

Males determined domestic roles for women and supported their engagement with children and older family members. This was problematic in the women's views, because they were more or less forced to focus on these particular tasks which limited opportunities to be involved in decision-making forums. Participant 8 supported this by saying:

Men are the main problem. They emphasise the importance of nurturing the children and attending to aging family members. And, poor women maintain these roles because of males' support. Hence, they can't see themselves as leaders.

Women in this study believed that the goals of male leaders was supporting them to focus on motherly tasks, disadvantaging them from participating in the leadership realm. Women were certain that village people supported the engagement of women in motherly tasks because only a few women participated in local government. Therefore, the invisibility of women in village council meetings of local government justified their inappropriate for leadership posts. Although other participants put the blame on men, two of the participants found faults in women for not putting themselves forward for leadership responsibilities. Participant 4 said:

Lack of participation in the decision-making of village communities weakens women's chances for leadership positions. Sometimes, it's the women's fault because they are fully occupied with family roles and do not worry about attending village council meetings.

Participant 11 commented that:

Women are comfortable in doing these domestic tasks regarding the communities' expectations. This is why most women don't have the confidence to become leaders. So, they allow men to hold leadership positions and accept motherly roles. No matter how hard we try, we can't push these women away from their comfort zones.

One of the seventy year old participants believed that people should be reminded to reflect back at the roles played in families. She argued that if a person was nurtured to become a leader, 
there should be no limits. She suggested that the problem was women who took up household tasks were quite comfortable in their performances:

If you grow up knowing your roles, there's no barrier to stop you from becoming a leader. This is where reflection comes into the picture. Women take their domestic roles seriously and think that they're seen as effective if they do well with these roles.

Participant 13 claimed that male companions and families were agents who associated women with either household chores or leadership duties. She saw these influences as crucial in determining people's particular responsibilities:

It's within your own relationship with your husband or partner whether the man respects your thoughts and ideas. To me personally, that's where this perception is either active or non-active. How the husband sees the wife's skills is important.

She continued saying:

If your husband or spouse believes you are better positioned at the kitchen and you don't reject it, then that's how things are. If families accept women as leaders, things will be easier. Support from acquaintances makes women leaders strong.

Participant 6 suggested that one of the reasons for relating women to domestic activities was women not being well versed in the cultural values pertaining to leadership. She explained that:

The reason why people associate women with domestic tasks is them lacking a fundamental understanding of the Samoan culture. The cultural values about leadership acknowledge the woman as the covenant (feagaiga). Her elite status is more honoured as a leader.

Participant 7 summed up by claiming current assumptions erroneous. In her opinion, these perceptions miscalculated the worthiness of women leaders. In addition, she advocated for educational training to enable Samoan society implement changes in the future:

These perceptions are wrong. They underestimate the leadership capabilities of women. The society needs to be educated about what to do in the next decade. Gender equality in participation and representation guarantee balanced, fair, and effective decisionmaking in local government.

Participants perceived that hindrances to women's leadership were caused by a number of assumptions about women. These include: connecting women to domestic tasks explains the 
Samoan context of leadership convenient to males, favouritism towards males enforced by Biblical teachings, and granting different salaries for men and women government representatives.

\subsubsection{Women Prefer to be Subordinates}

All participants agreed that they were ready to take on leadership roles. At the same time, six of the nine participants who lived permanently in village communities supported the allocation of leadership posts to males because they were comfortable with subordinate tasks assigned to them. One of the women expressed joy in doing work at home and admitted checking to see that her husband was ready for leadership obligations. Participant 14 revealed that:

I enjoy working at home. It's a comfortable environment. When my husband attends the village council meeting, I make sure he has prepared mentally for the leadership challenges. I give him advice, but the sole responsibility is all his.

The general understanding of some participants was that women benefitted from the success of male leaders. They also said that because women were very efficient and effective in domestic activities, they did not need to prove themselves in a new role. Participant 12, one of the village residents proudly confessed that women gained from supporting prosperous leaders:

Behind a good man is a good woman. Although the leader is the man, he can't be successful without the woman's support. The woman should be credited because without her backing, the man cannot attain what he has achieved.

Participant 15 admitted her readiness to take the leader's role but said she preferred to give advice and allow her male relatives to hold the position. This participant was very active in the sub-village of female daughters of the village (Nu'u o Tama'ita'i).

She said:

I'm ready to become a leader, but I'd rather leave that role to my male relatives. I advise, support, and contribute to village developments. I'm not comfortable to sit together with my male relatives in meetings of the local government.

There was strong support for local government as the authority of traditional communities from village participants. These women showed appreciation of the administration in handling village affairs. Participant 6 shared her support of local government by saying: 
Women are expected by families, churches, and villages to do domestic tasks, and they do them well. There's no need for a new role. As a proud village woman, I give my full support to the authority of local government.

She added:

Each person in the village is given a particular responsibility. Therefore, we need to abide by the particular norm. The local government is mandated to administer the community. I'm pleased to see that they are doing a good job.

Participant 9 explained that it was not good for people to look for faults in village councils, since they are the leaders of the community. However, people needed to give their support so that peace and harmony prevailed in the society. She believed that women could not be leaders of village communities. She commented:

If our responsibility is to support male leaders, we shouldn't complain. We need not upset the authorities. We can become leaders in our own organisations and other organisations outside of the village, but not the local government. That's men's work.

Participant 13's support for male leaders was due to a small number of women holding matai titles. Additionally, she was not ready for the leadership post. She said:

I am scared of being a leader, because not many women in the village hold cultural titles. What can a minority do? We'd rather do the safest thing. Give the support to the male leaders to run the community.

The reasons participants gave for women preferring to remain as subordinates included supporting local government, gaining benefits from successful male leaders, being better positioned to give advice, keeping peace and harmony in traditional communities, and not being ready to take the leadership challenge.

\subsubsection{Unequal Opportunities for Men and Women}

Some of the inequalities in the treatment of men and women were discussed by six participants. 
Participant 2 stated:

These government officials execute similar tasks of recording births and deaths and act as the intermediary between the government and the village. However, the male's salary is twice as much as what the female gets. This is not right.

Participant 3, another public servant commented that the higher number of women leaders in government and private entities did not transfer to decision-making forums of village communities. In her view, it would be better for these women leaders to contribute to decisions of local government:

There are more women holding leadership positions in the government and the private sector that are not members of local government. So, they cannot influence decisions in village communities. It is better to impart their decision-making skills to the local level.

The same participant saw the participation of women leaders in government ministries and private corporations as problematic because of the jurisdiction of local government. She said:

Women leaders are expected to adhere to the rules and sanctions established by male leaders, who are the supreme authorities. Therefore, the leadership capabilities of women leaders are compromised due to the male leaders' expectations.

Another three participants described opportunities where men were seen taking advantage of their leadership status.

Participant 1: Male leaders are the key actors in celebrating the culmination of women's projects. Their domination looks as if they participated in the activity. They distribute monetary donations and gifts presented to women while women serve food and entertain guests.

Participant 4: Male leaders are always in the forefront of every traditional ceremony. They control the affairs, direct people, make speeches, and are presented with money, food, and traditional materials like fine-mats and tapa. Women make sure that things are properly organised.

Participant 5: In church, male leaders dominate decision-making forums. Only a few women in leadership posts can speak. Most or all decisions are made by men. Gender inequality is common in decision-making bodies of churches. 


\subsection{Women's Second Ranking Status and their Development}

Women's committees are seen as the driving forces for most of the village development. Women build understanding and drive action for community projects which benefit village communities. Due to their participation in maintaining the economic position and well-being of the household, and the fact that in village communities the household is dependent on the use of natural resources, it is seen that women play a key role in that field. Participant 10, one the presidents said:

We don't depend on the local government because they only say yes to community projects, but they don't do it. We drive every single project to its success. Whatever kind of project we are approached to do, we do our best to do it because we know, it benefits ourselves, our families, and the community at large.

Participant 12 commented on the women's effort in utilising the natural resources available in the village community. She said:

Women make wise use of the natural resources in whatever way possible. For example, we make fine-mat from flax and tapa from fibre for family obligations and for earning money. We even work in the plantation and fish in the sea for family food. We don't just sit around. We do what we can to support our families and the community.

Women leaders in women's committees lead and connect to government ministries such as the Ministry of Women, Community, Social Development and Internal Affairs, Ministry of Health, and the Ministry of Education for leadership and empowerment training. Additionally, women's committees participate in training programmes of the United Nations for the advancement of women and creating small scale enterprises. Most women are especially interested in the production of traditional handicrafts such as fine-mats, tapa, and mats. If they get a small income, this contributes to the family well-being. When community women manage these small scale income-generation businesses, they enhance and improve their social and economic situations.

Participant 15, another president of one of the three women's committees said:

As a community group, we don't have the means and the skills to keep us going. Therefore, we approach government ministries and the division of women at the office of the United Nations for financial and training assistance. Specialists and funds from 
these organisations help us to conquer the odds, and we are happy to put the knowledge gained from trainings into action.

Although village women participate in these income-generating activities, decision-making is in most cases the privilege of male leaders of households within the patriarchal structure of families. Different values and norms attached to men and women mean that they have been assigned diverse status. For example, women leaders are second ranking leaders, while male leaders hold the first rank. This inferior status of women leaders in relation to male leaders does not daunt their developments to upgrade the standard of their families and village communities. Women are aware that they are marginalised because of the patriarchal nature of leadership in societies. However, most women leaders believe that their contribution to the communities is more important than holding a status of a leader. Leadership to most women is being able to build and maintain communities, provide services, and influence people's lives in a positive way.

Participant 7 said:

To us, the leadership status of men is ceremonial because they only make decisions, but don't do any work. So, we don't worry about what they do. Our main concern is to serve the community and influence people positively in whatever way we can.

Participant 9 added:

As a group, we gain strength to move forward from each other, and women's committees are getting stronger and stronger that they now become the backbone of all the village developments. So, we are leaders in our own rights because we work and live for others.

\subsubsection{Women's Achievements}

Training conducted for women in village communities has resulted in greater engagement by women and girls in advocacy against gender violence, disaster preparedness and management programmes, school enrolment and vocational training opportunities, improved birth registration for children, and livelihood programmes for unemployed mothers and young women (Ministry of Women Community \& Social Development, 2013-2014). Participant 1 commented on the positive outcome of these trainings. She stated: 
In women's committees, women are equipped with all sorts of skills, thanks to the ministries and organisations that provide all these trainings. The knowledge obtained from these training prepare women for natural disasters, protect them from violence and abuses, and help them to fund family and village obligations. So, the women are doing great.

The network of village women representatives was given as a strong mechanism to ensure the participation of rural women in development. The Government has strengthened the capacities of law-enforcement agencies to manage domestic violence, and financial support had been made available to support the work of non-governmental organisations by providing counselling and support for women victims. Additionally, some women in village communities also provide these services. Outreach programmes have worked at various levels, from the village council to the church, guaranteeing that the protection of victims became the collective responsibility of the whole family and the entire village. Further comments by participants regarding these achievements are stated below.

Participant 3: Women now have a voice in the decision-making of village communities through their government representative. We meet monthly with the government representative to discuss the impact of the trainings and to suggest further assistance for women's committees.

Participant 4: Women are making wise use of these training opportunities. The living standards, economy, and the general health and hygiene of families and communities are now improved as a result of these trainings. I think, people are much happier now and enjoy living in village communities.

Participant 5: Before, women never talked about violence and family abuses. Now, they are discussing these issues openly and are very vigilant in protecting theirfamilies and children from all sorts of abuse. Women are aware of the steps to take for further actions.

Participant 6: Women are doing well, and it is quite rewarding to see that the community is appreciative of the women's work. In my opinion, all village developments are successfully driven by women. The communal spirit of cooperation comes alive in these interactive activities, and women's committees are focal point of contact between the village and the government in community projects. 
In summary, then, participants noted a number of inequalities: men and women government representatives of village communities receive different salaries for doing the same tasks; not all women leaders in the government and private agencies are members of local government, so they cannot contribute to the power in the village; and male leaders enjoy the privileges of leadership opportunities on special occasions such as celebrations, traditional ceremonies, and church meetings while women carry out background tasks.

\subsection{Document Analysis}

In order to examine the relationship between women's understanding of leadership and the framing of women's leadership practices through policy, five reports, two other documents, and one documentary film were used for analysis. The documents from the Division for Women of the Ministry of Women, Community and Social Development include the Annual Report of the Ministry of Women and Social Development 2013-2014, A National Plan of Action for the Advancement of Women 2008-2012, and A Draft National Policy for Women 2007-2017. The same ministry provided two further reports: Skills Building Training 20122014, and Mothers and Daughters Program 2013-2015. A non-government organisation called "Every Home Samoa" provided a report on Women's Empowerment Projects 2015. One of the five reports, Pacific Women Advisory Board Meeting Report, April 2016 was obtained from the office of the United Nations Division for Women. A Samoan documentary, "Tulitulimatāgau le ufi a Sina" was provided by the Director of the Tiapapata Art Centre.

\subsubsection{Key Findings}

From the analysis of documents and reports as well as viewing the documentary it was evident that:

1. Empowerment and advancement trainings have resulted in $75 \%$ of women and young girls becoming engaged in income-generating activities;

2. Women leaders serve village communities through providing a variety of services.

According to these sources, gender perspectives, concerns for women and children, development, and economic growth were the main targets of ongoing training for women in the local and national levels. The Strategy for the Development of Samoa makes reference to the National Policy for Women 2007-2017 and the National Policy for Children 2007-2017 as guiding developmental activities for the advancement of women and the protection of children 
in Samoa. Women's successes gained from community projects are well documented while normal activities carried out in traditional village communities are narrated in women's committees (Ministry of Women Community \& Social Development, 2013-2014). Although many women's achievements are not reported to the Ministry of Women, Community and Social Development, and Internal Affairs, the benefits are not underrated as they apparently improved the living standards of people in traditional villages.

The reports document that $75 \%$ of women and girls have participated in community development projects funded by AusAID, NZAID, Canadian Fund, UNDP (United Nations Development Programmes) and SPBD (South Pacific Business Development Organisation) that operates a micro finance scheme for small businesses. Community women have been trained in weaving, cooking, sewing, baking, floral arrangement, basic farming, fishing, and creating small businesses. Another pressing aspect promoted by training is creating awareness of the CEDAW - Convention of the Elimination of Discrimination Against Women - as well as eradicating violence against women and children.

According to the annual reports of the Ministry of Women, Community and Social Development and Internal Affairs, Samoan women have experienced significant changes in their economic, social, and political lives over the last half century. There has been an increased participation of women in paid employment, increased interest and participation at national level, and more women holding senior management positions in the government.

\subsubsection{Participation}

It is obvious from the reports discussed above that more women have been in the leadership realm of government ministries and private sectors than in local government. Additionally, more women in traditional villages have participated in and benefitted from community-based projects. To date, a total number of 188 women representatives from village communities have established a National Government Women Representatives of Network in 2004 to coordinate, monitor, and evaluate programs on the village level, under the guidance of the Ministry of Women, Community and Social Development and Internal Affairs. The same ministry implements a Performance Management System to assess and evaluate these representatives' performances. There is also another similar body known as the Women's Advisory Committee which is comprised of representatives from selected villages. This is a policy-making body which monitors, reviews, and develops policies. One of the things this body proposes is the establishment of gender focal points. The proposal is part of the National Plan of Action for 
Women 2008-2012. To date, negotiations are continuing to finalise actions on this group's recommendations.

The work on the advancement of women is supported by government ministries and NonGovernment Organisations. For example, the Ministry of Health monitors women's health while the Ministry of Education continues to educate and train women. Non-Government Organisations contribute by participating in planning, implementation, monitoring, and evaluation of women developments. Local governments are able to facilitate the participation of women in remote areas in community-based programs. Around $75 \%$ of women and girls have participated in village-based activities, and the goal is to increase this number every five years. There is increased participation of women in economic and social developments which strengthens local economic and social development initiatives through the implementation of the Local Government Strategy. The participation level of women in leadership and decisionmaking processes at village levels has now increased to $30 \%$ of all relevant activities.

\subsubsection{Challenges}

The reports discussed above show that impediments to promoting women's human rights are embedded in attitudes and beliefs, as well as the gendered role of women in Samoa. These negativities obstruct the exercise and realisation of women's human rights. A need for amendments to existing legislation was recognised in the Draft National Policy for Women 2007-2017 in order to enhance the protection and application of women's human rights in Samoa in relation to its regional and international commitments. Another obligation is to conduct monitoring and evaluation to determine links between assessment and policy development.

The reports also documented the effect of the global financial crisis on resources to facilitate training and initiatives in the promotion of gender equality. Consequently, a reduction of the budget for the Division of Women created direct dependence on available resources to support the programme. The future of a microfinance scheme which funds small businesses for women is also in question as funding is external. Access to markets for selling products has declined as the only available markets are tourists and overseas relatives visiting the country. The effects of the global financial crisis has direct implications on community women who bear most of the domestic duties and who are responsible for feeding their families. 


\subsubsection{Women as Subordinates}

In village communities, women serve local government. In spite of the existence of a variety of women's initiatives ranging from specific projects to women's training programmes, according to the reports discussed above, women still feel marginalised and excluded from leadership positions in village councils. The reports found that while being active at the community level, women are less often found in influential positions within urban regeneration programmes. This is despite the fact that in public policy there is persistent attention to women's equality and systematic ways of ensuring women's needs and concerns are built into planning. Women also have the potential to access the places where decisions are made, priorities set, and resources distributed. However, it could be argued that while personal development work and confidence-building is a way forward, it is not enough to create real and lasting change. As well as being able to access existing services and resources, women need to be equally involved in decision-making that directs themselves, their families, and their communities.

\subsubsection{Women's Leadership is Providing Services}

The suite of reports and documents cited above record the success of women in making a variety of services available in village communities. One form of success is financial. The Micro Finance Facility is made available to finance income-generating activities of unemployed women in village communities. Although faced with tough conditions, women struggle to get involved in the small business system to earn for their families. Grants and donor-funded programs promote women's access to resources and small businesses in addition to providing training for basic farming and gardening.

Health is a second area of success where a culture of working together as a team grounds the successes of women in offering services to village communities. Besides being traditional healers and midwives, women also involve actively in health programmes to improve primary health care services, health promotion, and preventive programmes. The reports recorded a 95\% coverage of health training programmes for women's committees in the country. The effectiveness of preventive programmes has been monitored, reviewed, and evaluated by the Health Sector, concluding that a high number of community women effectively implement the programmes in families and villages.

Success in a number of environmental conservation and protection developments, projects, and initiatives for community women has also been documented. A number of government policies 
and regulations have been in place to facilitate training programmes for women in this area. Efforts to build family and community well-being have been spearheaded by the Ministry of Women in collaboration with the Disaster Advisory Committee (National Plan for Women 2008-2012). In this, women were invited to participate to gain understanding of various environmental effects, and how to respond by utilising disaster risk reduction strategies, as well as participating in the recovery process after any natural disaster.

\subsubsection{Women in Power and Decision-making}

The National Plan for Women 2008-2012 addresses issues pertaining to women in power and decision-making, and documents that more young women have taken up leadership posts in government ministries and the private sector, a sign of a transition in the orientation and mindset of decision makers to recognise potential women leaders.

A follow-up Draft National Policy for Women 2007-2017 is ready to be submitted for the endorsement of Cabinet. This document highlights the overarching aims for gender equality and the empowerment of women in Samoa in consistence with the Convention on the Elimination of Discrimination Against Women, the Beijing Declaration, the Platform for Action, and the Pacific Platform for Action. The National Government Women Representatives Forum consulted community women on developing new policies, programmes and services that impact on the general roles and responsibilities played in villages.

\subsection{Characteristics of Samoan Women Leaders}

This section outlines how the theoretical lenses of feminism, feminist leadership, and social constructionism theories scrutinizes the important components of women's leadership documented by the Ministry of Women, Community and Social Development and Internal Affairs, the United Nations' Office for Women in Apia, Samoa, Every Home Samoa, and in the Pacific Women Advisory Board Meeting Report on April, 2016.

While the meaning of leadership is debatable in many Pacific societies in response to political and socio-economic factors, Samoan women do not doubt their interpretation of the term nor their understanding of leadership (Le Tagaloa, 1996). They work together, provide equal opportunities, and are adaptable in moving forward, a reflection of their feminist leadership characteristics (Miles \& Huberman, 1994). The nature of habitual tasks and the projects implemented is participatory, non-hierarchical, flexible, and group-oriented (Eagly \& Johnson, 1990). Women are a group of interacting individuals who acknowledge each other's strengths 
and weaknesses and establish mechanisms to mutually boost each other's morale. They collectively construct knowledge and understanding of their activities through dialogic interactions. Women leaders are inclusive, interpersonally sensitive, and nurturing. Women gather together to discuss matters important to them, their families, and communities.

Nurturing young and new members is done through imparting knowledge, giving explanations, and doing demonstrations. Many people engage in incorporating a system of concepts to describe expectations and beliefs of the women's committees. These standardised norms and values guide performances. Planning strategies and tasks show the creativity in women, a skill which differentiates the way they lead from men. Their relationship-oriented nature brings members together to achieve the goals of women's committees. They socialise, interact, and support each other in communal tasks. Women share and exchange food, resources, knowledge, and money.

\subsubsection{Participatory Nature of Women Leaders}

Samoan women are empowered spiritually, socially, and economically in terms of participation. Participation results in learning, and learning is often a prerequisite for changing behaviours and practices. Participation enables women to meet social needs, increasing the effective utilisation of resources at the disposal of women's committees. Participation offers a sense of having influenced the decision-making process and an awareness of the consequences of the decision.

Feminist leadership proposes that true participation is the one in which everyone's perspective is considered (Mitchell, 1970). Women on many occasions believe in participation, support, and cooperation. In this study, the characteristic of being participatory was strongly reflected in accounts of the interactions of women while weaving fine-mat, making tapa, and hosting guests. In the testimony of participants, expertise and resources are shared, and knowledge is imparted to empower young and newly joint member of the associations. As a result, learning is seen as a social activity which takes place through communication and interaction. Learning is understood as a matter of participation in a social process of knowledge construction rather than as an individual endeavor. This indicates inclusiveness in leaders who are people-oriented. In women's committees, interaction stimulates deeper and more critical reflections of what they have learnt with opportunities for exposure to multiple perspectives and interpretations. 


\subsubsection{Non-hierarchical Behavior of Women Leaders}

According to study participants, although organisations may be hierarchically structured, women's committees only follow this norm in formal meetings. Daily routines and developments progress through informal procedures based on equality. Members share frustrations, jokes, and scenarios freely to ease out the pressure of the work. They deliberate on disputes and ensure harmony prevails. Women's committees are interconnected and collaborate. Gaps are bridged through regular communications and links. There is a high degree of involvement of members in decision-making, and women's committees are organised around teams, opportunities, and networking. They distribute authority, share information, draw out and dispense competency to increase the standard of services offered to traditional communities. Strategies consistently emphasise growth, innovation, and income.

Leadership in women's committees encourages functional diversity within roles, and with it, creativity, because employees aren't confined to specific areas of specialisation, which allows women's organisations to operate with less redundancy, as teams share resources more readily than hierarchical divisions. The flexibility inherent in non-hierarchical leadership structures allows women's committees to adapt very quickly to changing conditions. Overall, women take responsibility for the development of their leadership and collaborative skills. This facilitates the development of leadership for others.

\subsubsection{Flexibility and Group Orientation}

Traditional Samoan women have respected the unique individual differences among themselves. They verbalise personal thoughts or opinions when asked and returning this politeness is expected by many women as an expression of mutual respect. Many of the practices explain the flexibility and group oriented nature of women that Eagly and Johnson (1990) discuss.

In the experience of study participants, women generally work collaboratively and cooperatively in interactive activities. Women's committees have been established for a period of more than 100 years and they include certain group categories such as wives of chiefs and orators, unmarried, divorced, or widowed female descendants of the village and wives of untitled men. These classifications constitute additional and explicit dimension of the women's self-identification (Schoeffel, 1979) which are incorporated into committees' work. 
The inter-relationship of women not only serves to maintain society, but under certain circumstances provide women with material, emotional, and intellectual resources to challenge their conditions (Fairbairn-Dunlop, 1996). Women in this study show an ability to sustain each other and challenge patriarchy from positions of dependence and suppression is infrequent and of limited scope. However, women also work together in order to support their families and the village. Great is the wealth of experience, culture and ideas women share with each other (Ministry of Women Community \& Social Development, 2013-2014). According to their comments, they unite in sharing interest and beliefs, unite in appreciation of each other's skills, and unite in team spirit.

In this research, women's identity has incorporated a particular construction of what being communal involves. Like the traditional Samoan family, the women's committee have a particular set of identifiable meanings and associations which contribute in a particular way to their identity. This aspect is also reinforced by a variety of practical characteristics which have combined to ensure that the women's committee constitutes a powerful force that exercise power and authority in traditional communities.

\subsubsection{The Meaning of Dialogic Interactions}

The informants of this study made it clear that dialogues form the backbone of their communal life. The vernacular is fully utilised in the women's deliberations and discussions. It facilitates activities, solves issue, and establishes decisions. Arguments and differences in opinions are minimised and controlled in formal and informal discussions. Whatever the nature of the conflict is, women keep things under control through exchanging opinions and sharing views. Ideas reflect identity, and identity is constructed through dialogue. The construction of identity is the establishment of a leader's vision to accommodate the trust and dedication of her followers. Life by its very nature is dialogic and living means engaging in a dialogue according to social constructionism theory (Bakhtin, 1984). People engaging in dialogues invest their entire self in discourse and that this discourse enters into the dialogic fabric of human life and later into the world conversion.

One of the most interesting aspects of language is how dialogues explain and give meaning to each spoken message. These spoken messages are clearly interpreted both for the sake of the conversation and for the information of the audience. In this study it is clear that women in women's committees converse, joke, and hold formal discussions, making sure that language and meaning are clearly understood by elaborating on certain concepts. This is one of the key 
factors that facilitates communication in women's committees and their affiliates. This reveals that dialogue is important in terms of establishing new knowledge and validating old knowledge, enabling people of a community to have the same understanding of concepts that are meaningful in their setting.

Dialogical life is not new in Samoa. In Samoan thought, words have a historic and genealogical power so that when there is a reason for expression, it is generally done carefully. In social interaction, the emphasis is on affection rather than verbal communication. In earlier times, hearing, observing, and memorising were important skills since all aspects of the women's culture were transferred orally or through example. Storytelling, oratory, experiential, and observational learning were all highly developed.

\subsection{Chapter Summary}

This chapter has presented findings of the data from interviews, observations, and document analysis. The purpose was to present the reader with a picture of the barriers that restrict potential women leaders from positions of authority in local government in Samoa. Interviews explored leadership practicalities of women and differences in practice between urban and rural participants. Observations indicated assumptions, expectations, and beliefs of women, and authenticated the leadership characteristics of women as being participatory, non-hierarchical, flexible, and group oriented as well as verifying the collective construction of knowledge through women's dialogic interactions. The document analysis process scrutinised five documents, two reports, and one documentary. The implications of these findings are discussed in the next chapter. 


\section{CHAPTER SIX: DISCUSSION}

\subsection{Introduction}

This chapter underlines the viewpoints of Samoan women in explaining their positions in the Samoan society, as well as their willingness to advocate for gender equality in local government. The chapter also outlines the difficulties that disadvantage women from accessing leadership positions in local government, unequal opportunities for men and women, the leadership tasks of Samoan women, and the services provided by village women in their capacity as servant leaders. This discussion relates the study's findings to the existing literature, and critiques the ethicality of traditions that hold women back from leadership. The chapter offers a cultural leadership model to achieve gender equality in representation and participation in local government of village communities in Samoa.

Section 6.1 features the women's use of traditional proverbs to express their feelings about themselves, their positions, their appeal to male leaders to make allowance for prospective women leaders, and to encourage the women population to unite in the promotion of gender equity in participation and representation. The meaning contained in the proverbs are, in turn, linked to the literature. Section 6.2 presents discussion of issues affecting women's leadership, highlighting the impacts of cultural, religious, and social restrictions. Section 6.3 focusses on assessing the roles of women, emphasising unequal remuneration women and men get for doing similar tasks, and the unequal status of men and women leaders in village communities. Section 6.4 submits an analysis of the Samoan women's suppression through the theoretical lenses of the feminist, feminist leadership, and social constructionism theories. Section 6.5 provides justification of the practicality of the servant leader capacity of women in village communities. Section 6.6 focusses on practises of servant leaders offered by women. Section 6.7 gives reasons of the compromised status of women leaders in traditional societies, and Section 6.8 outlines a proposed leadership model for local government, concluded with the chapter summary in Section 6.9. 


\subsection{Women's Expressions of Themselves and their Positions}

In an effort to promote women leaders and advocate for gender equality in local government in Samoa, the participants of this study expressed their opinions using Samoan proverbs. Samoan proverbs form an important part of the traditions and culture of Samoa where oratory, poetry, metaphors, and its sensitivity in language art forms are held in high esteem as a form of communication in ceremony and ritual of fa'a Samoa (Keesing \& Keesing, 1956). According to the authors, proverbs are in the language of the matai, so people use proverbs when discussing matters of extreme importance. Schultz (1980) states that proverbial expressions are most regularly used by chiefs and orators (matai), and they are taken from the mythology, history, and everyday lives of the Samoan people to make opinions more meaningful. Furthermore, Schultz translates proverbs as the elaboration of the language's elevated style. Pratt (1984) notes that as chiefs and orators use proverbs frequently, they shed so much light into the past history and the present opinions of the Samoan people. Samoan proverbs are constructed from historical events and delivered as advice or reminders. A proverb is a linguistic tool such as an allusion, allegory, and metaphors which have the ability to make meaning to the expressions (Taisi, 2009).

I have used proverbs to analyse the results of this study since they meaningfully capture the essence of the women's voices. Proverbs encompass the women's thoughts, views, and future ambitions about leadership in local government of village communities in Samoa. Women in this study showed a good understanding of the origins of proverbs, their interpretation, as well as their application in advocating and appealing for gender equality in participation and representation in local government. Therefore, it was fitting to use proverbs as they incorporated the crux of the women's expressions and arguments.

Women spoke confidently of their spiritual power, their innate connection to their natural environment, and their complex understanding of conservation, sustainability, and maintaining good relationships with village communities, religious organisations, and local governments. Women's knowledge of what they could offer to the study when explained in proverbs provides a way of understanding the present in a wider context because proverbs are an important aspect of the Samoan culture since they explain historical events and leverage the richness of the vernacular. In my view, historical events and the vernacular clarify who we are, highlighting our uniqueness in terms of traditions, values, and perspectives. The women's pride in their roles, their development and achievements as well as their strive for leadership posts are clearly 
explained in the use of proverbs. Proverbs are deemed effective in simplifying the women's motives, arguments, and suggestions. The first proverb suggested is:

\section{'Ia tuliulimatāgau le ufi a Sina'.}

This refers to "the surface of a yam broken off"(Pratt, 1984, p. 214), with "tulitulioa meaning to give chase; tuliloa, a pursuit" (Pratt, 1984, p. 326). The legend tells how Sina, a Samoan female who married Tui Toga, secretly returned to her homeland by pursuing a trail of a yam - a starchy tuberous root. In pursuing her goal, Sina laboured hard in digging the ground to extract portions of the yam. Upon arrival, she immediately asked people of her village to quickly block the tuber's path so that no one could come through it again. The familiarity of the yam as a staple food and the crawling nature of its growth prevented the discovery of Sina's secret plan. Therefore, the message here is, 'be logical' in the goals that you pursue. Sina represents an archetypal female figure in Samoan culture depicting beauty, strength, and willpower.

Participant 14 who suggested the proverb stated:

This is a metaphor that symbolises perseverance, determination, and bravery, characteristics that should have been utilised by women to push gender equality issues. If Sina of the olden days had a strong will to achieve her goal, the Sinas (women) of today should do likewise. Local government must have realised that they are not doing justice to women. So, women need to bring this issue to the forefront.

The declaration by this participant aims at encouraging ambitious women leaders as well as the women population in general. The hardships Sina had gone through in masterminding a strategy to escape show great courage. Relatively, Samoan women are seen avoiding leadership status for fear of being ridiculed and underestimated by cultural values, religious beliefs, and social expectations. According to the participant, women can achieve gender equality in local government by persevering through the oppression that excludes them from positions of authority. Sina's determination and dedication to pursue her goal enlightens the notions of power and vital process in leadership that Burns (1978) alludes to. Burns notes that the power the leader holds requires being energetic and self-motivated, leadership characteristics depicted by Sina in her pursuit. In using this proverb, the participant gauges to motivate the idea of being interactive, one of the characteristics of women leaders mentioned by Blackmore (1999). The participant believes that a communal effort of women from all walks of life will make the push for gender equality more powerful. 
A second proverb provides more insight into the situation.

\section{'E lelei le to'ese a nu'u potopoto'.}

To'ese means to commit to a fault, to beg pardon, to confess to being wrong; or to'ese means to remove or to take off, like to take off a hat or to subtract (Pratt, 1984). The first meaning describes the spirit of this proverb since it's about the whole village, everyone together seeking forgiveness or showing humility. It is actually about a group doing what is considered right. Participant 10 in her capacity as a leader is communicating her goals to the rest of the women in an effort to involve everyone. Kase (2010) suggests this action as that of a decisive leader who includes everyone in the decision-making. In this case, the participant makes a decision and then makes it clear to women that as a group, they need to unite in advocating for gender equality in local government. This proverb proposes unity and is frequently used by leaders of civil wars to remind people of the importance of togetherness. The crux of the proverb is that, as a collective community, the people need to go to the battle field together, fight together, win or lose together. Togetherness also refers to the interdependence between a leader and his followers that Burns (1978) alludes to when he emphasises that a leader needs followers and followers need a leader. Participant 12, president of one of the women's committees used this proverb to express her belief that if the whole population of women stand strongly together, this would make the fight for gender equality stronger, more powerful, and more meaningful. The President also made reference to the saying: "United we stand, divided we fall," to inspire unity and collaboration. However, the Samoan saying:

\section{'Afai e le tutū fa'atasi, e faia'ina ma lē taulau le fa'amoemoe',}

translates nicely as, If we don't stand together, we will fail to achieve our dream. Le taulau in the proverb means not fulfilled. Participant 15 explained that working together is a core value in Samoa which is evident in any cultural entity of the family, village, church, and local government. She suggested that if women see the significance of this value in striving for gender equality, they are more likely achieve their goal. Togetherness values relationships between people, a concept explained by Tamasese, Peteru, Waldegrave, and Bush (2005) as a 'relational self'. They claim that Samoans cannot be taken out of the collective context, as a Samoan person is nothing without his or her connections. In the context of this study, women are all related to each other as members of the same gender. Therefore, they are sisters uniting. The understanding is, things must be done in a sisterly manner of bonding with each other. Participant 15 in using this proverb is stressing the importance of relationships within women's 
committees, a reflection of the relationship-oriented character of a female leader (Chliwniak, 1997). Since all women belong to the same group, therefore, it is crucial to utilise teamwork in searching for what is right for the group. According to Participant 11, it is imperative for all women to unite in pushing their agenda.

The next proverb requests women to be patient and to humble themselves before male leaders, in order to maintain peace:

'Ia fa'atamālii le seuga'. Even in game hunting, there is need for grace.

Hunting and catching pigeons (seugālupe) is a popular game among high chiefs in Samoa. Participant 7 who mentioned this proverb, it is about a competition between two high chiefs who are skilled pigeon hunters from Upolu and Savai'i. Before the competition started, the high chiefs agreed not to announce the first catch. The winner would only be made known when the game was completely over. Ulumū, the high chief from Savai'i caught the first pigeon. When his assistant asked if he could announce the first catch, the chief said, "No, we need to respect the rule of the chiefly game." The game progressed and was suddenly interrupted when Lefaoseu's assistant announced their first catch. The game ended immediately when Ulumū and his hunting team left the field knowing that they were betrayed by their rivals. Participant 7 further emphasised the importance of humbleness in the struggle for gender equality. In her opinion, the other party will consider the request if it is delivered in a humble manner. Furthermore, she reiterated that being humble is not only a chiefly behaviour, but is also regarded a core value of a female in Samoan society. Humbleness is central in being relationship-oriented, a characteristic of female leaders that Blackmore (1999) alluded to. The crux of this proverb shares a similar meaning with the next in the discussion.

\section{'Ia fa'aolooloma'au'.}

This proverb also is an appeal for humbleness in people. The term fa'aolooloma' au refers to a gentle approach to soothe feelings about a debated issue, and refers to a humble approach considering the relationship with people and the sacredness of the space (va) between debating parties. The sacredness of space in relation to people and relationships is very important in the Samoan way of living (fa'aSāmoa). It is deemed important for deliberation parties to acknowledge and respect the space between them in addition to paying tribute to the activities taken place in the space (Lee Hang, 2011). Lee Hang's inclusive definition of the sacred space (va tapuia) embraces people and activities, enquiring the former to place emphasis on the latter in maintaining the sacredness of the space. Another significant factor to pay attention to is 
space as a relational self (Tamasese et al., 2005). That is, the space relates people who come together to discuss matters of importance. Participant 8 who suggested the proverb pleas for peace in approaching male leaders about the importance of gender equality in local government. Fa'aolooloma'au aims at winning the debate by executing a calm approach. This calm approach is exemplified in the following participant quote:

A peaceful argument is more meaningful than a harsh one delivered in a loud voice. Not only that is, a loud voice annoying, but it is also disrespectful of the sacred space between people. That sacred space possesses the mana (spiritual power) to authorise people to speak with authority.

Authors like Le Tagaloa (1996) have acknowledged the relation between brother and sister as sacred (va tapuia). Likewise, Tuagalu (2008, p. 108) has accredited va fealoai as a "social space". Refiti (2002) refers to it as not a space that separates but a space that relates, and Ka'ili (2005) acknowledges it as a socio-spatial view of the relationship between people. In recognition of the sacred, social, and interpersonal space between the women and their male acquaintances, deliberations have to be peaceful, harmonious, and non-violent. This is a big ask for women who are battling being excluded from power and authority. However, myths and legends document the determination of women to overcome terrible circumstances (Fairbairn-Dunlop, 1996).

\section{'E au le īna'ilau a Tama'ita'i'.}

The proverb symbolises women's persistence in achieving their goal. The legend says that a group of women out-powered a group of males in thatching, re-thatching, and continued rethatching their part of the house until it was fully completed (Papali'i, 2002). The men's unfinished business brought shame and humiliation. Participant 9 said the message delivered by the proverb is, 'Women's power should not be underestimated'. She elaborated that women always have the courage, commitment, and dedication needed to accomplish a job. The participant believed that women are natural achievers; doers who do not just talk, but act. She further commented that the more effective the doers are at leading, the more the team achieves. The participant stresses the importance of team work as portrayed in the proverb. It was not an individual, but a group of women who completed the work. Working together as a team links leaders and followers in ensuring that the goals of the group are met (Gardner, 1990). Linking leaders and followers is crucial since within a group, "leaders need followers and followers need leaders" (Burns, 1978, p. 6). The proverb reflects women's interpersonal sensitive nature 
(Yukl, 2002) as well as being relationship- oriented (Blackmore, 1999) in the sense that while struggling to complete the task, members maintained a good relationship by being thoughtful of each other's strengths and weaknesses. Hence, their goal was successfully achieved. According to Fairbairn-Dunlop (1996, p. 1), "the implication of this proverb is that women will turn their hands successfully to any task that must be done, and will work hard until the task is completed".

In addition to the aforementioned proverbs, this study has highlighted other Samoan aphorisms that women leaders believe are worth considering when advocating for gender equality in local government of Samoan village communities. The following cultural perspectives propose new offerings for advocating for gender balance in the composition of local government forums. The main message in these traditional perspectives was the need for change in the construction of local government. According to the women, most local government bodies have become stagnant. Therefore, it is their vision to make known the advantages of women's participation in village decision-making. For example, one Participant 10 suggested the essence of the next proverb.

\section{'O le aso ma le fîlīga, o le aso foi ma le mata'igātila'.}

Mata'gātila means mata'iga or to observe. Tila means the spirit of a sail or spirit sail (Pratt, 1984). This proverb offers new innovation and examination. The filiga denotes the plaiting of sennit from dried coconut fibre and mata'igātila refers to inspecting the sail of the fishing boat to ensure its sea-worthiness and readiness for the next fishing expedition (alofaga). While the fishing excursion sets sail, old men plait sennit in a house to shelter the canoe (faleva'a) praying for the safety of the crew and for a hefty catch of fish. When the fishing trip returns, the sails of the fishing boat are examined and prepared for the next journey. Maintenance of the sails and most parts of the fishing boat is ongoing using the newly braided sennit. The implication is that, each new expedition requires new ways of observing and understanding the direction, speed, crafting, and purpose of the expedition relevant to the expedition.

Participant 5 stated that as new sennit is added to the pile, it guarantees the supply for the next maintenance task. Checking the boat regularly equates to the role the women matai would play in ensuring transparency and accountability in the work of local government. The participant said that women matai would act like check mechanisms in the executing of village rules and sanctions. 
In analysis, sennit acts like nails in the construction of a traditional Samoan house, and the strength of the house depends on how well the sennit holds compartments together. Old sennit is no longer used as it is torn and worn out. The proverb links with the work of local government in making decisions for village communities; the reference is that male-dominated local government is old-fashioned, needing to be repaired, overhauled, or renewed. As new sennit is needed for a new house, women are also needed to participate in local government since women look for change in leadership. The proverb proposes the need for fresh blood to join leadership forums, and new blood in this case refers to prospective women leaders.

\section{'O le fuata ma lona lou'.}

This proverb stresses the importance of using a new tool for a new harvesting season. The fuata refers to a harvesting season and the lou refers to a long pruning pole used to pick breadfruit. The proverb implies that it is practical to pick ripe breadfruits with a new pruning pole as it makes the job better and easier.

Participant 2 felt that the need for gender equality in local government is high because this is the entrance to national politics. According to this participant, the restriction of not allowing women to hold matai titles is equivalent to using an old pruning pole. This proverb implies that the old tool is no longer practical, as developing countries are moving towards implementing gender equality in political participation. Because Samoa is one of the developing countries, advocating for gender equality in politics should start from local government. The national government allocates ten percent of the seats in parliament for women, while most local government continue to disallow women to hold matai titles, and do not recognise their participation in village council meetings. This proverb, then, also indicates a need for national legislation for gender equality to remove the power of local government and cultural values that restrict aspiring women leaders. In advocating for a national legislation for gender equality in local government, Participant 5 suggested that male leaders need to re-examine and re-visit the rules of restricting women from holding matai titles.

\section{'Toe sasa'a le fafao'.}

The etymology of fafao or fao is to snatch, to fill, to pack in a basket, or to empty what was packed in a basket (Pratt, 1984). The proverb describes a role of a skilful fisherman who takes out all the fishing lures stored in a basket called 'utu', and examines them independently to ensure that they are in good state. Broken fishing lures are repaired and new ones constructed in preparation for the next fishing voyage. An experienced fisherman has a good understanding 
of each of the fishing lures and the fish it catches. Participant 10, president of one women's committee equated the importance of the examination process of fishing lures with decisions of local government. In her opinion, local government must revisit and verify the decisions that restrict women from leadership positions. She hoped that local government will soon realise the significance of having a gender equality forum that governs the affairs of village communities.

The proverb pleas for revisiting, re-examining, and repairing the antiquated rule of not allowing women to become matai, and can be related to the essence of the goals of the transformational leadership theory (Burns, 1978) in which leaders and followers help each other to advance to a higher level of morale and motivation. The participant states that in the light of the transformational leadership theory, male leaders must help women who are strong supporters of village developments. Furthermore, the participant believes that it is very helpful for male leaders to understand that the essence of this theory requires leaders and supporters to assist each other. In this case, potential women leaders need the support of male leaders to allow them to participate in village council meetings. She further refers to the importance of re-examining rules to ensure their practicality. Thus, discusses the spirit of this proverb as an appeal for revisiting and reassessment of village rules in general. This appeal is advised to be done in the approach portrayed by the next proverb.

\section{'Ia fetu'utu'una'i muniao'.}

Muniao is a trap, and fetu'utu'una'i is flexibility or being flexible. In advocating for gender equality in local government, Participant 3 refers to the responsibility of a pigeon hunter who readjusts the trap to restrain the approaching pigeon when it is trapped. The participant emphasised the principle of being flexible in adjusting to changes and wished for local government to do so in accepting prospective women leaders. She explained that the task of readjusting has to be done carefully and patiently so that the upcoming pigeon is neither disturbed nor threatened. People who are disturbed or threatened are distressed, an unfortunate situation that she did not want to be in. Therefore, she is appealing to local government not to disturb or threaten women, but to readjust their decisions and uplift the ban on women. Hence, creating space for additional members to improve the administration of village communities. Furthermore, the participant talked about the significance of a gender balanced view. She believed that it is fair to welcome perspectives from both genders on issues under discussion so that the decisions are gender-inclusive. She referred to two victims of gender-biased 
decisions. One is a girl who was banished after she was gang-raped by three boys; the other is a woman evicted by a church from a place she had been living for 47 years. The first decision was biased towards the male rapists because all members of the meeting (fono) were males who thought that the girl was a trouble-maker. The second reflects that the church has gone into self-preservation and self- protection mode to unethically defend the decisions of male authorities. She concluded by saying that she had seen no flexibility in leaders who are dysfunctional, anti-social, and harmful in some ways.

Participant 4 who pressed the issue of gender bias in making decisions said:

Gone are the days when people should still stick to the ancient rules and manners. We are now living in a changing world and we should be able to adjust to the changes that are practical in our society such as allowing women to become leaders.

This participant contemplated that local governments have enjoyed the sanctity of their actions which are discriminatory and harmful to women, and eventually result in violence against women. In her appeal, she wanted to advocate for flexibility, understanding, and patience in local government to provide opportunities for aspiring women leaders. In conclusion, she mentioned the importance of respecting each other regarding the sacred space (va fealoa'i) between people. In her view, showing respect to parties in the dialogue is expected to be practiced and observed as the space itself has cultural values attached to it. Tamasese et al. (2005) have identified the relational space that links a Samoan person to the collective context of being related, connected, and togetherness. Va fealoa'i extends to include mutual respect that manages the deliberations and exchanges occurred within the vicinity of these sacred spaces (Lee Hang, 2011). The participant suggests that if male leaders acknowledge the sacredness of the space between them and women leaders who are either connected to them through blood or marriage, then, they should consider the women's plea since they are arguing to give people a chance to be heard. Initially, women advocate for flexibility in local government to adhere to changes and at the same time maintain traditional values that should not be changed. The next proverb discusses the benefits of a new day, signalling the positive effects of the petition for change. 


\section{'Toe āfua se taeao'.}

O le taeao afua, means the new morning (Tamasese et al., 2005). The proverb equates implementing changes to the offerings a new morning brings. It is a plea to re-examine the norm in light of the new morning which brings potential prosperities, hope, and new thoughts.Participant 1 remarked:

A new morning symbolises new life, just like new shoots of plants in a garden which appease feelings and create happiness. If local government allows new changes, they will be able to visualise the advantages of women leaders' participation in terms of balancing views about an issue. This will also motivate women leaders to support village developments.

In the light of the appeals from the participants of this study, as expressed in their choice of these proverbs, it is essential for local government to consider allowing women to be bestowed with matai titles, and to participate in village council meetings. The women leaders who have made the appeals are serving village communities in their capacities as servant leaders, and feel that, due to cultural restrictions barring them from most local government, they are unable to fully exercise their leadership potentials.

\subsubsection{Leadership tasks of Samoan women}

Women in village communities are responsible for a wide range of health-related and economic activities, many of which they initiated themselves (Ministry of Women Community \& Social Development, 2013-2014). In addition to their health activities, women also engage in small businesses and agricultural projects and become the leading fundraising organisation in the village (Participant 15, interview, July 28, 2015). Women's committees have become so well integrated into village life that they are considered to be a traditional organisation Samoan women always belong to. There is power and status the women's committees confer on women (Participant 3, interview, June 15, 2015. The women's committees have been in operation for more than 100 years, and their remarkable resilience due in large part to the specific context of their formation, adherence to their traditional values and beliefs, the high status the committees are afforded, women's pride in what they continuously achieve, the increased power and status that the committees afforded village women, the very real improvement made in children and mothers' health, as well as the general hygiene in village communities (Schoeffel, 1979). Women's committees fulfil a need, allow women to make decisions, encourage new initiatives that women feel are important, support and strengthen traditional, social, and political values 
and norms, have on-going support and encouragement, and an ability to adapt to change (Samoa Women Empowerment Project Report, 2015).

Against all the odds such as cultural, religious, and social assumptions that restrict women from leadership positions in local government of village communities, women have survived in women's committees with a strongly felt, time-honoured identity (Ministry of Women Community \& Social Development, 2013-2014). Their claims and aspirations are communal, and their common ground is a pursuit for the preservation and flourishing of a permanent culture, and often spiritually, tied to their ancestral land. This specific relationship to the land aligns with their role of traditional healers and differentiates them from local government in terms of power or wealth. Women in their handicraft weaving fosters communal, cooperation, and teamwork in the protection of their heritage, language, rituals, and lands. They are seen as a vehicle of change, and at the same time hold on to their perspectives, values, and beliefs (Ministry of Women, 2016). Women feel parts of the village community, their birth into the tradition and societal categories, their upbringing in social settings such as families, the association of female descendants of the village as well as their conscious choices make them proud members of a traditional society (Fairbairn-Dunlop, 1996). Membership and belonging to village communities is of ultimate importance to each individual in terms of self-realisation, and participation in village activities enables growth and maturity. Women in women's committees encompass collective efforts in almost all their tasks and have made and maintained conscious decisions on how to move traditional communities forward, irrespective of the circumstances that surround them (Participant 6, interview, June 8,2015).

Women in village communities believe that their obligation to local government and village communities is shaped and strengthened by participating in community projects aimed at enhancing the general living and health standards. However, the local government, a traditional community that is supposed to be protecting them establish cultural structures to restrain them from participating in decision-making (Participant 7, interview, June 5, 2015). Women are not concerned about the restrictions, but are more willing to provide services for their families, churches, and village communities (Participant 9, interview, July 17, 2015). According to women in village communities, leadership is not about status, but about putting the needs of others first. Although leadership is an imported concept (Chu, 2009), Samoan women prefer not to pay attention to it, but to focus on meeting people's needs, thus catering for the population of village communities. The unfriendliness of some leadership concepts (Chu, 2009) can downgrade women, but does not undermine their perception of development and 
achievements. Leadership as a "story of hardship, hard work, determination, courage and hope" (Fito'o, 2009. p. 23) explains the situation of Samoan women leaders in village communities. However, women's successes as leaders fall nicely into Raivoka's (2009) explanation which states, "leadership is about ordinary people showing care and taking responsibility for themselves and those around them" (p.71).

\subsection{Issues Affecting Women's Leadership}

The discussion now focusses on issues affecting women's leadership in village communities including cultural restrictions (6.2.1), patriarchal ruling (6.2.2), the influence of the matai system (6.2.3), religious beliefs (6.2.4), and social assumptions about women's roles (6.2.5). Firstly, the discussion pays attention to cultural restrictions, since they are the most influential factor that disadvantage prominent women leaders.

\subsubsection{Cultural restrictions}

It was identified in the study that male leadership was deep-rooted in the cultural norms of families, churches, and village communities, and has the potential to discourage and threaten capable women leaders. Continuity in culture to a large extent results in the rejection of women leaders, a common practice of traditional Samoan village communities. During ceremonies, celebrations and festivities, male leaders dominate the stage and obtain all the glory. For example, they present speeches and gifts as well as receiving gifts from women at the completion of community projects implemented by women. Therefore, the reality of moving towards equality with men (Lewis, 2016) is limited.

In terms of economic activity, community women are empowered with income-generating initiatives. Women's earnings from these activities cater for daily needs, health care, and education of their children, but do not contribute to upgrading their cultural status to equate with men. Likewise, the women in some African tribes spend their earnings from labouring jobs on everyday needs of the family, basic medical care, and education (Boserup, 1970) indicating a similar determination for the women to provide for the families daily survival. The author argues that these commitments impact on women's lives as they shoulder the additional burden of providing social services (Boserup, 1970). In the provision of communal services, community women show their belief that they can do anything. According to Miles and Huberman (1994), the philosophy of believing in themselves directs most interactive activities of women. To date, in Samoa, women have been very successful in completing community projects (Samoa Women Empowerment Project Report, 2015) which benefit both the 
individual and the larger community. However, women in Samoan communities are not recognised in their efforts to drive these projects to success.

The cultural disparities between men and women continue to exist as it is claimed to be a true cultural value in village communities. The same scenario occurs in the law of some countries where women lack equality. Even when there is legal equality, decisions are most often made by male heads of households or male local chiefs and leaders (Our Africa, 2016). This is consistent with the results of this study which found that almost all decisions come from the father who is the head of the nuclear family, the matai who is the male leader of the extended family, and male chiefs and orators in the local government. Male leaders seem to be in full control of all entities, including the family, church, village, and local and national governments. This corresponds with people's expectations. Although potential women leaders seek equality, it is a difficult battle because Samoan structures and systems favour male leaders (Participant 1, interview, August 4, 2015).

In a recent study conducted in the United Kingdom of women as global leaders, Ngunjiri and Madsen (2015) found that cultural barriers that did not allow women to become leaders continued to exist. This dilemma happens in Samoa where some traditional villages restrict women from holding matai titles and restrain their participation in village council meetings (Centre for Samoan Studies, 2015). Faced with difficulty in leadership forums, women lack representation and participation (Martire, 2014). Hence, the status quo thrives, strengthening supremacy and extending influence of allies to live, practice, and respect the mandate. Because of how things stand as they have been for more than 100 years now, people think it is their true culture (Aiono, 1986). However, the myths, legends, and documented articles about the success of Samoan Queens, matriarchal leadership pre-date colonisation and Christian eras.

Although various commentators argue that the participation of women in decision making world-wide is increasing, it is generally recognised that women have largely remained outside of the formal leadership roles due to cultural restrictions (Meaza, 2009). These cultural constraints, according to Meaza, persistently hinder the active pursuit of women to gain leadership positions, and allow males to remain in powerful positions.

Cultural conventions of village communities in Samoan society can be understood by a comparison with other traditional societies. A similar scenario of the ultimate authority of male leaders in local government in Samoa was observed in the Aboriginal communities of Victoria, Australia by Smyth (1878), who observed that the government was patriarchal; the head of 
each family had full control over his household; and that the chief (a male) of each tribe directed the movements of community members, policing everyone's location. Rost (1991) also establishes that leadership was most frequently seen as male in Aboriginal society, a notion parallel to the Samoans' cultural practice of perceiving males to be more suitable leaders (Le Tagaloa, 1996). Clearly, this is unethical as the focus needs to be on the capabilities of the leader rather than simply a male-oriented preference. Consequently, male leaders multiply in numbers and dominate local government while women leaders become the minority (Participant 10, interview, August 12, 2015). The reasons for gender inequality in leadership are entrenched in the Samoan culture (Davidson, 1967).

In refuting this argument, Participant 5 said:

Women need to drive cultural change and hold male leaders accountable for their progress to achieve gender equality in the leadership of local government. Women need to tackle this problem at its root, and take a long, hard look at our cultural values and attitudes towards gender.

\subsubsection{Patriarchal Ruling}

Another challenge for women's leadership in village communities is the domination of males. Male leadership dominance is considered to be the norm in many context since "feminization of an occupation or a job refers to women's disproportionate entry into a customarily male occupation" (Fondas, 1997, p. 258). Further to this, Fondas argue that an uneven entry implies a rough attempt in feminising a profession that is claimed to be culturally male-oriented. The refusal of male leaders to recognise gender equality in local government, is evident in 41 out of 240 local government that refuse women to be bestowed with matai titles and 34 other villages that decline to accept the participation of women matai in village council meetings (Centre for Samoan Studies, 2015). This is problematic considering that global leadership is progressively incorporating elements of what are sometimes considered as feminine characteristics admirable in both men and women (Calas \& Smircich, 1993). Some traditional village communities in Samoa, however, continue to conserve male preference for leaders although some of the leaders of village communities have contacts with foreigners through community projects (Participant 1, interview, August 4, 2015). The informant reported that things went back to normal at the completion of projects, and women's contribution to the success of the projects were no longer acknowledged. She went further to say that women leaders are only brought into the context to facilitate a new project. 
In the original Samoan culture, women such as the war goddess Nafanua and the tafa'ifă (holder of four paramount chiefly titles) Queen Salamasina - did aspire to very high positions (Meleisea, 1987). Holmes (1980) who wrote about leadership in traditional villages in Samoa notes that there were two distinct decision-making groups of men and women. Holmes explains that men were more utilitarian while the women's functions were mostly as moral judges and they were trusted to ensure social harmony. However, the total number of female judges in village councils at the moment is only about $10 \%$, as evident in 41 out of 240 local government that do not allow women to hold matai titles, and not recognising their participation in village council meetings.

The sovereignty in the patriarchal authority of local government raises a question about the quality of power they hold. Burns (1978) notes that leadership determines the value of power. This power in restraining women from leadership positions is exercised imperfectly because not allowing women to hold matai titles stops then from political opportunities in the national government as it is specified in the Electoral Act 1963, that only matai are eligible to run or serve as Parliament members (Papali $\left.{ }^{\circ} i, 2002\right)$. Thus, the quality of power of local government has consequences for women beyond their village communities. Other factors to query in the leadership of local government are process and property (Jago, 1982). In examining the processes of decision-making in local government, I can see the absence of transparency and accountability, qualities of good governance stipulated by McLeod (2008). Furthermore, local government claim leadership as a property of their own, giving them the freedom to make decisions to their advantage. The idea of chiefly leadership (Bhim, 2006) is very much upheld by local government and they continue to safeguard the leadership territory for their benefit, claiming it to be the only traditional way. However, Schoeffel (1979) postulates that the subvillage of female descendants of the village (Nu'u o Tama'ita'i) as a group can overturn the decision of the matai. Conflictingly, the supremacy of local government triumphs as it is culturally disrespectful to challenge their power and authority. 


\subsubsection{The Influence of the Matai System}

The discussion of challenges restricting women leaders now turns to the matai system, since it is the centre and embodiment of the fa'aSamoa, or the Samoan way and culture. "The emblem of traditional authority in Samoa is the fa'amatai (in the way of matai)" (Toleafoa, 2007, p. 207). Toleafoa documents that the fa'amatai operates on a village level consisting of a hierarchy of chiefs and orators selected by family consensus. In his interpretation, Toleafoa suggests that these chiefs and orators make up the village council or local government, a decision making body for traditional village communities which functions independently.

The matai system approves matai to be the leaders of traditional village communities, while their wives and sisters form other social institutions perform roles of their unique organisations (Schoeffel, 1979). As a result, women who hold matai titles are faced with the difficulties of role switching and are uncomfortable about joining the leadership arena as it is predominantly male. Historically, the matai system had been in existence before male leadership was officially introduced into the Samoan society by colonial administrators and missionaries (Feinberg \& Watson-Gegeo, 1996). However, the matai system has adopted the male leadership phenomenon and treated it as the only appropriate cultural way (Le Tagaloa, 1996). According to Le Tagaloa, male leadership is central in most administration of the matai system and obvious in cultural ceremonies and everyday activities of people.

The matai system in Samoa is regulatory, controlling, and firm according to the participants of the study. Because of the non-consultative nature of the matai system, women think that they might as well be silent about the appointment of matai, and leave the process to take its course (Participant 5, interview, August 23, 2015). Iati (2000) explains that all extended families are headed by matai who represent them in the village council or local government. The origins of matai titles are remembered in genealogies, legends and myths and matai positions are elected posts within a family, not inherited (MacQuoid, 1995). Women were elected to positions of a matai, assuming the matai duties of the matai title as would a male matai (Aiono, 1986). In supporting Aiono (1986), Holmes (1980) advocates that a matai is genderless. That is, it does not matter if the person is male or female. As long as the person is a descendant of the title. Nonetheless, it was gathered from this study that most of the extended families predominantly opt for male matai in respect of the fa'amatai system. 
The matai system supports male matai on the belief that they have a better oratory knowledge than women, as understanding the culture is essential (Te'o, 2011). This argument was strongly contested by participants who believed that oratory knowledge is only one of the many skills a matai needs to possess. The bestowal of matai titles is a noteworthy aspect of the Samoan culture, a complex connection system rotating around the holders of family matai title, and is the footing of the Samoan socio-political structure (MacQuoid, 1995). MacQuoid states that the Samoan socio-political structure influences the selection of matai pertaining to village regulations and people's preferences. For example, the male leadership mentality weakens opportunities for potential women matai as the matai system has the power to overrule the decisions of families in the selection of matai. Another challenge is male matai appointing men as their successors (Participant 15, interview, August 18, 2015). This attitude of male matai selecting male successors increase the population of male matai, and decreasing the number of women matai. It was evident from the participants' responses that selection criteria must be in place to recruit family matai. In this manner, the recommended person is well prepared to carry out the duties of a matai. Additionally, transparency will provide more opportunities for women to be involved in the selection process. The women's reasoning in terms of enacting transparency and accountability supports what McLeod (2008) describes as aspects of good governance. In current practice, good governance is only an idol to maintain the good reputation of local and national governments irrespective of the practices (Participant 9, interview, July 17, 2015). Although the roles and responsibilities of women leaders may have been hindered in the matai context, women are still enacting leadership and carry out leadership roles in village communities. Women leaders believe that leadership is non-hierarchical, inclusive, and people-oriented, characteristics of female leaders noted by Eagly and Johnson (1990). Implementing these characteristics contribute to the success of women in communal activities such as fine-mat weaving, tapa making, and hosting guests observed in women's committees. Women believe that committing to leadership tasks and responding to leadership obligations is more important than holding a leadership status.

\subsubsection{The Impacts of Religious Beliefs}

It was evident in the study that the preference for male leaders is also influenced by a religious belief that the man is the head of the family. Religious barriers such as this reinforce cultural structures which signify women as unworthy for leadership positions; thus these standardised norms are valued as the only true Christian way. Conversely, participants felt this to be negative and claimed this practice unreligious. 
In defending their leadership capabilities, participants believed that the interpretation of being a leader results from the missionaries' self-centred construction of what it meant to be the head and the leader. This caused some psychological barriers to participants who did not want these roles because they saw themselves as servants. Since this idea became entrenched, both men and women have fully embraced the notion that men are the leaders. Because these beliefs come from what people see as divinely inspired teachings, the patterns of behaviour have become ingrained (Participant 2, interview, July 14, 2015). There is a problem in the way people perceive the power relationship between men and women. The participants said that the missionaries brought Victorian culture along with the teachings of the Bible and the gospel. In my interpretation of the data, it also appears that our ancestors introduced elements of the Samoan culture that further reinforce some of these power dynamics. The church minister and the local government discounted gender equality in power relations, and some villages became powerful in enforcing systems that differentiate the rights of men and women. This is consistent with Okon's (2011) stance that religion has marginalised women and provided the platform for male domination of society, and that such patriarchy and gender inequality continue in the twenty-first century.

The missionaries forced a gender relationship that was common among the English in the 1830s which put a lot of emphasis on the husband as the boss and the wife as the helper (Participant 15, interview, August 18, 2015). This was quite foreign to Samoan society because in the preChristian era, it was the sisters of the high chief who were as just as important as the high chief because they had spiritual power (Schoeffel, 1979). Schoeffel thinks that the nature of the church is very patriarchal, similar to the local government. The influence of missionaries is unfortunate and paradoxical because today in the United States, Europe, and Britain in particular, the Congregational Christian Church is very progressive and have been ordaining women priests for over a hundred years; furthermore, they advocate for social justice and equality as a very democratic sort of church (Participant 2, interview, July 14, 2015). According to this participant, Samoans received the Congregational Christian Church in the 1830s, where it was a different social system, and the Samoans have preserved it in that state.

The missionaries, then, are seen to be responsible for introducing male leadership into Samoan society, which resulted in dismantling the cultural protocols of the sub-village of female descendants of the village as well as a decrease in the elite status they used to hold. Today, Samoans have preserved this belief and claim it to be the only Christian way. As shown in many countries, the churches can be very progressive, but in Samoa, the Christian way is very 
conservative (Participant 15, interview, August 18, 2015). Overall, the church has created a lot of problems with gender inequalities.

\subsubsection{Social Assumptions About Women's Roles}

Having discussed the negative influence of religious beliefs on women's leadership, the discussion now centres on social assumptions which have played a critical role in the shape of women's leadership in village communities. For example, as explained in Chapter 5, many people believe that women are responsible for domestic tasks, child rearing, and looking after the welfare of the family. Sixty percent of the participants of this study think that women are fully occupied with these roles and have no time to do leadership tasks. These participants reside permanently in village communities, and have based this conclusion on their village life experiences.

Another social assumption raised is the prevention of the sacred relationship (va tapuia) between the brother and sister, or within close relatives. The village women believe that women must not be bestowed with matai titles because they cannot discuss sensitive issues with male relatives. It was observed in the field work that women were informally discouraged to attend village council meetings. Some women matai felt that the village council was not the right place for them. It appears that the negative impact of the social assumptions is that men are leaders and women are subordinates. Most of the community women participants support male leaders regarding social interactions in communal activities.

A number of assumptions visible in the findings serve to hinder access to leadership opportunities for women in Samoa. The relationship between the husband and wife is seen recognisable in traditional village communities. In this regard, the nuclear family was ideal in changing the status of the woman to be the help mate and the husband to be the leader. The model of the father being the head of the family was adopted by the church and local government in making the man the consistent leader. It is meaningless to hold various leadership positions without understanding the dynamic process of leadership. As Burns (1978) notes, leaders should demonstrate the qualities required to achieve the goals of the organisation. Therefore, allocating leadership roles solely to men is inappropriate because the leadership qualities of the person are more important than the gender. 
One assumption about women as leaders is related to the areas in which women lead. This assumption is that women have considerable power when it comes to public health. For example, they have the power to impose fines on families or households that do not meet health standards. Women's committees also summon mothers to bring young children for vaccination and post-natal care (Schoeffel, 1979). They do many other things like keeping the village clean and raising funds for community projects. However, these tasks give the impression that these are the only chores women are capable of doing. Hence, the community expect women to fully participate in these particular activities, leaving administrative jobs to men. However, in context, these visible roles of women strengthen their leadership capabilities and they are more suitable for leadership posts than men.

It is assumed that when a matai achieves something, then he's got a strong family behind him including his wife. The participants believe that this is how the women are kept in the place of the subordinate or the adviser, and the Samoan society appreciates this idea, maintaining the belief that women are supposed to be leading from the back while men are forefront leaders. These assumptions limit the women's chances to leadership in local government of village communities.

\subsection{The Reality of Women in Village Communities}

While this chapter has, so far, presented a series of difficulties women face in abstracted terms, as if they are experienced separately, in actuality the lives of Samoan women who live in villages is a reality of intersection between these issues. In other words, the issues both occur together and reinforce each other.

First of all, women leaders are democratic in the sense that they involve everyone in the decision-making process. This democracy in decision-making is evident in meetings of the women's committees and their interactive activities. As Sanga (2005) notes, democratic leaders are participatory and consultative; characteristics observed in women leaders as they lead, monitor, and supervise the communal activities of a fine-mat expeditions, tapa making, and hosting guests. The democratic leadership style maintains and keeps women's committees intact. Women's committees are the backbone of almost every development in village communities, and their leaders are strong advocates to promote gender equality in local government. 
However, not all women leaders in women's committees aspire leadership positions in local government. Those who respect their brothers, male relatives, and husbands as leaders and women whose social and economic status are not strong are the sole women who decide to be supporters (Participant 1, interview, August 4, 2015). Another reality of women in village communities is that the practice of honouring the daughters of high chiefs and talking orators is now ceremonial, and the ceremonial honorifics no longer attach to the right to decisionmaking these prestigious females used to have (Participant 3, interview, June 15, 2015). The participant goes further to say that some women choose to hand over the leadership privilege to the opposite gender, while they concentrate on their assigned roles defined by men, the church, and by common practices.

Women who value the nurturing and caring roles focus on making sure that they play these roles effectively. In elaboration, the participants explain that these women do their best in these roles rather than involving themselves in additional tasks like becoming a leader. Some of the women in the study were worried about existing family relationships, and preferred to give the leadership role to a very senior, experienced relative. These particular women felt they could not afford to speak as representatives of their families, and were not comfortable in making decisions. Where women have opportunities to lead, these are secondary positions, kept in lower status below the positions of men. The participants gauge that the traditional hierarchical structure ranks men and women leaders differently. For instance, wives of chiefs and orators are titled second ranking leaders (pule na lua), meaning they can be leaders of the women's committee and other women organisations. Pule na lua connotation suits women married into the village. However, this study examines the decision-making rights of female descendants of the village, especially daughters of high chiefs and talking orators. Making reference to a Samoan covenant, (feagaiga), a concept of relationship between women and the kinship system (MacQuoid, 1995), I can relate to this sacred status which incorporates kinship and gender, religion and political relations to entitle women to become members of the local government. The status of Samoan women changed as they were expected to accept roles as submissive Christian wives and mothers (Martire, 2014). This influence inappropriately ranks village maidens lower than male matai. I additionally question the disparity between the matai and village maiden (taupou) when both historically had equivalent status. At this point in time, let me refer to a quote by Participant 14 who said: 
In the play Shakespeare wrote called 'Hamlet', there is a reference by Marcella which says: "There has been something rotten in the state of Denmark".

In this participant's view, the entire system of local government was corrupt, just like the government of Denmark as depicted in Shakespeare's play. She reiterated the importance of finding what was rotten and extracting it because part of that rottenness could be referred to as shackles that keep women in the places where they are kept, such as in the second level of the traditional ranking system. Participant 15 explained the differences in rank for men and women leaders as:

The dictatorship is the majority rule of the village council. In that system, where do we find the voice of women? The power has been held by a system dominated by men which cannot be challenged by second class leaders.

According to Ritterbush (1987), a gendered leadership structure is unethical when the original status were the same. Ritterbush stipulates that women exercised considerable power in the traditional Samoan political structure. I think, the political structure the author refers to is the local government pertaining to the organisational structure of the Samoan village which depicts the equal leadership status of the sub-village of chiefs and orators (Nu'u o ali'i) and the subvillage of female descendants (Nu'u o Tama'ita'i).

\subsubsection{Salary packages for men and women village representatives}

These barriers and stereotypes - including differences in salaries, entitlements, and working conditions - create and reinforce unequal opportunities for women in accessing leadership positions. For example, one informant was in the position to tell me that male village representatives of the Samoan government receive double the salary of woman representatives, for the same responsibilities (Participant 7, interview, July 5, 2015).

That men have more chances of entitlement to leadership is evidenced by reports that only five percent of women Chief Executive Officers and 17\% board members in America's 500 Fortune companies (Pew Research Center, 2015). This dilemma of unequal access to leadership positions is similarly encountered by Samoan women in traditional communities today where the adoption of the 'chiefly leadership' style (Bhim, 2006) supports male chiefs and orators. However, in government ministries and private sector institutions in Samoa, women outnumber men in positions of responsibility (Participant 3, interview, June 15, 2015). 
Members of local government are eligible to run for parliamentary seats in the general election every five years. Consistent with the few women in local government, only four made it to parliament in the March election of 2016. The recently implemented 10\% allowance for women representatives - a basic attempt to advocate for gender equality in politics - enables another member to make up the total number of five women out of 49 parliament members. This model, set at a national level may have potential to keep the momentum going, but most local government continue to censor openings for women in accessing leadership positions. Statistics show that the general assembly in Samoa is disproportional in terms of gender. This is an unfortunate situation in view of the projection that women will make up $48 \%$ of the total population of the country in this year's census (Sāmoa Bureau of Statistics, 2015).

Speeches in the Samoan and Maori cultures is another avenue which disadvantages women and is based on the assumption that males are better informed in cultural knowledge. This supposition facilitates the traditional concepts of 'maluali' $i$ and onomea', denoting 'salience and appropriateness' of the male orator in performing this role. Similarly, leadership within the Maori communities is generally the domain of men (Buck, 1958). Like the Samoan orators, Maori male leaders present speeches on the marae, signalling the suitability of male to become leaders. Mahuika (1992), too, documents that leadership in Maori is the domain of men. This reservation for males is a disparity which limits opportunities for women who are culturally knowledgeable and are enthusiastic in presenting traditional speeches in the Samoan and Maori cultures.

In addition to establishing cultural norms to disadvantage women from leadership positions, male leaders also come up with excuses to restrict women from politics. In Pacific island countries, there are many forms of traditional governing bodies that may have excluded women such as the matai system in Samoa which only a minor population of women hold matai titles, and the Tongan government which allocates many seats to nobles only, a title that women cannot hold (Huffer, 2006). According to Crocombe (2008), women have higher formal education than men in most Pacific countries and many are established in well-paid jobs. However, this high number is not translated into local government or basic decision-making forums of most traditional communities. Equality for women is not practised in many Pacific Island countries, although legal frameworks are provided for this purpose (Crocombe, 2008). Hence, giving lip service to gender equality appears to be the norm in families, churches, and government. A difference could be made if administrators of local government realised the importance of having a gender-balanced voice in decision making. The participants believe 
that in most cases, male leaders utilise cultural and religious sanctions against participation of women as convenient excuses which effectively block the discussion of women's rights to share the leadership positions with men.

Good governance breeds positive developments which may exclude women from decisionmaking processes which results in weakening democracy and political capability (Fraenkel, 2006). These positive developments include women generating income for family obligations and church commitments, but by doing so, women are seen as performing the domestic roles required of them, not acting as leaders; thus underestimating the leadership potential of women and associating them solely with household tasks. The participants envisage that this misconception is used as a convenient excuse by male leaders.

It was evident in this study that rural participants (60\%) support male leadership due to their being permanently located in village communities, and their reluctance to disturb peace and harmony in a place they call home. On the contrary, urban participants who make up $40 \%$ of the study participants resented being ranked second, and felt that it was unfair, discriminative, and oppressive. Exposure to national and international forums that are concerned with gender equality is urging urban participants to contest for gender equality opportunities in leadership. In addition, urban participants are more educated and well-informed of the consequences of gender inequalities in Samoa and further afield.

\subsection{Theoretical Assessment of the Samoan Women's Suppression}

Having discussed the ethical aspects of women's position in Samoa, the findings are now considered in relations to the theoretical lenses of feminist, feminist leadership, and social constructionism.

\section{- $\quad$ Feminist Theory}

Feminist theory refers to a diverse variety of beliefs, ideas, movements, and agendas for action (Lewis, 2016). For instance, feminism considers ideas and beliefs about what culture is like for women, compared to what the world is like for men. Specifically in the field of leadership, the theory seeks for equal recognition of females and males. In the light of the theoretical lens of feminism, the demonstrations in communal activities of village communities show no recognition of women and their achievements. Furthermore, neither women leaders nor people of high status in the community query the males' authority. Consequently, male domination continues to prosper while the women's field of authority is very narrow. For example, the 
notion of empowerment as the outcome of the general movement of women worldwide (Malabre, 1978), is constrained since the large part of the women's effort goes into maintaining the status quo. In the case of Samoa, the Convention on the Elimination of all Forms of Discrimination Against Women (CEDAW) was ratified in 1990, almost 26 years from the time of writing. When it comes to the work of the Division of Women, the biggest item in their agenda is promoting the weaving of fine-mats, producing tapa, making handicrafts, and providing empowerment through household task initiatives. All come under the general terms empowerment and empowering women (Ministry of Women Community \& Social Development, 2013-2014). But it may be asked how that is elevating the status of women. Thus, the men are at the forefront, making speeches and displaying the products women had laboured for months. In this way, the communal activities women engage in promote the status quo, without promoting women's rights to leadership.

Claiming leadership as a male occupation opposes the goals of feminist theory which demonstrates the importance of women and embraces gender equity (Malabre, 1978). According to the findings of this study, the significance of women holding positions of responsibility is underestimated by most male leaders, and some women as well. This results from cultural values, religious beliefs, and social preference for male leaders. The finding is consistent with feminist theory which scrutinises the authority and power of males, and claim that resistance to changing the status quo comes from fear of upsetting the cultural balance of societies, respecting religious beliefs, and valuing social assumptions of women's roles.

In ethical terms, the assumption in feminism is that women are not treated equally to men, and that women are disadvantaged in comparison to men (Wilfred \& Paulus, 1994). This hypothesis is consistent with the unfair and underprivileged treatment of community women in Samoa by local government. Like the struggle of women who initiated the feminist theory, community women silently struggle to either decrease or overcome the difficulties they have been through.

\section{- $\quad$ Feminist Leadership Theory}

Leadership from a feminist standpoint is informed by the power of the feminist lens, which enable the feminist leader to identify injustices and oppressions, and inspires her to facilitate the development of more inclusive, holistic communities (Barton, 2006). Feminist leadership in context is considered communal, rather than an individual entity (Hartman, 1999). The transition of achieving leadership positions by women has gained minimal success (Malabre, 1978), although Jewell (1977) notes that the feminist movement results in a better participation 
of women in leadership roles in the 1970s. In Samoa, the majority of leaders for government ministries and the private sector are women, but only a few of them participate in local and national governments (Participant 3, interview, June 15, 2015). The slim chance of women to participate actively in politics is an issue of human rights and good governance. The women's democracy and political credibility are weakened, since they are excluded from decisionmaking processes of good governance (Fraenkel, 2006).

With reference to the work of women leaders in village communities, it is evident that they were more collaborative than men leaders, a feature of feminist leadership that Northouse (2004) has also noted. The spirit of collaboration enables women to successfully complete projects, look after the overall hygiene of village communities, and provide numerous services they can possibly offer. Women are oppressed by the serial and controlling leadership of local government, a situation which Raelin (2005) explains as when leaders sustain and increase power by obstructing potential leaders. Sustaining and increasing power are the norms of local government which reinforce policies to disadvantage aspiring women leaders. The controlling power of local government according to the participants is rigid and hard to challenge. As a result, local government bodies continue to rule, sometimes with force in village communities. For example, imposing hefty fine, not giving the victims fair trials, and not allowing people to counter decisions (Va'a, 2000).

In the context of the feminist leadership principles of doing justice (Barton, 2006) the top down structure of local government and continual domination need to change. As Komives, Lucas, and McMahon (2006) describe, leadership is an interpersonal and moral process of people working together endeavouring to accomplish positive changes. Leadership executed in local government is neither interpersonal nor moral, which creates many contradictions with the feminist leadership characteristics of being personal, relational, and interactive (Antrobus, 2000).

In the context of teamwork as a personal contribution and family commitment according to Grogan (1998), community women leaders were seen active in fulfilling these roles. They work together in women's committees, make contributions in forms of money, time, and effort to improve the living standards of families in the community. However, more characteristics of women leaders tend to be overlooked (Fletcher, 1994). In context, Fletcher (1994) discusses that local government and men in general do not consider the many tasks women leaders do. Although attention is not paid to women's success, women continue to labour on assigned tasks 
to strengthen the relationship (Bolman \& Deal, 1997) between the women's committees and the government, as well as keeping the women's committees intact. Roles such as attending to needs of the family, and serving the community and church are normal operations of the women's committees.

In the light of the principles of the feminist leadership, women leaders persevere in determination to accomplish their goals and influence others to find a greater sense in their work (Jung \& Avolio, 2000). The feminist leadership styles of women leaders are not in full swing because of the oppressions they have encountered in traditional village communities.

\section{- $\quad$ Social Constructionism Theory}

The social constructionism theory hypothesises how meaning is constructed through people's everyday dialogues (Bakhtin, 1984). It examines the way language communicates meaning and how people make sense of the communicated meanings. According to Andrews (2012), knowledge is viewed by social constructionists as constructed, not created. With reference to the construction of knowledge, community women leaders are proven capable of knowing the exact construction that fits a task, incident, or an occasion. They impart knowledge of their experiences and recite what has been passed by their ancestors to new members of women's committees. The richness in language emerges from interactive activities since most of the work is attached to proverbs, myths, and legends. The problem is, the vocabulary is not recorded but verbally taught and learnt. This may have caused some inconsistencies in retelling the stories and the meaning the words carry. The interaction taking place in communal activities is another means of gaining knowledge. In fact, interactions and socialisations are integral factors to creating new knowledge (Schwandt, 2003). Community women's network is actively intact in family, church, and village activities, as seen in the observations. This network strengthens partnerships, relationships, and working commitments amongst members of women's committees. Hence, maintain cooperation, teamwork, and collaboration. These values are understood to align with the characteristics of the social constructionism theory.

Shifting the discussion to the social influences on communal life (Owen, 1990) of women's committees, it is evident that sharing of ideas and the collective effort of women contribute to achieving the tasks allocated to them by local government as well as their assigned tasks. These tasks of women imply their concern of culture and society, the psychological aspects of social constructionism (Gergen, 1985). Gergen notes that the communal existence of women is maintained through interaction and individuals learning the group culture. According to the 
author, the individuals are influenced by the people around them, much more by their own personalities. The culture of interdependence continues to strive and comes alive in women's interactive activities as seen in the observations. This is significant since human behaviour can only be understood within its overall social context (Owen, 1990). Apparently, there are some changes in knowledge and social practices of women. For example, in women's committees in Samoa, experiences and perceptions differ in old and new members, where old strict to traditions and new advocate for changes. The varied perspectives sometimes upset the organisation, but leaders calm down the situation and seek for consensus. The compromises normally reflect the processes, strategies, and goals of the organisation.

Social constructionism regarding the creation of knowledge is also related to the personality and emotional behaviour of people (Harre \& Gillett, 1994). The Samoan women's capacity to live in a meaningful way is reflected in engaging in traditional and social activities such as weaving and crafting handicrafts, hosting guests, and involving in income-generating activities. In investigating the ways in which events, processes, and qualities are modelled (Edwards, et al., 1992), community women through their work describes what is real, what needs to pass on, and what changes through time. Overall, social constructionism is clearly reflected in the work of women's committees, and all other interactive activities women involve in.

\subsection{A Practical Exploration of the Tasks of Servant Leaders}

The term 'servant leader' was coined by Greenleaf (1977) who not only devised the idea, but was also concerned for the outcome of servant leadership in growing people, making them healthier, knowing how to judge right, enjoying personal rights, making decisions independently, and being more willing to become a servant. The key term in the given definition is 'servant', which can also be explained as putting the needs of others first, or providing service for the betterment of others. According to Greenleaf, serving and leading complement each other. The author further alludes to the significance of being involved in the services of the organisation, as it makes the leader visible, creates a non-hierarchical atmosphere, demonstrates group-orientation, and bridges gaps. These are universal feminist leadership characteristics of women leaders that Eagly and Johnson (1990) have indicated, evident in the everyday activities of women's committees in Samoa. The term 'servant leader' is fitting for women leaders in traditional village communities who align their performances with the standardised norm of serving through utilising the skills and knowledge they possess. 
Other authors of literature which describes servant leadership include Prichard (2013); Spears (2010), and Turner, (1999). These authors conclude that servant leadership is both a legitimate field and viable leadership practice. Service leadership is built on a solid theory, based on existing evidence, and frames potentially enlightening future research (Bryant \& Steven, 2014). The legitimacy and viability of the servant leadership scholarship foregrounds the women leaders' narratives, along with the analysis of interviews, observations, and official documents. This is because it seeks to hear voices at the 'grass roots' servant level. In the leadership context of this study, leaders in general need to remind themselves that success is earned, not bestowed. It is important for leaders to consider the leader's post as a privilege, not a right. These considerations must be taken into account by male leaders who dominate local government in Samoa. The next section of the discussion focusses on the aspects of servant leadership practical in traditional village communities in Samoa. It will be based on a discussion informed by studying, observing, and assessing the interactive and communal activities of women leaders in women's committees.

Servant leadership encompasses the attributes portrayed by the diagram on the next page, and are discussed in detail in a clockwise manner in the document.

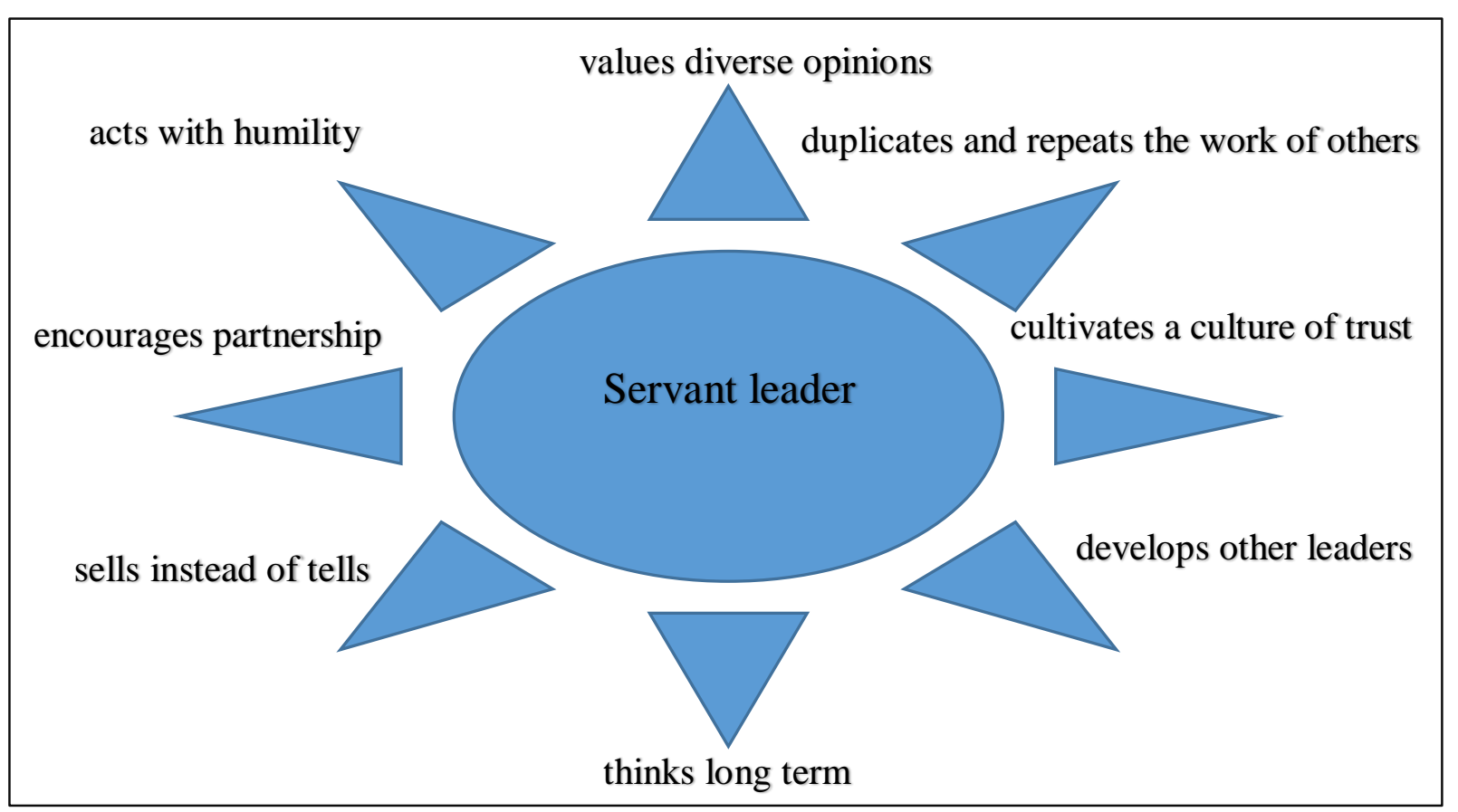

\section{Diagram B. Qualities of servant leadership (adapted from (Prichard, 2013)}

Diagram B gives a graphical account of the concept of servant leadership adopted in this study. The eight attributes of women leaders are discussed in detail in the following sections. 


\subsubsection{Values Diverse Opinions}

One attribute of a servant leader is that, they value diverse opinions. That is, a servant leader considers everyone's different opinions with respect and sincerity (Prichard, 2013). It is very important to acknowledge people's contributions in the achievement of goals, although considering everyone's opinion in making decisions may result in delays (De Cremer, 2006). In meeting procedures of women's committees, the notion of valuing an individual's view is very much upheld. The delays placed no impact on the progression of meetings, as women were patience in ensuring that individuals' views and opinions are taken into account. Generally, equality is practiced in discussions, and it is the responsibility of the leaders to ensure that those who are willing to contribute to decisions are given a chance (Bruce, 2004).

\subsubsection{Duplication and Repeating}

The notion of duplicating and repeating the work of others is significant in the servant leadership process (Prichard, 2013). Duplication is dangerous when it does not constitute accomplishing a purpose (Lee, 2010). Lees emphasises that if duplication does not yield any opportunities for growth, then repetition is unnecessary. The author warns servant leaders to be careful of 'history repeats itself' if the previous service was not helpful. On the other hand, it is beneficial to repeat work which produces good results. It is evident in this study that women repeat weaving fine-mat, making tapa, and acting as traditional healers and midwives to honour the spirits of their ancestors who blessed them with the wisdom to continue these roles. As time goes by, duplication and repetition are practised in effect modification.

\subsubsection{Cultivates a Culture of Trust}

Servant leadership is about deliberating and collaborating to nurture and promote the culture of trust (Prichard, 2013). Pritchard alludes to the significance role trust plays in the operations of any organisation. Further to this, the author suggests that if trust is manifested, the leader needs to assure that the degree of trust enables the organisation to prosper. In the context of this study, the culture of trust is evident in the women's engagement in interactive activities. Trust enables young and new members to obtain leadership skills from the experts, experienced, and old. Trust was maintained in the sharing of expertise, imparting knowledge, and performing hands on activities. The culture of trust survives through stories, dialogic interactions, and the spirit of team work. 


\subsubsection{Develops Other Leaders}

Servant leadership fosters the development of followers to become leaders, and develop leaders for leadership maturity. It may have been in a leader's capacity to influence others towards the leader's goal (Chemers, 1997). Chemers argues that the goal of enabling the full potential in others enables the leader to make the most out of every situation. Developing others and allowing them to grow is the natural groundwork of women's committee leaders. Developmental guidance is imparted through discussions and demonstrations, as members do not go through a formal learning process. New members are given hands on activities to test what has been observed, and learning continues while engaging in activities such as weaving, crafting, and producing traditional materials.

\subsubsection{Long-term Planning}

In the development process, the servant leader has to determine what is important today versus tomorrow, and making choices to benefit the future (Prichard, 2013). Bass (1990) also notes that the leader's involvement is significant in attaining long term goals of any organisation. Interviews, observations, and document analysis for this study capture the capacity of women leaders in village communities to foster long term goals. Members are encouraged to influence the younger generations to continue the work that the women's committees are currently doing. Leaders of women's committees are usually involved not only in administration, but also by engaging in the production, and by connecting to people outside of the women's committees, and in leisure activities. Presidents of women's committees were seen making essential choices to benefit the organisations in the long run.

\subsubsection{Sells Instead of Tells}

A servant leader does not dictate, but employs a leadership style of persuading, not commanding (Prichard, 2013). Selling the goals of women's committees is the focus of all activities women engage in. They do this by working on community development projects, showcasing the products they make, and running small businesses. Presidents of women's committees do not demand or force other women, but provide opportunities for engagement. For example, women are asked to participate in interactive activities at a time convenient for them, and that flexibility allows women who take care of young children and old people not to miss out on any of the activities. The leaders of women's committees are very strong in promoting the goals of their organisations, and encouraging people to give them support. 


\subsubsection{Encourages Partnership}

Servant leaders need to encourage partnership by persuasive, but not dictating, since encouragement is more powerful in boosting people's morale, and motivating them to do better (Prichard, 2013). Perhaps for encouragement to be effective, it has to occur on a certain level, taking into account the diverse background of people (Schwepker \& Schultz, 2015). Engaging in interactive activities strengthens women's partnership and guides them to success. Companionship, team work, and friendship facilitate partnerships in women's committees. These partnerships boost women's morale and maintain the security of their organisations. The encouragement from leaders gives hope to the rest of the crew, and having comfort in one's company keep the women going.

\subsubsection{Acts with Humility}

Servant leaders act with humility when considering other people's ideas. It is an act of admission when you make a mistake or learn from other people's mistakes (Prichard, 2013). As humility is a leader's moral compass, it is deemed valuable to distinguish between the ethical and unethical behaviours. This is a challenging decision for leaders because of existing relationships such as blood relations, marriage ties, and friendship. However, leaders of women's committees were seen just in making challenging decisions. Furthermore, the notion of acting with humility creates peace and makes people comfortable in women's committees. It was always seen that women apologise for their faults, and the apologies are accepted on the understanding that everyone makes mistakes.

The characteristics of servant leadership observed in women's committees include, valuing diverse opinions, duplication and repeating, cultivating a culture of trust, developing other leaders, developing long term plans, selling instead of just telling the goals, encouraging partnerships, and acting with humility. 


\subsection{Practices of Servant Leaders}

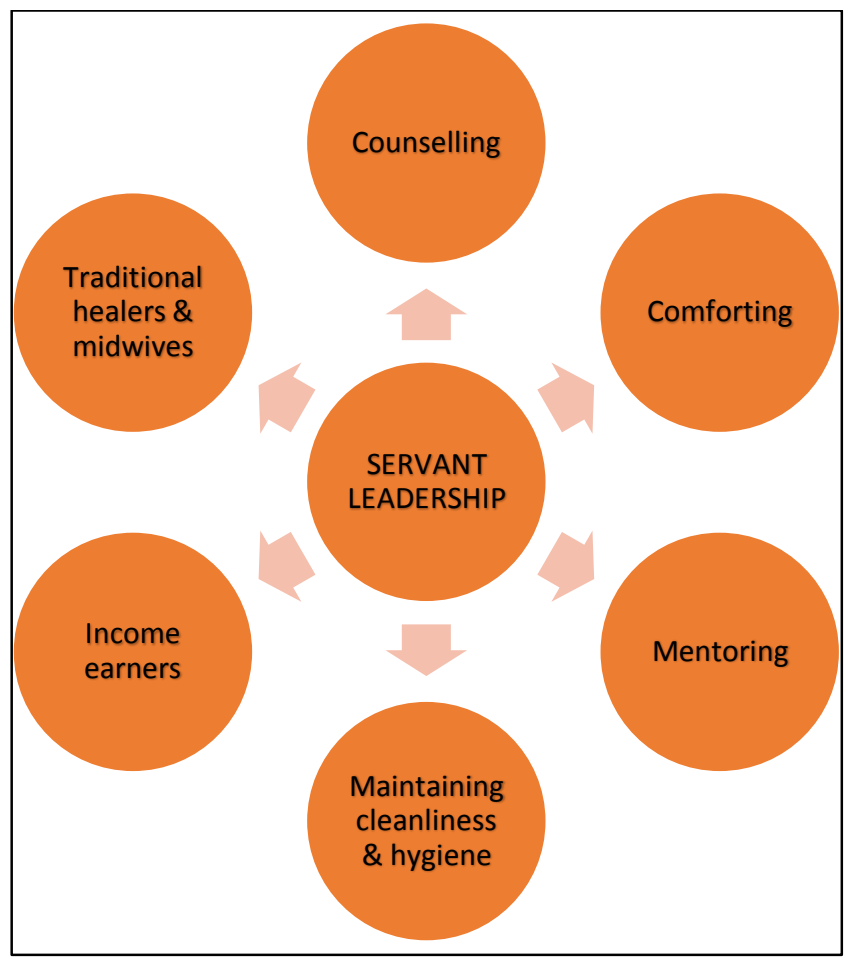

\section{Diagram C. Services offered by servant leaders}

Having discussed the attributes of women leaders, the discussion now focusses on the kinds of service provided by women who have these qualities. Six categories of services can be identified as a result of my findings. A number of attractions apply to all these services. Firstly, it was found that people in traditional communities resorted to these services because of easy access and free of charge. 'Easy access' means the services are available 24 hours due to the women's location within the vicinity of the communities. 'Free services' refers to the women's engagement in the provision of services without requiring the recipients to pay fees.

Communal and interactive activities are the normal tasks of women's committees. In analysing the women's services to village communities, there is evidence of them sharing power, putting the needs of others first, and helping people develop as highly as possible. It is relevant at this point in time to appraise the servant leadership capacity of community women, in the light of the definition of a servant leader by Greenleaf (1977) who suggested that servant leadership should aim at growing people, making people healthier, knowing how to judge right, enjoying personal rights, making decisions independently, and more willing to become a servant. As the discussion progresses, it will highlight matters pertaining to the servant leadership nature of community women apparent in the interviews, observations, and document analysis. 


\subsubsection{Counselling}

One area of service given by women leaders is counselling. Women leaders in traditional village communities understand the importance of counselling. Although the majority of them were not qualified counsellors, they had a strong sense of compassion and commitment to deliver this service. Support was given by two qualified counsellors to enable community women to take care of the people's emotional and psychological problems. Counsellors explained that they were able to address the concerns of people, and that their clients learnt ways to make informed and healthy decisions about themselves, their relationships, and their futures. The integrity of the counselling process according to Makinde (1983), combines together a client who is at risk of seeking assistance and a counsellor who is trained and educated to give help. Unless the qualified counsellors were present, counselling was only a 'fill in a gap' activity. This is not undermining the effort of women to do counselling. Despite this concern, women must be acknowledged for their bravery and commitment to this task as Cole (2002) indicates, it is an expensive and time-consuming exercise.

Counselling by women in this study aims at creating awareness of different forms of abuses, empowering women, informing teenagers of youth problems, as well as suggesting solutions and recommendations. Abuse were revealed after the training, and counsellors directed the victims to organisations to get help. Some of the abuse were referred to the local government or the police subject to the consent of the victims, and the seriousness of the case. Women felt that they were responsible for saving children from misbehaving and making wrong choices through counselling. This was positive feedback as Janda (1972) suggests that the leader's power should influence people to change the way they behave. As counselling results in people amending their behaviours, it can also be expressed as exercising power and influence (McFarland, 1969) in the sense that leaders exercise their leadership power through counselling to affect people's choices. Overall, counselling was observed influential in changing people's choices in life.

\subsubsection{Comforting}

A second area of service is comforting. Women leaders assumed that comforting is part of the nurturing process. As mothers, they were sure to show care, kindness, and support to their children whenever possible. One of the women described comforting as a feeling, a description aligned with Burns (1978, p. 409) who suggests that leaders who are policy makers "operate by feel and feedback". Women felt better and less distress when comforted. In a case when 
someone comforted them, they knew why they wanted to be in that situation, and their intention was clear. To the women, comfort is not an accident. Comfort is built on compassion, which means helping a person to feel understood, not alone.

Comforting happened when women accept the problems and distress of people close to them and even share their suffering. In comforting, women maintained a certain closeness, availability, listening, displaying the touching signal "You can count on me." According to the comforters, non-verbal behavior is crucial and signifies truth, and commonly includes eye contact, proximity, forward body lean, expressions of interest, acceptance, and concern. In comforting, women took into account what someone needed and what made them feel cared for. Comfort occurred when there is a clear distinction between self and other. While comforting people in the community, women carried their love and good intentions in the same basket as their empathy for people's pain. This was done with clarity and self-awareness.

\subsubsection{Mentoring}

Mentoring is a form of leadership according to Western literature, a concept which was well adopted but contextualised by community women. Home mentoring conducted by community women targeted children, while general mentoring focused on empowering young and new members of women's committees. Empowering is imparting the knowledge required to utilise power (Baldwin \& Grayson, 2004). Women leaders activated power through mentoring in order to grow future leaders. Women leaders believed that basic mentoring was to guide children to making good choices in life. Mentoring was a way of fulfilling the customary role of the covenant (feagaiga) supported by the traditional Samoan way (fa'aSamoa) (MacQuoid, 1995). It was acknowledged in the interviews that most of these tasks were part of the woman's traditional responsibilities. Therefore, there is significance in continuing this task, irrespective of the fact that women were not trained mentors.

Women traced back the history of mentoring to the time of the epidemic influenza when many male leaders and untitled men of the families did not survive, leaving the young, and women to guide the family (Hempenstall \& Rutherford, 1984). Since then, women had been directing families by giving guidance and mentoring. Women described their seriousness in mentoring children to avoid them from getting into troubles. The strategies they used consist of engaging in a meaningful conversation with children, factoring in everyday problems, and creating a set of possibilities for minimising or completely avoiding these problems from happening again. I 
interpret this service as empowering children, just as a leader empowers employees to gain success and boost self-determination (Stander \& Rothmann, 2010).

According to the mentors, it is very important for the children to know that they have a crucial contribution to make in solving problems. Women also alluded to their dedication to mentoring by making flexible schedules to attend to problems immediately. Most importantly, they are committed to seeing the growth of children through their ups and downs, navigating them out of their comfort zones, and make something extraordinary happen. Women are caring mentors for their children, who enquire about what is happening with the children, family or the community. They continue to do that in order to check the results expected, giving cues, checking routines, and rewarding improvements. Women believe that a good mentor opens up the doors to curiosity so that you get back that childlike enthusiasm to learn and grow. Mentors consider clarity as the side-effect of a good mentoring relationship. As a caring guardian of the children and family members, mentors engage in conversations to discover the goals of mentees. Thus, provide support to achieve those actions.

\subsubsection{Maintaining Cleanliness and Hygiene}

One of the core functions of servant leaders in village communities is maintaining the overall cleanliness and general hygiene. I can relate the task of sustaining health and sanitation to promoting particular morals and standards besides maintaining the group focus that (Myers, 2015) alludes to. According to Myers (2015), leaders must maintain what is most important and should not lose the group focus in the promotion of morals and standards. The group focus is sometimes compromised to upgrade these activities. Nevertheless, women were seen accommodating core functions, morals, standards, as well as their group focus in their busy schedule.

Women carry out monthly inspection of all village premises to ensure that they are kept clean and healthy. Fines are imposed on families that do not adhere to the standard of cleanliness. Women's committees host monthly visits of the district nurse to provide basic medical treatment, prenatal and postnatal care, and inspect the progress of health promotion activities in the village. All health promotion campaigns are administered by the local government and run by women's committees. Women sometimes receive funds from foreign donors and the national government through the Ministry of Health for health initiatives, but maintaining the healthy standard of the village is the sole responsibility of women's committees. Much time is 
spent on planning and implementing health projects to improve people's health. Women were fully dedicated to doing these tasks for the benefit of the whole community.

Women embrace the idea of 'cleanliness is next to holiness' as the theme for all health initiatives. Making the society looks beautiful is the basic task that genuinely promotes people's religious belief of being holy or free from sins. Women clarified that associating cleanliness to holiness helps to alleviate most of the community problems. Women have a sense of belonging and affection towards the community. These act as incentives towards effective leadership as Maslow (1970) notes. With pride, women ensure cleanliness in a place that is dear to their hearts. Promoting health and hygiene affiliates community women to the Ministry of Health, Ministry of Tourism and Industry, and the Ministry of Education, Sports, and Culture.

\subsubsection{Traditional Healers and Midwives}

Practising traditional healing and midwifery are other services made available by servant leaders in village communities. Travelling to health centres from remote areas and rural villages is hard for patients. The cost of purchasing medication from pharmacies in town is unaffordable as well as meeting doctors' bills. Consequently, it is convenient to seek help from local traditional healers. This situation is related to what Van Dijk (2006) refers to as the facilitation process to use in everyday situations. Considering the problems mentioned, it is easy to resort to traditional healers.

Deihl (1932) explains that another powerful position held by women is the traditional healer, or one trained in special arts relating to healing or medicine. The author writes:

The woman was the doctor and even today was a skilled one. Many of the native medicines are in the control of women and are handed down from mother to daughter. The natives have great faith in their own doctors and try them first before coming to the white doctors (Deihl, 1932, p. 26).

Women engaged in these practices admitted that they do this work with pride and integrity because they are either a blessing from their ancestors, or a gift from a former artist. Traditional healing is complimented with a knowledge of plants and draws on blessings from the ancestral spirits. Traditional doctors declared that herbal medicine have no side effects, so they are very safe for consumption. The general belief is, any female descendant of the village must be a 
traditional healer because it is one of her core roles (MacQuoid, 1995). Both traditional healing and midwifery are performed with care and pride to save lives.

\subsubsection{Income Earners}

The common service of women as servant leaders is earning for their families. Community projects were wisely used by women to gain survival skills such as weaving, cooking, sewing, floristing, tapa making, crafting, and fabric dyeing. Expertise obtained allowed women to run small businesses in the village. These small businesses generate income and assist village people by paying lower charges. Although women run their businesses independently, their goal was to have a direct impact on people and the community as Lichtenstein (2005) recommends, the communal performance of people should have a significant effect on people and the organisation. While women engage in these money-generating activities, they interact in supporting each other's business. For example, those with the expertise in repairing sewing machines offer help when needed and those who were in need of money borrowed from others. Income generated from the women's businesses finance their children's education, and assist with obligations of the family, church, and village.

\subsection{Samoan Women's Leadership in Traditional Village Communities is Compromised}

This section focusses on a comparison of the organisation of a traditional Samoan village before colonisation and Christianity to reveal the history of women losing their previously held leadership status.

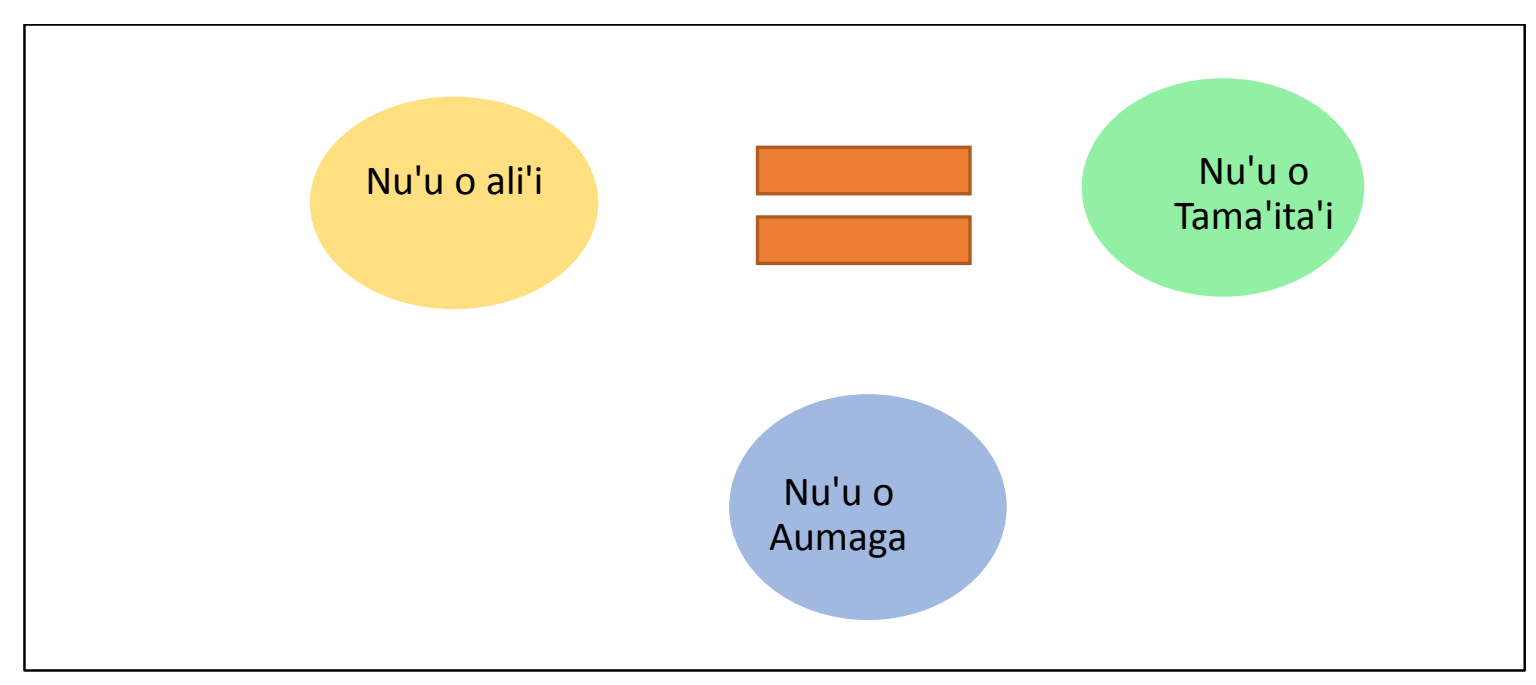

Diagram D. A traditional Samoan village in the pre-colonisation and Christianity eras Adapted from Le Tagaloa (1996) 
Diagram D shows an original traditional Samoan village, with three sub-villages of the Nu'u o Ali'i, Nu'u o Tama'ita'i and Nu'u o Aumaga. Members of the Nu'u o Ali'i are chiefs and orators, while female descendants of the village belong to the Nu'u o Tama'ita'i, and male descendants without matai titles make up the Nu'u o Aumaga. Each of the sub-villages were run concurrently with the exception of the services provided by the Nu'u o Aumaga to the Nu'u o Ali'i and Nu'u o Tama'ita'i when required. The Nu'u o Aumaga was more frequent in serving the Nu'u o Ali'i than the Nu'u o Tama'ita'i. Status wise, the Nu'u o Ali'i and Nu'u o Tama'ita'i were equivalent with dissimilar administrations. However, the two could work together to make decisions regarding village activities on particular occasions. Each administrative unit created its own rules and sanctions for the betterment of the community at large. At that time, the village was peaceful and harmonious with the three sub-villages collectively supporting each other. The Nu'u o Tama'ita'i had the privacy of functioning independently, at the same time offering assistance with village developments, and communal activities.

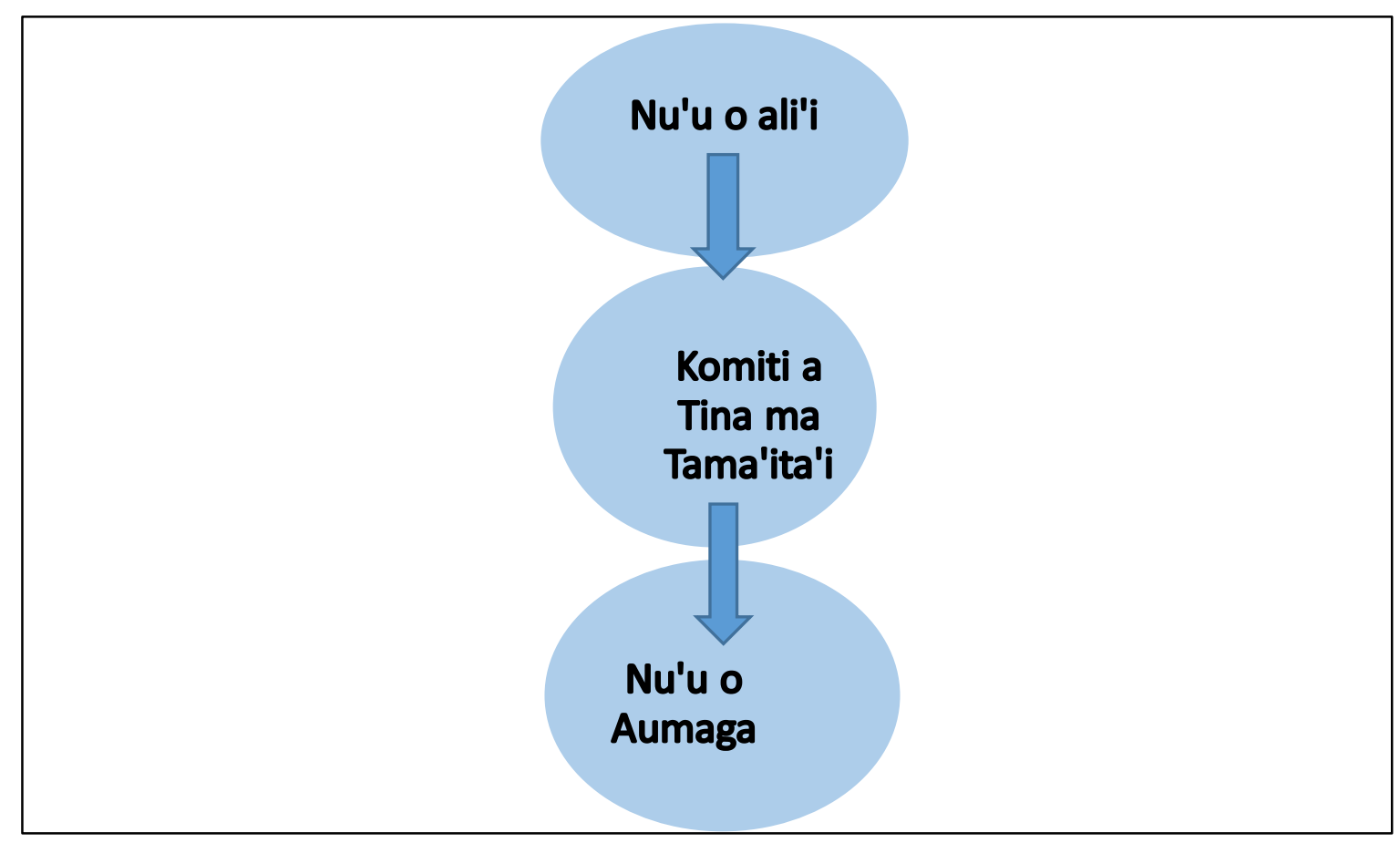

\section{Diagram E. A modern Samoan village}

Diagram E explains the new composition of sub-villages in a traditional Samoan village, as an influence of both colonisation and Christianity. During these eras, the administrators dismantled the sub-village of female descendants of the village (Nu'u o Tama'ita'i) and merged them with wives of chiefs, orators, and untitled men into women's committees, to facilitate basic health care programs for village communities. Leadership in women's committees is now with wives of chiefs and orators, while female descendants of the village play an advisory role. 
Inappropriately, tama'ita'i or female descendants of the village who originally participated in decision making are no longer acknowledged as leaders.

Leadership of Samoan women in traditional villages is limited. It is very constrained as its field of authority is very narrow. It is a very restricted sphere that operates and unfortunately, this is why leadership in local government is criticised for establishing structures and social processes to disadvantage women leaders. A large part of the women's effort goes to maintaining the status quo of male leaders.

\subsubsection{The Role of Samoan Women in Moving the Matai System Forward}

Since women's roles in village communities are dictated by the fa'aSamoa (the Samoan way), it is very difficult for them to go beyond tradition for the mere sake of change and development. For example, any new development has to be approved by the village council or the local government, as these are the judiciary of village communities. The local government plays a supervisory role, represents the women's committees in negotiations with the government or donors, and officially opens and closes a project. Participants of a project only show-case the end products and work from the background. The government together with non-government organisations and the Division of Women of the United Nations Office in Apia support women through community projects, developmental projects, and empowerment training, which give confidence to women's committees to upkeep environmental and economic developments for village communities (Shon, 1998). The successes of women in income-generating activities are well documented in annual reports of the Division of Women, Ministry of Women, Community and Social Development and Internal Affairs as well as in reports of non-governmental organisations like Women in Business, Samoa Umbrella of Non-Government Organisation, and others. Women's small businesses upgrade the standard of living in many village communities. These contributions of women are commended by matai, and women are sometimes invited to discuss these developments with the village council. Within this study, women discussed participating in making decisions about village developments, although they are summoned to these tasks (Ministry of Women Community \& Social Development, 20132014).

Another strategy women use to move the matai system forward is serving the community as servant leaders. In providing these services, women's main aim is for the community to be healthy, happy, and be comfortable in the environment (Ministry of Women, 2016). Matai commend women in doing these services, and therefore depend on them to drive village 
developments. The national government in its effort to give a $10 \%$ allowance for female participation in parliament is sending a message to local government to revisit and re-examine the rules that restrict women from holding matai titles (Centre for Samoan Studies, 2015). This move of the government in establishing five seats for women in parliament may motivate many families that bestow matai titles to many females in 2016 as reported by the Samoa Observer, the country's leading newspaper. Another way women use to move the matai system forward is holding informal discussions with high chiefs and talking orators of the local government. In these informal talks, women speak peacefully in a very respectable manner, acknowledging the fact that the matai holds a higher status than them (Participant 11, interview, July 24, 2015). These participants believe that it is very important to approach matai in a humble way for them to pay attention to their petition. Most of the participants gauge that things are moving forward, but on a very slow basis. Although the progress is slow moving, women are confident that changes will gradually override the traditions (Participant 3, interview, June 15, 2015). With that goal in mind, women cooperate, interact, and support each other in working towards initiating new changes, ensuring that the cultural protocols are safeguarded and maintained.

\subsection{Proposed Leadership Model for Local Government in Samoa}

The leadership of women with lived experiences of suppression is neither recognised nor considered particularly important in patriarchal societies like village communities in Samoa. In the absence of recognition, a values-base of empowerment and equality is required. Women's movements have not yet created an explicit model of leadership based on the values of empowerment and equality in decision-making of local government in Samoa. Therefore, the following model is created to empower women leaders and to create gender equality in the decision-making of village council or local government. The model is intended to provide similar opportunities to both genders in deliberating and making decisions on matters concerning village communities. 


\section{Level One}

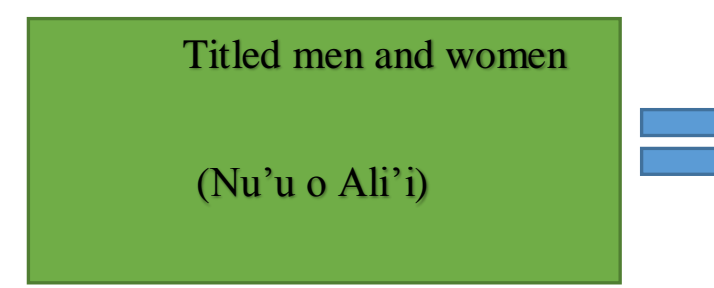

Female descendants of the village

(Nu'u o Tama'ita'i)
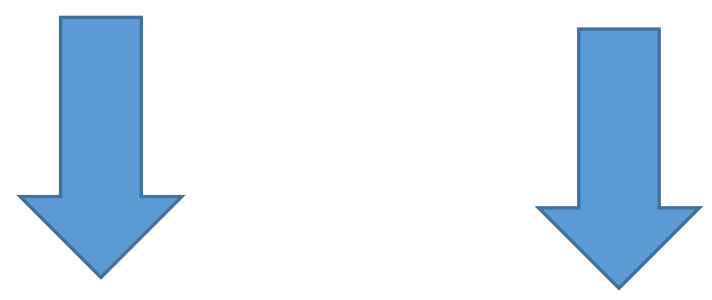

Level Two
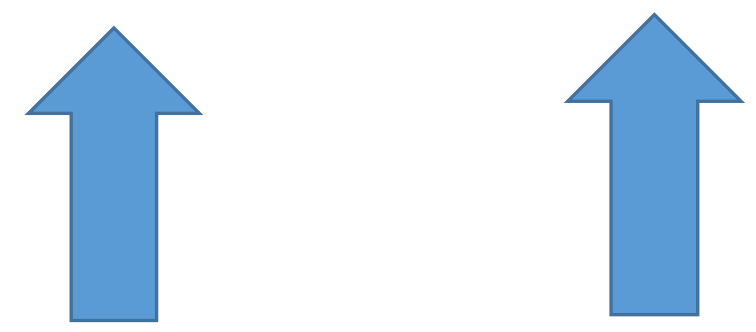

Untitled men \& their wives

(Nu'u o Aumaga)

\section{Diagram F. Proposed leadership model for local government of village communities}

The proposed model revives the re-establishment of the three traditional sub-villages in Samoa before the advent of colonised powers and Christianity. Hierarchically, level one accommodates titled men and women, (Nu'u o Ali'i) as well as female descendants of the village (Nu'u o Tama'ita'i), both with equivalent powers to decision making. Specifically, only senior females from the Nu'u o Tama'ita'i participate in making decisions about village matters. The arrows going down describes instructions and directions passed down from decision-making forums to the Nu'u o Aumaga as they are responsible for executing orders and punishments. The arrows going up indicate services provided by the Nu'u o Aumaga for the two villages of Nu'u o Ali'i and Nuu o Tama'ita'i. Service is either demanded on separate 
occasions, or the same time, depending on the nature of the request and the forum that requests it. In many instances, the services of the Nu'u o Aumaga is normally required when the village council meets. The up-keeping of the village is within the jurisdiction of the decision-making bodies, and general health and hygiene activities are led by the Nu'u o Tama'ita'i and supported by women from the Nu'u o Aumaga. If harmony prevailed in ancient Samoa through the guidance of these three sub-villages, there is a likelihood that traditional villages will go back to being peaceful with the revival of the old administration system. That is, conflicts between genders over the exercise of influence will be removed and inter-gender peace will prevail.

The model intends to activate the cultural values of consulting others with respect, (fa'aaloalo), promoting consultation (soālaupule), advocating for flexible thinking (tōfā fetu'utu'una'i) and seeking consensus (maliliega 'autasi), in ensuring transparency and accountability -principles of good governance. Each is discussed in details in the following section of the chapter.

\section{- Ava fatafata}

Ava carries a more respectful meaning of the term respect, and fatafata is the literal translation of the chest. The term explains the respectful position supposed to be enacted when people of high authority discuss matters of extreme importance such as village rules and punishments. Ava fatafata is the act of humbleness in delivering and countering opinions. This particular gesture is also known as a behaviour particular to the chiefs (aga fa'atamāli'i) in the Samoan culture. The practicality of ava fatafata cannot be underestimated in cultural deliberations as mutual respect is always expected to be practised and observed. Respecting the space (va) with reference to human relationships is spiritual, psychological, and social. These sacred elements are supposed to be honoured and protected with good behaviour (Autagavaia, 2001). An important aspect of practising the value of ava fatafata lies within the use of high opinion language to facilitate the mutual respect and to maintain the sacred space within relationships (Autagavaia, 2001). Hence, it is meaningful to practice the value of ava fatafata in making decisions of local government in Samoa.

\section{- Soālaupule}

Soa is literally a pair or partner. Lau refers to the other person and pule is authority. Soālaupule refers to a respectful negotiation involving the authorities. Soālaupule is literally an exchange of opinions between people of high ranks. Furthermore, soālaupule explains the notion of seeking, supporting, and paring authorities of people in the discussion. Coupling or partnering authority is usually expected to result in consensus. Irrespective of the circumstances 
surrounding the deliberations, the value of respect (fa'aaloalo) must always be observed by all parties at all times. Soālaupule is practical in the Samoan culture as being a Samoan is described as having meaning in the relationship with other people, not as an individual (Tamasese et al., 2005). The authors stress the significance of acknowledging the relationship between dialoguing parties.

\section{- Tōfā fetu'utu'una'i}

Tōfā describes perceptions and fetu'utu'una'i refers to flexibility and democratic notions of sharing. The term indicates the chief's flexibility in not sticking to a rigid decision to ensure trustworthiness, just, and integrity. The term is alerting decision makers to be open-minded in vetting issues, and imposing appropriate punishments. Additionally, it advocates making adjustments to the old- aged rules to suit the current ways of living and circumstances surrounding people's behaviour. Like the other core values, tôfâ fetu'utu'una'i has to be exercised with respect to other people's opinion and a willingness to compromise if there is a need to do so. The term does not entertain rigid structures and strict systems, but flexible and approachable strategies to motivate people to become useful citizens to village communities and to the country at large. Tōfă fetu'utu'una'i typically makes reference to a chief's way of thinking, but is generalisable in the sense that every decision maker can think like a chief if he respects the importance of relationships. The phrase reminds everyone about the significance of being approachable, flexible, and adjustable to certain situations. Another important aspect of tōfă fetu'utu'una'i is making leaders accountable for their actions and the decisions they make.

\section{- $\quad$ Māliliega 'autasi}

Māliliega is agreement and autasi literally means unanimous. The whole term refers to a consensus. Coming to a consensus is not easy because it involves compensation and compromise. Consensus is closely associated with balance and harmony in opinions, values, and relationships. Human connections should be central in striving for consensus with regards to respecting status and space. The issue of space is common as it brings to the fore the importance of viewing relationships between people using a socio-spatial perspective (Ka'ili, 2005). According to the author, space defines the natural features of our land boundaries. It can either separate or connect us with our neighbours, depending on the nature of our relationships. In discussions, it is crucial to be respectful of what happens between us and our partners in the 
negotiating process, ensuring that respect is maintained until a consensus is reached. According to Autagavaia (2001, p. 59):

It is in relation to others that the integrity of the self is shaped and realised, the self does not exist alone, and the Samoan individual does not survive in isolation.

This quotation reminds us that it is important to be communal as it enables you to honestly regard the fact that you cannot endure through independence. It is evident that a consensus is an interactive and collective agreement which is more powerful, meaningful, and healthy for people concerned. It is the overall concern of this study that community women leaders will gradually equate themselves with male leaders, and that male leaders will be able to acknowledge women to be bestowed with matai titles, and participate in village council meetings.

The adoption of the four traditional values described above offers an opportunity to create a ground on which women can unite both among themselves and with male leaders to recapture the essence of a past situation beneficial for all. Specifically this study calls for unity among women to advocate for gender equality in local governments. For women who are comfortable in the subordination role, they are encouraged to support women who are eager to take on the leadership challenges. However, the only way to solve the problem of women's subordination is to change people's mind-set and to plant the new idea of gender equality into every woman's mind. The women's achievements in village communities are the mere signs of their leadership potential since these achievements are the outcome of effective planning, organising, implementing, supervising, assessing, and monitoring. All these tasks require the involvement of a leader, and many women have proven themselves in taking these leadership roles.

The spirit of communal, interactive, and cooperative is crucial in pushing gender equality in local government, as this is the normal manner of women in women's committees. Present women leaders must be inspired by the historical achievements of past women leaders as told by myths and legends. Therefore, it is significance to work towards reinstating the leadership positions originally held by women before colonial and Christian influence. The servant leadership capacity of women is currently highly regarded in steering community projects and village developments to success. This demonstrates that holding a lesser ranking leadership status does not undermine the perception of women leaders to implement changes and pursuing income-generating avenues to benefit families and the community at large. Instead it is the field of influence which is restricted. This study intends to feed a desire to create awareness of 
women's right to leadership, as well as depicting the advantage of having gender equality in local government of village communities, and promoting a gradual increase in the population of women leaders in churches, cultural organisations, and politics. I envision a lot of challenges to oppose the entrenched mentality of male leadership, but my mission is to start the ball rolling, and hope for gradual changes that will finally contribute to achieving gender equality in leadership in Samoa.

\subsection{Chapter Summary}

This chapter illustrates women's expressions of themselves and their positions in village communities within this study, voices which advocate and appeal for gender equality in representation and participation in local government or village councils. The chapter outlines the leadership tasks of women, highlighting the issues affecting women's leadership such as cultural restrictions, the patriarchal ruling of local government, the influence of the matai system in the selection of leaders, the impact of religious beliefs, and social assumptions about women's roles. The chapter also reflects the reality of women in village communities, underlining unequal opportunities for male and female representatives of the government. It also presents a theoretical assessment of the women's activities using the theoretical lenses of feminist, feminist leadership, and social constructionism. The chapter provides a practical exploration of the tasks and practices of women as servant leaders, and portrays the compromised leadership status of Samoan women leaders. The chapter concludes with proposing a leadership model for local government that reflects gender equality in representation and participation, as well as making a strong case and aspirational statement in favour of achieving gender equality in leadership in Samoa. 


\section{CHAPTER SEVEN: CONCLUSION}

\subsection{Introduction}

This chapter presents the concluding ideas for this thesis. Section 7.1 presents major findings of the study, featuring responses to the research questions. Section 7.2 reiterates on the significance of the study, and Section 7.3 highlights contributions the study can make to the literature, while Section 7.4 provides the study's offerings for further studies. Section 7.5 provides recommendations, Section 7.6 explains the limitations of the study, Section 7.7 has suggestions for further studies, and Section 7.8 accents the overall conclusion of this study.

To my knowledge, this is the first study that examines the challenges of restricting Samoan women from local government in traditional village communities. Some of the findings are consistent with the results of a study conducted by the Centre for Samoan Studies, National University of Samoa in 2015 titled: "Village government in Samoa: Do women participate?". For example, the process of not allowing women to hold matai titles thereby not recognising their participation in village council meetings are major impediments for women's leadership in Samoa.

The results of this research are broadly consistent with international literature regarding cultural, religious, and social challenges that have hindered women from leadership positions in cultural communities, the private sector, churches, and public entities. However, there were a few distinctions between traditional encounters in other cultural societies and Samoa, where the prestigious status of the female is very much upheld.

\subsection{Major Findings}

Three major challenges surface in the course of this study that answer the question: "What are the gender inequalities pertaining to Samoan women's leadership, representation, and participation in the local government of the village?". The challenges are cultural values, religious beliefs, and social assumptions of the assigned roles for women. Cultural values is the most powerful impediment affecting women's leadership, enforced by the traditional belief that community administration has been the domain of men. Religious beliefs and Biblical teachings that emphasise the leadership position of the father or the man as the head of the family adds more vigor to cultural challenges. Social assumptions that associate women to household tasks has become the norm in traditional society, and the impact of such norms discourage women to take up leadership positions. 
This study has answered the question: "What are the challenges that prevent Samoan women from being positional leaders?". Women have long been the backbone of traditional village communities, and are heavily involved in community projects, money-generating initiatives, and service delivery. Though often the un-recognised heroes of community activities, traditional functions, and ceremonies, women's contribution has become increasingly important. Women have established themselves leaders of women's committees and other organisations for women, and are the main key players of networking, maintaining relationships, and group-oriented activities. However, they encounter cultural, religious, and social challenges in their leadership roles, and are silently overcoming those challenges by keeping women's committees intact. Women leaders in encountering the suppressions against them harmonise families, churches, and communities in respect of their core role of 'pae ma le auli' (peace-maker). While the women's approach has influenced the advancement of community developments, women's contribution have been neither acknowledged nor credited in most of the village activities.

This study also provides answers for the question: "What is leadership for women in traditional village communities in Samoa?’. In traditional village communities, women claim themselves as 'servant leaders' by offering services at no cost and for 24 hours a day. Women are sincere in the provision of counselling, comforting, mentoring, maintaining cleanliness and hygiene, earning income, and being traditional healers and midwives. In doing these services, women put the needs of the community first, and themselves as servants. They believe that the community appreciates their services. In offering services, women communicate well with people and are committed to provide service when it is required. As servant leaders, women always try to understand and empathise with people. They accept and recognise people for their unique spirits, and are empathetic listeners. Women in their healing capacities not only heal individuals, but they also heal people's relationship with others, as there are people in the communities who have broken spirits and have suffered from a variety of emotional hurts. The women's comforting and counselling in addition to their healing potentials also help with reducing suicide in village communities. Since most of the women leaders reside permanently in villages, therefore, they have a general awareness and understanding of issues involving morals, power, and values. Knowledge of the existing relationships within the village also help women in performing their servant leadership roles. Women leaders soothe, and persuade victims of abuse. They do not point fingers, blame, or gossip about the defendants. They only do what they can afford to do to help or seek further assistance if it is required. Women leaders 
trust people and are expected to be trustworthy stewards of the society. Their dedication, commitment, and perseverance in developing families, churches, and the village communities should not be underestimated. Although the women's leadership opportunities are compromised, they continue to support the communities through their talents, skills, and resources.

The other question the study addresses is: "What are the strategies Samoan women use to serve as leaders?". It was evident in the interviews, observations, and document analysis that women have potential leadership capacities to organise their families, women's committees, women's organisations in churches, and village communities. There were recordings of minute meetings, financial statements, rules, fines, and tasks of women to justify that women leaders are transparent and accountable. Women's organisations under the guidance of women leaders meet to plan, organise, and implement communal tasks. The activities women do benefit families, churches, organisations, and village communities. The answer to this question also reveals the servant leader characteristics of women who continue communal activities in groups, and individually looking after the welfare of families and children. Furthermore, women fully utilise empowerment skills gained from community projects and incomegenerating initiatives to earn for financial obligations, and funding their children's school fees. In terms of leadership strategies, it was found that women leaders had a sound knowledge of planning, organising, and implementing skills evident in the successful completion of community projects and interactive activities. Women leaders have adopted the characteristics of being participatory, non-hierarchical, flexible, and group-oriented (Eagly \& Johnson, 1990).

Responses to the question: "How do Samoan social philosophies, cultural beliefs, and perceptions inform women's leadership?" indicate that the stated aspects influence the people's choice for leaders. In most cases, male leaders are predominantly preferred by most people in village communities because that is the norm. It was evident from the interviews and observations that people maintain the respect for male leaders in the everyday operations of villages. For example, ceremonies, functions, or activities held in the village have to be opened and closed by a chief or an orator in adherence to cultural protocols. The people who participated and completed the task do not matter as cultural protocols require that all acknowledgement and credits go to the local government. Some of the participants were reluctant to fight for their leadership rights due to the sensitivities concerning women's leadership. According to some women in women's committees, women heirs attain the augafa' apae title, while men descendants become matai. This perception is strongly refuted by 
participants of this study because it strengthens the support for male leaders, and restrain opportunities for prospective women leaders. It was observed that people very much uphold the cultural norm of respecting male leaders, the main reason why challenges for women leaders continue.

\subsection{Significance of the Study}

This interpretive qualitative case study about the challenges that impede women from leadership positions in local government in Samoa has five major contributions. Firstly, the study sets a platform to generate dialogues about gender inequality in representation and participation in local government. Secondly, it enlightens the role of Samoan women in moving the matai system forward by illustrating leadership roles that should be adopted by local government in ensuring that people of the community benefit from the administration. Thirdly, the study contributes to literature pertaining to general gender inequality issues in Samoa and the Pacific. Fourthly, the study provides an outline of cultural values, religious beliefs, and social assumptions that affect women's leadership in Samoa. Therefore, potential women leaders should look for solutions that either minimises or resolves the restrictions so that traditional village communities implement gender equality in the membership of matai in local government. Most importantly, this study establishes the foundation for further research about the challenges that restrict women from leadership positions in local and national governments. Although it appears hard to challenge the status quo, it is the intention of this study to start addressing the issues that restrain women from positions of authority by initiating awareness of the existing scenarios.

\subsection{Contribution to the Literature}

This study has contributed to the literature in four aspects. First of all, in terms of culture, this was the first interpretive qualitative study of the challenges that impede Samoan women from leadership positions in traditional village communities. Therefore, literature from this study could be used in further studies that target the cultural challenges affecting women's leadership in Samoa. Furthermore, the leadership scholarship of this study is also very important for Pacific cultural leadership in general. This study also makes a valuable contribution to feminism thinking in indigenous societies.

Secondly, in terms of academic contributions, traditional leadership scholarship from this study could be added to the academic scholarship of leadership research since some of the leadership skills and styles are appropriate for formal and informal learning settings. For example, a leader 
can either be autocratic, democratic, or laissez faire ((Lewin et al., 1939) in a government ministry, a private corporation, or a village community. Furthermore, literature from this study enable other researchers to compare and contrast the behavior of leaders of local government and women's organisations with the behavior of leaders in other traditional societies.

Thirdly, in terms of research methodology, this interpretive qualitative study employed three data collection instruments of interviews, observations, and document analysis to capture the reality of women leaders in village communities, and the struggle they encounter while striving for leadership positions. Hiep (2006) mentions the important of using document analysis and interviews to collect data, whereas Hien (2010) indicates the significance of using government documents. This study analysed government documents, surveys, and reports, as well as conducting interviews to collect data. Interviews, observations, and document analysis helped with the exploration of the challenges that restrain women in village communities from leadership positions in local government.

Fourthly, in terms of research results, this study identified challenges affecting women's leadership in Samoa as cultural values, religious beliefs, and social assumptions. Findings also show that women leaders hold specific power that are interpersonal, communal, and decisive that Burns (1978) allude to. For example, valuing relationships, working together, and supporting the goals of women's organisations such as Komiti a Tinā ma Tama'ita'i, Faalapotopotoga a Tina o Ekalesia, Saofaiga a Tama'ita'i, were evident in the interactive activities women engaged in. Furthermore, research results also signpost the characteristics of female leaders as being participatory, non-hierarchical, flexible, and group-oriented mentioned by Eagly and Johnson (1990). Therefore, this study has a significant contribution to the literature for feminist, feminist leadership, and social constructionism theories, and justifies that there are similarities in the challenges that obsessed women world-wide from leadership positions.

\subsection{Contribution to Future Studies}

In addition to the contributions to the literature, this study has also identified potential studies about the challenges affecting women's leadership in traditional villages in Samoa. Findings of this research also makes a contribution to studies of traditional leaders in indigenous societies in the Pacific and the world. The study also proposes the significance of examining cultural protocols, rules, and punishments of local government to reflect transparency and accountability. At the local government level, it is important for male chiefs and orators (matai) 
to revisit the rules of not allowing women to become matai and not recognising the participation of women matai in village councils so that leadership opportunities are equally accessed by both men and women.

In conclusion, the study suggests that leaders of extended families must be selected on the basis of an heir, rendering service (tautua) to the family. Furthermore, gender should not be an issue in the selection of matai. So, whoever is appropriate, a man or woman, as long as he or she is a good decision-maker, and a doer. Overall, the study appeals for gender equality in representation and participation in local government of traditional village communities in Samoa.

\subsection{Recommendations}

The first set of recommendations from this study focuses on the selection of leaders for extended families, churches, local and national governments in Samoa. The second set of recommendations emphasises training to empower women in village communities, leadership training for young women, and community women to aspire to leadership positions in local government.

\section{Extended families}

The findings of this study show that the preference for male leaders in extended families need to change, so that men and women have equal opportunities to the selection process. The recommendations are as follows:

- Extended families ('āiga potopoto) need to select matai on the merits of an heir (male or female), so that there is gender equality in accessing matai titles. Extended families should additionally consider other skills in the selection of matai. For example, a sound knowledge of the Samoan culture, an understanding of family genealogy, a mature personality, and some leadership skills.

\section{Churches}

From the study findings, it is recommended that churches focus on giving similar opportunities to men and women to run for leadership positions. Therefore, the three mainline churches of the Congregational Christian Church, Methodist, and Catholic must consider the following recommendation. 
- Churches need to design selection criteria to appoint people to positions of authority in order to provide equal opportunities for men and women.

\section{Local government}

Findings of the study reveal gender inequality in representation and participation in most local government of village communities in Samoa. Hence, provide the recommendation below.

- Local government must revisit the decisions that restrict women from holding matai titles and not recognising their participation in village council meetings, as the restrictions impact on potential candidates for Parliament.

\section{National government}

The study finds that the national government makes and enforces laws for the whole country and all government institutions. Since the local government is an entity supervised by the national government, the study suggests the following recommendation.

- It is recommended that the national government establishes a legislation to void the rules of local government that do not allow women to be bestowed with matai titles and not recognising their participation in village council meetings.

\subsubsection{Training to empower community women}

The findings of this study show the need to change the focus of empowerment trainings for women in village communities. Since $75 \%$ of community women now engage in incomegenerating activities, therefore, trainings must target other skills.

- It is recommended that training must focus on areas such as women's right to leadership, effective leadership skills, and the roles of leaders practical in village communities.

\subsubsection{Leadership training for young women}

The study gathers a need to train young women to become leaders to prepare them to compete with males in leadership positions.

- Trainers should consider conducting leadership training for young women in their final year at colleges. 


\subsubsection{Leadership is providing service}

It is gathered from the study that women in village communities in Samoa provide a variety of services for their families, churches, and the community at large. Therefore, it is recommended that:

- Women must believe in their leadership potentials, and strive for leadership positions in local government of village communities.

\subsection{Limitations of the Study}

All studies have some limitations, and this study is no exception. Limitations of this study are explained below.

Firstly, this qualitative research designed with 15 cases is only a reflection of a minority of women, though women represent $48 \%$ of 194,899 - population estimates of the country based on annual growth rates between actual census for 2016 (Sāmoa Bureau of Statistics, 2015). Secondly, the opinions of interview participants in this study are fundamentally personal, not collectively representing the women's committees and village communities they belong to. Thirdly, although a triangulated methodology was used consisting of interviews, observations, and document analysis tools, the data collected were not considered to either indicate all participating women matai or the interactive activities of their village communities. Specifically, in replying to open-ended questions, the rural participants appeared reluctant when providing their personal ideas about the problems with local government, and the reasons why local government restrict women from holding matai titles, and not recognising the participation of women matai in village council meetings. The rural participants were uncomfortable as these sensitive issues are either discussed privately, or not discussed at all.

Although this PhD study was only conducted in the two main islands (Upolu and Savai'i), the findings suggest that this approach would also be beneficial for women leaders in other islands of Samoa, as well as Samoans who live abroad. Findings of this study will alert Samoan women matai outside of Samoa about the reality of leadership in local government. However, several questions remain to be resolved. In particular; "Why are women restricted to holding matai titles easily accessed by men?" "Why do village councils refuse to acknowledge women matai and threaten their participation in meetings?". These crucial questions need to be researched further, based on the initial findings of this study. 


\subsection{Suggestions for Further Studies}

Suggestions for further studies that could be taken into consideration include studies of the reasons why village councils do not approve the bestowal of matai titles to women and refuse the women's participation in village council meetings. Further studies could be focussed on the village councils' views on the rationale of enforcing these restrictions since they are the ones responsible. Furthermore, the insights of village councils who allow women to hold matai titles should also be explored to yield a comparative study.

For the effects of leadership on families and churches, some research could be conducted on men's attitude towards women's leadership. Inquiry of the nexus between leadership styles and research engagement or inquiry of nexus leadership can also be conducted in local government. Furthermore, other concerns that could create possibilities for future research include the relational issues in the selection process of matai, the possibility of dismantling women committees and re-establish the sub-village of female descendants of traditional villages (Nu'u o Tama'ita'i), and strategies to create a gender-balanced local government.

\subsection{Concluding Comments}

Providing equal opportunities for men and women in Samoa to hold matai titles of their extended families acknowledges constitutional rights of descendants. This provision also contributes to the integrity of the selection process for matai because it abolishes a genderbiased appointment. Thus, allowing both male and female equal openings to other leadership avenues. For example, church, and politics. There is evidence that the national government is making an initial move to implement gender equality in participation in parliament. Therefore, it is important for local government to adopt this movement in order for the decision-making forum (village council) to be gender-balanced. Abolishing cultural values that are no longer practical such as restricting women to become matai is adjusting to changes and a global integration of equality. The study gauges the importance of ordaining women pastors in the mainstream churches of the Congregational Christian Church, the Methodist, and the Catholic for gender-balanced in conducting services and the overall administration of the church. As social assumptions that associate women to household chores is identified to be a barrier for women's leadership, this study emphasises that shared responsibilities is healthy, as both men and women can do domestic tasks, depending on the situation and people's circumstances. For example, an unemployed father or husband can look after the children, cook, wash, and take care of old family members while the mother or wife is working fulltime. The woman helps 
with these tasks when she finishes work, in the weekend, or when she takes leave. One of the arguments this study tries to establish is flexibility in people to make wise choices, and do what is practical, instead of behaving according to cultural norms and the society's expectation. Furthermore, the study encourages people to adapt in order to adjust to the changes as no society remains static forever. In comparing traditional villages of Samoa today to 1830, we see a lot of changes in the way of living and how people behave. Therefore, it is appropriate for people to adjust to the current situation.

Aspiring women leaders openly affirmed an intention to start dialogues and open discussions about gender inequality in representation and participation in local government of village communities. They understand that gender equality yields fairness and just in decisionmaking. Furthermore, some of the potential women leaders are targeting the political arena, and are very resilient in advocating for women to hold matai titles. This study has done the groundwork of identifying problems which restrain women from becoming matai. Therefore, the next step for women is to begin dialogue with the local government, and convince them of the significance of allowing women to be bestowed with matai titles, and permit their participation in village council meetings.

This study demonstrates that gender equality in participation and representation in local government could be achieved by overcoming cultural, religious, and social challenges restricting prospective women leaders. It envisions that the supremacy of patriarchy dominance will gradually decrease in local government as a result of petitioning for gender inclusive. Lastly, women will be promoted to an equal status with men leaders while continuing to serve the community through a variety of experiences.

The study's findings have contributed to an understanding of the challenges that hinder leadership opportunities for women in local government of traditional village communities in Samoa. Importantly, these findings provide evidence for local government and church authorities to revisit the decisions that affect women's leadership. Furthermore, these findings assist women who are advocating for gender equality in representation and participation in local government, as well as the political participation of women. It may also be possible that these findings alert the national government to influence the decisions of local government that do not allow women to be bestowed with matai title, and not recognising the participation of women matai in village councils. In my view, allowing women to hold matai titles will never add or subtract an element of the dignitary connotations (fa'alupega) framed for traditional 
villages. Women's participation will bring new ideas and new offerings to the leadership realm of local government. Overall, the study intends to support the promotion of gender equity in decision-making forums as well as women with political aspirations. I'd like to leave you with a reminder that Samoan women must be provided with the opportunity to enjoy their Godgiven entitlement to holding matai titles of their families, as strengthens by the Samoan saying: "E aia tutusa suli tamatane ma tamafafine i suafa matai o aiga", translated as: All men and women descendants of extended families in Samoa have equal rights to holding matai titles. Therefore, it is just to provide equal opportunities for both genders to hold matai titles of their families, and participate equally in local government of traditional villages in Samoa. 


\section{REFERENCES}

Adler, N. J. (1994). Competitive frontiers: Women managing across borders. In N. J. Adler \&

D. N. Izraeli (Eds.), Competitive frontiers: Women managers in global economy (pp. 22-40). Cambridge, MA: Blackwell.

Adler, N. J. (1997). Global leadership: Women leaders. Management International Review, 37(1), 171-196.

Aiono, F. (1986). Western Samoa: The sacred covenant. In land rights of Pacific women (pp. 102-109). Suva, Fiji: Institute of Pacific Studies, University of the South Pacific.

Aiono, F., \& Crocombe, R. G. (1992). Culture and democracy in the South Pacific. Suva, Fiji: Institute of Pacific Studies, University of the South Pacific.

Akao, S. (2008). Seen but not heard: Women's experiences of educational leadership in Solomon Island Secondary Schools. (Master's thesis), University of Waikato, Hamilton, New Zealand.

Anae, M., Mila-Schaaf, K., Coxon, E., Mara, D., \& Sanga, K. (2010). Teu le va. Relationships across research and policy in Pasifika education: A collective approach to knowledge generation and policy development for action towards Pasifika education success. Auckland, New Zealand: Auckland University Press.

Andersen, J. A., \& Hansson, P. H. (2011). At the end of the road? On differences between women and men in leadership behaviour. Leadership \& Organization Development Journal, 32(5), 428-441.

Andersen, L. M., \& Taylor, H. F. (2009). Sociology: The essentials (6th ed.). Wadsworth, USA: Sage Publications.

Anderson, L. (1997). The introduction of generic workers into the ward team: An exploratory study. Journal of Nursing Management, 5(2), 69-75.

Anderson, N., Lievens, F., Van Dam, K., \& Born, M. (2006). A construct-driven investigation of gender differences in a leadership-role assessment center. Journal of Applied Psychology, 9(6), 555-566.

Andrews, T. (2012). What is social constructionism? Grounded theory review. An International Journal, 11(1), 1-32.

Antrobus, P. (2000). Transformational leadership: Advancing the agenda for gender justice. Gender and Development, 8(3), 50-56.

Autagavaia, M. K. (2001). Social work with Pacific Island communities. In M. Connolly (Ed.), New Zealand social work: Contexts and practice (pp. 72-84). Melbourne, Australia: Oxford University Press. 
Ayman, R. (1993). Leadership perception: The role of gender and culture. In M. M. Chemers \& R. Ayman (Eds.), Leadership theory and research (pp. 137-166). San Diego, CA: Academic Press.

Bakhtin, M. M. (1984). Problems of Dostoevsky's poetics. Minnieapolis: University of Michigan Press.

Baldwin, D., \& Grayson, C. (2004). Influence gaining commitment, getting results. Greensboro, NC: Center for Creative Leadership.

Barclay, L. (2005). Midwives' tales: Stories of traditional and professional birthing in Samoa. London, England: Vanderbilt University Press.

Bart, C., \& McQueen, C. (2013). Why women make better directors. International Journal of Business Governance and Ethics, 8(1), 93-99.

Barton, T. R. (2006). Feminist leadership: Building nurturing academic communities. Advancing Women in Leadership Online Journal, 24 (6), 1-8.

Bass, B. M. (1985). Leadership and performance beyond expectations. New York: Free Press.

Bass, B. M. (1990). Theory, research, and managerial applications. Bass and Stogdill's handbook of leadership (3rd ed.). New York: Free Press.

Bass, B. M., \& Avolio, B. J. (1993). Transformational leadership: A response to critiques. In M. M. Chemers \& R. Ayman (Eds.), Leadership theory and research (pp. 49-80). San Diego: Academic Press.

Bass, B. M., \& Bass, R. (2008). The Bass handbook of leadership: Theory, research, managerial applications. New York: Free Press.

Bate, P. (1990). Using the culture concept in an organisation development setting. Journal of Applied Behavioural Science, 26(1), 83-106.

Baxter, P., \& Jack, S. (2008). Qualitative case study methodology: Study design and implementation for novice researchers. The Qualitative Report, 13(4), 544-559.

Beck, C. T. (1997). Developing a research program using qualitative and quantitative approaches. Nursing Outlook, 45(6), 265-269.

Becker, M. E. (1994). Strength is diversity: Feminist theoretical approaches to child custody and same sex relationships. Law Review Journal, 70(1), 1-23.

Benbasat, I., Goldstein, D. K., \& Mead, M. (1988). Letter to the editor. MIS Quarterly, 12, 522.

Bengsston, P. (1999). Multiple case studies - not just more data points? Term paper in graduate course. Software Engineering and Computer Science. University of Karlskrona, Ronneby. 
Bennett, N., Wise, C., Woods, P., \& Harve, J. A. (2003). Distributed leadership: Full report. Retrieved from www.ncsl.org.uk/mediastore/image2/bennettdistributed-leadershipfull.pdf

Bennis, W. (2003). On becoming a leader (Revised ed.). Cambridge, MA: Perseus Publishing.

Bensimon, E. M. (1989). A feminist reinterpretation of presidents' definitions of leadership. Journal of Education, 66(3), 32-46.

Berger, P., \& Luckmann, T. (1991). The social construction of reality. London, England: Penguin Books.

Bergeron, D. M., Block, C., \& Echtenkam, A. (2006). Disabling the able: Stereotype threat and women's work performance. Human Peformance, 19(2), 133-138.

Bernard, H. R. (2002). Research methods in anthropology: Qualitative and quantitative approaches (3rd ed.). Walnut Creek, CA: Altamira Press.

Bernard, H. R. (2006). Research methods in anthropology: Qualitative and quantitative approaches (4th ed.). Lanham, Rowman: Altamira Press.

Bernard, H. R. (2011). Research methods in anthropology: Qualitative and quantitative approaches (5th ed.). New York: Altamira Press.

Berrett, T., \& Slack, T. (2001). A framework for the analysis of strategic approaches employed by non-profit sport organisations in seeking corporate sponsorship. Sport Management Review, 4(1), 21-45.

Berthoin, A., \& Izraeli, D. N. (1993). A global comparison of women in management: Women managers in their homelands and as expatriates. In E. Fagenson (Ed.), Women in management: Trends, issues and challenges in managerial diversity (pp. 52-96). Newbury Park, CA: Sage Publications.

Besnier, N. (1996). Authority and egalitarianism: Discourses of leadership. In R. Feinberg \& K. A. Watson-Gegeo (Eds.), Leadership and change in the Western Pacific. London, United Kingdom: The Athlone Press.

Bevir, M., \& Kedar, A. (2008). Concept formation in political science: An anti-naturalist critique of qualitative methodology. Perspectives on Politics, 6(3), 503-517.

Bhim, M. (2006). Public leadership in the Pacific: Ethically challenged. In C. Williams (Ed.), Leadership accountability in a globalizing world. London: Palgrave Macmillan.

Bisman, J. E., \& Highfield, C. (2012). The road less travelled: An overview and example of constructivist research in accounting. Australasian Accounting, Business and Finance Journal, 3(22), 227-245.

Blackmore, S. J. (1999). Some advice on questionaire research. Parapsychology Foundation Journal, 4(6), 67-82. 
Blumer, H. ( 1969). Symbolic interactionism: Perspective and method. Englewood Cliffs, NJ: Prentice-Hall.

Bolman, L., \& Deal, T. (1991). Leadership and management effectiveness: A multi-frame, multi-sector analysis. Human Resource Management, 30(4), 509-534.

Bolman, L., \& Deal, T. (1997). Reframing organizations: Artistry, choice, and leadership. San Francisco: Jossey-Bass.

Bonoma, T. V. (1985). Case research in marketing: Opportunities, problems, and a process. Journal of Marketing Research, 22(6), 199-208.

Booth, M., \& Philip, G. (1998). Technology, competencies, and competitiveness: The case for reconfigurable and flexible strategies. Journal of Business Research, 41(1), 29-40.

Boserup, E. (1970). Women's role in economic development. London: George Allen and Unwin.

Boyatzis, R. E. (1998). Transforming qualitative information: Thematic analysis and code development. London: Sage Publications.

Braun, V., \& Clarke, V. (2006). Using thematic analysis in psychology. Qualitative Research in Psychology, 3 (2), 77-101.

Brayboy, B. M. J., Gough, H. R., Leonard, B., Roell, R. F., \& Solyom, J. A. (2012). Reclaiming scholarship: Critical indigenous research methodologies. In S. D. Lapan, M. T. Quartaroli, \& F. J. Riemer (Eds.), Qualitative research: An introduction to methods and designs (pp. 423-450). San Francisco: Jossey-Bass.

Broughton, A., \& Miller, L. (2009). Women in senior management: Is the glass ceiling still intact. The Journal of Industrial Relations \& Human Resources, 11(4), 7-23. doi:10.4026/1303-2860.2009.0122.x

Brown, M., \& Ralph, S. (1996). Barriers to women managers advancement in education in Uganda. International Journal of Educational Management, 10(6), 18-23.

Bruce, E. (2004). Servant leadership at Heritage Bible College: A single-case study. Leadership \& Organization Development Journal, 25(7), 600-617.

Bryant, P., \& Steven, B. (2014). Enthusiastic skepticism: The role of servant leadership theory and practice in advancing servant leadership. Servant Leadership, Theory, and Practice, 1(1), 11-14.

Bryce, R. (1970). Characteristics of women holding executive, managerial, and other high level positions in formal areas of business. Dissertation Abstracts International, 30(5), 42164217.

Buck, P. (1958). The coming of the Maori. Christchurch, New Zealand: Whitcomb \& Tombs Limited. 
Burningham, K., \& Cooper, G. (1999). Being constructive: Social constructionism and the environment. Journal of Sociology, 33(2), 297-316.

Burns, J. M. (1978). Leadership. (reprint ed.). New York: Harper \& Row Publishers.

Burr, V. (1995). Introduction to social constructionism. London: Routledge.

Burrows, E. (1939). Breed and border in Polynesia. Journal of American Anthropologists, 41(1), 1-21.

Butler, D. H. (2007) The woman's reader: The first quarterly century of womanist thought. Journal of Pan African Studies, 2(1) 77 http://www/jpanafrican.org/

Butler, M. J. (2014). Operationalizing interdisciplinary research: A model of co-production in organizational cognitive neuroscience. Journal of Frontiers in Human Neuroscience, 7(720). doi:10.3389/fnhum.2013.00720

Butterfield, D., \& Powell, D. (1981). Sex effects in evaluating leaders. Organizational Behavior and Human Performance, 28(2), 129-141.

Calas, M. B., \& Smircich, L. (1993). The feminine in management meets globalization. Business Horizons, 36(8), 71-81.

Campbell, D. J., Bommer, W., \& Yeo, E. (1993). Perceptions of appropriate leadership style: Participation versus consultation across two cultures. Asia Pacific Journal of Management, 10(3), 1-19.

Carby, H. In Wallace, M. \& Dent, G. (1992). The multicultural wars: Black popular culture (pp. 187-199). Seattle: Bay Press.

Cavana, R. Y., Delahaye, B. L., \& Sekaran, U. (2001). Applied business research: Qualitative and quantitative methods. Queensland, Australia: John Wiley and Sons.

Centre for Samoan Studies. (2015). Village government in Samoa: Do women participate? Retrieved from www.nus.edu.ws/

Chambers, R. (1983). Rural development: Putting the last first. London: Longman.

Chemers, M. M. (1997). An integrative theory of leadership. Mahway, New Jersey: Lawrence Erlbaum Associates.

Cherry, K. A. (2006). Leadership styles. Retrieved from http://psychology.about.com/od/leadership/a/leadstyles.htm

Chliwniak, L. (1997). Higher education leadership: Analyzing the gender gap. ERIC Clearinghouse on Higher Education. Retrieved from www.ed.gov/databases

Chodorow, N. (1978). The reproduction of mothering: Psychoanalysis and sociology of gender. Berkeley: University of California Press. 
Chreim, S. (2006). Postscript to change: Survivors retrospective views of organizational changes. Personnel Review Journal, 35(3), 315-335.

doi:org/10.1108/00483480610656711

Chu, C. (2009). To sink or swim: Leadership begins with a splash. In K. Sanga \& C. Chu (Eds.), Living and leaving a legacy of hope: Stories by new generation Pacific Leaders (pp. 15-21). Wellington: Institute for Research and Development in Maori and Pacific Education, Victoria University of Wellington.

Churchward, C. M. (1959). Tongan dictionary. London: Oxford University Press.

Churney, R. (1998). Political culture and political process: Fiji, American Samoa, and Palau. In D. Schuster, P. Larmour, \& K. von Strekirch (Eds.), Leadership in the Pacific Islands: Traditions and the future (pp. 102-125). Standford: Standford University Press.

Ciulla, J. (1998). Leadership ethics: Mapping the territory. In J. Ciulla (Ed.), Ethics: The heart of leadership (pp. 3-25). Westport, CT: Praeger.

Cliff, J. E. (2005). Walking the talk? Gendered rhetoric vs action in small firms. Organization Studies Journal, 26, 63-91.

Cohen, S. B. (2003). The Essential difference: The truth about the male and female brain. New York: Basic Publisher.

Cole, G. A. (2002). Personnel and human resource management. Continnum, 5(22), 291.

Coleman, D., Boyatzis, R. E., \& McKee, A. (2004). Primal leadership. Boston: Harvard Business School Press.

Collins, P. H. (1990). Black feminist thought: Knowledge, conciousness, and the politics of empowerment. New York: Routeledge.

Collins, P. H. (2002). Black feminist thought: Knowledge, conciousness, and the politics of empowerment. New York: Routeledge.

Collins, P. H. (2015) Black feminist thought: Knowledge, conciousness, and the politics of empowerment. Ethnic and Racial Studies, 38(13), 2314-2314.

Commonwealth Local Government Forum. (2016). Samoa: Country profile. Retrieved from www.clgf.org.uk/samoa

Conger, J. A. (1989). Leadership: The art of empowering others. Academy of Management Executive, 3(1), 17-24.

Connelly, L. M., Bott, M., Hoffart, N., \& Taunton, R. L. (1997). Methodological triangulation in a study of nurse retention. Nursing Research, 46(5), 299-302. 
Corbin, J., \& Strauss, A. (2008). Basics of qualitative research: Techniques and procedures for developing grounded theory (3rd ed.). Thousand Oaks, CA: Sage Publications.

Coulthard, G. (2006). Indigenous peoples and the politics of recognition. New Socialist. doi:10.1.1.472.83442rep=rep1.

Counts, G. S. (1951). The central ideological conflict of our time: Educational leadership. Journal of Educational Psychology, 9(4), 128-143.

Covey, S. (1990). The 7 habits of highly effective people. New York: Simon \& Schuster.

Craib, I. (1997). Social constructionism as a social psychosis. Journal of Educational Psychology, 31(4), 1-15.

Creswell, J. W. (1998). Qualitative inquiry and research design: Choosing among five designs. Thousand Oaks, CA: Sage Publications.

Creswell, J. W. (2007). Qualitative inquiry and research design: Choosing among five approaches. Thousand Oaks, CA: Sage Publications.

Creswell, J.W. (2012). Educational research: Planning, conducting, and evaluating quanitative and qualitative research. New York: Pearson Education.

Creswell, J. W., \& Clark, V. L. (2011). Designing and conducting mixed method research (2nd ed.). Thousand Oaks, CA: Sage Publications.

Crocombe, R. (2008). The South Pacific. Suva, Fiji: University of the South Pacific.

Crocombe, R., Neemia, U., Ravavu, A., \& Vom Busch, W. (1992). Culture and democracy in the South Pacific. Suva, Fiji: Institute of Pacific Studies: KIN Publications.

Danesi, M. (1996). What are the implications for second-language teaching? Mosaic, 3(4), 110.

Davidson, J. (1967). Samoa mo Samoa. Melbourne: Oxford University Press.

Davidson, J. (1970). Samoa 1830 to 1900: The politics of a multi-cultural community (Vol. 1). Sydney: Halstead Press.

De Cremer, D. (2006). Effective and motivational consequences of leader self-sacrifice: The moderating effect of autocratic leadership. The Leadership Quarterly, 17(1), 79-93.

De Lauretis, T. (1990). Feminism and its differences. Pacific Coast Philology, 25(1/2), 24-30.

De Vos, A. S. (1998). Research at grass roots: A primer for the caring professions (1st ed.). Pretoria, South Africa: Van Schaik Publishers.

Deaux, K., \& Kite, M. (1993). Gender stereotypes. In F. Denmark \& M. Paludi (Eds.), Handbook on the Psychology of Women (pp. 107-139). New York: Greenwood Press. 
Deihl, J. (1932). The position of woman in Samoan culture (Vol. 5). Washington DC: Institute for Ethnographic Research, The Geroge Washington University,

Denmark, F. L. (1993). Women, leadership, and empowerment. Psychology of Women Quarterly, 17(3), 343-356.

Denzin, N. K. (1978). The research act (2nd ed.). New York: McGraw-Hill.

Denzin, N. K. (1999). Biographical research methods. In J. P. Keeves \& G. Lakomski (Eds.), Issues in educational research (pp. 92-102). Oxford: Elsevier Science.

Denzin, N. K. ( 1970). The research act. Chicago: Aldine.

Denzin, N. K., \& Lincoln, Y. S. (1998). Collecting and interpreting qualitative materials. California: Thousand Oaks.

Dobbins, G., \& Platz, S. (1986). Sex differences in leadership: How real are they? Academy Management Review, 11(1), 18-27.

Dorfman, P. W., Howell, J. P., Hibino, S., Lee, J. K., Tate, U., \& Bautista, A. (1997). Leadership in Western and Asian countries: Commonalities and differences in effective leadership processes across cultures. Leadership Quarterly, 8(3), 233-274.

Dotson, K. (2015) Inheriting Patricia Hill Collins' Black Feminist epistemology. Ethnic and Radical Studies, 38(13).

DuBrin, A. J. (2001). Leadership. London: Mifflin.

Eagly, A., \& Carli, L. (2003). The female advantage: An evaluation of the evidence. The Leadership Quarterly, 14, 807-834.

Eagly, A., \& Johnson, B. (1990). Gender and leadership style. Psychological Bulletin, 108(2), 233-256.

Eagly, A., \& Karau, S. (2002). Role congruity theory of prejudice towards female leaders. Psychological Review, 109(3), 573.

Eagly, A., \& Mladinic, A. (1994). Are people prejudiced against women? Some answers from research on attitudes, gender stereotypes, and judgments of competence. European Review of Social Psychology, 5(12), 35.

Edwards, D., Potter, J., \& Middleton, D. (1992). Towards a discursive psychology of remembering. The Psychologists, 3(12), 441-446.

Edwards, R. (1998). A critical examination of the use of interpreters in the qualitative research process. Journal of Ethnic and Migration Studies, 24, 197-208.

Eisenhardt, K. M. (1989). Building theories from case study research. The Academy of Management Review, 14(4), 532-550. 
Elving, L. (2005). The role of communication in organizational change: Corporate communications. An International Journal, 10(2), 129-138.

Engel, K. (2005). What are three waves of Feminism? In C. Krolokke \& A. S. Sorensen (Eds.), Gender communication theories and analyses: From silence to performance. London: Sage Publications.

Engen, M. L., Leeden, R., \& Willemsen, T. M. (2001). Gender, context, and leadership styles: A field study. Journal of Occupational and Organizational Psychology, 74(5), 581598.

Evans, D. E., \& Ward, P. L. (2007). Management basics for information professionals (2nd ed.). New York: Neal-Schumann Publishers.

Fa'avae, D., Jones, A., \& Manu'atu, L. (2016). Talanoa'i 'a e talanoa: Talking about talanoa. Alternative, 12(2), 139-150. doi:10.20507/AlterNative.2016.12.2.3

Fairbairn-Dunlop, P. (1996). Tamaitai Samoa: Their stories. Suva, Fiji: Institute of Pacific Studies, University of the South Pacific, KIN Publications.

Farrelly, T., \& Nabobo-Baba, U. (2014). Talanoa as empathic apprenticeship. Asia Pacific Viewpoint, 55(3), 319-330. doi:http://doi.org/bd7h

Feinberg, R., \& Watson-Gegeo, K. A. (1996). Leadership and change in the Western Pacific. London: Athlone Press.

Fielding, N. G., \& Fielding, J. L. (1986). Linking data (Vol. 4). Beverly Hill, CA: Sage Publications.

Fito'o, B. (2009). On courage and hope. In K. Sanga \& C. Chu (Eds.), Living and leaving a legacy of hope: Stories by new generation Pacific leaders (pp. 23-39). Wellington: Institute for Research and Development in Maori and Pacific Education, Victoria University of Wellington.

Fletcher, J. K. (1994). Castrating the female advantage. Journal of Management Inquiry, 3(1), 74-82.

Fondas, N. (1997). The origins of ferminization. Academy of Management Review, 22, 257282.

Foster, R. P. (1997). Addressing epistemologic and practical issues in multimethod research: A procedure for conceptual triangulation. Advances in Nursing Science, 20(2), 1-12.

Fox, J., \& Cumberland, K. (1962). Western Samoa. Christchurch, New Zealand: Whitcombe and Tombs.

Fraenkel, J. (2006). The political consequences of Pacific Islands electoral laws. In R. Rich, L. Hambly, \& M. Morgan (Eds.), Political parties in the Pacific Islands (pp. 60-84). Canberra: Pandanus. 
Freire, P. (1983). The pedagogy of the oppressed. New York: Seabury Press.

French, J. R., \& Raven, B. H. (1959). The bases of social power. In D. Cartwright (Ed.), Studies in social power (pp. 150-167). Ann Arbor: University of Michigan Press.

Gardner, H. (1996). Leading minds: An anatomy of leadership. New York: Basic Books.

Gardner, J. W. (1990). On leadership. New York: The Free Press.

Garfinkel, H., \& Englewood, N. J. (1967). Studies in ethnomethology. Cambridge: Polity.

Gegeo, D. W., \& Watson-Gegeo, K. A. (2001). How we know: Kwara'ae rural villagers doing indigenous epistemology. The Comtemporary Pacific, 13(1), 55-88.

Gergen, K. J. (1985). The social constructionist movement in modern psychology. American Psychologist, 40(3), 266-275.

Gergen, K. J. ( 1994). Realities and relationships: Soundings in social constructionism. Cambridge: Harvard University Press.

Getzels, J. W., \& Thelen, H. A. (1960). The classroom group as a social system. In N. B. Henry (Ed.), The dynamics of instructional groups: Sociopsychological aspects of teaching and learning (Vol. 59). Chicago: National Society for the Study of Education.

Gill, R. (2001). Can you teach leadership? Paper presented at the Best Conference Business, Management and Accountancy Education: Maintaining Quality in Changing Times, Windermere, Cubria.

Gilligan, C. (1982). In a different voice: Psychological theory and women's development. Cambridge, UK: Harvard University Press.

Gilson, R. P. (1970). Samoa 1830-1900: The politics of a multi-cultural community. London: Oxford University Press.

Goddard, W., \& Melville, S. (2004). Research methodology: An introduction (2nd ed.). Durban, South Africa: Juta and Company Limited.

Goetz, J. P., \& LeCompte, M. D. (1984). Ethnography and qualitative design in educational research. New York: Academic Press.

Goleman, D. (1995). Emotional intelligence: Why it can matter more than an IQ. London: Bloomsbury.

Graneheim, U. H., \& Lundman, B. (2004). Qualitative content analysis in nursing research: Concepts, procedures, and measures to achieve trustworthiness. Nurse Education Today(24), 105-112.

Grattan, F. J. H. (1985). An introduction to Samoan custom. New Zealand electronic text collection (pp. 10-24). Wellington, New Zealand.: R. McMillan. 
Greene, J. C., \& Caracelli, V. J. (1997). Advances in mixed-method evaluation: The challenges and benefits of integrating diverse paradigms. San Francisco: Jossey-Bass.

Greenleaf, R. K. (1977). Servant leadership: A journey into the nature of legitimate power and greatness. New Yok: Paulist Press.

Greenwald, A. G., Leippe, M. R., Pratkanis, A. R., \& Baumgardner, M. H. (1986). Under what conditions does theory obstruct research progress? Psychological Review, 93(2), 216229.

Grieco, J. (1988). Anarchy and the limits of cooperation: A realist critique of the newest liberal institutionalism. Journal of International Organization, 42(6), 485-507.

Griffen, V. (1989). Women, development, and empowerment. Kuala Lumpur: Asian and Pacific Development Centre.

Griffin, J. (2004). Research on students and museums: Looking more closely at the students in school groups. Science Education, 88(1), 259-270.

Grogan, M. (1998). Feminist approaches to educational leadership. In B. J. Irby \& G. Brown (Eds.), Women leaders: Structuring success. Dubuque, IA: Kendall/Hunt Publishing Co.

Guba, E. G. (1981). Criteria for assessing the trustworthiness of naturalistic inquiries. ERIC( Educational Resource Information Centre), 29(2), 75-91.

Guba, E. G., \& Lincoln, Y. S. (1985). Naturalistic inqiry. Beverly Hills, CA: Sage Publications.

Guba, E. G., \& Lincoln, Y. S. (1994). Competing paradigms in qualitative research. In N. K. Denzin \& Y. S. Lincoln (Eds.), Handbook of qualitative research (pp. 105-117). Thousand Oaks, CA: Sage Publications.

Gunson, N. (1987 ). Sacred women chiefs and female headmen in Polynesian history. Journal of Pacific History, 22(3), 139.

Gustafsson, B. (1992). Houses and ancestors: Continuities and discontinuities in leadership among the Manus. New Haven, Conn: The Institute for Advanced Studies in Social Anthropology, University of Gothenburg.

Haider, H. (2009). Community-based approaches to peace-building in conflict-affected and fragile contexts. Birmingham: Governance and Social Development Resource Centre, University of Birmingham.

Halcomb, E. J., \& Davidson, P. M. (2006). Is verbatim transcription of interview data always necessary? Applied Nursing Research, 19(1), 38-42.

Hammersley, M. (1992). What's wrong with ethnography? London: Routledge. 
Harding, S. (1997). Comment on Hekman's, Truth and Method: Feminist standpoint theory revisited. Whose standpoint needs the regimes of truth and reality? Signs: Journal of Women in Culture and Society, 22(2), 382-391.

Harding, S. (1998). Is science multicultural? Postcolonialisms, feminisms, and epistemologies. Bloomington, IN: Indiana University Press.

Harre, R., \& Gillett, G. (1994). Discursive mind. London: Sage Publications.

Harris, M. (1991). Cultural anthropology (3rd ed.). New York: Harper Collins.

Hartman, M. (1999). Talking leadership: Conversations with powerful women. New Brunswick: Rutgers University Press.

Hassall, G. (2012). Who is leading the Pacific Islands as a region? Canterbury Law Review, $18,5-13$.

Hatch, J. A. (2002). Doing qualitative research in education settings. Albany: State University of New York Press.

Hau'ofa, E. (2008). We are the ocean. Honolulu: University of Hawaii Press.

Heikkurinen, P. (2010). Image differentiation with corporate environmental responsibility. Corporate Social Responsibility and Environmental Management, 17(3), 142-152.

Helgesen, S. (2011). The female advantage. New York: Crown Business.

Helu-Thaman, K. H. ( 1997). Kakala: A Pacific concept of teaching and learning. Paper presented at the Australian College of Education National Conference, Cairns, Australia.

Hempenstall, P., \& Rutherford, N. (1984). Protest and colonial dissent in the colonial Pacific. Suva, Fiji: University of the South Pacific.

Hennings, W. (2007). Big man or businessman? The impact of global development on the nature of Samoan chieftainship. Sociologus, 57(2), 157-175.

Herriott, R. E., \& Firestone, W. A. (1983). Multisite qualitative research: Optimizing description and generalizability. Educational Research Journal, 12(4), 14-19.

Hersey, P. (1985). The situational leader. New York: Warner Books.

Hersey, P., \& Blanchard, K. H. (1988). Management of organizational behavior. Prentice Hall, New Jersey: Englewood Cliffs.

Hien, P. (2010). A comparative study of research capacity of East Asian countries and implications for Viet Nam. Springer Netherlands, 60(6), 615-625. doi:10.1007/s10734010-9319-5 
Hiep, P. (2006). Researching the research culture in English language education in Vietnam. The Electronic Journal for English as a Second Language, 10(2), 1-20.

Hofstede, G. (1980). Culture's consequences. London: Sage Publications.

Hofstede, G. (1993). Cultural constraints in management theories. Academy of Management Executive, 7(1), 81-94.

Hollander, E. P. (1992). Leadership, followership, self and others. Leadership Quarterly, 3(1), 43-54.

Holloway, I., \& Todres, L. (2003). The status of method: Flexibility, consistency, and coherence. Qualitative Research, 3(3), 345-357. doi:10-1177/1468794103033004

Holme, L. D., \& Holme, E. R. (1992). Samoan village: Then and now (2nd ed.). Fort Worth: Harcourt Brace College Publishers.

Holmes, L. (1980). Factors contributing to the cultural stability of Samoa. Anthropological Quarterly, 53(3), 188-197.

Hoobler, J. M., Lemmon, G., \& Wayne, S. J. (2011). Women's under-representation in upper management: New insights on a persistent problem. Organizational Dynamics(40), 151-156.

Huffer, E. (2006). Desk review of the factors which enable and constrain the advancement of women's political representation in forum island countries. Retrieved from: www.forumsec.org

Hughes, K., MacKintosh, A. M., \& Hastings, G. (1997). Young people, alcohol, and designer drinks: A quantitative and qualitative study. British Medical Journal(314), 414-418.

Humm, M. (1995). The dictionary of feminist theory. Columbus: Ohio State University Press.

Hunt, C. (2000). What have we learned about generic competitive strategy? A meta-analysis. Strategic Management Journal, 21(2), 127-154.

Hyun, C., \& Choi, J. (2011). A study on residents' participation and characteristic of cohousing in USA. Journal of the Korean Housing Association, 22(2), 11-20.

Iati, I. (2000). The good governance agenda for civil society: Implications for the fa'aSamoa. In E. Huffer \& A. So'o (Eds.), Governance in Samoa: Pulega i Samoa (pp. 67-77). Canberra: Asia Pacific Press.

Inglehart, R., \& Norris, P. (2000). The development theory of the gender gap: Women's and men's voting behaviour in global perspective. International Political Science Review, 21(4), 441-463.

Isaia, M. (1999). Coming of age in American anthropology: Margaret Mead and paradise. Parkland: Universal Publishers. 
Jackofsky, E. F., Slocum, J. W., \& McQuaid, S. J. (1988). Cultural values and the CEO: Alluring companies? Academy of Management Executive, 2(1), 39-49.

Jago, A. (1982). The transfer of learning to the workplace: A practical study. Journal of European Industrial Training, 6(7), 21-24.

James, K. (1995). Rank overrules everything: Hierarchy, social stratification, and gender in Tonga. In J. Huntsman (Ed.), Tonga and Samoa: Images of gender and polity (pp. 122). Christchurch, New Zealand: Centre for Pacific Studies, Macmillan Brown.

Janda, K. F. (1972). Towards the explication of the concept of leadership in terms of the concept of power. In G. D. Paige (Ed.), Political Leadership (pp. 45-68). New York: Free Press.

Jensen, D. (2008). Transferability. Thousand Oaks, CA: Sage Publications.

Jervis, R. (1988). Realism, game theory, and cooperation. World Politics, 40(4), 340-344.

Jewell, M. (1977). The legislative process in the United States. New York: Random House.

Jick, T. D. (1979). Mixing qualitative and quantitative methods: Triangulation in action. Administrative Science Quarterly, 24, 602-611.

Jill, N. (1974). Matriliny and modernisation: The Nagovisiougnvilie. New Guinea Research Bulletin, 5(3), 55-72.

Johansson Fua, S. (2014). Kakala research framework: A garland in celebration of a decade of rethinking education. In M. 'Otukunu, U. Nabobo-Baba, \& S. Johansson Fua (Eds.), Of waves, winds, and wonderful things: A decade of rethinking Pacific education (pp. 5060). Suva, Fiji: University of the South Pacific Press.

Jones, P. B. (1997). Exploring the limits of Western leadership theory in Asia and Africa. Personnel Review, 26(1-2), 6-23. doi:10.1108/00483489710157760.

Jung, D. I., \& Avolio, B. J. (2000). Opening the black box: An experimental investigation of the mediating effects of trust and value congruence on transformational and transactional leadership. Journal of Organizational Behavior, 21(8), 949-964.

Ka'ili, T. (2005). Tauhi va: Nurturing Tongan sociospatial ties in Maui and beyond. The Contemporary Pacific, 17(1), 83-115.

Kamu, L. (1996). The Samoan culture and the Christian gospel. Apia, Samoa: Government Printing Press.

Kase, L. (2010). Great leaders are great decision-makers. Graziadio Business Review. A Peer Reviewed Journal of Relevant Information and Analysis, 13(4).

Keesing, F. M., \& Keesing, M. M. (1956). Elite communication in Samoa: A study of leadership (Vol. 3). Standford, CA: Standford University Press. 
Kennedy, P. (2009). How to combine multiple research options: Practical triangulation. Better Evaluation Online.

Retrieved from:http://johnnyholland.org/2009/08/20/practical_triangulation.

Kets De Vries, M. F. (1998). Leadership in organizations. International Encyclopedia of the Social and Behavioral Sciences, 26.

Kirk, J., \& Miller, M. (1986). Reliability in qualitative research. Newbury Park, CA: Sage.

Klein, H. (2013). Seeing what others don't: The remarkable ways we gain insights (Vol. 1). New York: Perseus Books Group.

Klein, H., \& Myers, B. (1999). A set of principles for conducting and evaluating interpretive field studies in information systems. Management Information Systems Quarterly, 23(1), 67-88.

Klitgaard, R. (1994). Taking culture into account. In I. Serageldin \& J. Taboroff (Eds.), Culture and development in Africa. Washington, DC: World Bank.

Komives, S. R., Lucas, N., \& McMahon, T. (2006). Taxonomy for followership rooted in the study of leadership. San Francisco, CA: Jossey-Bass.

Kotter, J. P. (1990). A force for change: How leadership differs from management. New York: The Free Press.

Krefting, L. (1990). Rigor in qualitative research:The assessment of trustworthiness. American Journal of Occupational Therapy, 45(3), 214-222.

Krolokke, C., \& Sorensen, A. S. (2005). Gender communication theories and analysis: From silence to performance. London: Sage Publications.

Kuhn, T. S. (1970). The structure of scientific revolutions. International Encyclopedia of Unified Science (Vol. 2). Chicago: University of Chicago Press.

Labuschagne, A. ( 2003). Qualitative researc-airy fairy or fundamental? The Qualitative Report, 8(1), 100.

Lakatos, I. (1970). Falsification and the methodology of scientific research programmes. In I. Lakatos \& A. Musgrave (Eds.), Criticism and the growth of knowledge (pp. 59-89). Cambridge, UK: Cambridge University Press.

Lasswell, H., \& Kaplan, A. ( 1950). Power and society: A framework for political enquiry. New Haven, CT: Yale University Press.

Laudan, L. (1977). Progress and its problems: Towards a theory of scientific growth. Berkeley, CA: University of California Press.

Le Tagaloa, F. (1996). O motuga-afa. Apia, Samoa: Le Lamepa Press. 
Lee Hang, D. (2011). A culturally appropriate formative assessment in Science lessons: Implications for initial science teacher education. (Doctoral dissertation), University of Waikato, Hamilton, New Zealand. Retrieved from http://researchcommons.waikato.ac.nz

Lee, J. (2010). The correlation between leadership and organisational culture influence on employees' job attitude in hotel industry. The Journal of the Korea Contents Association, 10(2), 452-461.

Lewin, K., Lippit, R., \& White, R. K. (1939). Patterns of aggressive behavior in experimentally created social climates. Journal of Social Psychology, 10, 271-301.

Lewis, J. (2016). Feminism definitions: Ideas, beliefs, movements. Women's History. Retrieved from:www.womenhistory.about.com

Lichtenstein, S. (2005). Strategy co-alignment: Strategic, executive values, and organizational goal orientation and their impact on performance. (Unpublished doctoral dissertation). Brunel University, London, United Kingdom.

Lindstrom, L., \& White, G. (1997). Chiefs today: Traditional Pacific leadership and the postcolonial state. California, USA: Stanford University Press.

Locks, G. (1989). Upping the anti in feminist theory. In M. Hirsh \& E. Keller (Eds.), Conflicts in feminism. New York: Routledge.

Lord, R., \& Hall, R. (2005). Identity, deep structure ,and the development of leadership skill. The Leadership Quarterly, 16, 591-615.

Macpherson, C. (1985). Public and private views of home: Will Western Samoans return? Pacific Viewpoint, 26(1), 242-262.

Macpherson, C. (1997). The persistence of chiefly authority in Western Samoa. In G. M. White \& L. Lindstrom (Eds.), Chiefs Today: Traditional Pacific leadership and the postcolonial state (2nd ed., pp. 19-48). Stanford, CA: Stanford University Press.

Macpherson, C., \& Macpherson, L. (2000). Where theory meets practice: The limits of the good governance program. In E. Hugger \& A. So'o (Eds.), Governance in Samoa: Pulega i Samoa (pp. 17-39). Canberra: Asia Pacific Press.

MacQuoid, L. P. (1995). The Women's Mau: Female peace warriors in Western Samoa. (Master of Arts in Pacific Studies), University of Hawaii, Honolulu. Retrieved from http://hdl.handle.net/10125/21186

Mahuika, A. (1992). Leadership: Inherited and achieved. Te Ao Hurihuri. M. King. Auckland, New Zealand: Reed Publishing Group Limited.

Maiava, S. (2001). A clash of paradigms: Intervention, response, and development in the South Pacific. Aldershot, England: Ashgate Publishing Limited.

Makinde, O. (1983). Fundamentals of guidance and counselling. London: MacMillan. 
Malabre, A. (1978). As their ranks swell, women holding jobs reshape US society. The Wall Street Journal, 1, 1-21.

Mallon, S. (2002). Samoan art and artists: O measina a Samoa. Honolulu: University of Hawaii Press.

Manu'atu, L. (2000). Katoanga faiva: A pedagogical site for Tongan students. Educational Philosophy and Theory, 32(1), 73-80. doi:http://doi.org/b6n35g

Martire, K. (2014). Challenges to women in political leadership in Samoa. Independent Study Project (ISP) Collection Paper. Retrieved from http://digitalcollections.sit.edu/isp_collection/1823

Martyn, B. (2006). Practical and ethical issues in planning research. In S. H. Glynis, M. Breakwell, \& J. Fife-Schaw (Eds.), Research methods in psychology (pp.24-48). London: Sage Publications.

Maslow, A. H. (1970). Motivation and personality. New York: Harper \& Row.

Massey, D., Denton, N. (1993). American apartheid: Segregation and the making of the underclass. Cambridge: Harvard University Press.

McCall, M. (2003). Seeking good governance in participatory: A review of processes and governance dimensions to participatory spatial planning. Habitat International, 27(4), 549-573.

McFarland, A. S. (1969). Power and leadership in pluralist systems. Stanford: Stanford University Press.

McLeod, A. (2008). State, society, and governance in Melanesian. Paper presented at the Research School of Pacific and Asian Studies, Canberra, Australian National University.

McNamee, S., \& Shotter, J. (2004). Dialogue, creativity, and change. Dialogue: Theorizing difference in communication studies, 6(22), 91-104.

Mead, M. (1928). Coming of age in Samoa: A psychological study of primitive youth for Western civilisation. New York: William Morrow and Company.

Meaza, A. (2009). Factors affecting women's participation in politics and public decisionmaking in Ethiopia (Vol. 5). Addis Ababa: Forum for Social Studies, Addis Abada University Press.

Meek, V. L. (1992). Organisational culture: Origins and weaknesses. Organization Studies, 9(4), 453-473.

Meleisea, M. (1987). The making of modern Samoa: Traditional authority and colonial administration in the history of Western Samoa. Suva, Fiji: Institute of Pacific Studies, University of the South Pacific. 
Mertens, D. M. (1998). Research methods in education and psychology: Integrating diversity with quantitative and qualitative approaches. Thousand Oaks, CA: Sage Publications.

Miles, M. B., \& Huberman, A. M. (1984). Qualitative data analysis: A sourcebook of new methods. Thousand Oaks, CA: Sage Publications.

Miles, M. B., \& Huberman, A. M. (1994). Qualitative data analysis: An expanded sourcebook. Thousand Oaks, CA: Sage Publications.

Miller, D. (1992). The generic strategy trap. Journal of Business Strategy, 13(1), 37-41.

Milner, G. B. (1966). Samoan dictionary: Samoan-English, English-Samoan. Newton, Auckland: Pasifika Press.

Ministry of Women, Community and Social Development, \& Internal Affairs. (2013-2014). Annual Report. Apia: Government Printing Press.

Ministry of Women, Community and Social Development, \& Internal Affairs. (2016). Local government, Samoa.Retrieved from: www.commonwealthgovernance.org/countries/pacific/samoa/local-government/

Mitchell, D. (1970). Gender communication theories and analyses. In C. Krolokke \& A. S. Sorensen (Eds.), Three waves of feminism: From suffragettes to girls. London: Sage Publications.

Morgan, G. (2004). Women in a man's world: Gender differences in leadership at the military academy. Journal of Applied Psychology, 34(12), 2482-2502.

Morgan, G., \& Smircich, I. (1980). The case for qualitative research. The Academy of Management Review, 5(4), 491-500.

Morrison, S. L., Vaioleti, L. M., \& Veramu, J. (2002). Participatory approaches to learning and training. Nabua, Fiji: Commissioned report for the European Commission, Soqosoqo ni Vakamarama.

Morse, J. M. (1994). Designing funded qualitative research. In N. K. Denzin \& Y. S. Lincoln (Eds.), Handbook of qualitative research. Thousand Oaks, CA: Sage Publications.

Myers, B. (2015). Ideological leadership. Retrieved from http://www.teamtechnology.co.uk/careers//test/jdq/.

Nabobo-Baba, U. (2005). Voices and silences of what and how we know: Indigenous Fijian epistemology and implications for education. (Doctoral dissertation), University of Auckland, Auckland, New Zealand.

Nabobo-Baba, U. (2008). Decolonising framings in Pacific research: Indigenous Fijian Vanua research framework as an organic response. Alternative, 4(2), 141-154.

Nabobo-Baba, U. (2009). Fijian epistemology: Examining aspects of Vugalei cultural pedagogies, processes, and possible futures. In K. Sanga \& K. Helu-Thaman (Eds.), Re- 
thinking education curricula in the Pacific: Challenges and prospects. Wellington: Institute for Research and Development in Maori and Pacific Education, Victoria University of Wellington.

Ngunjiri, F. W., \& Madsen, S. R. (2015). Women as global leaders: Challenges and strategies for getting to the top. Charlotte, NC: Information Age Publishing.

Northouse, P. G. (2004). Leadership: Theory and practice (3rd ed.). Thousand Oaks, CA: Sage Publications.

Northouse, P. G. (2007). Leadership: Theory and practice (4 th ed.). Chicago: Sage Publications.

Nye, J. (1988). Neorealism and neoliberalism. Journal of World Politics, 40(11), 235-251.

Okon, E. (2011). Religion and human rights education. Calabar: University of Calabar Press.

Opdenakker, R. (2006). Advantages and disadvantages of four interview techniques in qualitative research. Qualitative Social Research, 7(4), 11.

Orb, A., Einsenhauer, L., \& Wynaden, D. (2000). Ethics in qualitative research. Journal of Nursing Scholarship, 33(1), 93-96.

Orlikowski, W. J., \& Baroudi, J. J. (1991). Studying information technology in organizations: Research approaches and assumptions. Information Systems Research, 2(1), 1-28.

Ortner, S. (1974). Is female to male as nature is to culture? In M. Rosaldo \& L. Lamphere (Eds.), Woman, culture, and society (pp. 67-82). Standford, CA: Standford University Press.

Otukunu, M. (2011). Talanoa: How can it be used effectively as an indigenous research methodology with Tongan people? Pacific-Asian Education Journal, 23(2), 43-52.

Our Africa. (2016). Status of women. (CB2 1NL). Retrieved 09/06/2016 from http://www.ourafrica.org/contact-us

Owen, I. R. (1990). Re-emphasising a person-centred approach. Counselling, 1(3), 92-94.

Papali'i, A. M. S. (2002). O si manu a Ali'i: Polokalame o le Gagana Samoa. Manoa: University of Hawaii Press.

Patton, M. Q. (1990). Qualitative evaluation and research methods (2nd ed.). Newbury Park, CA: Sage Publications.

Patton, M. Q. (2002). Qualitative research and evaluative methods (3rd ed.). Thousand Oaks, CA: Sage Publications.

Pew Research Center. (2015). Women in leadership: Social and demographic trends. Women and Leadership Newspaper. 
Pfeffer, J., \& Salanick, G. R. (1978). The external control of organizations: A resource dependence perspective. New York: Harper \& Row.

Porat, K. L. (1991). Women in administration: The difference is positive. Clearing House, 64, 412-415. Retrieved from www.wpnet.com/cgi-bin/epwtop/page website:

Pounder, J. S., \& Coleman, M. (2002). Women, better leaders than men? In general and educational management it still all depends. Leadership \& Organization Development Journal, 23(3), 122-133. doi:10.1108/01437730210424066

Prajogo, D. I. (2007). The relationship between competitive strategies and product quality. Industrial Management and Data Systems, 107(1), 69-83.

Pratt, G. (1984). A grammar and dictionary of Samoan language with English and Samoan vocabulary (3rd and revised edition ed.). Papakura, NZ: R. McMillan.

Prescott, S. M. (2008). Using talanoa in Pacific business research in New Zealand: Experiences with Tongan entrepreneurs. Alternative, 4(1), 127-148.

Prichard, S. (2013). 9 qualities of the servant leader. Retrieved from http://www.skipprichard.com/9-qualities-of-the-servant-leader/

Quay, I. L. (2006). Pacific leadership program: International Women's Development Agency. Retrieved from www.plp.org.fj

Quinn, K. M. (2004). Bayesian factor analysis for mixed ordinal and continuous responses. Political Analysis, 12(4), 338-353.

Raelin, J. A. (2005). We are the leaders: In order to form a leaderful organization. Journal of Leadership and Organizational Studies, 12(2), 18-30. doi:10.1177/107179190501200202

Raivoka, M. (2009). Creating opportunities: The village at the university. In K. Sanga \& C. Chu (Eds.), Living and leaving a legacy of hope: Stories by new generation of Pacific leaders (pp. 69-79). Wellington: Institute for Research and Development in Maori and Pacific Education, Victoria University of Wellington.

Ryan, F., Coughlan, M., \& Cronin, P. (2007). Step-by-step- guide to critiquing research. Part 2: Qualitative research. British Journal of Nursing, 16(12), 738-744.

Reeves, S., Albert, A., Kuper, A., \& Hodges, B. D. (2008). Why use theories in qualitative research? British Medical Journal, 337(9), 4-9. doi:http://dx.doi.org/10.1136/bmj.a949

Refiti, A. (2002). Making spaces: Polynesian architecture in Aotearoa, New Zealand. In S. Mallon \& P. F. Pereira (Eds.), Pacific Art Niu Sila: The Pacific dimension of contemporary New Zealand arts (pp. 209-225). Wellington: Te Papa Press.

Richards, J. C., \& Schmidt, R. W. (2014). Language and communication: Applied linguistics and language study (Vol. 4). New York: Routledge, Taylor \& Francis Group. 
Riggio, R. (2010). Cutting edge leadership. Why women make better leaders than men. Psychology Today.

Rimoni, F. (2009). Leadership as tautua: Service to the church. In K. Sanga \& C. Chu (Eds.), Living and leaving a legacy of hope: Stories by new generation Pacific leaders (pp. 5155). Wellington: Institute for Research and Development in Maori and Pacific Education, Victoria University of Wellington.

Ritterbush, D. (1987). Booty, bait, bystander or brains? The woman's role in political change in 18th and 19th century Polynesia. Paper presented at the Concepts and Strategies: Women's studies in different cultural contexts, Honolulu, University of Hawaii.

Ritzer, G., \& Goodman, D. (2004). Symbolic interactionism: Modern sociological theory. Boston: McGraw Hill.

Robinson, D., \& Robinson, K. (2005). Pacific ways of talk: Hui and talanoa. Paper drawn on material from a research project. Social and Civic Policy Institute, Wellington, New Zealand and Council on Public Policy Education, Dayton, Ohio. New Zealand Institute for Economic Research. Wellington, New Zealand.

Rosener, J. (1995). America's competitive secret: Utilizing women as a management strategy. New York: Oxford University Press.

Rost, J. C. (1991). Leadership for the twenty-first century. New York: Praeger.

Rost, J. C. (1995). A discussion about ethics. Business Ethics Quarterly, 5(1), 129-142.

Ruiz-Ortega, M., \& Garcia-Villaverde, M. (2008). Capabilities and competitive tactics influences on performance: Implications of the moment of entry. Journal of Business Research, 61(4), 332-345.

Samala, I. (2009). Rediscovering leadership. In K. Sanga \& C. Chu (Eds.), Living and leaving a legacy of hope: Stories by new generation Pacific leaders (pp. 63-66). Wellington: Institute for Research and Development in Maori and Pacific Education, Victoria University of Wellington.

Samoa Bureau of Statistics. (2011). Population and demography indicator summary. Retrieved from http://www.sbs.gov.ws/index.php/population-demography-and-vital-statistics.

Samoa Bureau of Statistics. (2015). Population and demography indicator summary. Retrieved from http://www.sbs.gov.ws/index.php/population-demography-and-vital-statistics.

Samoa Millennium Development Goals Progress Report (2010). Retrieved from: www.indexmundi.com/samoa/millennium-development-goals.html

Samoa State of the Environment Report. (2013). Apia: Ministry of Natural Resource and Environment. 
Samoa Women Empowerment Project Report. (2015). Progressive report on vocational education training program for women in the rural villages of Samoa. (2). Apia: Maali Company.

Sandelowski, M. (1995). Focus on qualitative methods. Qualitative analysis: What it is and how to begin. Research in Nursing \& Health(18), 371-375.

Sandelowski, M. (2000). Focus on research methods: Whatever happened to qualitative description? Research in Nursing \& Health, 23(4), 334-340.

Sanga, K. (2005). Pacific Leadership: Hopeful and hoping. Paper presented at the Pacific Regional Workshop on Leadership Development, Suva, Fiji, University of the South Pacific.

Sanga, K., \& Chu, C. (2009). Living and leaving a legacy of hope: Stories by new generation Pacific leaders. Wellington: Institute for Research and Development in Maori and Pacific Education, Victoria University of Wellington.

Sanga, K., \& Walker, K. D. (2005). Apem moa: Solomon Islands leadership. Wellington: Institute for Research and Development in Maori and Pacific Education, Victoria University of Wellington.

Saolotoga, F. S. M. (1995). Feminism and the changing roles of women in society and the church in Samoa. Masters Thesis. Suva, Fiji: Pacific Theological College.

Schein, V. E. (1973). The relationship between sex role stereotypes and requisite management characteristics. Journal of Applied Psychology, 57, 95-100.

Schein, V. E. (2001). A global look at psychological barriers to women's progress in management. Journal of Social Issues, 57(4), 675-688.

Schoeffel, P. (1979). Daughters of Sina: A study of gender, status, and power in Western Samoa. (Unpublished dissertation). Australian National University, Canberra, Australia.

Schoeffel, P. (1995). The Samoan concept of feagaiga and its transformation. In J. Huntsman (Ed.), Tonga and Samoa: Images of gender and polity (pp. 85-105). Christchurch: Macmillan Brown Centre for Pacific Studies, University of Canterbury.

Schoeffel, P. (Producer). (2015). Interpretations of tradition that hold back Samoan women leaders.Retrieved from: http://www.radionnz.co.nz/international/programmes/datelinepacific/audio/20176238 2/

Schultz, E. (1980). Samoan proverbial expressions: Alaga'upu fa'a-Samoa. Ponsonby, Auckland: Polynesian Press.

Schwandt, T. A. (1994). Constructivist and interpretist approaches to human inquiry. In N. K. Denzin \& Y. S. Lincoln (Eds.). Thousand Oaks, CA: Sage Publications. 
Schwandt, T. A. (2003). Three epistemological stances for qualitative inquiry: Interpretivism, hermeneutics, and social constructionism. In N. K. Denzin \& Y. S. Lincoln (Eds.), The landscape of qualitative research: Theories and issues (pp. 292-331). CA, USA: Sage Publications.

Schwanke, D. A. (2013). Barriers for women to positions of power: How societal and corporate structures, perceptions of leadership, and discrimination restrict women's advancement to authority. Earth Common Journal, 3(2), 1-2.

Schwepker, C., \& Schultz, R. (2015). Influence of the ethical servant leader and ethical climate on customer value enhancing sales performance. Journal of Personal Selling and Sales Management, 35(2), 93-107.

Seeley, D. S. (1992). Visionary leaders for reforming public schools. Issues about Change, 2(3), 24-26.

Sergiovanni, T. (1991). Moral leadership: Getting to the heart of school reform. San Francisco: Jossey-Bass.

Shenton, A. K. (2004). Strategies for ensuring trustworthiness in qualitative research projects. Education for Information, 22(2), 63-75.

Shields, C., \& Sayani, A. (2005). Leading in the midst of diversity: The challenge of our times. In F. English (Ed.), The SAGE Handbook of Educational Leadership (pp. 380-402). Thousand Oaks, CA: Sage Publications.

Shon, T. (1998). Role of women in Samoan society: The sacred convenant. South Pacific Commision Women in Fisheries Information Bulletin, 2.

Sier, M. (1999). Indigenous rights and women's rights in the Samoan Baha'i community. Baha'i Studies Review, 9.

Silipa, R. (2008). Punavai o le Malamalama: Spring of illumination. Canterbury, NZ: Macmillan Brown.

Simpson, R. (1997). Have times changed? Career barriers and the token woman manager. British Journal of Management, 8(1), 121-130.

Smith, A. (2005). Native American feminism, sovereignty, and social change. Feminist Studies, 31(1), 116-132. doi:10.2307/20459010

Smith, I. (2005). Achieving readiness for organizational change. Library Management, 26(6/7), 408-412. doi:http://dx.doi.org/10.1108/0413510623764

Smith, P. B., Misumi, J., Tayeb, M., Peterson, M., \& Bond, M. (1989). On the generality of leadership styles measures across cultures. Journal of Occupational Psychology, 62(2), 97-109.

Smith, P. B., \& Peterson, M. F. (1988). Leadership, organizations, and culture: An event management model. Beverly Hills, CA: Sage Publications. 
Smyth, R. B. (1878). The aborigines of Victoria (Vol. 2). Melbourne: Government Printer.

Southon, P. (2009). To you, my precious gift. In K. Sanga \& C. Chu (Eds.), Living and leaving a legacy of hope: Stories by new generation Pacific leaders (pp. 43-49). Wellington: Institute for Research and Development in Maori and Pacific Education, Victoria University of Wellington.

Sowell, T. (2000). Worn with pride: Celebrating Samoan artistic heritage. Oceanside, CA: Oceanside Museum of Art.

Spears, L. C. (2010). Character and servant leadership: Ten characteristics of effective, caring leaders. The Journal of Virtues and Leadership, 1(1), 25-30.

Spillane, J. (2004). Distributed leadership: What's all the hoopla? Illinois: Institute for Policy Research, Northwestern University.

Spradley, J. P. (1979). The ethnographic interview. New York: Holt, Rinehart \& Winston.

Stake, R. E. (2005). Multiple case study analysis (1st ed.). New York: The Guilford Press.

Stander, M. W., \& Rothmann, S. (2010). Psychological empowerment, job insecurity, and employee engagement. Journal of Industrial Psychology, 36(1), 8. doi:10.4102/sajip.v36i1.849

Stanfield, A. W. (2009). Defining effective leadership. Mustang, Oklahoma: Tate Publishing \& Enterprises, LLC.

Steedman, M. (2000). The syntactic process. Cambridge: MIT Press.

Stogdill, R. M. (1974). A survey of theory and research. Handbook of Leadership. New York: The Free Press.

Taisi, T. A. T. T. (2009). Su'esu'e manogi: In search of fragrance. Apia, Samoa: Government Printing Press, Ministry of Women, Community, Social Development and Internal Affairs.

Tamasese, K., Peteru, C., Waldegrave, C., \& Bush, A. (2005). O le taeao afua, the new morning: A qualitative investigation into Samoan perspectives on mental health and culturally appropriate services. Australian and New Zealand Journal of Psychiatry, 39, 300-309.

Taufe'ulungaki, A. (2009). Tongan values in education: Some issues and questions. In K. Sanga \& K. Helu-Thaman (Eds.), Re-thinking education curricula in the Pacific: Challenges and prospects. Wellington: Institute for Research and Development in Maori and Pacific Education, Victoria University of Wellington.

Taylor, C. (1995). Philosophy and human sciences: Philosophical Paper 2. Cambridge: Cambridge University Press. 
Tcherkesoff, S. (2000). The Samoan category matai (Chief): A singularity in Polynesian? Historical and etymological comparative queries. The Journal of Polynesian Society, 109(2), 151-190.

Te'o, T. (2011). An account of Samoan history up to 1918. New Zealand Electronic Text Collection. Wellington, N.Z.: New Zealand Electronic Text Centre.

Teaero, T. (2009). Curriculum policies and framework in the context of Pacific values: A veiw from Kiribati. In K. Sanga \& K. Helu-Thaman (Eds.), Re-thinking education curricula in the Pacific: Challenges and prospects. Wellington: Institute for Research and Development in Maori and Pacific Education, Victoria University of Wellington.

Techera, E. J. (2006). Samoa: Law, custom, and conservation. New Zealand Journal of Environmental Law, 10, 361-379.

Terborg, J. (1977). Women in management: A research review. Journal of Applied Psychology, 62(6), 647.

Terrell, M. C. (1998). The progress of colored women. Washington, DC: Smith Brothers Printers.

Toleafoa, A. F. (2007). A changing fa'amatai and implications for governance. In A. So'o (Ed.), Changes in the matai system (pp. 207-228). Apia, Samoa: Centre for Samoan Studies,

National University of Samoa.

Tong, R. (1989). Feminist thought. San Francisco, CA: Westview Press.

Triandis, H. C. (1993). Cross-cultural industrial and organizational psychology. In M. Dunnette \& L. Hough (Eds.), Handbook of Industrial and Organizational Psychology (Vol. 4, pp. 103-172). Alto, CA: Consulting Psychologists Press.

Tuagalu, I. (2008). The heuristics of the va. Alternative: An International Journal of Indigenous Peoples, 4(1), 107-126.

Tucket, A. G. (2005). Applying thematic analysis theory to practice: A researcher's experience. Contemporary Nurse Journal, 19, 75-87.

Turner, G. (1884). Samoa, a hundred years ago and long before. Papakura, New Zealand: Southern Reprints.

Turner, W. B. (1999). The learning of love: A journey towards servant leadership. Macon, GA: Smyth and Helwys Publishers.

Va'a, U. (2000). Local government in Samoa and the search for balance. In E. Huffer \& A. So'o (Eds.), Governance in Samoa: Pulega i Samoa (pp. 151-169). Canberra: Asia Pacific Press.

Vaioleti, T. (2006). Talanoa research methodology: A developing position on Pacific research. Waikato Journal of Education(12), 21-34. 
Valentine, E. R. (1982). Conceptual issues in psychology. London: Allen \& Unwin.

Vali, K. S. (2010). Women leading in silence in Papua New Guinea higher education. (Master's thesis). University of Waikato, Hamilton, New Zealand.

Van Dijk, T. (2006). Ideology and discourse analysis. Journal of Political Ideologies, 11(2), 115-140. doi:10.1080/13569310600687908

Vecchio, R. P. (2002). Leadership and gender advantage. The Leadership Quarterly, 13(6), 643-671.

Villaverde, L.E. (2008). Feminist theories and education: Primer. New York: Peter Lang Publishing Incoporation.

Vojta \& Associates. (2010). Consultants in human performance management. TargetYou ${ }^{\mathrm{TM}_{-}}$a technology-based retention strategy tool. Stamford, CT: Vojta \& Associates Press.

Vunariri, D. (2009). From reluctance to advocacy: Are there more like me out there? In K. Sanga \& C. Chu (Eds.), Living and leaving a legacy of hope: Stories by new generation Pacific leaders (pp. 57-66). Wellington: Institute for Research and Development in Maori and Pacific Education, Victoria University of Wellington.

Walker, A. (1972). Womanist is to feminist as purple is to lavender. In C. Krolokke \& A. S. Sorensen (Eds.), Gender communication theories and analyses. London: Sage Publications.

Walker, A. (1983). In search of our mothers' gardens. New York: Harcourt, Brace Jovanovick.

Wang, X. (2012). The construction of researcher-researched relationships in school enthnography: Doing research participating in the field and reflecting on ethical dilemmas. International Journal of Qualitative Studies in Education, 26(7), 763-779.

Webb, E., Campbell, D., Schwartz, R., \& Sechrest, L. (1996). Unobtrusive measures: Nonreactive research in the Social Sciences. Chicago: IL Rand McNally.

West-Burnham, J. (2003). Educational leadership and the community. In T. Gelsthorpe \& West-Burnham (Eds.), Strategies for school improvement through community engagement (pp. 1-14). London: Pearson Education.

White, G. M., \& Lindstrom, L. (1997). Chiefs today: Traditional Pacific leadership and the post-colonial state. California: Stanford University Press.

White, H. D., \& McCain, K. W. (1998). Visualizing a discipline: An author co-citation analysis of information science, 1972-1995. Journal of the American Society of Information Science, 49(4), 327-355.

Wiersma, W., \& Jurs, S. (2005). Research methods in education: An introduction (9th ed.). Boston: Pearson/Allyn and Bacon. 
Wijnen, E., \& Wildschutt, M. (2015). Narrating goals: A case study on the contribution of digital storytelling to cross-cultural leadership development. Sports in Society, 18(8), 938-951.

Wilfred, H., \& Paulus, J. (1994). Making common sense: Leadership and meaning-making in a community of practice, issues, and observations. Center for Creative Leadership, 21(6), 44-62.

Williamson, R. W. (2013). The social and political systems of Central Polynesia (Vol. 2). London: Cambridge University Press.

Wolfensberger, W. (1967). Counselling the parents of the retarded In A. A. Baumeister (Ed.), Mental retardation: Appraisal, education, and rehabilitation (pp. 329-400). Chicago: Aldine.

Wright, L. (2009). The universal qualities of effective leadership. Security Magazine, 46(10), 30 .

Yamin, S., Mavondo, F., Gunasekaran, A., \& Sarros, J. C. (1997). A study of competitive strategy, organisational innovation, and organisational performance among Australian manufacturing companies. International Journal of Production Economics, 52(1-2), 161-172.

Yin, R. K. (1994). Case study research: Design and methods (2nd ed.). Thousand Oaks, CA: Sage Publications.

Yin, R. K. (2009). Case study research: Design and methods (4th ed.). Thousand Oaks, CA: Sage Publications.

Yin, R. K. (2011). Qualitative research from start to finish. New York: Guilford Press.

Yukl, G. A. (2002). Leadership in organizations (5th ed.). Upper Saddle River, N.J: PrenticeHall International. 


\title{
APPENDICES
}

\section{APPENDIX A}

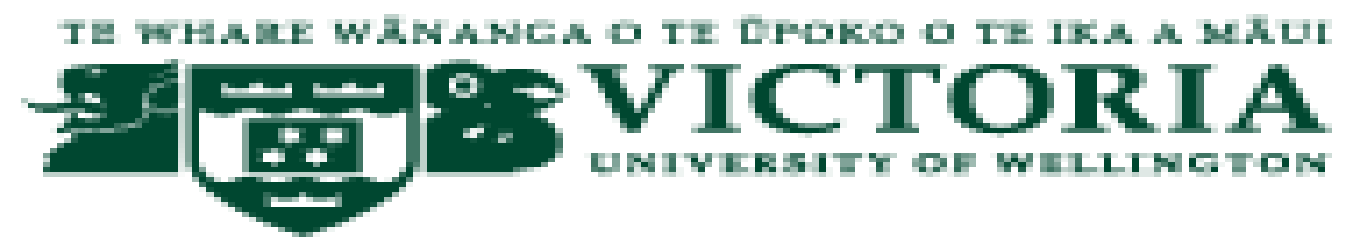

\section{Research Information Sheet}

(To be given to the participants)

\section{Thesis Title: Women's leadership in traditional villages of Samoa: The cultural challenges}

\author{
Researcher: Silia Pa'usisi Finau \\ Faculty of Education \\ Victoria University of Wellington
}

\section{Dear Madam}

I am a doctoral student at Victoria University of Wellington in New Zealand. As part of this degree I am required to conduct a research leading to a thesis. My thesis aims to explore the Samoan women in villages and how they exercise their leadership roles.

I would like to invite you to participate in this study. I highly appreciate your participation and believe that your cooperation will be very valuable in providing crucial information for this research. If you agree to participate in this study, you will be interviewed for a period of one hour. The interview will be audio-recorded and a transcription will be presented to your good-self after two weeks for verification purposes. The interview is about the social and cultural challenges that prevent Sāmoan women from being positional leaders. It will also explore the strategies Sāmoan women use to serve as leaders as well as examining the social and cultural beliefs and perceptions that inform Sāmoan women leadership. Most importantly, it will scrutinize the leadership context for Sāmoan women in their villages.

The interviews will be recorded to enable me to transcribe and analyse the data at a later stage in the research. I will contact interviewees personally to set up a convenient time for the interview sessions. Due to the nature of the research framework employed in this study, I will hold three scheduled meetings with each participant to ensure the completion of the research cycle. Following the interviews are the observations of the village activities your good-selves engage in. These observations will be arranged at a time convenient to you. 
Participants' identity and confidentiality will be protected at all stages of the study. All research findings reported will remain confidential. Any information related to participants' identity will remain confidential to the researcher (and her supervisors). You will not be identified by name in any reports of the completed study. You will be sent a copy of your interview transcripts for verification, review and clarification. Data collected will be destructed after 5 years of the project's completion.

The research findings will be published in academic or professional journals. It will also be disseminated at academic or professional conferences. The research paper or thesis will be deposited in the University Library and Institutional Repository. During your participation, if you feel hesitant or uneasy you may decline to answer any specific questions or withdraw from this research at any time with no harm at all.

I confirm that the study will strictly adhere to the Human Ethics Policy promulgated by the Victoria University of Wellington. This research has been approved by the Human Ethics Committee, Faculty of Education at Victoria University of Wellington.

If you agree to participate in this project, please go through this information sheet carefully before signing the attached consent form. Should you have any queries, please do not hesitate to contact me at 0211038471 or email me at: Silia.Finau@vuw.ac.nz.

You can also contact my supervisors, Dr. Cherie Chu at Cherie.Chu@vuw.ac.nz or Dr. Lex McDonald at Lex.McDonald@vuw.ac.nz for further information about the project.

Yours sincerely,

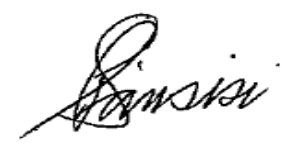

Silia Pa'usisi Finau 


\section{APPENDIX B}

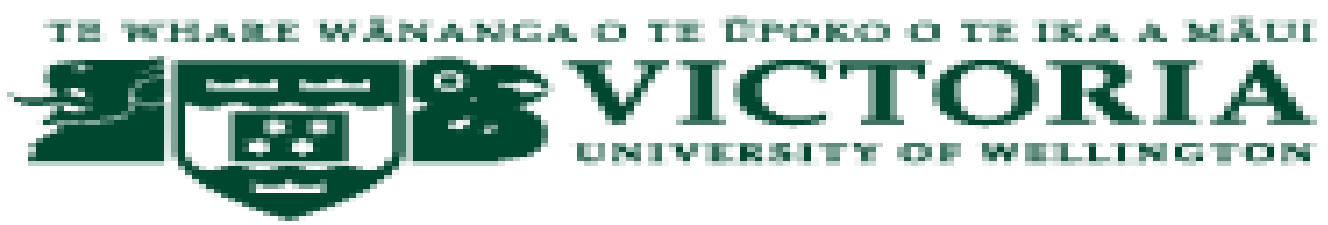

\section{Consent to participate in research: Audio-recorded interview}

Title of project: Women's leadership in traditional villages of Samoa: The cultural challenges.

\section{Surname:}

Given name(s):

Matai title:

\section{Village/Distric/Island:}

I have been given information about this research and have understood the explanation of this research project. I have had an opportunity to ask questions and have them answered to my satisfaction.

I understand that I may withdraw myself (or any information I have provided) from this research (before data collection and analysis is complete) with no need to give reasons or without penalty of any kind.

I understand that any information I provide will be kept confidential by the researcher, the supervisors, the published results will not use my name, and that no opinions will be attributed to me in any way that will identify me.

I would like to receive feedback on the findings of this research.

I have given my consent to be involved in this project.

Participant's Signature: Date:

(The participant will be given a copy to keep after signing this form) 


\section{APPENDIX C}

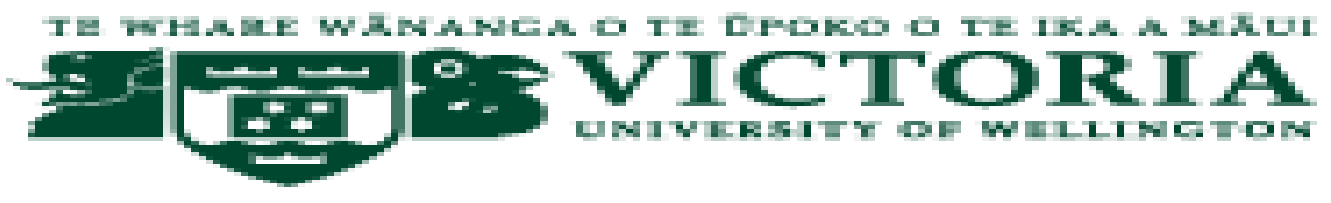

\section{Consent to participate in research- Observation (Tick the box on the right hand side after reading the explanations)}

Title of project: Women's leadership in traditional village of Samoa: The cultural challenges

\section{Surname and given name:}

\section{Matai title:}

\section{Village/District/Island:}

Telephone:(optional): Address (optional):

I have been given information about this research and I have understood the explanation of this research project. I have had an opportunity to ask questions and have them answered to my satisfaction.

I understand that I may withdraw myself (or any information I have provided) from this research (before data collection and analysis is complete) with no need to give reasons or without penalty of any kind.

I understand that any information I provide will be kept confidential to the researcher, the supervisors, the published results will not use my name, and that no opinions will be attributed to me in any way that will identify me.

I would like to receive feedback on the findings of this research.

I have given my consent to the researcher to collect observational data on a time and date time suitable for me.

Participant's signature: Date: 


\section{APPENDIX D}

\section{CODES AND DEFINITIONS}

\begin{tabular}{|c|c|}
\hline Code & Definition \\
\hline 1. CCK & $\begin{array}{l}\text { Having no or not enough cultural knowledge to present oratory } \\
\text { speeches in cultural ceremonies. }\end{array}$ \\
\hline 2. CNBM & $\begin{array}{l}\text { The village rules of not allowing women to be bestowed with } \\
\text { matai titles and not recognising their participation in village council } \\
\text { meetings. }\end{array}$ \\
\hline 3. CAR & $\begin{array}{l}\text { The allocation of roles to men and women widens the gap in } \\
\text { leadership status. Men lead and women work from behind the scene. }\end{array}$ \\
\hline 4. CTML & $\begin{array}{l}\text { The think male think leader mentality that is entrenched in the } \\
\text { culture and accepted by the majority, and enforced by male leaders. }\end{array}$ \\
\hline 5. COHS & $\begin{array}{l}\text { The hierarchical structure of traditional village societies which } \\
\text { categorise matai as the supreme rulers and women leaders as second } \\
\text { in rank. }\end{array}$ \\
\hline 6. $\mathrm{COFH}$ & $\begin{array}{l}\text { Claiming the father as the head of the family and the leaders at } \\
\text { the same time. }\end{array}$ \\
\hline 7. CORB & $\begin{array}{l}\text { Religious beliefs influence people's perception of a leader. For } \\
\text { example, the Biblical teaching that the father is the head of the family } \\
\text { impacts heavily on people's preference for leaders. }\end{array}$ \\
\hline 8. COCE & $\begin{array}{l}\text { The cash economy -family income are in most cases controlled } \\
\text { by men. Therefore, they are leaders in the sense that they either budget } \\
\text { money for family obligations, or work in a paid job while the women } \\
\text { attend to household chores. }\end{array}$ \\
\hline 9. COA & $\begin{array}{l}\text { Husbands sometimes beat up their wives, or the in-laws are not } \\
\text { treated fairly by the sisters of their husbands. }\end{array}$ \\
\hline 10. COW & $\begin{array}{l}\text { The acceptance of the western idea of leadership since male } \\
\text { leadership was only introduced by missionaries and colonial powers. } \\
\text { Before Samoa's contact with outside influence, leadership had been } \\
\text { matriarchal in the times of Queens. }\end{array}$ \\
\hline 11. COMW & $\begin{array}{l}\text { Women matai are a minority, as they only make up } 10 \% \text { of the } \\
\text { matai population. }\end{array}$ \\
\hline
\end{tabular}




\begin{tabular}{|c|c|}
\hline 12. COMT & $\begin{array}{l}\text { Women are leaders of modern organisations such as ministries, } \\
\text { private entities, and non-governmental organisations, but that total } \\
\text { population is not translated to leadership in local government. }\end{array}$ \\
\hline 13. COTV & $\begin{array}{l}\text { Traditional village communities and local government or } \\
\text { village councils are patriarchal. }\end{array}$ \\
\hline 14. CORB & $\begin{array}{l}\text { The majority of leadership positions in churches are held by } \\
\text { men. Women can only occupy those positions if they are a widow or } \\
\text { single. }\end{array}$ \\
\hline 15. CONR & $\begin{array}{l}\text { Women do not have a voice in local government and cannot } \\
\text { represent themselves in village council meetings. }\end{array}$ \\
\hline 16. COPV & $\begin{array}{l}\text { Samoans are always preventive of the va tapuia- the space } \\
\text { between people and relationships. Therefore, people think that it is not } \\
\text { appropriate for male and female relatives to discuss fragile issues } \\
\text { together in a village council meeting. }\end{array}$ \\
\hline 17. COS & $\begin{array}{l}\text { Women are silently discouraged to participate in meetings of } \\
\text { the village council. }\end{array}$ \\
\hline 18. COEX & $\begin{array}{l}\text { Male matai always bring excuses of convenience to discourage } \\
\text { women from attending local government. }\end{array}$ \\
\hline 19. COOW & $\begin{array}{l}\text { There are women who prefer to become subordinate since they } \\
\text { cannot carry out the roles and responsibilities of a leader. }\end{array}$ \\
\hline 20. COD & $\begin{array}{l}\text { Many of the women's cultural activities were deplored by } \\
\text { missionaries, so their leadership status was diminished at the same } \\
\text { time. }\end{array}$ \\
\hline 21.COC & $\begin{array}{l}\text { Most churches do not allow women to hold leadership } \\
\text { positions unless they have matai titles. }\end{array}$ \\
\hline 22. $\mathrm{COO}$ & $\begin{array}{l}\text { The three main line churches of the Congregational Christian } \\
\text { Church, Catholic and Methodist do not ordain women priests. }\end{array}$ \\
\hline 23. COINR & $\begin{array}{l}\text { The introduction of new roles for women is very hard to } \\
\text { change now. For example, the wives of the missionaries taught women } \\
\text { to cook for their husbands and their families, while before, it was the } \\
\text { men who cook for their sisters as their feagaiga. }\end{array}$ \\
\hline 25. COAR & $\begin{array}{l}\text { The social assumption that assigns women to household chores } \\
\text { disadvantage women from becoming leaders. }\end{array}$ \\
\hline
\end{tabular}




\begin{tabular}{|c|c|}
\hline 26. CRW & $\begin{array}{l}\text { Women are informally discouraged to sit in village council } \\
\text { meetings. }\end{array}$ \\
\hline 27. CONC & $\begin{array}{l}\text { Some women are not confidence to becoming leaders and } \\
\text { don't see themselves fit for village councils. }\end{array}$ \\
\hline 28. COD & $\begin{array}{l}\text { Missionaries deplored the women's cultural activities such as } \\
\text { visiting other communities (Malaga), dancing, and entertaining guests. }\end{array}$ \\
\hline 29. COGI & $\begin{array}{l}\text { The church is progressing in other countries of the world but } \\
\text { very conservative in Samoa, and has a lot of gender inequality issues. }\end{array}$ \\
\hline $\begin{array}{l}30 . \\
\text { COWPA }\end{array}$ & $\begin{array}{l}\text { Women's political aspirations are affected by systems and } \\
\text { male authority. }\end{array}$ \\
\hline 31.COCC & $\begin{array}{l}\text { The culture of cargo cult where necessities are stored in bulk } \\
\text { made women the keeper of these things, and therefore have no time to } \\
\text { become leaders. }\end{array}$ \\
\hline 32. COFV & $\begin{array}{l}\text { Foreign values were passed on to Samoans through teaching } \\
\text { as the pastors taught the people how to read and write. }\end{array}$ \\
\hline 33. COM & $\begin{array}{l}\text { Missionaries introduced a trust mandate government which is } \\
\text { now adopted by churches, local and national governments. }\end{array}$ \\
\hline 34. COPS & $\begin{array}{l}\text { The concept of male leadership is ingrained in our political } \\
\text { system, which results in men creating barriers for aspiring women } \\
\text { leaders. }\end{array}$ \\
\hline 35. WAH & $\begin{array}{l}\text { Women are household attendees, home carers who should stay } \\
\text { home to look after the old people and children, as well as the welfare } \\
\text { of the family. }\end{array}$ \\
\hline 36. TR & $\begin{array}{l}\text { The way people talk to each other shows the respect for status. } \\
\text { Eg: the respect language is for matai, and everyday language is for } \\
\text { women and children. }\end{array}$ \\
\hline 37. IAS & $\begin{array}{l}\text { The identity is another challenge. It's about what I think of } \\
\text { people and what other people think about me too. }\end{array}$ \\
\hline 38. LTP & $\begin{array}{l}\text { The loyalty of people to one another is obvious in the } \\
\text { relationship of people and the matai. The servants such as the untitled } \\
\text { men and women are very loyal in maintaining the status quo. }\end{array}$ \\
\hline
\end{tabular}




\begin{tabular}{|c|c|}
\hline 39. CVA & $\begin{array}{l}\text { The cultural values that restrict women from leadership } \\
\text { positions is all in context. That is, the level of leadership people hold } \\
\text { has to be in the Samoan context. }\end{array}$ \\
\hline 40. SAL & $\begin{array}{l}\text { Social assumption about the meaning of leadership came from } \\
\text { somewhere else. Not from the Samoan culture. }\end{array}$ \\
\hline 41. SCC & $\begin{array}{l}\text { There are so many social changes that influence and change } \\
\text { some cultural values, but not the male leadership mentality. }\end{array}$ \\
\hline 42. SAOG & $\begin{array}{l}\text { Women are assumed to be gossiping, and the gossiping attitude } \\
\text { disqualifies women from leadership opportunities. }\end{array}$ \\
\hline 43. DOF & The division of roles discriminate tasks of men and women. \\
\hline 44. DAOO & $\begin{array}{l}\text { There are different settings where men and women operate in. } \\
\text { (e.g., leadership is men, and services is women). }\end{array}$ \\
\hline 45. VOR & $\begin{array}{l}\text { Women are still influenced by the cultural value of respect, } \\
\text { which stops them from accessing matai titles, and querying the } \\
\text { leadership of their male relatives. }\end{array}$ \\
\hline 46. DOR & $\begin{array}{l}\text { There is the general belief that there are things which women } \\
\text { can do, and there are also things which they cannot do. For men, they } \\
\text { can do anything, especially holding leadership positions. }\end{array}$ \\
\hline 47. MABL & $\begin{array}{l}\text { The general feeling in most people is that men are better } \\
\text { leaders. }\end{array}$ \\
\hline 48. EAAS & $\begin{array}{l}\text { Economics as a subject was introduced by the wives of } \\
\text { missionaries, and now Samoan women cook for their husbands } \\
\text { whereas in the past, it was the brothers and male relatives who cook } \\
\text { for their sisters and female relatives. }\end{array}$ \\
\hline 49.COS & $\begin{array}{l}\text { The other challenge for Samoan women is themselves and } \\
\text { their understanding of their identity, heritage and values. }\end{array}$ \\
\hline 50. WNR & $\begin{array}{l}\text { Women must reflect on the things their ancestors did in the } \\
\text { past, and therefore be able to know what they are capable of doing. }\end{array}$ \\
\hline 51. ROE & $\begin{array}{l}\text { Women need to reflect on education that was introduced to our } \\
\text { country where there was no restriction for girls to be educated. }\end{array}$ \\
\hline 52. CM & $\begin{array}{l}\text { There are so many confusing messages about education and } \\
\text { about western values of education that influence people's perception } \\
\text { for leadership. }\end{array}$ \\
\hline
\end{tabular}




\begin{tabular}{|c|c|}
\hline 53. CCP & $\begin{array}{l}\text { The contradicting leadership style introduced by missionaries } \\
\text { influence the esteemed status of the Tamaitai Samoa. }\end{array}$ \\
\hline 54. COM & $\begin{array}{l}\text { The change of mentality about leadership affects women's } \\
\text { leadership as the original form of leadership in Samoa before outside } \\
\text { influence. }\end{array}$ \\
\hline 55. NUOTT & $\begin{array}{l}\text { Leaders in general do not have any understanding of the } \\
\text { Transformational Theory which states that women and men have the } \\
\text { same leadership attributes. }\end{array}$ \\
\hline 56. PITM & $\begin{array}{l}\text { Politics is strictly in tendency towards males everywhere in the } \\
\text { society and churches. }\end{array}$ \\
\hline 57. MDSW & $\begin{array}{l}\text { Generally, men leaders do not support women to become } \\
\text { leaders as they do not want to compromise their leadership status. }\end{array}$ \\
\hline 58. OWAC & $\begin{array}{l}\text { Other women who prefer to remain as subordinates and give } \\
\text { their support to male to hold leadership posts. }\end{array}$ \\
\hline 59. WSIF & $\begin{array}{l}\text { The status of women in the family is assumed to be lower than } \\
\text { the men. }\end{array}$ \\
\hline 60. NGR & $\begin{array}{l}\text { In some traditional villages, females do not hold the position } \\
\text { of government officials. }\end{array}$ \\
\hline 61. BT & $\begin{array}{l}\text { Most of the teachings of the Bible about the head as the head } \\
\text { of the family affects women's chances for leadership. }\end{array}$ \\
\hline 62. RP & $\begin{array}{l}\text { The respect the general public have for pastors who are all } \\
\text { males influence their perception of a leader. }\end{array}$ \\
\hline 63. NWP & $\begin{array}{l}\text { No woman is ordained as a pastor in the three mainline } \\
\text { churches of the Congregational Christian Church, Methodist and } \\
\text { Catholic. }\end{array}$ \\
\hline 64. NWL & $\begin{array}{l}\text { Only a few or no woman holds a leadership position in any of } \\
\text { the mainline churches unless they are a widow, or title holder. }\end{array}$ \\
\hline $65 . \mathrm{WO}$ & $\begin{array}{l}\text { Women's organisations are the driving forces in supporting } \\
\text { churches. Therefore, men prefer women to play that active role, and } \\
\text { leave the leadership arena to them. }\end{array}$ \\
\hline 66.WACP & $\begin{array}{l}\text { Women are aware of the hierarchical leadership structure and } \\
\text { cultural protocols, and therefore serve the community through their } \\
\text { talents as servant leaders. }\end{array}$ \\
\hline
\end{tabular}




\begin{tabular}{|c|c|}
\hline 67.SWL & $\begin{array}{l}\text { There are strong women leaders who are well educated \& have } \\
\text { moved up the leadership ladder in village communities. }\end{array}$ \\
\hline 68. WLC & Women leaders counsel families, especially victims of abuse \\
\hline 69. WLGF & $\begin{array}{l}\text { Women leaders groom and nurture young members of } \\
\text { women's committees to become leaders. }\end{array}$ \\
\hline 70. WLPS & $\begin{array}{l}\text { Services provided by women are through weaving and making } \\
\text { handicrafts, child rearing, income-generating businesses, and some } \\
\text { work fulltime. }\end{array}$ \\
\hline 71. WBW & $\begin{array}{l}\text { Most women budget family income wisely. They are aware } \\
\text { that they only have limited money and resources, so they budget } \\
\text { according to the cash on hand and the available resources. }\end{array}$ \\
\hline 72.WPBS & $\begin{array}{l}\text { Women are planners behind the scene, organising and } \\
\text { implementing activities for the betterment of the village. }\end{array}$ \\
\hline 73. WUVD & $\begin{array}{l}\text { Women upgrade and maintain village developments and } \\
\text { community projects. }\end{array}$ \\
\hline 74. WSMM & $\begin{array}{l}\text { Women are superior to men in terms of moral judgements and } \\
\text { progressive attitudes. }\end{array}$ \\
\hline 75. WBFC & $\begin{array}{l}\text { John Williams documented that it was women who built the } \\
\text { very first church in Samoa. A sign of perseverance and determination } \\
\text { of the Nuu o Tamaitai. }\end{array}$ \\
\hline 76. WHSQ & $\begin{array}{l}\text { Women possess spiritual qualities from their ancestors that } \\
\text { allow them to perform actively in families and villages. Eg: ositaulaga, } \\
\text { taulasea. }\end{array}$ \\
\hline 77. WPRW & $\begin{array}{l}\text { Women play their roles with high esteem and dignity. This is } \\
\text { proven by all the tasks that are successfully done in village } \\
\text { communities. }\end{array}$ \\
\hline 78. WAL & $\begin{array}{l}\text { Women are leaders in their own right since they are active in } \\
\text { families, women's committees, churches, and villages. }\end{array}$ \\
\hline 79. WAS & Women always serve to the best of their abilities. \\
\hline 80. WPK & $\begin{array}{l}\text { Women are peace-keepers. They harmonise people and } \\
\text { feguard relationships in organisations and village communities. }\end{array}$ \\
\hline
\end{tabular}




\begin{tabular}{|c|c|}
\hline 81. WDWF & $\begin{array}{l}\text { Women leaders dominate the middle and top management } \\
\text { level of government ministries, private entities, and non-governmental } \\
\text { organisations. }\end{array}$ \\
\hline 82. WAC & $\begin{array}{l}\text { Women are seen to be cooperative, interactive, and group- } \\
\text { oriented not only in the women's organisations, but also in } \\
\text { organisations they belong to. }\end{array}$ \\
\hline 83. WAL & $\begin{array}{l}\text { Women are positional leaders such as principals, nurses, } \\
\text { lawyers, Chief Executive officers, and Court Judges. }\end{array}$ \\
\hline 84. WADL & $\begin{array}{l}\text { Women believe that they are 'doing leaders' by getting } \\
\text { involved in activities of families, churches, and villages. }\end{array}$ \\
\hline 85. WAHL & $\begin{array}{l}\text { Women are strong leaders who make just decisions, are hard } \\
\text { to manipulate, and always consider people. }\end{array}$ \\
\hline 86.WATAC & $\begin{array}{l}\text { Women leaders believe that they do things on a transparent } \\
\text { basis, are responsible and accountable for the decisions they make. }\end{array}$ \\
\hline 87.WTLP & $\begin{array}{l}\text { Wives of chiefs and orators are supposed to hold leadership } \\
\text { positions in women's organisations. Eg: women's committees. }\end{array}$ \\
\hline 88.WCML & $\begin{array}{l}\text { Women's chance of holding matai titles is very limited as } \\
\text { respect must be given to males to become matai title holders. }\end{array}$ \\
\hline 89. WIID & $\begin{array}{l}\text { Women must be involved in ensuring that the village is clean, } \\
\text { the church is well maintained as well as other communal places in the } \\
\text { village. }\end{array}$ \\
\hline 90. WLAM & $\begin{array}{l}\text { Women leaders are a minority. Therefore, they need to leave } \\
\text { the administration of the village to male leaders. }\end{array}$ \\
\hline 91. TRSB & $\begin{array}{l}\text { The traditional ranking system is good, so there is no need for } \\
\text { change. The idea of matai to become leaders in entrenched as it is } \\
\text { culturally appropriate. }\end{array}$ \\
\hline 92. WAS & $\begin{array}{l}\text { Women are supposed to be subordinates to align with the } \\
\text { saying: "Behind a strong man is a strong woman". }\end{array}$ \\
\hline 93. HWC & $\begin{array}{l}\text { The original practice of honouring the daughters of high chiefs } \\
\text { and talking orators is now ceremonial. Therefore, the right of those } \\
\text { women to leadership is currently compromised, decreased and } \\
\text { gradually fading. }\end{array}$ \\
\hline
\end{tabular}




\begin{tabular}{|c|c|}
\hline 94. IOL & $\begin{array}{l}\text { The interpretation of leadership is generally male. So, women } \\
\text { must play other roles such as doing domestic chores, child rearing, and } \\
\text { looking after old people in the household. }\end{array}$ \\
\hline 95.KOCBM & $\begin{array}{l}\text { Males are more prominent in understanding the culture, so they } \\
\text { are fitting leaders. Women cannot do that properly. }\end{array}$ \\
\hline 96. CCB & $\begin{array}{l}\text { The changes in cultural beliefs does not influence people's } \\
\text { preference for male leaders. }\end{array}$ \\
\hline 97. WKO & $\begin{array}{l}\text { Women must be kept out of decision making forums because } \\
\text { they are not strong in making hard decisions. They are only good in } \\
\text { giving advice. }\end{array}$ \\
\hline 98. WASC & $\begin{array}{l}\text { The women's advices are either considered or rejected, but the } \\
\text { final decision comes from males. Therefore, males are usually proper } \\
\text { leaders. }\end{array}$ \\
\hline 99. PBML & $\begin{array}{l}\text { Most people believe in male leaders although there are many } \\
\text { effective women leaders out there. }\end{array}$ \\
\hline 100. PADV & $\begin{array}{l}\text { People are divided in viewing men and women as leaders and } \\
\text { their appropriateness in holding leadership positions. However, the } \\
\text { preference for male leaders is predominant. }\end{array}$ \\
\hline 101. PMIH & $\begin{array}{l}\text { The ingrained notion of male leadership is very hard to } \\
\text { challenge as the society has been controlled by males since } 1830 \text {. }\end{array}$ \\
\hline 102. GRIE & $\begin{array}{l}\text { The government representation in traditional village } \\
\text { communities is gender balance as both genders has a representative. } \\
\text { However, this does not change people's support for male leaders. }\end{array}$ \\
\hline 103. NWM & $\begin{array}{l}\text { Although there are more women than men in churches, male } \\
\text { dominate the leadership arena because the majority hold matai titles, } \\
\text { which eligible them to occupy leadership posts. }\end{array}$ \\
\hline 104.MWL & $\begin{array}{l}\text { There are more women leaders in government ministries, } \\
\text { private sector, and non-government organisations, but that number is } \\
\text { not translated into local government. }\end{array}$ \\
\hline 105. SCP & $\begin{array}{l}\text { The social and cultural perspectives are the basis to work from, } \\
\text { and these social assumptions and cultural perspectives about women } \\
\text { affect their chance for leadership posts. }\end{array}$ \\
\hline
\end{tabular}




\begin{tabular}{|c|c|}
\hline 106. WSUC & $\begin{array}{l}\text { The general population in village communities think that } \\
\text { women when they become matai can do whatever they want to do } \\
\text { when they have the power. Therefore, it would be better for them not } \\
\text { to get involved in decision-making. }\end{array}$ \\
\hline 107.LWWC & $\begin{array}{l}\text { Leadership for women is based on the role they play in } \\
\text { women's committees. }\end{array}$ \\
\hline 108. WIL & $\begin{array}{l}\text { Leadership for some women is supporting their husbands who } \\
\text { are leaders. }\end{array}$ \\
\hline 109.WAHL & $\begin{array}{l}\text { Women believe that they are already leaders in their capacities } \\
\text { as daughters of high chiefs and talking orators who run and administer } \\
\text { the affairs of the sub-village of female descendants. }\end{array}$ \\
\hline 110. LPBP & $\begin{array}{l}\text { A leader is someone who puts the basic things in place. Eg: } \\
\text { organising the children, tasks, and people in the family on their daily } \\
\text { routine. }\end{array}$ \\
\hline 111. LPIC & $\begin{array}{l}\text { A leader is someone who can present issues and challenges } \\
\text { surrounding people in the community, and someone who cares for the } \\
\text { community. }\end{array}$ \\
\hline 112. WTL & $\begin{array}{l}\text { Most of the women believe in themselves as transparent and } \\
\text { accountable leaders. }\end{array}$ \\
\hline 113. LSSS & $\begin{array}{l}\text { Leadership should start from somewhere like the family, and } \\
\text { extends to other spheres such as the local and national governments. }\end{array}$ \\
\hline 114. WNL & $\begin{array}{l}\text { Women are natural leaders because they drive every single } \\
\text { development in the family, and extends to the church and the village. }\end{array}$ \\
\hline 115. WSL & $\begin{array}{l}\text { Women are successful leaders in all sorts of avenues they } \\
\text { engage in (e.g., income-generating, planning, organising, } \\
\text { implementing, crafting, and traditional healing). }\end{array}$ \\
\hline 116. LIAP & $\begin{array}{l}\text { Women believe that leadership is inherited and predetermined. } \\
\text { So, both males and females have equal rights to family leadership, as } \\
\text { well as other leadership posts in the church and the village. }\end{array}$ \\
\hline 117. LISAP & $\begin{array}{l}\text { Leadership to most women is about participation and } \\
\text { contribution. If you don't participate in village activities and can't } \\
\text { contribute, then you cannot be a leader. }\end{array}$ \\
\hline
\end{tabular}




\begin{tabular}{|c|c|}
\hline 118. GWFL & $\begin{array}{l}\text { There is a lot of ground work needed to make people } \\
\text { understand about the importance of gender equality in leadership in } \\
\text { Samoa. }\end{array}$ \\
\hline 119. LIAT & Leadership is about togetherness, team work, and connections. \\
\hline 120. WAPO & $\begin{array}{l}\text { Women are people-oriented, so they will make good leaders if } \\
\text { they are given a chance to do so. }\end{array}$ \\
\hline 121. WMC & $\begin{array}{l}\text { Women can easily make connections to anyone as they are } \\
\text { non-hierarchical, a good characteristic of a leader. }\end{array}$ \\
\hline 122. LSR & $\begin{array}{l}\text { Leadership is standing for what is considered right, and many } \\
\text { women leaders do that. }\end{array}$ \\
\hline 123. LIG & $\begin{array}{l}\text { Leadership in Samoa is genderless, as the constitution of the } \\
\text { independent state of Samoa says that all heirs, male or female are } \\
\text { entitled to holding matai titles of their respective families. }\end{array}$ \\
\hline 124. LIO & $\begin{array}{l}\text { Leadership is an obligation to serve people and putting their } \\
\text { needs first. }\end{array}$ \\
\hline 125. LID & $\begin{array}{l}\text { Leadership in Samoa is supposed to be democratic, not } \\
\text { autocratic. }\end{array}$ \\
\hline
\end{tabular}




\section{PATTERNS}

\section{Pattern One:}

\section{Cultural challenges that restrict women from leadership positions in local government of} traditional village communities.

\begin{tabular}{|c|c|}
\hline $\begin{array}{l}\text { Code } \\
\text { Number }\end{array}$ & Definition \\
\hline 1 & $\begin{array}{l}\text { Having no or not enough cultural knowledge to present oratory } \\
\text { speeches in cultural ceremonies. }\end{array}$ \\
\hline 2 & $\begin{array}{l}\text { The village rules of not allowing women to be bestowed with matai } \\
\text { titles and not recognising their participation in village council meetings. }\end{array}$ \\
\hline 4 & $\begin{array}{l}\text { The think male think leader mentality that is entrenched in the } \\
\text { culture and accepted by the majority, and enforced by male leaders. }\end{array}$ \\
\hline 5 & $\begin{array}{l}\text { The hierarchical structure of traditional village societies which } \\
\text { categorise matai as the supreme rulers and women leaders as second in rank. }\end{array}$ \\
\hline 10 & $\begin{array}{l}\text { The acceptance of the western idea of leadership since male } \\
\text { leadership was only introduced by missionaries and colonial powers. Before } \\
\text { Samoa's contact with outside influence, leadership had been matriarchal in } \\
\text { the times of Queens. }\end{array}$ \\
\hline 11 & $\begin{array}{l}\text { Women matai are a minority, as they only make up } 10 \% \text { of the matai } \\
\text { population. }\end{array}$ \\
\hline 12 & $\begin{array}{l}\text { Women are leaders of modern organisations such as ministries, } \\
\text { private entities, and non-governmental organisations, but that total } \\
\text { population is not translated to leadership in local government. }\end{array}$ \\
\hline 13 & $\begin{array}{l}\text { Traditional village communities and local government or village } \\
\text { councils are patriarchal. }\end{array}$ \\
\hline 15 & $\begin{array}{l}\text { Women do not have a voice in local government and cannot } \\
\text { represent themselves in village council meetings. }\end{array}$ \\
\hline 16 & $\begin{array}{l}\text { Samoans are always preventive of the va tapuia- the space between } \\
\text { people and relationships. Therefore, people think that it is not appropriate }\end{array}$ \\
\hline
\end{tabular}




\begin{tabular}{|c|c|}
\hline & $\begin{array}{l}\text { for male and female relatives to discuss fragile issues together in a village } \\
\text { council meeting. }\end{array}$ \\
\hline 17 & $\begin{array}{l}\text { Women are silently discouraged to participate in meetings of the } \\
\text { village council. }\end{array}$ \\
\hline 18 & $\begin{array}{l}\text { Male matai always bring excuses of convenience to discourage } \\
\text { women from attending local government. }\end{array}$ \\
\hline 26 & Women are informally discouraged to sit in village council meetings. \\
\hline 30 & $\begin{array}{l}\text { Women's political aspirations are affected by systems and male } \\
\text { authority. }\end{array}$ \\
\hline 34 & $\begin{array}{l}\text { The concept of male leadership is ingrained in our political system, } \\
\text { which results in men creating barriers for aspiring women leaders. }\end{array}$ \\
\hline 36 & $\begin{array}{l}\text { The way people talk to each other shows the respect for status (e.g., } \\
\text { the respect language is for matai, and everyday language is for women and } \\
\text { children). }\end{array}$ \\
\hline 38 & $\begin{array}{l}\text { The loyalty of people to one another is obvious in the relationship of } \\
\text { people and the matai. The servants such as the untitled men and women are } \\
\text { very loyal in maintaining the status quo. }\end{array}$ \\
\hline 39 & $\begin{array}{l}\text { The cultural values that restrict women from leadership positions is } \\
\text { all in context. That is, the level of leadership people hold has to be in the } \\
\text { Samoan context. }\end{array}$ \\
\hline 43 & The division of roles discriminate tasks of men and women. \\
\hline 44 & $\begin{array}{l}\text { There are different settings where men and women operate in (e.g., } \\
\text { leadership is men, and services is women). }\end{array}$ \\
\hline 45 & $\begin{array}{l}\text { Women are still influenced by the cultural value of respect, which } \\
\text { stops them from accessing matai titles, and querying the leadership of their } \\
\text { male relatives. }\end{array}$ \\
\hline 46 & $\begin{array}{l}\text { There is the general belief that there are things which women can do, } \\
\text { and there are also things which they cannot do. For men, they can do } \\
\text { anything, especially holding leadership positions. }\end{array}$ \\
\hline 47 & The general feeling in most people is that men are better leaders. \\
\hline 49 & $\begin{array}{l}\text { The other challenge for Samoan women is themselves and their } \\
\text { understanding of their identity, heritage and values. }\end{array}$ \\
\hline
\end{tabular}




\begin{tabular}{|c|c|}
\hline 54 & $\begin{array}{l}\text { The change of mentality about leadership affects women's } \\
\text { leadership as the original form of leadership in Samoa before outside } \\
\text { influence. }\end{array}$ \\
\hline 56 & $\begin{array}{l}\text { Politics is strictly in tendency towards males everywhere in the } \\
\text { society and churches. }\end{array}$ \\
\hline 57 & $\begin{array}{l}\text { Generally, men leaders do not support women to become leaders as } \\
\text { they do not want to compromise their leadership status. }\end{array}$ \\
\hline 59 & $\begin{array}{l}\text { The status of women in the family is assumed to be lower than the } \\
\text { men. }\end{array}$ \\
\hline 60 & $\begin{array}{l}\text { In some traditional villages, females do not hold the position of } \\
\text { government officials. }\end{array}$ \\
\hline 63 & $\begin{array}{l}\text { No woman is ordained as a pastor in the three mainline churches of } \\
\text { the Congregational Christian Church, Methodist and Catholic. }\end{array}$ \\
\hline 73 & $\begin{array}{l}\text { Women upgrade and maintain village developments and community } \\
\text { projects. }\end{array}$ \\
\hline 79 & Women always serve to the best of their abilities. \\
\hline 84 & $\begin{array}{l}\text { Women believe that they are 'doing leaders' by getting involved in } \\
\text { activities of families, churches, and villages. }\end{array}$ \\
\hline 88 & $\begin{array}{l}\text { Women's chance of holding matai titles is very limited as respect } \\
\text { must be given to males to become matai title holders. }\end{array}$ \\
\hline 89 & $\begin{array}{l}\text { Women must be involved in ensuring that the village is clean, the } \\
\text { church is well maintained as well as other communal places in the village. }\end{array}$ \\
\hline 90 & $\begin{array}{l}\text { Women leaders are a minority. Therefore, they need to leave the } \\
\text { administration of the village to male leaders. }\end{array}$ \\
\hline 91 & $\begin{array}{l}\text { The traditional ranking system is good, so there is no need for } \\
\text { change. The idea of matai to become leaders in entrenched as it is culturally } \\
\text { appropriate. }\end{array}$ \\
\hline 92 & $\begin{array}{l}\text { Women are supposed to be subordinates to align with the saying: } \\
\text { "Behind a strong man is a strong woman". }\end{array}$ \\
\hline 93 & $\begin{array}{l}\text { The original practice of honouring the daughters of high chiefs and } \\
\text { talking orators is now ceremonial. Therefore, the right of those women to } \\
\text { leadership is currently compromised, decreased and gradually fading. }\end{array}$ \\
\hline
\end{tabular}




\begin{tabular}{|c|c|}
\hline 94 & $\begin{array}{l}\text { The interpretation of leadership is generally male. So, women must } \\
\text { play other roles such as doing domestic chores, child rearing, and looking } \\
\text { after old people in the household. }\end{array}$ \\
\hline 95 & $\begin{array}{l}\text { Males are more prominent in understanding the culture, so they are } \\
\text { fitting leaders. Women cannot do that properly. }\end{array}$ \\
\hline 96 & $\begin{array}{l}\text { The changes in cultural beliefs does not influence people's } \\
\text { preference for male leaders. }\end{array}$ \\
\hline 97 & $\begin{array}{l}\text { Women must be kept out of decision making forums because they } \\
\text { are not strong in making hard decisions. They are only good in giving } \\
\text { advice. }\end{array}$ \\
\hline 98 & $\begin{array}{l}\text { The women's advices are either considered or rejected, but the final } \\
\text { decision comes from males. Therefore, males are usually proper leaders. }\end{array}$ \\
\hline 99 & $\begin{array}{l}\text { Most people believe in male leaders although there are many } \\
\text { effective women leaders out there. }\end{array}$ \\
\hline 100 & $\begin{array}{l}\text { People are divided in viewing men and women as leaders and their } \\
\text { appropriateness in holding leadership positions. However, the preference for } \\
\text { male leaders is predominant. }\end{array}$ \\
\hline 101 & $\begin{array}{l}\text { The ingrained notion of male leadership is very hard to challenge as } \\
\text { the society has been controlled by males since } 1830 \text {. }\end{array}$ \\
\hline 102 & $\begin{array}{l}\text { The government representation in traditional village communities is } \\
\text { gender balance as both genders has a representative. However, this does not } \\
\text { change people's support for male leaders. }\end{array}$ \\
\hline 104 & $\begin{array}{l}\text { There are more women leaders in government ministries, private } \\
\text { sector, and non-government organisations, but that number is not translated } \\
\text { into local government. }\end{array}$ \\
\hline 106 & $\begin{array}{l}\text { The general population in village communities think that women } \\
\text { when they become matai can do whatever they want to do when they have } \\
\text { the power. Therefore, it would be better for them not to get involved in } \\
\text { decision-making. }\end{array}$ \\
\hline 107 & $\begin{array}{l}\text { Leadership for women is based on the role they play in women's } \\
\text { committees. }\end{array}$ \\
\hline 108 & $\begin{array}{l}\text { Leadership for some women is supporting their husbands who are } \\
\text { leaders. }\end{array}$ \\
\hline
\end{tabular}




\section{Pattern Two:}

Social assumptions that affect women's chances for leadership positions in local government.

\begin{tabular}{|c|c|}
\hline $\begin{array}{l}\text { Code } \\
\text { Number }\end{array}$ & Definition \\
\hline 8 & $\begin{array}{l}\text { The cash economy -family income are in most cases controlled by men. } \\
\text { Therefore, they are leaders in the sense that they either budget money for } \\
\text { family obligations, or work in a paid job while the women attend to household } \\
\text { chores. }\end{array}$ \\
\hline 9 & $\begin{array}{l}\text { Husbands sometimes beat up their wives, or the in-laws are not treated } \\
\text { fairly by the sisters of their husbands. }\end{array}$ \\
\hline 19 & $\begin{array}{l}\text { There are women who prefer to become subordinate since they cannot } \\
\text { carry out the roles and responsibilities of a leader. }\end{array}$ \\
\hline 20 & $\begin{array}{l}\text { Many of the women's cultural activities were deplored by missionaries, } \\
\text { so their leadership status was diminished at the same time. }\end{array}$ \\
\hline 25 & $\begin{array}{l}\text { The social assumption that assigns women to household chores } \\
\text { disadvantage women from becoming leaders. }\end{array}$ \\
\hline 27 & $\begin{array}{l}\text { Some women are not confidence to becoming leaders and don't see } \\
\text { themselves fit for village councils. }\end{array}$ \\
\hline 35 & $\begin{array}{l}\text { Women are household attendees, home carers who should stay home to } \\
\text { look after the old people and children, as well as the welfare of the family. }\end{array}$ \\
\hline 41 & $\begin{array}{l}\text { There are so many social changes that influence and change some } \\
\text { cultural values, but not the male leadership mentality. }\end{array}$ \\
\hline 42 & $\begin{array}{l}\text { Women are assumed to be gossiping, and the gossiping attitude } \\
\text { disqualifies women from leadership opportunities. }\end{array}$ \\
\hline 46 & $\begin{array}{l}\text { There is the general belief that there are things which women can do, } \\
\text { and there are also things which they cannot do. For men, they can do anything, } \\
\text { especially holding leadership positions. }\end{array}$ \\
\hline 58 & $\begin{array}{l}\text { Other women who prefer to remain as subordinates and give their } \\
\text { support to male to hold leadership posts. }\end{array}$ \\
\hline 62 & $\begin{array}{l}\text { The respect the general public have for pastors who are all males } \\
\text { influence their perception of a leader. }\end{array}$ \\
\hline
\end{tabular}




\begin{tabular}{|c|c|}
\hline 88 & $\begin{array}{l}\text { Women's chance of holding matai titles is very limited as respect must } \\
\text { be given to males to become matai title holders. }\end{array}$ \\
\hline 90 & $\begin{array}{l}\text { Women leaders are a minority. Therefore, they need to leave the } \\
\text { administration of the village to male leaders. }\end{array}$ \\
\hline 93 & $\begin{array}{l}\text { The original practice of honouring the daughters of high chiefs and } \\
\text { talking orators is now ceremonial. Therefore, the right of those women to } \\
\text { leadership is currently compromised, decreased and gradually fading. }\end{array}$ \\
\hline 94 & $\begin{array}{l}\text { The interpretation of leadership is generally male. So, women must play } \\
\text { other roles such as doing domestic chores, child rearing, and looking after old } \\
\text { people in the household. }\end{array}$ \\
\hline 95 & $\begin{array}{l}\text { Males are more prominent in understanding the culture, so they are } \\
\text { fitting leaders. Women cannot do that properly. }\end{array}$ \\
\hline 97 & $\begin{array}{l}\text { Women must be kept out of decision making forums because they are } \\
\text { not strong in making hard decisions. They are only good in giving advice. }\end{array}$ \\
\hline 100 & $\begin{array}{l}\text { People are divided in viewing men and women as leaders and their } \\
\text { appropriateness in holding leadership positions. However, the preference for } \\
\text { male leaders is predominant. }\end{array}$ \\
\hline 104 & $\begin{array}{l}\text { There are more women leaders in government ministries, private sector, } \\
\text { and non-government organisations, but that number is not translated into local } \\
\text { government. }\end{array}$ \\
\hline 105 & $\begin{array}{l}\text { The social and cultural perspectives are the basis to work from, and } \\
\text { these social assumptions and cultural perspectives about women affect their } \\
\text { chance for leadership posts. }\end{array}$ \\
\hline 107 & $\begin{array}{l}\text { Leadership for women is based on the role they play in women's } \\
\text { committees. }\end{array}$ \\
\hline 108 & $\begin{array}{l}\text { Leadership for some women is supporting their husbands who are } \\
\text { leaders. }\end{array}$ \\
\hline
\end{tabular}


Pattern Three:

Religious beliefs that influence people's preference for leaders.

\begin{tabular}{|c|c|}
\hline $\begin{array}{l}\text { Code } \\
\text { Number }\end{array}$ & Definition \\
\hline 6 & Claiming the father as the head of the family and the leaders at the same \\
\hline 7 & $\begin{array}{l}\text { Religious beliefs influence people's perception of a leader. For } \\
\text { example, the Biblical teaching that the father is the head of the family impacts } \\
\text { heavily on people's preference for leaders. }\end{array}$ \\
\hline 14 & $\begin{array}{l}\text { The majority of leadership positions in churches are held by men. } \\
\text { Women can only occupy those positions if they are a widow or single. }\end{array}$ \\
\hline 21 & $\begin{array}{l}\text { Most churches do not allow women to hold leadership positions unless } \\
\text { they have matai titles. }\end{array}$ \\
\hline 22 & $\begin{array}{l}\text { The three main line churches of the Congregational Christian Church, } \\
\text { Catholic and Methodist do not ordain women priests. }\end{array}$ \\
\hline 23 & $\begin{array}{l}\text { The introduction of new roles for women is very hard to change now. } \\
\text { For example, the wives of the missionaries taught women to cook for their } \\
\text { husbands and their families, while before, it was the men who cook for their } \\
\text { sisters as their feagaiga. }\end{array}$ \\
\hline 28 & $\begin{array}{l}\text { Missionaries deplored the women's cultural activities such as visiting } \\
\text { other communities (Malaga), dancing, and entertaining guests. }\end{array}$ \\
\hline \multirow[t]{2}{*}{29} & $\begin{array}{l}\text { The church is progressing in other countries of the world but very } \\
\text { conservative in Samoa, and has a lot of gender inequality issues. }\end{array}$ \\
\hline & $\begin{array}{l}\text { Women's political aspirations are affected by systems and male } \\
\text { authority. }\end{array}$ \\
\hline 31 & $\begin{array}{l}\text { The culture of cargo cult where necessities are stored in bulk made } \\
\text { women the keeper of these things, and therefore have no time to become } \\
\text { leaders. }\end{array}$ \\
\hline 32 & $\begin{array}{l}\text { Foreign values were passed on to Samoans through teaching as the } \\
\text { pastors taught the people how to read and write. }\end{array}$ \\
\hline 33 & $\begin{array}{l}\text { Missionaries introduced a trust mandate government which is now } \\
\text { adopted by churches, local and national governments. }\end{array}$ \\
\hline
\end{tabular}




\begin{tabular}{|c|c|}
\hline 48 & $\begin{array}{r}\text { Economics as a subject was introduced by the wives of missionaries, } \\
\text { and now Samoan women cook for their husbands whereas in the past, it was } \\
\text { the brothers and male relatives who cook for their sisters and female relatives. }\end{array}$ \\
\hline 53 & $\begin{array}{r}\text { The contradicting leadership style introduced by missionaries influence } \\
\text { the esteemed status of the Tamaitai Samoa. }\end{array}$ \\
\hline 61 & $\begin{array}{r}\text { Most of the teachings of the Bible about the head as the head of the } \\
\text { family affects women's chances for leadership. }\end{array}$ \\
\hline 63 & $\begin{array}{r}\text { Nongregational Christian Church, Methodist and Catholic. } \\
\text { Only a few or no woman holds a leadership position in any of the } \\
\text { mainline churches unless they are a widow, or title holder. }\end{array}$ \\
\hline 65 & $\begin{array}{l}\text { Women's organisations are the driving forces in supporting churches. } \\
\text { Therefore, men prefer women to play that active role, and leave the leadership } \\
\text { arena to them. }\end{array}$ \\
\hline 103 & $\begin{array}{l}\text { Although there are more women than men in churches, male dominate } \\
\text { the leadership arena because the majority hold matai titles, which eligible them } \\
\text { to occupy leadership posts. }\end{array}$ \\
\hline
\end{tabular}




\section{Pattern Four:}

Samoan women leaders' perception of leadership

\begin{tabular}{|c|c|}
\hline $\begin{array}{l}\text { Code } \\
\text { Number }\end{array}$ & Definition \\
\hline 3 & $\begin{array}{l}\text { The allocation of roles to men and women widens the gap in leadership } \\
\text { status. Men lead and women work from behind the scene. }\end{array}$ \\
\hline 17 & $\begin{array}{l}\text { Women are silently discouraged to participate in meetings of the village } \\
\text { council. }\end{array}$ \\
\hline 18 & $\begin{array}{l}\text { Male matai always bring excuses of convenience to discourage women } \\
\text { from attending local government. }\end{array}$ \\
\hline 25 & $\begin{array}{l}\text { The social assumption that assigns women to household chores } \\
\text { disadvantage women from becoming leaders. }\end{array}$ \\
\hline 26 & Women are informally discouraged to sit in village council meetings. \\
\hline 36 & $\begin{array}{l}\text { The way people talk to each other shows the respect for status (e.g., the } \\
\text { respect language is for matai, and everyday language is for women and } \\
\text { children). }\end{array}$ \\
\hline 37 & $\begin{array}{l}\text { The identity is another challenge. It's about what I think of people and } \\
\text { what other people think about me too. }\end{array}$ \\
\hline 39 & $\begin{array}{l}\text { The cultural values that restrict women from leadership positions is all } \\
\text { in context. That is, the level of leadership people hold has to be in the Samoan } \\
\text { context. }\end{array}$ \\
\hline 40 & $\begin{array}{l}\text { Social assumption about the meaning of leadership came from } \\
\text { somewhere else. Not from the Samoan culture. }\end{array}$ \\
\hline 50 & $\begin{array}{l}\text { Women must reflect on the things their ancestors did in the past, and } \\
\text { therefore be able to know what they are capable of doing. }\end{array}$ \\
\hline 51 & $\begin{array}{l}\text { Women need to reflect on education that was introduced to our country } \\
\text { where there was no restriction for girls to be educated. }\end{array}$ \\
\hline 52 & $\begin{array}{l}\text { There are so many confusing messages about education and about } \\
\text { western values of education that influence people's perception for leadership. }\end{array}$ \\
\hline 54 & $\begin{array}{l}\text { The change of mentality about leadership affects women's leadership } \\
\text { as the original form of leadership in Samoa before outside influence. }\end{array}$ \\
\hline
\end{tabular}




\begin{tabular}{|c|c|}
\hline 55 & $\begin{array}{l}\text { Leaders in general do not have any understanding of the } \\
\text { Transformational Theory which states that women and men have the same } \\
\text { leadership attributes. }\end{array}$ \\
\hline 57 & $\begin{array}{l}\text { Generally, men leaders do not support women to become leaders as } \\
\text { they do not want to compromise their leadership status. }\end{array}$ \\
\hline 62 & $\begin{array}{l}\text { The respect the general public have for pastors who are all males } \\
\text { influence their perception of a leader. }\end{array}$ \\
\hline 67 & $\begin{array}{l}\text { There are strong women leaders who are well educated } \& \text { have moved } \\
\text { up the leadership ladder in village communities. }\end{array}$ \\
\hline 71 & $\begin{array}{l}\text { Most women budget family income wisely. They are aware that they } \\
\text { only have limited money and resources, so they budget according to the cash } \\
\text { on hand and the available resources. }\end{array}$ \\
\hline 72 & $\begin{array}{l}\text { Women are planners behind the scene, organising and implementing } \\
\text { activities for the betterment of the village. }\end{array}$ \\
\hline 74 & $\begin{array}{l}\text { Women are superior to men in terms of moral judgements and } \\
\text { progressive attitudes. }\end{array}$ \\
\hline 75 & $\begin{array}{l}\text { John Williams documented that it was women who built the very first } \\
\text { church in Samoa. A sign of perseverance and determination of the Nuu o } \\
\text { Tamaitai. }\end{array}$ \\
\hline 76 & $\begin{array}{l}\text { Women possess spiritual qualities from their ancestors that allow them } \\
\text { to perform actively in families and villages (e.g., ositaulaga, taulasea). }\end{array}$ \\
\hline 77 & $\begin{array}{l}\text { Women play their roles with high esteem and dignity. This is proven } \\
\text { by all the tasks that are successfully done in village communities. }\end{array}$ \\
\hline 78 & $\begin{array}{l}\text { Women are leaders in their own right since they are active in families, } \\
\text { women's committees, churches, and villages. }\end{array}$ \\
\hline 79 & Women always serve to the best of their abilities. \\
\hline 80 & $\begin{array}{l}\text { Women are peace-keepers. They harmonise people and safeguard } \\
\text { relationships in organisations and village communities. }\end{array}$ \\
\hline 81 & $\begin{array}{l}\text { Women leaders dominate the middle and top management level of } \\
\text { government ministries, private entities, and non-governmental organisations. }\end{array}$ \\
\hline 82 & $\begin{array}{l}\text { Women are seen to be cooperative, interactive, and group-oriented not } \\
\text { the women's organisations, but also in organisations they belong to. }\end{array}$ \\
\hline
\end{tabular}




\begin{tabular}{|c|c|}
\hline 83 & $\begin{array}{l}\text { Women are positional leaders such as principals, nurses, lawyers, Chief } \\
\text { Executive officers, and Court Judges. }\end{array}$ \\
\hline 84 & $\begin{array}{l}\text { Women believe that they are 'doing leaders' by getting involved in } \\
\text { activities of families, churches, and villages. }\end{array}$ \\
\hline 85 & $\begin{array}{l}\text { Women are strong leaders who make just decisions, are hard to } \\
\text { manipulate, and always consider people. }\end{array}$ \\
\hline 86 & $\begin{array}{l}\text { Women leaders believe that they do things on a transparent basis, are } \\
\text { responsible and accountable for the decisions they make. }\end{array}$ \\
\hline 104 & $\begin{array}{l}\text { There are more women leaders in government ministries, private sector, } \\
\text { and non-government organisations, but that number is not translated into local } \\
\text { government. }\end{array}$ \\
\hline 105 & $\begin{array}{l}\text { The social and cultural perspectives are the basis to work from, and } \\
\text { these social assumptions and cultural perspectives about women affect their } \\
\text { chance for leadership posts. }\end{array}$ \\
\hline 109 & $\begin{array}{l}\text { Women believe that they are already leaders in their capacities as } \\
\text { daughters of high chiefs and talking orators who run and administer the affairs } \\
\text { of the sub-village of female descendants. }\end{array}$ \\
\hline 110 & $\begin{array}{l}\text { A leader is someone who puts the basic things in place (e.g., organising } \\
\text { the children, tasks, and people in the family on their daily routine). }\end{array}$ \\
\hline 111 & $\begin{array}{l}\text { A leader is someone who can present issues and challenges surrounding } \\
\text { people in the community, and someone who cares for the community. }\end{array}$ \\
\hline 112 & $\begin{array}{l}\text { Most of the women believe in themselves as transparent and } \\
\text { accountable leaders. }\end{array}$ \\
\hline 113 & $\begin{array}{l}\text { Leadership should start from somewhere like the family, and extends } \\
\text { to other spheres such as the local and national governments. }\end{array}$ \\
\hline 114 & $\begin{array}{l}\text { Women are natural leaders because they drive every single } \\
\text { development in the family, and extends to the church and the village. }\end{array}$ \\
\hline 115 & $\begin{array}{l}\text { Women are successful leaders in all sorts of avenues they engage in } \\
\text { (e.g., income-generating, planning, organising, implementing, crafting, } \\
\text { traditional healing). }\end{array}$ \\
\hline 116 & $\begin{array}{l}\text { Women believe that leadership is inherited and predetermined. So, both } \\
\text { males and females have equal rights to family leadership, as well as other } \\
\text { leadership posts in the church and the village. }\end{array}$ \\
\hline
\end{tabular}




\begin{tabular}{|r|r|}
\hline 117 & $\begin{array}{c}\text { Leadership to most women is about participation and contribution. If } \\
\text { you don't participate in village activities and can't contribute, then you cannot } \\
\text { be a leader. }\end{array}$ \\
\hline 118 & $\begin{array}{l}\text { There is a lot of ground work needed to make people understand about } \\
\text { the importance of gender equality in leadership in Samoa. }\end{array}$ \\
\hline 119 & $\begin{array}{l}\text { Leadership is about togetherness, team work, and connections. } \\
\text { Women are people-oriented, so they will make good leaders if they are } \\
\text { given a chance to do so. }\end{array}$ \\
\hline 122 & $\begin{array}{l}\text { Women can easily make connections to anyone as they are non- } \\
\text { hierarchical, a good characteristic of a leader. }\end{array}$ \\
\hline 123 & $\begin{array}{l}\text { Leadership is standing for what is considered right, and many women } \\
\text { leaders do that. } \\
\text { independent state of Samoa says that all heirs, male or female are entitled to } \\
\text { holding matai titles of their respective families. }\end{array}$ \\
\hline 124 & \begin{tabular}{l} 
Leadership is an obligation to serve people and putting their needs first. \\
\hline 125
\end{tabular} \\
\hline
\end{tabular}




\section{Pattern Five:}

Women leaders categorise themselves as servant leaders by providing numerous services to village communities.

\begin{tabular}{|c|c|}
\hline $\begin{array}{l}\text { Code } \\
\text { Number }\end{array}$ & Definition \\
\hline 66 & $\begin{array}{l}\text { Women are aware of the hierarchical leadership structure and cultural } \\
\text { protocols, and therefore serve the community through their talents as servant } \\
\text { leaders. }\end{array}$ \\
\hline 67 & $\begin{array}{l}\text { There are strong women leaders who are well educated } \& \text { have moved } \\
\text { up the leadership ladder in village communities. }\end{array}$ \\
\hline 68 & Women leaders counsel families, especially victims of abuse cases. \\
\hline 69 & $\begin{array}{l}\text { Women leaders groom and nurture young members of women's } \\
\text { committees to become leaders. }\end{array}$ \\
\hline 70 & $\begin{array}{l}\text { Services provided by women are through weaving and making } \\
\text { handicrafts, child rearing, income-generating businesses, and some work } \\
\text { fulltime. }\end{array}$ \\
\hline 72 & $\begin{array}{l}\text { Women are planners behind the scene, organising and implementing } \\
\text { activities for the betterment of the village. }\end{array}$ \\
\hline 73 & $\begin{array}{l}\text { Women upgrade and maintain village developments and community } \\
\text { projects. }\end{array}$ \\
\hline 76 & $\begin{array}{l}\text { Women possess spiritual qualities from their ancestors that allow them } \\
\text { to perform actively in families and villages (e.g., ositaulaga, taulasea). }\end{array}$ \\
\hline 77 & $\begin{array}{l}\text { Women play their roles with high esteem and dignity. This is proven by } \\
\text { all the tasks that are successfully done in village communities. }\end{array}$ \\
\hline 78 & $\begin{array}{l}\text { Women are leaders in their own right since they are active in families, } \\
\text { women's committees, churches, and villages. }\end{array}$ \\
\hline 79 & Women always serve to the best of their abilities. \\
\hline 80 & $\begin{array}{l}\text { Women are peace-keepers. They harmonise people and safeguard } \\
\text { relationships in organisations and village communities. }\end{array}$ \\
\hline 82 & $\begin{array}{l}\text { Women are seen to be cooperative, interactive, and group-oriented not } \\
\text { only in the women's organisations, but also in organisations they belong to. }\end{array}$ \\
\hline 84 & $\begin{array}{l}\text { Women believe that they are 'doing leaders' by getting involved in } \\
\text { activities of families, churches, and villages. }\end{array}$ \\
\hline
\end{tabular}




\section{Pattern Six:}

The Fa'amatai system does not undermine the women's perceptions developments and achievements

\begin{tabular}{|c|c|}
\hline $\begin{array}{l}\text { Code } \\
\text { Number }\end{array}$ & Definition \\
\hline 40 & $\begin{array}{l}\text { Social assumption about the meaning of leadership came from } \\
\text { somewhere else. Not from the Samoan culture. }\end{array}$ \\
\hline 50 & $\begin{array}{l}\text { Women must reflect on the things their ancestors did in the past, and } \\
\text { therefore be able to know what they are capable of doing. }\end{array}$ \\
\hline 51 & $\begin{array}{l}\text { Women need to reflect on education that was introduced to our country } \\
\text { where there was no restriction for girls to be educated. }\end{array}$ \\
\hline 55 & $\begin{array}{l}\text { Leaders in general do not have any understanding of the } \\
\text { Transformational Theory which states that women and men have the same } \\
\text { leadership attributes. }\end{array}$ \\
\hline 66 & $\begin{array}{l}\text { Women are aware of the hierarchical leadership structure and cultural } \\
\text { protocols, and therefore serve the community through their talents as servant } \\
\text { leaders. }\end{array}$ \\
\hline 67 & $\begin{array}{l}\text { There are strong women leaders who are well educated \& have moved } \\
\text { up the leadership ladder in village communities. }\end{array}$ \\
\hline 68 & Women leaders counsel families, especially victims of abuse cases. \\
\hline 69 & $\begin{array}{l}\text { Women leaders groom and nurture young members of women's } \\
\text { committees to become leaders. }\end{array}$ \\
\hline 70 & $\begin{array}{l}\text { Services provided by women are through weaving and making } \\
\text { handicrafts, child rearing, income-generating businesses, and some work } \\
\text { fulltime. }\end{array}$ \\
\hline 71 & $\begin{array}{l}\text { Most women budget family income wisely. They are aware that they } \\
\text { only have limited money and resources, so they budget according to the cash } \\
\text { on hand and the available resources. }\end{array}$ \\
\hline 72 & $\begin{array}{l}\text { Women are planners behind the scene, organising and implementing } \\
\text { activities for the betterment of the village. }\end{array}$ \\
\hline 73 & $\begin{array}{l}\text { Women upgrade and maintain village developments and community } \\
\text { projects. }\end{array}$ \\
\hline
\end{tabular}




\begin{tabular}{|c|c|}
\hline 74 & $\begin{array}{l}\text { Women are superior to men in terms of moral judgements and } \\
\text { progressive attitudes. }\end{array}$ \\
\hline 75 & $\begin{array}{l}\text { John Williams documented that it was women who built the very first } \\
\text { church in Samoa. A sign of perseverance and determination of the Nuu o } \\
\text { Tamaitai. }\end{array}$ \\
\hline 76 & $\begin{array}{l}\text { Women possess spiritual qualities from their ancestors that allow them } \\
\text { to perform actively in families and villages (e.g., ositaulaga, taulasea). }\end{array}$ \\
\hline 77 & $\begin{array}{l}\text { Women play their roles with high esteem and dignity. This is proven } \\
\text { by all the tasks that are successfully done in village communities. }\end{array}$ \\
\hline 78 & $\begin{array}{l}\text { Women are leaders in their own right since they are active in families, } \\
\text { women's committees, churches, and villages. }\end{array}$ \\
\hline 79 & Women always serve to the best of their abilities. \\
\hline 80 & $\begin{array}{l}\text { Women are peace-keepers. They harmonise people and safeguard } \\
\text { relationships in organisations and village communities. }\end{array}$ \\
\hline 81 & $\begin{array}{l}\text { Women leaders dominate the middle and top management level of } \\
\text { government ministries, private entities, and non-governmental organisations. }\end{array}$ \\
\hline 82 & $\begin{array}{l}\text { Women are seen to be cooperative, interactive, and group-oriented not } \\
\text { only in the women's organisations, but also in organisations they belong to. }\end{array}$ \\
\hline 83 & $\begin{array}{l}\text { Women are positional leaders such as principals, nurses, lawyers, Chief } \\
\text { Executive officers, and Court Judges. }\end{array}$ \\
\hline 84 & $\begin{array}{l}\text { Women believe that they are 'doing leaders' by getting involved in } \\
\text { activities of families, churches, and villages. }\end{array}$ \\
\hline 85 & $\begin{array}{l}\text { Women are strong leaders who make just decisions, are hard to } \\
\text { manipulate, and always consider people. }\end{array}$ \\
\hline 109 & $\begin{array}{l}\text { Women believe that they are already leaders in their capacities as } \\
\text { daughters of high chiefs and talking orators who run and administer the affairs } \\
\text { of the sub-village of female descendants. }\end{array}$ \\
\hline 114 & $\begin{array}{l}\text { Women are natural leaders because they drive every single } \\
\text { development in the family, and extends to the church and the village. }\end{array}$ \\
\hline 115 & $\begin{array}{l}\text { Women are successful leaders in all sorts of avenues they engage in } \\
\text { (e.g., income-generating, planning, organising, implementing, crafting, } \\
\text { traditional healing). }\end{array}$ \\
\hline
\end{tabular}




\begin{tabular}{|r|r|}
\hline 117 & $\begin{array}{l}\text { Leadership to most women is about participation and contribution. If } \\
\text { you don't participate in village activities and can't contribute, then you cannot } \\
\text { be a leader. }\end{array}$ \\
\hline 119 & $\begin{array}{l}\text { Leadership is about togetherness, team work, and connections. } \\
\text { Women can easily make connections to anyone as they are non- } \\
\text { hierarchical, a good characteristic of a leader. }\end{array}$ \\
\hline
\end{tabular}

\section{APPENDIX F}

\section{THEMES}

\begin{tabular}{|c|c|}
\hline & THEMES \\
\hline 1 & $\begin{array}{l}\text { Samoan women leadership in village communities is servant but not } \\
\text { status leadership. }\end{array}$ \\
\hline 2 & $\begin{array}{l}\text { Cultural restrictions, religious beliefs, and social assumptions } \\
\text { pertaining to women's roles prevent Samoan women from leadership positions } \\
\text { in local government of village communities. }\end{array}$ \\
\hline 3 & $\begin{array}{l}\text { The ascribed lower status of women leaders in the Fa'amatai system } \\
\text { does not undermine their perception of developments and achievements. }\end{array}$ \\
\hline
\end{tabular}

